Universidade de São Paulo

FFCLRP- Departamento de Psicologia

Programa de Pós-Graduação em Psicologia

\title{
Consumo de drogas entre pessoas em sofrimento psíquico: sentidos, significados e percursos
}

Fernanda de Sousa Vieira

Tese apresentada à Faculdade de Filosofia, Ciências e Letras de Ribeirão Preto da USP, como parte das exigências para obtenção do título de Doutora em Ciências, Área: Psicologia em Saúde e Desenvolvimento

Ribeirão Preto - SP

2016 
Universidade de São Paulo

FFCLRP- Departamento de Psicologia

Programa de Pós-Graduação em Psicologia

\section{Consumo de drogas entre pessoas em sofrimento psíquico: sentidos, significados e percursos}

Fernanda de Sousa Vieira

Tese apresentada à Faculdade de Filosofia, Ciências e Letras de Ribeirão Preto da USP, como parte das exigências para obtenção do título de Doutora em Ciências, Área: Psicologia em Saúde e Desenvolvimento

Orientadora: Profa. Dra. Clarissa Mendonça Corradi-Webster

Ribeirão Preto - SP

2016 
Autorizo a reprodução e divulgação total ou parcial deste trabalho, por qualquer meio convencional ou eletrônico, para fins de estudo e pesquisa, desde que citada a fonte.

FICHA CATALOGRÁFICA

Vieira, Fernanda de Sousa.

Consumo de drogas entre pessoas em sofrimento psíquico: sentidos, significados e percursos / Fernanda de Sousa Vieira; Orientadora: Clarissa Mendonça Corradi-Webster. - Ribeirão Preto, 2016.

$206 \mathrm{f}$.

Tese (Doutorado) - Universidade de São Paulo, 2016.

1. Diagnóstico Duplo. 2. Substâncias Psicoativas. 3. Transtornos Mentais. 4. Serviços Comunitários. 5. Pesquisa Qualitativa 


\section{Folha de Aprovação}

Nome:Vieira, Fernanda de Sousa

Título: Consumo de drogas entre pessoas em sofrimento psíquico: sentidos, significados e percursos

Tese apresentada à Faculdade de Filosofia, Ciências e Letras de Ribeirão Preto da USP, como parte das exigências para obtenção do título de Doutora em Ciências, Área: Psicologia em Saúde e Desenvolvimento

Aprovado em:

\section{BANCA EXAMINADORA}

Prof. Dr.

Instituição: Assinatura:

Prof. Dr.

Instituição: Assinatura:

Prof. Dr.

Instituição: Assinatura:

Prof. Dr.

Instituição: Assinatura:

Prof. Dr.

Instituição: Assinatura: 



\section{Dedicatória}

Dedico esse trabalho àqueles que me ensinaram na prática que o sofrimento psíquico não é igual a doença mental. Dedico também a quem me ensinou na prática que drogas são parte sempre de um caminho trilhado e compartilhado, com idas e vindas e que precisamos escutar as histórias desses caminhos para poder trilhar outros possíveis. 


\section{Agradecimento}

Agradeço aos participantes e profissionais dos serviços onde este estudo se desenvolveu.

Agradeço também à Cynthia Cassoni, companheira de conversas, conselhos, trocas, sofrimentos e risadas. Agradeço a Laura Cremonte, Diana de Lucca, Cleber Tiago Cirineu, Federica Lanzi, Nicoletta Sciarrino, Scilla Passeri, Dalila Ingrande, Gino Petrollini pelo acolhimento e pelas trocas de experiências e explicações teóricas durante o período na Itália. Agradeço à Thaís Oliveira pelas portas que abriu não só aqui no Brasil, mas também na Itália.

Não poderia deixar de agradecer ao Programa de Pós Graduação em Psicologia da Faculdade de Filosofia, Ciências e Letras de Ribeirão Preto da Universidade de São Paulo, à Comissão de Aperfeiçoamento de Pessoal de Nível Superior pelas bolsas concedidas de Doutorado (demanda social) e Doutorado Sanduíche.

Agradeço ao Prof. Dr. Egberto Turato e ao Prof. Dr. Rubens Adorno pelo acolhimento junto aos seus respectivos programas, me permitindo assistir às suas disciplinas. Agradeço ao Prof. Dr. Massimiliano Minelli pelo acolhimento em seu departamento, pelos ensinamentos não só como professor como também como pessoa, a quem tenho muita admiração.

Meus agradecimentos também à minh família e amigos que me ajudaram a construir este trabalho, com apoio e carinho e que trouxeram contribuições valiosíssimas! 


\section{Epígrafe}

"Sou quinhentos, sou quinhentos e cinquenta

Quem sabe um dia, toparei comigo". (Fernando Pessoa) 
Verso da dedicatória 


\section{Resumo}

VIEIRA, Fernanda de Sousa Consumo de drogas entre pessoas em sofrimento psíquico: sentidos, significados e percursos, \{Tese de doutorado $\}$ Ribeirão Preto: FFCLRP-USP, 2016.

O diagnóstico duplo, ou comorbidade, é considerado prevalente tanto pela literatura do discurso médicopsiquiátrico, como na realidade clínica de serviços de saúde mental e de drogas. Considera-se que o campo da saúde está imerso em sistemas de crenças, influenciadas por aspectos culturais e sociais, inclusive sobre o que se considera sofrimento psíquico como sinônimo de diagnóstico psiquiátrico, que inserido em contexto mais amplo, se conectaria a sofrimentos compartilhados socialmente. O consumo de drogas estaria imerso nesse mesmo contexto histórico e social compartilhado. Este trabalho se caracterizou como pesquisa qualitativa, cuja abordagem conversou com autores que consideram a pesquisa qualitativa como um exercício de sensibilidade, cujo foco na experiência em primeira pessoa. O objetivo geral foi conhecer sentidos e significados do consumo de drogas a partir de narrativas de história de vida de pessoas descritas com duplo diagnóstico. O objetivos específicos foram conhecer descrições sobre a experiência de sofrimento psíquico ao longo da vida; conhecer descrições sobre a experiência de consumo de drogas ao longo da vida; e conhecer descrições sobre experiências em que o consumo de drogas esteja associado a sofrimentos psíquicos. Este estudo exploratório, foi realizado em um CAPS II e um CAPS AD, da rede de atenção psicossocial, de um município do interior paulista. Participaram dezoito adultos, homens e mulheres, selecionados de maneira a diversificar possibilidades de quadros clínicos e consumo de drogas, em padrão considerado problemático. A coleta de dados foi feita por meio de entrevista de história de vida temática e anotações em caderno de campo. A análise foi feita a partir do material emergente de trabalho de campo, da literatura sobre diagnóstico duplo e sobre sofrimento social. As entrevistas foram consideradas narrativas, sendo selecionadas dez para sua apresentação pormenorizada, cujos critérios de seleção foram exequibilidade e diversificação dos quadros clínicos, sendo distribuídos quanto ao gênero e serviços onde eram atendidos. Os resultados foram apresentados juntamente com a discussão, foi descrito o processo de construção do campo e do tema estudado e depois, foram descritas as narrativas. As narrativas dos participantes, na sua maioria homens e vindos de classes trabalhadoras urbanas, foram circunscritas pelo universo cultural e social onde se inseriam, mas também pelas possibilidades de escuta de demandas dos serviços da rede estudada. Esta se conformou em serviços que os descreviam de maneira excludente entre "usuários de drogas" e "doentes mentais", estando comprometidas com perfis construídos nas diversas relações sociais e institucionais estabelecidas, considerando-se contextos e discursos mais amplos. Os sentidos e significados do consumo de drogas para os participantes foram construídos ao longo da vida, junto aos diversos eventos e situações vividos nas diversas relações sociais e culturais, em que o sofrimento psíquico, por vezes, fazia presente. O consumo de drogas, compreendido como dispositivo, permitia agir diante das situações de sofrimentos psíquicos e sociais, vividos singularmente, mas compartilhados socialmente. Considera-se importante refletir sobre as experiências vividas por pessoas em sofrimento psíquico e que fazem uso de drogas, considerando-os inseridos em um contexto mais amplo de relações sociais e institucionais, em que sofrimentos sociais estão presentes

Palavras-chave: Diagnóstico Duplo; Substâncias Psicoativas; Transtornos Mentais; Serviços Comunitários; Pesquisa Qualitativa 


\begin{abstract}
VIEIRA, Fernanda de Sousa Consumo de drogas entre pessoas em sofrimento psíquico: sentidos, significados e percursos, \{Tese de doutorado $\}$ Ribeirão Preto: FFCLRP-USP, 2016.
\end{abstract}

Dual diagnosis, or comorbidity, is considered prevalent by literature of medical-psychiatric discourse, as much as, in mental health services and those for drug use treatment. It is considered that the health field is immerse in systems of beliefs influenced by cultural and social aspects, including what is considered psychological suffering as a synonym of psychiatric diagnosis, which is, in a broader context, connected with sufferings shared socially. Drug use is also immersed in the same historical and social shared context. This work is characterized as qualitative research, whose approach is related to authors that consider qualitative research as a sensibility exercise, focusing in first person experience. The main objective was to acknowledge senses and meanings of drug use from life history narratives of persons described as dually diagnosed. The specific objectives were to acknowledge descriptions of drug use along life course, descriptions of psychological suffering along life course and descriptions of drug use associated to psychological suffering. This exploratory study has been developed in one CAPS II and one CAPS AD, part of psychosocial attention network of an inner city of São Paulo. Eighteen adults participated, men and women, selected to permit diversification of clinical presentations of psychiatric diagnosis and drug use, in pattern od use considered problematic. Data collection has been thematic life histories interview and field notes. Analysis emerged from fieldwork, dual diagnosis' literature and social suffering's literature. Interviews were considered narratives, and ten were presented with more details, selected by practicability, diversification of clinical presentations criteria, distributed among genders and services where they came from. Results were presented concomitantly with discussion, and were described the process of construction of the field and of the theme studied, then narratives were described and discussed. Participants' narratives, mainly men from urban labourer's class, were circumscribed by cultural and social universe where they came from, as well as the possibility of storytelling to be heard in the health services network studied. This 
network was also constructed by describing their patients exclusively as "drug users" or "mentally ill", compromised with profiles constructed in many social and institutional relationships, considering broader context and discourses. Senses and meanings of drug use for the participants were constructed along life course, together with diverse events and situations lived in diverse social and cultural relations, and social and psychological sufferings could, sometimes, be present. Drug use, understood as a device, allowed the participant to act in situations of psychological sufferings that were experienced singularly, but socially shared. It is considered important reflect upon experiences lived by people in psychological suffering that also use drugs, considering them as part as a broader context of social and institutional relations, in which social sufferings may be present.

Key-words: Dual diagnosis, psychoactive substances, mental illness, communitary services, qualitative research 


\section{Lista de Ilustrações}

FIGURA 1: CRITÉRIOS DE SELEÇÃO DAS NARRATIVAS PARA DESCRIÇÃO PORMENORIZADA ….....................................................82

FIGURA 2: SENTIDOS E SIGNIFICADOS DO CONSUMO DE DROGAS POR PESSOAS EM SOFRIMENTO PSÍQUICO 


\section{Lista de Tabelas}

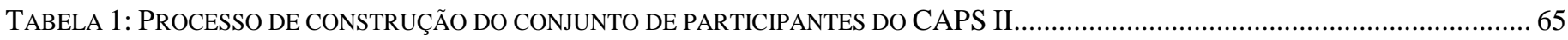

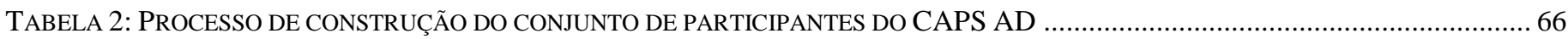

TABELA 3: CARACTERÍSTICAS SOCIODEMOGRÁFICAS E CLÍNICAS DOS PARTICIPANTES SELECIONADOS PARA ANÁLISE ...................... 67

TABELA 4: CARACTERÍSTICAS SOCIODEMOGRÁFICAS DOS PARTICIPANTES DO CAPS II ............................................................... 86

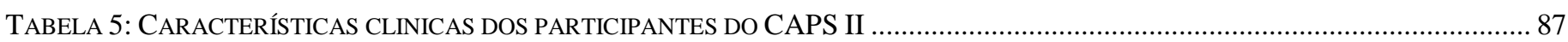

TABELA 6: CARACTERÍSTICAS SOCIODEMOGRÁFICAS DOS PARTICIPANTES DO CAPS AD ............................................................... 90

TABELA 7: CARACTERÍSTICAS CLÍNICAS DOS PARTICIPANTES DO CAPS AD …............................................................................ 91

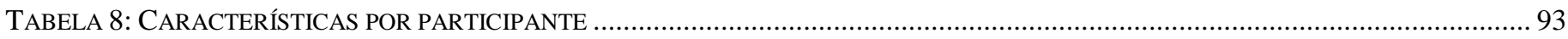




\section{Lista de Siglas e abreviaturas}

LePsis Laboratório de Ensino e Pesquisa em Psicopatologia, Drogas e Sociedade

CAPES Comissão de Aperfeiçoamento de Pessoal de Nível Superior

RAPS Rede de Atenção Psicossocial

OMS Organização Mundial de Saúde

DSM-III Manual Diagnóstico e Estatísticos de Transtornos Mentais - terceira edição

CID Classificação Internacional de Doenças

DSM Manual Diagnóstico e Estatístico de Doenças Mentais

SUS Sistema Único de Saúde

CAPS Centros de Atenção Psicossocial

CAPS I Centro de Atenção Psicossocial de nível I

CAPS II Centro de Atenção Psicossocial de nível II

CAPS III Centro de Atenção Psicossocial de nível III

CAPS-i Centro de Atenção Psicossocial info-juvenil

NAPS Núcleo de Apoio Psicossocial

CID-10 Classificação Internacional de Doenças - décima edição

DSM-IV-TR Manual Diagnóstico e Estatístico de Doenças Mentais em sua quarta edição revisada

DSM-V Manual Diagnóstico e Estatístico de Doenças Mentais em sua quinta edição

AIDS Síndrome da imunodeficiência adquirida

CAPS AD Centro de Atenção Psicossocial para problemas relacionados ao consumo de álcool e outras drogas

ASSIST Alcohol, Smoking and Substance Involvement Screening Test

TCLE Termo de Consentimento Livre e Esclarecido 


\section{Sumário}

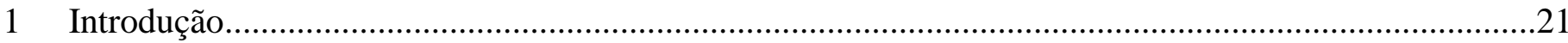

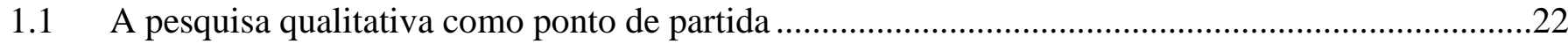

1.2 O consumo de drogas entre pessoas com outros diagnósticos psiquiátricos ....................................26

1.3 O Diagnóstico Psiquiátrico e a Questão do Sofrimento Psíquico .........................................................37

1.4 O tema das drogas e o contexto de tratamentos de saúde mental .....................................................47

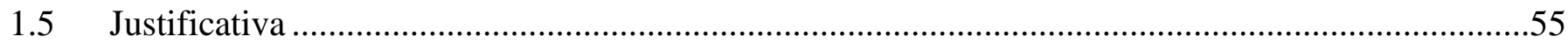

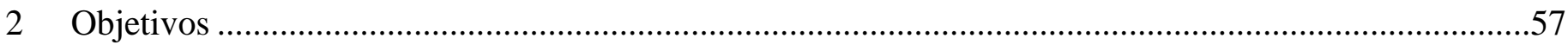

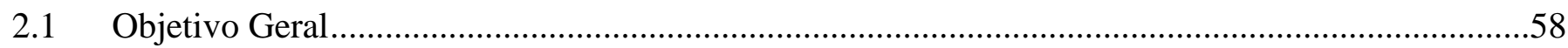

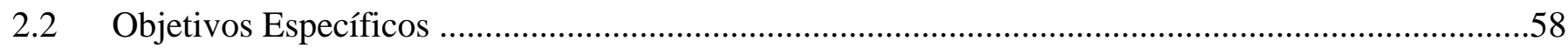

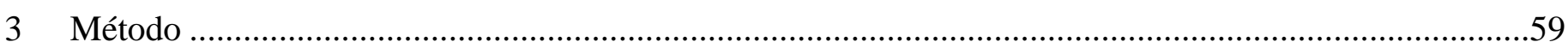

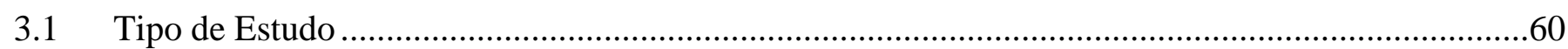

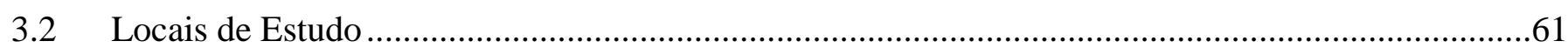

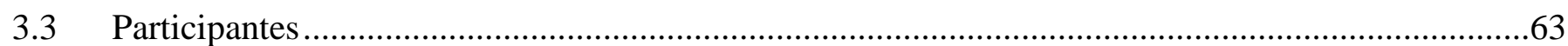

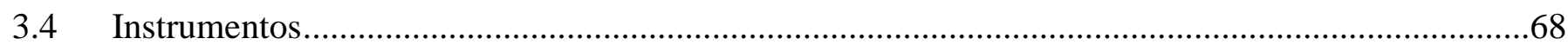

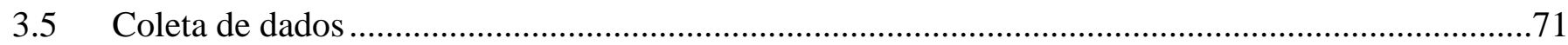

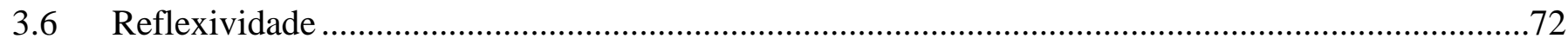

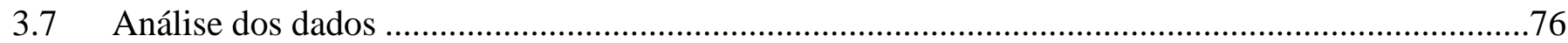

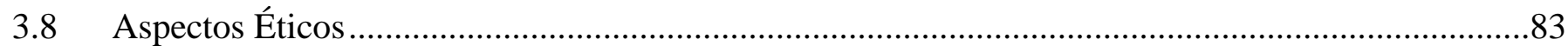

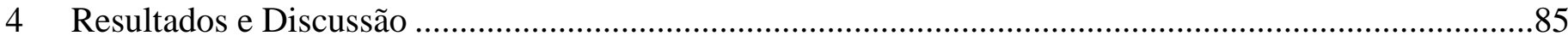

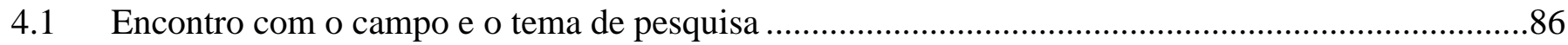

4.2 As narrativas e os sentidos do consumo de drogas associados ao sofrimento psíquico ...................107

4.2.1 Outras percepções da realidade associadas ao consumo de drogas ..........................................107

4.2.2 Variações emocionais e o consumo de drogas ...........................................................................135

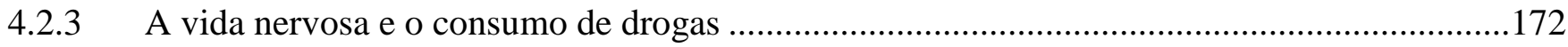

4.3 O mosaico dos Sentidos e Significados do consumo de drogas associados ao sofrimento psíquico 208

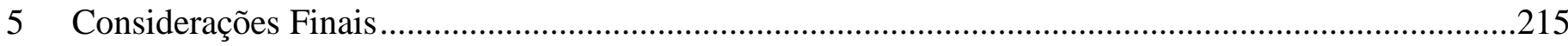

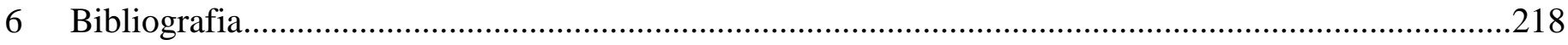

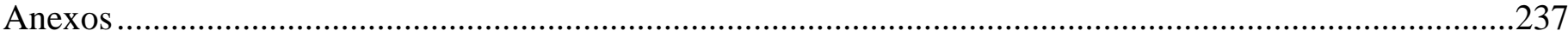

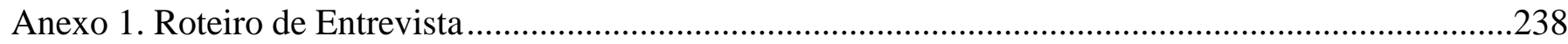

Anexo 2. Aprovação no Comitê de Ética em Pesquisa..........................................................................241 
Anexo 3. Aprovação no Comitê de Ética em Pesquisa - Segunda Fase.........Erro! Indicador não definido.

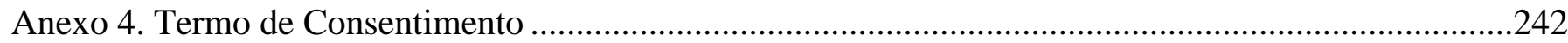




\section{Prólogo}

Conversar sobre temas polêmicos como a temática das drogas tem sido um desafio tanto no campo acadêmico quanto em conversas cotidianas. É um campo sensível a preconceitos e o discurso moral pode tomar grande parte da conversa e ficam de fora outros discursos que poderiam construir descrições de diferentes sentimentos e experiências. Isso parece ser ainda mais difícil quando se adentra no campo da saúde mental. Campo também cheio de estigmas em que muitas vezes a perspectiva da pessoa com diagnóstico de transtorno mental não é autorizada ou legitimada pelos interlocutores. Nesses momentos são mais fortes discursos culturais hegemônicos frequentemente alicerçados pelo modelo médico-psiquiátrico. Um desafio, portanto, é conversar, de maneira confortável sobre esse tema sem que julgamentos e diagnósticos sirvam como obstáculo ao encontro e à conversa. Busquei, neste trabalho adotar uma abordagem que permitisse que o consumo de drogas e o sofrimento mental, pudessem ser interpretados de maneira menos classificatória ou acusatória e mais compreensiva, abrindo espaço para o diálogo, à pergunta e à reflexão.

Meu percurso de pesquisa foi desafiador. Eu nunca havia trabalhado com o tema diretamente. O convite oferecido pela Profa. Dra. Clarissa Mendonça Corradi-Webster para integrar uma pesquisa em seu Laboratório de Ensino e Pesquisa em Psicopatologia, Drogas e Sociedade (LePsis), que na época havia sido recém-criado, foi para mim um misto de desafio para percorrer caminhos abertos pelo meu mestrado e construir trilhas e picadas em um campo do conhecimento cheio de controvérsias. Com o entendimento de que a pesquisa é entremeada pelo percurso pessoal, também na minha vida pessoal fui intimada a prestar atenção a discursos e práticas relacionadas ao consumo de drogas, associados ao sofrimento psíquico, sinônimo aqui de transtorno mental. Nessa questão, também me vi muito tocada pela interrupção da orientação da tese pela Profa. Dra. Regina Helena Lima Caldana, minha orientadora do mestrado e professora na graduação a quem tenho muita estima e respeito. 
Sem substituí-la, mas complementando a minha trajetória de pesquisa, entrei em contato com o Prof. Dr. Massimiliano Minelli, que junto com seus estudantes veio nos visitar no Brasil para construir percursos de pesquisa etnográfica. Trocamos contatos e eu fui para a Itália passar sete meses no departamento ao qual é filiado, período financiado pela Comissão de Aperfeiçoamento de Pessoal de Nível Superior (CAPES), por meio do Doutorado Sanduíche. Na ocasião participei de sua disciplina de "Metodologia della Ricerca Etnografica”, ministrada em seu departamento, na Universitá di Perugia, Úmbria, Itália. Nesse período no exterior, entrei em contato com autores da Antropologia Crítica da Saúde e com a observação do cotidiano de serviços comunitários de saúde mental e de drogas na cidade, onde aprendi muito sobre capacidades de agir. Este período contribuiu para que eu construísse uma visão da pesquisa qualitativa diferente daquela que eu tinha antes de ir para a Itália e que só depois de algum tempo, já no momento de escrever este texto, eu comecei a compreender. Só comecei!

Esse mergulho sobre o campo da pesquisa qualitativa não iniciou nessa experiência. Eu inicialmente fiz a disciplina de Pesquisa Qualitativa na Escola de Enfermagem de Ribeirão Preto da Universidade de São Paulo, fiz também a disciplina de Pesquisa Clínico-Qualitativa com o Prof. Dr. Egberto Turato no departamento de Tocoginecologia da Faculdade de Ciências Médicas da Unicamp. Depois, já no Programa de Pós-graduação de Psicologia, fiz a disciplina ministrada pela Profa. Dra. Clarissa Mendonça CorradiWebster e pela Profa. Dra. Francirosy Campos Barbosa de Metodologia Qualitativa. Portanto, parti de compreensões de pesquisa que se aproximavam da epistemologia qualitativa e caminhei em direção ao afastamento do modelo de pesquisa positivista, indo me encontrar com textos etnográficos. A pesquisa que desenvolvi, no entanto, não foi etnográfica, mas fortemente influenciada por essa abordagem. Os percursos trilhados na pesquisa ao longo do trabalho de campo, junto a experiências da minha vida pessoal, me aproximaram de leituras sobre o sofrimento social. Questão que nos une a todos, embora seja possível perceber que alguns grupos sociais são mais sensíveis a ele em termos históricos e sociais, sendo vivenciados com nuances locais. 
O contato com o campo e em conjunto com discussões feitas no LePsis também me provocaram reflexões sobre os caminhos da Rede de Atenção Psicossocial (RAPS) municipal sobre a questão do consumo de drogas por pessoas diagnosticadas com transtornos psiquiátricos. Esse contato redirecionou a pesquisa em termos de locais de estudo e ampliou as possibilidades de compreensão sobre a problemática estudada, trazendo a necessidade de olhar para a complexidade dessa questão nas narrativas de vida dos participantes. O resultado desse percurso de quase quatro anos foi este trabalho, construído em várias mãos: oficiais como as dos professores Dra. Clarissa Mendonça Corradi-Webster, Dra. Regina Helena Lima Caldana e Dr. Massimiliano Minelli. Espero que a leitura do texto dessa tese, apesar de feita para a academia, seja acessível também a profissionais de saúde que trabalham em serviços da RAPS, que na prática, são os maiores interessados deste trabalho. Espero que eu possa oferecer uma pequena contribuição para a reflexão crítica sobre a demanda de pessoas com diagnósticos duplos recebida nos serviços das RAPS todos os dias. 
1 Introdução 


\subsection{A pesquisa qualitativa como ponto de partida}

Inicio este trabalho apresentando elementos que me ajudaram na construção da problemática deste estudo sobre sentidos e significados do consumo problemático de drogas por pessoas diagnosticadas com transtornos mentais. Essas pessoas são comumente descritas pela literatura científica emergente do discurso médico-psiquiátrico como pessoas que receberam duplo diagnóstico, ou comorbidade. Para delinear as bases sobre as quais construí este trabalho, eu procurei apresentar uma literatura científica que se utiliza da ótica do discurso médico-psiquiátrico para falar sobre o duplo diagnóstico.

As pesquisas nesse campo são, em sua maioria, estudos quantitativos epidemiológicos, embora eu tenha buscado também apresentar pesquisas qualitativas sobre essa questão, mas que, no entanto, adotam como referencial esse mesmo discurso. No entanto, autores como MacRae (2004) consideram que persiste a hegemonia discurso médico-psiquiátrico diante de outros discursos possíveis. Portanto, para além dessa literatura, procurei um posicionamento crítico e reflexivo, inserindo problematizações sobre o diagnóstico psiquiátrico nas quais a questão do sofrimento psíquico foi retratada sob o ponto de vista do sofrimento no cotidiano.

Como um campo cujo estudo teve desenvolvimento paralelo ao do sofrimento psíquico, o tema do consumo de drogas como problema de saúde vem sendo tomado como uma questão complexa (Fiore, 2008). A literatura médico-psiquiátrica, no entanto, vem discutindo essa questão como parte do campo da Psiquiatria, focalizando no indivíduo a atenção sobre aspectos relacionados a processos associados ao adoecimento. Em consequência, o consumo de drogas passa a ser considerado problemático, de maneira que literaturas no campo vêm procurando situar a questão dos problemas de comportamento e nas relações das pessoas que fazem uso de drogas como questão que tem por base elementos biológicos (Vargas, 2008).

Como contraponto, autores das ciências humanas e de outras áreas da saúde têm produzido estudos que problematizam o que consideram o consumo de drogas como uma questão individual e localizada no 
corpo. Eles vêm colocando ênfase maior em perspectivas que entendem a droga como uma temática histórica, social e culturalmente localizada e enfatizam que ela não pode ser concebida de maneira destacada de seus significados psíquicos e culturais (MacRae, 2004). Assim, parti de pressupostos que entendem pesquisa qualitativa como um exercício reflexivo e de sensibilidade, conforme teorizou (Adorno \& Castro, 1994).

A partir da leitura de textos desse autor (Adorno, 2011), procurei adotar um posicionamento considerando que a pesquisa que produzi está inserida em discussões de que o discurso científico qualitativo opera por meio de intencionalidades, onde são levadas em conta valores crenças e intenções, que podem ser utilizados como potência para resistência e transformação de processos de exclusão (Adorno \& Castro, 1994). Por essa perspectiva, procurei construir este trabalho problematizando determinismos como categorias estanques, de maneira a evidenciar o modo de perceber dos participantes do estudo, a partir da minha percepção como pesquisadora inserida nesse campo. Esse posicionamento localiza-se em discussões epistemológicas que compreendem a subjetividade como constructo complexo e processual, sendo social, histórico e localmente situado e produzido (Biehl, Good, \& Kleinman, 2007).

Consideram que as subjetividades estão conectadas a um contexto mais amplo de globalização do mundo capitalista ocidental (Biehl et al., 2007). Assim, busquei trilhar um caminho de pesquisa que procurasse um tipo de informação que permitisse conhecer as experiências descritas em primeira pessoa em vez de buscar relações entre causa-efeito das situações estudadas (Turato, 2011). Filiei-me, portanto, às propostas de pesquisa qualitativa que a compreendessem como um processo em que a realidade estudada é múltipla e, nesse sentido, entendo que a pesquisa qualitativa é uma ferramenta importante para oferecer interpretações e compreensões de sentidos e significados relacionados ao consumo de drogas, conforme considerou MacRae (2004).

Parti de compreensões de pesquisa que entendem que seu processo não se define a priori, mas se adequa às demandas do campo e do foco que se quer dar com ela, permitindo que se use da sensibilidade 
para perceber questões não antecipadas e que apareçam ao longo do processo de pesquisa (Turato, 2011). Esse modo de entender pesquisa não a posiciona como oposta ao modo quantitativo de produzir conhecimento, ao contrário complementa os achados da pesquisa quantitativa (Turato, 2005). Sobre esta, pela pesquisa qualitativa é possível produzir interrogações, associações e explicações, sempre temporárias, sobre o tema pesquisado, em intenso diálogo.

Para pensar sobre essas questões, emprestei de autores como Bourgois (1998), Biehl (2011) e Young (1995) a noção de que saúde, doença e cuidados em saúde são aspectos associados a modos de vida social e cultural de maneira articulada em sistemas de crenças. Esses sistemas são construídos por significados, valores e normas que se entrelaçam em experiências inseridas em diferentes âmbitos das relações sociais e comunitárias (Young, 2006). Duarte (1993) questionou sobre a produção de conhecimento que se pauta em compreensões de que o adoecimento estaria muito ligado ao modo como o discurso médico-psiquiátrico foi construído pela cultura norte-americana enquanto regime de verdade e padrão hegemônico de produção de conhecimento.

Young (2006), procurou problematizar o modo como ideologias e práticas cotidianas moldam a forma como compreendemos saúde e doença. Esses conceitos, quando inseridos em determinadas convenções, permitem a compreensão do que é conversado de maneira que a discussão sobre processos de adoecimento é ampliada. Isso implica em conectar experiências singulares a contextos mais amplos e globais. No contexto de serviços de saúde, a conversa sobre processos de saúde e doença acontece quando os participantes dela interagem segundo determinados scripts pré-negociados em termos de discursos e respaldados por determinados posicionamentos (Corradi-Webster, 2014). Estes permitem ou limitam trânsitos entre descrições de si nas relações do cotidiano, em que são estabelecidas relações de poder que se posicionam em dicotomia entre compreensões de "pacientes"/“usuários" e "profissionais de saúde”, que se utilizam desses discursos internamente à lógica de tratamento (Minelli, 2013). 
O referencial de pesquisa, portanto, compôs-se a partir desses elementos, cujo olhar para a situação complexa do duplo diagnóstico se configurou como um caleidoscópio. Por isso, como pesquisadora me posicionei de maneira crítica no que se referiu à construção do conhecimento (Adorno \& Castro, 1994), formulando reflexões percepções a partir da literatura sobre sofrimento psíquico e consumo de drogas, inseridos em contextos culturais específicos, como é o caso do contexto de serviços comunitários da rede pública de saúde brasileira. Interessou, portanto, fazer uma retomada na literatura que se baseia no discurso médico-psiquiátrico e conhecer como esta vem produzindo e compreendendo o tema de pesquisa: o diagnóstico duplo, ou melhor, o consumo de drogas por pessoas diagnosticadas com transtornos psiquiátricos. 


\subsection{O consumo de drogas entre pessoas com outros diagnósticos psiquiátricos}

Em termos epidemiológicos, a Organização Mundial de Saúde (OMS) estima que 10\% da população urbana geral, em todo mundo, consome, de maneira prejudicial, substâncias psicoativas, independentemente das características de idade, gênero, instrução e status social (Delgado et al., 2007). No Brasil, na população geral, estima-se que seja a mesma proporção, tendo como principais drogas de abuso o álcool, o tabaco, maconha, solventes, benzodiazepínicos e cocaína (Carlini et al., 2010).A literatura médico-psiquiátrica tem descrito a prevalência elevada de pessoas com diagnósticos psiquiátricos entre aquelas que buscam tratamento para o consumo de drogas (Szerman et al., 2011), e o abuso de substâncias tem sido considerado o transtorno comórbido mais frequente entre pessoas que fazem tratamento para transtornos mentais (Zaleski et al., 2006).

O termo "comorbidade" nasce, segundo Krueger, Markon, Patrick, \& Iacono (2008), nos anos 1970. O início de seu uso se deu com os estudos epidemiológicos, pela referência à composição de problemas, ou morbidades, que se associam quando uma pessoa é acometida por dois ou mais de eventos clínicos relevantes. Segundo o Glosario de Terminos de Alcohol y Drogas (World Health Organization [WHO] \& Ministerio de Sanidad y Consumo, 1995), a associação de diagnósticos de transtornos mentais, descrita duplo diagnóstico, pode ter ou não correlação ou relação etiológica ou de causa-efeito. Entretanto, o termo foi apropriado pela Psiquiatria e pela Psicologia somente nos anos 1980 e 1990, coincidindo com o desenvolvimento do Manual Diagnóstico e Estatísticos de Transtornos Mentais em sua terceira edição (DSM-III) e com a construção de critérios mais específicos de diagnóstico (Krueger et al., 2008).

O autor aponta que ao longo dos anos 1990, a questão começou a ser problematizada, discutindo-se a utilidade desse termo por sua tendência a reificar categorias diagnósticas. Nessa época, pesquisadores procuraram definir padrões de associação entre transtornos mentais de um determinado conjunto de 
diagnósticos psiquiátricos. Nos anos 2000, foi sugerido que o termo duplo diagnóstico fosse usado somente quando relacionado a algumas categorias diagnósticas, sendo melhor empregado em termos dimensionais (Krueger et al., 2008). Santucci (2012) defendeu que o termo duplo diagnóstico fosse empregado somente quando referido a transtornos mentais graves, ou seja, diagnóstico de transtornos do tipo psicóticos ou de humor. Outra sugestão sobre o uso do termo foi na direção de evitar seu uso em contextos de comunicação com os pacientes e seus familiares, buscando-se comunicar características presentes às duas condições.

Por essas críticas e considerações, Krueger et al. (2008) orientou que o termo fosse empregado com "refino consciente", pois a emergência de pesquisas nesse campo evidenciou que esse fenômeno ocorria mais como regra do que como exceção. Pareceu ser mais comum em populações clínicas do que na população em geral, talvez pela percepção de que uma pessoa que é descrita com um diagnóstico psiquiátrico tem maior probabilidade de ser descrita com outro diagnóstico do que simplesmente a casualidade. Apesar disso, produção de literatura do discurso médico-psiquiátrico sobre o duplo diagnóstico não deixou de ser feita. E importou para os objetivos deste estudo, conhecer aspectos ligados a essa condição em termos da literatura epidemiológica e qualitativa quanto ao uso problemático de drogas por pessoas com diagnósticos psiquiátricos.

Essa literatura é vasta no que se refere à variedade de desenhos de pesquisa e métodos de estudo utilizados. Assim, para conhecer melhor esse universo, realizei, durante todo o processo de pesquisa, revisão de literatura sobre estudos que tratavam do consumo de drogas por pessoas usuárias de serviços de saúde mental. Estudo de prevalência na população em geral realizado nos Estados Unidos por Regier et al.(1990) encontrou que entre os participantes identificados com diagnósticos de transtorno mental, a prevalência de dependência de drogas era de $29 \%$. Outro estudo, mais recente, realizado nesse mesmo país, 53,5\% da amostra de uma população clínica psiquiátrica tinham diagnóstico transtornos por uso de substâncias associados a outros diagnósticos de transtornos psiquiátricos (Mericle et al., 2012). 
Estudos europeus, na Noruega, por exemplo, em pesquisa com pessoas em episódio agudo atendidas em serviço de internação identificou que $63 \%$ destas faziam uso de substâncias, sendo que metade destas faziam uso problemático de álcool (Mordal et al., 2011). No Reino Unido, Sinclair, Latifi, \& Latifi, (2008) realizou estudo com pessoas nessa mesma condição e identificou que 79,5\% faziam consumo problemático de álcool e 46,4\% faziam consumo de maconha. Na Escócia, 20\% da amostra de pessoas com diagnósticos de esquizofrenia tinham uso problemático de drogas na vida (McCreadie, 2002). Na Espanha, estudo encontrou que $24,9 \%$ das pessoas internadas em hospital psiquiátrico poderiam ser descritas pelo duplo diagnóstico (Rodríguez-Jiménez et al., 2008). Nesse mesmo país, das pessoas em serviços comunitários de saúde mental e de tratamento para problemas com o consumo de drogas foram 61,8\% (Arias et al., 2013).

No continente africano, um estudo realizado na África do Sul estimou que 51\% dos entrevistados tinham duplo diagnóstico (Weich \& Pienaar, 2009), enquanto na Tanzânia, 65,8\% dos participantes internados em unidade psiquiátrica para tratamento por transtornos mentais, faziam também uso de substância (Hauli, Ndetei, Jande, \& Kabangila, 2011). Na Ásia e Oriente Médio, as prevalências se mostraram distintas e muito menores do que nos outros estudos encontrados. Em Taiwan, estudo identificou que $10,5 \%$ dos participantes com diagnósticos psiquiátricos pontuaram positivo para transtornos por uso de substâncias (Huang et al., 2009). Em Israel, a porcentagem de uso ao longo da vida relatado pelos pacientes internados em serviço de saúde mental foi de 24\% (Katz, Durst, Shufman, Bar-Hamburger, \& Grunhaus, 2008).

No contexto brasileiro, um estudo encontrou uma prevalência de duplo diagnóstico entre pessoas com diagnóstico de transtornos mentais graves de 10,4\%, sendo 7,3\% destes faziam uso problemático de álcool e 4,7\% para drogas ilícitas (Ratto, 2000). Já entre pessoas em tratamento para dependência de álcool e cocaína/crack, encontrou-se a ocorrência de diagnósticos psiquiátricos em 83,9\% da amostra (Silva, Kolling, Carvalho et al., 2009). Entre pessoas em sofrimento psíquico de uma maneira geral, a porcentagem 
encontrada entre pessoas que estavam fazendo tratamento para problemas com o consumo de drogas foi de $34 \%$ (Leal et al., 2012).

De acordo com a revisão, houve grande variação das prevalências de duplo diagnóstico, encontradas nos diversos países que realizaram estudos epidemiológicos. Além disso, autores como (Zaleski et al., 2006) discutem a grande variedade de substâncias utilizadas por esta população, embora grande parte da literatura tenha buscado principalmente as drogas que eram ilícitas nos países estudados. A maior parte dos estudos, segundo esse autor encontrou que as mais prevalentes eram aquelas drogas mais utilizadas na população em geral. A ordem das prevalências pareceu depender das drogas descritas nas publicações da área, bem como os países onde o estudo foi realizado. Além disso, pareceu comum o consumo associado de múltiplas substâncias (Costa, 2011).

Os quadros clínicos associados a essa condição pareceram ser diversos (Rodríguez-Jiménez et al., 2008), embora o diagnóstico mais encontrado ao longo de toda busca bibliográfica foi o de transtornos de humor e transtornos psicóticos. Essa dado coincidiu com o critério levantado por (Santucci, 2012) de busca por utilizar o termo duplo diagnóstico somente para transtornos mentais severos. Os sinais e sintomas mais descritos foram as ideações e tentativas de suicídio (Szerman \& Lopez-Castroman, 2012). Estudos realizados em diferentes países descrevem perfis relativamente homogêneo quanto às características sociodemográficas (Mewton, Teesson, Slade, \& Cottler, 2011). Alguns estudos têm discutido que diferenças nas prevalências do consumo de substâncias na população clínica de pacientes psiquiátricos está relacionada a características socioculturais envolvidas nos processos de adoecimento mental e uso de drogas (Menezes \& Ratto, 2004).

Essa literatura apontou que dentre as variáveis sociodemográficas, as que mais significativamente mostram relação com o uso problemático de drogas são o gênero, idade, relacionamento estável, associação com o emprego e ocupação, morar sozinho e ter autonomia para o cuidado de si, conforme foi apontado em estudos como estudos de autores como (Wüsthoff, Waal, Ruud, \& Gråwe, 2011). Entre essas características, 
foi possível identificar nos estudos um perfil de pessoas usuárias de serviços de saúde mental na faixa etária de trinta a cinquenta anos tendo, na maior parte dos estudos, encontrado prevalência maior entre trinta e quarenta anos (Pomerleau et al., 2012). Autores indicaram que foi mais prevalente o duplo diagnóstico entre indivíduos do gênero masculino (Huang, Schwandt, Ramchandani, George, \& Heilig, 2012), embora essa relação entre a prevalência de consumo de drogas entra pessoas com diagnósticos psiquiátricos variasse quanto ao contexto onde os estudos foram realizados.

O nível educacional das pessoas identificadas nos estudos revisados tendia a ser pelo menos nível fundamental completo, sendo que alguns chegavam ao nível médio, dependendo também dos países onde foram realizados os estudos (Hauli et al., 2011; Keizer, Gex-Fabry, Eytan, \& Bertschy, 2009; Meade, Kershaw, Hansen, \& Sikkema, 2009). Foi relevante também a condição de autonomia e renda dessas pessoas, sendo que em alguns contextos socioculturais permitiam maior autonomia, enquanto em outros ambientes, menos. Isso pareceu refletir na condição de autocuidado como, morar sozinho, ter trabalho remunerado, receber aposentadoria, bem como condições de estabilidade da rede de apoio social (Ries, Yuodelis-Flores, Roy-Byrne, Nilssen, \& Russo, 2009; Stahler \& Mennis, 2009).

Como consequências do duplo diagnóstico a piora no tratamento de saúde mental, maior número de recaídas em relação ao consumo de drogas, maior número de reinternações, aumento do uso de serviços de saúde, maiores níveis de debilidade física, sintomas mais severos dos transtornos psiquiátricos, dificuldade de adesão ao tratamento medicamentoso, mudanças de humor, aumento da agressividade e aumento na vulnerabilidade psicossocial (Glasner-Edwards et al., 2011; Jiménez-Castro, Raventós-Vorst, \& Escamilla, 2012). Apesar disso, Caetano e Babor (2006) consideram que diagnosticar transtornos mentais em pacientes que fazem uso problemático de substâncias é complexo pela sobreposição entre os sintomas, suas flutuações e limites dos instrumentos de triagem, fazendo-se necessárias diretrizes adequadas para a abordagem do assunto. 
Mueser, Drake, \& Wallach (1998) afirmaram que é muito difícil delinear estudos que encontrem fatores etiológicos precisos para a ocorrência de diagnóstico duplo entre transtornos mentais e uso problemático de drogas. Entretanto, a literatura tem discutido quatro hipóteses que podem ser explicativas do diagnóstico duplo de transtornos mentais e uso problemático de substâncias, ainda que com diferentes abordagens teórico-metodológicas. O diagnóstico duplo pode estar associado a um fator em comum que promoveria tanto o desenvolvimento do uso problemático de substâncias, quanto sofrimentos psíquicos passíveis de serem diagnosticados como transtornos mentais. Nesse sentido, esses estudos têm defendido que o uso de drogas descende de piores antecedentes e levam ao início precoce do transtorno mental, bem como a ocorrência de diagnóstico duplo e cursos da doença mais severos, conforme apontaram Pompili et al. (2009).

Outros estudos aponta que problemas com o consumo de drogas são decorrentes de sofrimentos psíquicos severos, sendo o indivíduo nesta condição mais vulnerável a desenvolver uso problemático de drogas. Um exemplo dessa teoria associa o consumo de drogas à automedicação para alívio para determinados comportamentos identificados como sintomas dos transtornos mentais (Swendsen et al., 2010). O sofrimento psíquico diagnosticável como transtorno mental também poderia ser secundário a problemas relacionados ao uso de drogas, a situação de abuso poderia precipitar comportamentos compatíveis com o diagnóstico de transtorno psiquiátrico em indivíduos mais vulneráveis (Cohn et al., 2011).

Sugere-se também como hipótese que o consumo problemático de drogas influencia e é influenciado pelo sofrimento psíquico intenso diagnosticado como transtorno mental. Essa hipótese chamada bidirecional leva em conta que, independentemente da condição que começou primeiro, as duas situações se influenciam ao longo do tempo (Kavanagh \& Connolly, 2009). Estudo com pessoas na condição de diagnóstico duplo tinham dificuldades em parar com o consumo e uso associado de múltiplas drogas (Lineberry, Allen, Nash, \& Galardy, 2009). Além disso, estudos internacionais têm discutido que o diagnóstico de transtorno por uso 
de substância apresentou-se como o terceiro maior preditor de mortalidade segundo o relatório Global Burden of Disease (World Bank, 2007).

Esdras (2004) considera que o tratamento para pessoas que recebem o duplo diagnóstico, na maioria das vezes, não é eficaz. Justifica que essas pessoas podem ter dificuldades em entender e articular seus sentimentos, pensamentos e objetivos, além de não identificar a relação entre o transtorno mental recebido e o comportamento de usar drogas de maneira problemática. A literatura médico-psiquiátrica sugere que estratégias de intervenção em pacientes com duplos diagnósticos devem considerar também a avaliação de diagnósticos psiquiátricos e do consumo durante a intervenção e avaliação do prognóstico para a compreensão dos sintomas (Corradi-Webster, Laprega, \& Furtado, 2009). Essa mesma literatura aponta que o tratamento ideal para o paciente com transtornos psiquiátricos e por uso de substâncias requer atenção, sendo necessário que profissionais de saúde estejam atentos a essa problemática, necessitando ações multiprofissionais integradas.

Para Pinho, Oliveira, \& Almeida (2008) essa forma de atenção vem sendo pouco estudada na literatura no que se refere a essa população, embora tenham sido realizadas algumas tentativas de aplicação da multidisciplinaridade como apontado por Giampieri et al. (2013). Hoff e Rosenheck (1999) relataram que o tratamento de pessoas com diagnósticos duplos é mais caro do que aquele de pacientes com apenas uma dessas condições. Estes autores firmam que essa diferença diminui com o tempo, complementando que diante da lógica de diminuição de custos com o tratamento de pacientes psiquiátricos, aqueles com duplo diagnóstico podem perder espaço dentro dos serviços de atenção em saúde mental. Além disso, alguns autores comentam que eles devem apresentar menos problemas de saúde para serem encaminhados a serviços de saúde mental, por causa da não legitimidade do consumo de drogas (Wüsthoff et al., 2011).

Autores propõem como estratégias para o tratamento a avaliação da influência da rede social no tratamento, a motivação para a mudança de padrão de consumo e o manejo de sentimentos e emoções 
emergentes, principalmente negativos que podem estar envolvidas no processo de tratamento (Todd, Douglas Sellman, \& Robertson, 2002). Enfatiza-se também a necessidade de consideração do contexto circundante onde a pessoa se insere e suas influências na adesão e continuidade no tratamento (MacDonald et al., 2004). Acier, Nadeau, \& Landry (2011) perceberam que os vínculos estabelecidos pelos seus entrevistados eram com familiares, amigos, cônjuge, terapeuta estavam associados ao aumento e diminuição do consumo de drogas. A atenção individual ao paciente tem sido apontada como forma de motivá-lo a aderir ao tratamento, bem como acolher familiares e pessoas de seu círculo social (Fontanella, 2010).

Considera-se que um tratamento cuidadoso é necessário em pessoas com sintomas depressivos ao longo da vida e a efetividade das intervenções com pessoas com uso problemático de drogas deve ser complementada pelo tratamento para depressão (Cohn et al., 2011). Importa, no entanto, ressaltar que para garantir maior efetividade do tratamento, tem sido discutido que é necessário conhecer os significados que são atribuídos a essas experiências, bem como entender que são diferentes os sentidos sobre o diagnóstico duplo (Asher \& Gask, 2010). Isso que pode contribuir para a compreensão das possibilidades de mudança de comportamentos (Corradi-webster, 2013). Assim, intervenções deveriam ser orientadas no sentido de favorecer a construção de sentidos dessa experiência, auxiliando na escolha do paciente de como fazer uso de drogas de maneira a não aumentar os prejuízos, já vivenciados pelo sofrimento psíquico (Childs, McCarthy-Jones, Rowse, \& Turpin, 2011).

\section{Literatura qualitativa sobre o diagnóstico duplo, pelo discurso médico-psiquiátrico}

A literatura qualitativa sobre o diagnóstico duplo tem buscado conhecer sentidos, significados e motivações para o consumo de drogas por pessoas com diagnósticos psiquiátricos. A maior parte dessa 
literatura versou sobre transtornos psicóticos e sobre os transtornos mentais graves em geral e tem compreendido o consumo de drogas como uma estratégia de automedicação, relacionando a cada tipo de droga sentidos específicos do consumo. Essa literatura pareceu estar atrelada ao discurso médicopsiquiátrico, descrevendo as pessoas que receberam o diagnóstico duplo de maneira parecida com o modo como eles foram descritos pela literatura epidemiológica.

Lobbana et al.(2010) descrevem que as motivações para o consumo são dependentes da escolha ativa do indivíduo, mas também apontam que há motivações externas, como aquelas influenciadas por outras pessoas e pelo ambiente cultural. Segundo esses autores, o consumo também pode fazer parte da construção da identidade e do processo de socialização. Outros autores apontaram que o consumo poderia ser promovido por sua legitimidade no ambiente onde ele era feito (Asher \& Gask, 2010). Como respaldo a essa compreensão, essas experiências, quando compartilhadas em grupo e valorizadas por ele, poderiam envolver a vontade de pertencer ao grupo e estar associadas ao início do consumo e à vontade de experimentação de algumas drogas (Laudet \& Magura, 2004).

Algumas pessoas diagnosticadas com transtornos mentais relataram ter dificuldades na socialização e consideraram o consumo de drogas como uma ajuda no engajamento com grupos de pares (Bradizza \& Stasiewicz, 2003). Esse aspecto pareceu conectar essas pessoas ao sentimento de normalidade ao buscar compartilhar com outras pessoas sensações agradáveis (Thornton, Baker, Johnson, Kay-Lambkin, \& Lewin, 2012). Outras pessoas disseram que o que era valorizado no consumo de drogas era a habilidade de oscilar entre a realidade da vida cotidiana e às experiências de sair dela (Bradizza \& Stasiewicz, 2003). Assim, o consumo de drogas poderia ser uma estratégia de descontração e de intoxicação, mas também estratégia de saída de padrões de pensamentos considerados problemáticos (Thornton et al., 2012), uma tentativa de controlar o estado de humor (Healey, Peters, Kinderman, McCraken, \& Moriss, 2009), a ansiedade, a irritação e o estresse (Schofield et al., 2006). 
Essas experiências eram descritas como variáveis em relação ao tipo de droga consumida, mas também variavam de pessoa para pessoa em termos de efeitos, sentidos e significados (Pettersen, Ruud, Ravndal, \& Landheim, 2013). O consumo de cigarro foi descrito como promotor de alívio do estresse, tendo características uso ritual e hábito, dando às pessoas vivenciaram o processo de institucionalização a sensação de controle da própria vida (Thornton et al., 2012). Algumas pessoas relataram o consumo de drogas como álcool, cocaína ou crack, como promotores do esquecimento de situações traumáticas como abusos sexuais e violências sofridas ao longo da vida. Para elas, pelo menos durante o período da intoxicação, era possível diminuir o sentimento de dor e sofrimento (Sou \& Dantas, 2009). O consumo de drogas pareceu influenciar o modo como a pessoa percebe a questão do sofrimento psíquico associado a quadros psicopatológicos (Asher \& Gask, 2010).

No estudo de Costain (2008), algumas drogas também foram percebidas como facilitadoras do sono e da sensação de fome, potencializando nesse caso, os efeitos da medicação antipsicótica, mas também contrabalanceando seus efeitos colaterais. O consumo de drogas poderia promover crises descritas como psicóticas em que as alucinações e delírios eram vividos com intenso sofrimento e isso pareceu ser percebido pelas pessoas que buscavam tratamento para o consumo de drogas (Peters et al, 2009). Nesse grupo, Laudet e Magura (2004) buscaram conhecer razões para a interrupção e para a recaída do consumo de substâncias, descrevendo que as razões para a interrupção pareceram estar associadas a desejos de melhora na qualidade de vida e às consequências negativas do consumo de drogas.

Um aspecto interessante comentado por Costain(2008) foi que a persecutoriedade talvez estivesse relacionada ao status de ilegalidade da maconha e que se ela fosse legalizada, essas sensações não seriam compreendidas da mesma maneira. Além disso, a percepção da associação entre o transtorno mental e o consumo de drogas envolve um processo complexo de construção de sentidos, e as pessoas que vivenciam essa situação pareceram perceber piora nos sintomas quando usavam drogas; entretanto, em alguns relatos, 
as pessoas não estabeleceram essa relação, conforme pontuou (Childs et al., 2011). Com isso, para esse autor, a abstinência ou o controle do consumo vêm sendo descritos como potencialmente prejudicados, merecendo atenção dos profissionais de saúde de serviços de saúde mental e de tratamento para o consumo de drogas.

Portanto, apesar de receberem críticas quanto aos critérios para o que se considera duplo diagnóstico, a literatura qualitativa ainda produz conhecimento sobre essa condição por se apresentar como relevante na prática clínica. A questão vem sendo chamada frequentemente nos serviços de saúde brasileiros como comorbidade e neste trabalho procurei me referir a essa questão em termos de "pessoas identificadas com consumo problemático de drogas, descritas por meio de diagnósticos psiquiátricos" ou descrições parecidas. Essa descrição foi utilizada a fim de promover conversa entre diversos campos do saber, permitindo trânsitos entre diferentes perspectivas. Essa atitude pareceu útil por ampliar o a compreensão sobre a questão estudada, aproximando da experiência vivida em primeira pessoa. Para isso importou refletir sobre a questão do diagnóstico psiquiátrico, procurando elementos que permitissem a construção de compreensões alternativas ao posicionamento médico-psiquiátrico, tradicionalmente utilizado nas pesquisas qualitativas sobre o tema estudado. 


\subsection{O Diagnóstico Psiquiátrico e a Questão do Sofrimento Psíquico}

Autores como Das, Kleinman e Lock (1997), Biehl (2008) discutem que processos culturais legitimam ações compreendidas como tratamentos em resposta a problemas descritos como doença, no caso deste trabalho, aquelas descritas como doença mental. Esses autores, discutem que essas ações derivam de sistemas de crenças que assim as classificam. A literatura médico-psiquiátrica, apresentada no capítulo anterior, historicamente se organizou a partir de compreensões de que as experiências descritas como loucura eram tidas como doença (Estellita-lins, 2000). Estas pessoas passaram a ser classificadas por meio de diagnósticos, sendo alvo de estudo da disciplina Psiquiatria, que se configurou como discurso, regendo formas de compreender e agir sobre o comportamento humano. Nesse discurso, diferentes classificações e justificativas do que se considerava doença mental foram construídas ao longo do tempo e das culturas pertencentes ao bloco de países ocidentais onde este se desenvolveu.

Ganharam legitimidade movimentos que tentavam universalizar condições de saúde no sentido de reunir em compêndios de classificação diagnóstica comportamentos descritos como sinais e sintomas, identificados por estudos clínicos e epidemiológicos, fomentando esforços de identificação de bases biológicas para o aparecimento de doenças ditas mentais. Exemplos atuais do discurso médico-psiquiátrico hegemônico sobre a doença mental são a Classificação Internacional de Doenças (CID) (WHO, 1992) e o Manual Diagnóstico e Estatístico de Doenças Mentais (DSM) (American Psychiatric Association [APA], 1994), que vêm sendo atualizados e ampliados periodicamente. Com esses manuais, buscou-se homogenizar questões de saúde em termos populacionais, focalizando esforços na construção de parâmetros cada vez mais detalhados de diferenciação entre os chamados transtornos mentais (Biehl,2007).

No entanto, pessoas que receberam diagnósticos psiquiátricos foram também alvo de processos de exclusão e controle, em que autores de diversos campos criticaram a postura de anulação do "sujeito-louco" 
e a centralização do poder de produzir verdades sobre a o que se considerava loucura (Severo, 2006). Movimentos contrários a essas práticas ganharam força, levantando-se como contraponto à Psiquiatria enquanto disciplina fundamental para o estudo de transtornos mentais. Esses movimentos compreendiam novas perspectivas sobre comportamentos tidos como loucura, construindo um discurso alternativo, chamado genericamente de Psicossocial (Amarante, 2007).

Enquanto o discurso médico-psiquiátrico recebeu e ainda recebe críticas por seu foco em aspectos constitucionais e biológicos da doença mental, o discurso psicossocial buscou se utilizar de um posicionamento crítico sobre a doença mental, considerando-a como parte de processos de resistência à norma estabelecida, segundo Severo (2006). O discurso psicossocial, segundo este autor, se utiliza da lógica de construção de práticas de "restituição da subjetividade" das pessoas que foram alvo de diagnósticos psiquiátricos sem, no entanto, negar seus comportamentos como doença. Esse discurso se orienta pela compreensão dessas pessoas como cidadãs que sofrem psiquicamente (Rovatti, 2013).

No entanto, a crítica que se faz ao discurso psicossocial, ao menos no caso brasileiro, é que ele não se contrapõe epistemologicamente ao discurso médico-psiquiátrico, antes o amplia e o engloba (Severo, 2006). Tanto o discurso médico-psiquiátrico como o discurso psicossocial foram discursos que influenciaram a construção do sistema de saúde brasileiro, embora vários outros discursos e modelos de atenção em saúde mental tenham sido importantes para a criação deste (Amarante, 2007). No entanto, estes dois discursos são de tal maneira importantes que integram e se misturam nas práticas cotidianas dos serviços, compondo o sistema de crenças hegemônico em saúde mental brasileiro. Eles foram adotados por diferentes lideranças do Movimento de Reforma Psiquiátrica Brasileira e Reforma Sanitária Brasileira (Terra, Ribas, Sarturi \& Erdmann, 2006), sobre os quais estão pautadas políticas públicas em saúde mental e drogas.

Dentre os objetivos do movimento político da Reforma Psiquiátrica se buscou, e ainda busca, reformulações no modo de lidar com a saúde mental em serviços públicos de saúde. Sua proposta foi 
orientar esforços em recursos no território onde a pessoa se inseria, de maneira a sair da lógica asilar hospitalocêntrica, procurando instituir serviços comunitários de atenção em saúde mental (Guerra, 2004). No entanto, essa proposta encontra vários obstáculos para sua realização como por exemplo a falta de investimentos financeiros em equipamentos comunitários (Andreoli, Almeida-Filho, Martin, Mateus, \& Jesus, 2007). (Minelli, 2013) ressaltou que no campo da saúde mental existem cotidianamente, embates político-ideológicos que fortalecem determinados interesses e práticas de cuidado em detrimento de outras propostas. Nesse sentido, o modelo público de atenção em saúde mental atual, partiu de um modelo asilar centralizado na figura do médico para uma proposta descentralizada, multiprofissional e territorial (Pitta, 2011).

Foram criadas estratégias de cuidado e de incentivo à desinstitucionalização, além de serviços substitutivos ao hospital psiquiátrico, por meio de leis e portarias, ao longo dos anos 1990 e 2000, com avanços e retrocessos no campo político e institucional quanto às práticas de atenção aos usuários dos serviços (Luzio \& Yasui, 2010). Assim, o equipamento de saúde mental brasileiro vem se organizando por meio de princípios comunitários, caracterizando-se por uma Rede de Atenção Psicossocial (RAPS) em saúde mental em três níveis de atenção. A RAPS se integra ao Sistema Único de Saúde (SUS), nos níveis Municipal, Estadual e Federal, atendendo às políticas de atenção e promoção de saúde (Alvarenga \& Dimenstein, 2006).

Essa rede organiza-se em: Centros de Atenção Psicossocial (CAPS), unidades extra hospitalares divididas por níveis de complexidade de atendimento e consideração do território onde se inserem (I, II, III): CAPS I para cidades de pequeno porte, CAPS II: serviço de semi-internação a ambulatorial, CAPS III: serviços de semi-internação, CAPS-i para atendimento infantil. Além desses, também conta com Núcleo de Apoio Psicossocial (NAPS), Hospitais-Dia e Ambulatórios de Saúde Mental, Unidades de Emergência Psiquiátrica, leitos psiquiátricos em Hospitais Gerais e em Hospitais Especializados em Psiquiatria, 
Enfermaria Psiquiátrica em Hospitais Gerais, Moradias Assistidas, Serviços Residenciais Terapêuticos, Centros de Convivência e atendimento na Atenção Básica, como porta de entrada do usuário no serviço de saúde e tratamento de transtornos mentais mais comuns integrados a outros serviços por meio de matriciamentos (Brasil, 2004).

Na RAPS, também estão dispostos serviços de atenção à problemas relacionados ao consumo de drogas, estratégia de atenção que foi implementada na Política Nacional de Atenção à Saúde Mental (Brasil, 2004), tema que será explorado no próximo capítulo. Esse processo, que se iniciou nos anos 1980 e se considera que ainda está em curso (Pitta, 2011), vem sendo visto por autores como Luzio e Yasui, (2010) como em um período de transição entre um modelo manicomial e esforços de desinstitucionalização. Além de pessoas classificadas tradicionalmente com transtornos mentais, outras categorias de pessoas têm sido alvo de constantes movimentos de exclusão e asilamento, tais como usuários de drogas e pessoas em situação de rua, representando um desafio à valorização da subjetividade, por meio da promoção de saúde nos diversos aparelhos interventivos do SUS (Pitta, 2011).

Apesar disso, alguns autores discutam que a inclusão desse grupo como alvo de ações no campo da saúde seriam reflexos do processo de medicalização da vida (Biehl, 2008). Portanto, é possível observar uma mistura de discursos e práticas sobre a saúde mental e seu tratamento. Por um lado, o processo de Reforma Psiquiátrica brasileiro buscou substituir o manicômio por serviços de base territorial, por outro lado, é possível encontrar intensos movimentos contrários à desinstitucionalização, como é o caso relacionado a políticas de drogas, que será explorada mais adiante. Com movimentos de avanços e retrocessos do processo de implantação do Modelo de Atenção Psicossocial, o tratamento proposto, em linhas gerais, teve como objetivo destacar a pessoa da doença (Dalmolin \& Vasconcellos, 2015), pretendendo olhar para o contexto onde ela se insere, buscando também traçar modos de agir sobre ele, entendendo que a pessoa também pode ser descrita para além de seu diagnóstico psiquiátrico. 
Autores sustentam que atualmente processos de medicalização das experiências sob a forma de normalização e regulação das pessoas em categorias patológicas podem ser por vezes úteis ao entendimento de determinada condição, orientando práticas de atenção à saúde (Das et al, 1997). Em um trabalho anterior (Vieira, 2012), identifiquei que profissionais de saúde consideraram que houve, nos últimos anos, avanços quanto a tecnologias de tratamento em saúde mental em termos de medicamentos. No entanto, consideraram que esses avanços não foram maiores por conta das dificuldades nas relações institucionais, tanto para profissionais como para os usuários dos serviços da RAPS. Além disso, a costura dessa rede e a comunicação entre serviços parece favorecer o fenômeno de idas e vindas de serviços de internação por dificuldades de manutenção da rede de relações com o território.

Quando se toma como ponto de vista dos usuários atendidos em serviços comunitários, as repercussões do diagnóstico psiquiátrico na vida e as relações de quem recebeu essa descrição, autores como Aragaki, (2006) perceberam que houve certa diminuição das possibilidades de trocas sociais mesmo depois do movimento de reforma psiquiátrica. Estas pessoas, segundo este autor, ainda eram posicionadas em lugares de exclusão e submissão em suas relações sociais e institucionais. (Dalmolin \& Vasconcellos, 2015) identificaram que os profissionais de saúde de serviços comunitários de saúde mental concebiam de duas maneiras as pessoas que atendiam: de uma maneira "manicomial" e de uma maneira "comunitária". E essas identificações se envolvem em uma teia complexa de relações como as familiares, entre pares, de trabalho que são influenciadas pelas descrições recebidas nos serviços de saúde mental.

Autores como Kleinman e Kleinman, (1991) argumentam que frequentemente as relações institucionais que envolvem as pessoas do entorno de quem recebe diagnósticos psiquiátricos podem tomar formas de violência. Apesar de serem naturalizadas ,talvez em outro período histórico ou contexto, essas descrições poderiam ser diferentes em outros contextos. Assim, para Biehl (2007) as relações de poder estabelecidas entre quem recebe diagnósticos e quem não recebe ou tem o poder de posicionar pessoas desse modo, no cotidiano das instituições, parecem aprofundar mais que auxiliar processos de exclusão e 
sofrimento. Segundo esse autor, descrições de sinais e sintomas, na prática de serviços de saúde, vêm sendo utilizados a partir da padronização dos quadros clínicos, sendo construídos a partir de determinados regimes de tratamento e de verdade em compreensões sobre saúde, como por exemplo a construção de políticas públicas pautadas no discurso médico-psiquiátrico.

Minelli (2014) discute que, no processo de desinstitucionalização, o trabalho de profissionais de saúde mental faz parte do processo de construção das práticas nesse campo. De um lado, por meio dele se desenvolvem relações potencialmente transformadoras, por outro lado, carregam aspectos rígidos burocráticos. O autor argumenta que esse processo acontece no cotidiano, contextualizado em políticas públicas, interesses e possibilidades ao nível internacional, nacional, estadual, municipal e local específicas. Faz, então, parte desse processo, a adequação dos processos de cuidado em saúde na lógica de mercado. Ou seja, processos de dor e sofrimento são transformados por racionalidades e tecnologias, produzindo um mercado de produtos, serviços e práticas que visam a remissão, a diminuição ou a melhora de experiências descritas como patológicas (Das et al., 1997).

Por outro lado, deslegitimam outros recursos disponibilizados pela cultura local como resposta a processos de sofrimento (Das et al., 1997). Esse processo acaba por tornar homogênea experiências de sofrimento, aprofundando o poder do discurso médico-psiquiátrico sobre as descrições de experiências, de maneira que se suprime formas próprias e criativas de lidar com elas (Biehl, 2008). Reforça-se, então, a busca por estratégias quase mágicas de solução de problemas que são mais complexos que a necessidade de ingestão de medicamentos (Biehl, 2011). Nesse panorama crítico delineado, busquei me orientar sobre a questão do sofrimento psíquico como alternativa ao discurso médico-psiquiátrico.

Com base na leitura feita por Dalmolin e Vasconcelos (2008), a questão do sofrimento psíquico, muitas vezes é colocada como sinônimo de doença mental, sendo atravessada por condições que promovem vulnerabilidade para seu aparecimento enquanto transtorno mental, sendo sempre contextualizado local e 
historicamente. Ao tomar o sofrimento psíquico como sinônimo de doença mental, a autora compreende essa categoria de maneira a abranger fenômenos complexos de pensamentos e experiências inseridas em um contexto mais amplo, mas também vividas de maneira singular. Ela define sofrimento psíquico como manifestações de características psíquicas na vida de uma pessoa, o que pode ter como sinônimo a doença mental. Esses elementos descritos como doença mental trazem à pessoa também expressivo sofrimento psíquico, o que repercute na história de vida e transcende os momentos pontuais de crise (Dalmolin, 2006).

Olhar para essa questão, para Dalmolin e Vasconcellos (2015), significa compreender o sujeito em seu contexto intersubjetivo e sociocultural, como possibilidade de ampliar a identificação com outro que não foi descrito dessa maneira, inserido em papeis sociais mais ou menos legitimados em um determinado território que se conecta a um contexto mais amplo. Essa visão reforça a necessidade de superação de uma prática que transforma esse processo em experiências destituídas de sentido. A proposta dessas autoras, portanto, foi buscar aproximação com questões descritas como sofrimento psíquico como forma de produzir conhecimento sobre relações sociais inseridas no cotidiano de territórios urbanos. Essas autoras compreendem que o sofrimento psíquico está inserido em trajetórias subjetivas que são muito mais que sintomas de doença mental.

São aspectos que emergem de determinadas rupturas entre o mundo pessoal e o social, provocando um descompasso entre o que é vivido e o que é esperado socialmente e culturalmente. Isso significa reconhecer que também se fazem presentes possibilidades de enfrentamento desde que não se persiga a "normalidade" estabelecida e hegemônica (Dalmolin, 2006). Essas pessoas, para (Dalmolin \& Vasconcellos, 2015) também estão imersas em diferentes dinâmicas sociais em que emergem diferentes formas de apropriação de si mesmos e dos espaços frequentados. Portanto, o sofrimento psíquico envolve sistemas de significação para a pessoa compreendida como inserida no contexto onde vive. Quanto a isso, Young (1997) qualificou que o sofrimento psíquico também pode ser observado em sua dimensão social, sendo 
identificado e compreendido localmente pelos grupos e comunidades, com base em códigos culturais e sociais.

Duarte (2003), propôs que o termo sofrimento também se referia a situações ou eventos que afetam aspectos das relações de valor e auto-representação. Esse autor (Duarte, 1993), criticou a postura de orientar pesquisas sobre sofrimento de maneira a encaixá-los em categorias comparáveis às existentes em diferentes culturas. Nesse sentido, propôs que, ao menos na cultura brasileira, sob diferentes formas o sofrimento parece comunicar uma experiência social ao mesmo tempo, mais ampla e diversificada do que pode ser a “doença", e que não se limita a uma categoria diagnóstica, senão várias. Farmer (1997) também considerou que sofrimento congrega uma variedade de experiências, que podem ser vividas individualmente, embora sejam ao mesmo tempo experiências singulares e sociais. Suas raízes, portanto, estariam ligadas a processos sociais e políticos de violência e a opressão.

Algumas situações, nesse sentido, provocariam sofrimentos compartilhados socialmente e se considera que a violência descrita como estrutural (Farmer, 1997) ou subjetiva (Adorno et al. ,2011) é uma delas. Essa violência se caracterizaria por situações cotidianas experimentadas direta ou indiretamente, mas também são possíveis de serem percebidas histórica e imaginariamente diante da brutalidade de relações sociais e institucionais em eventos críticos que transformam os modos vividos anteriormente (Carvalho, 2008). Portanto, sofrimentos sociais, neste trabalho, foram compreendidos como sendo vividos individualmente também como sofrimentos psíquicos, que podem ter como sinônimo o diagnóstico de transtorno mental, embora não se limitem a ele. Contemplam ainda expressões de resistência por meio da criação de um uso da linguagem e do corpo de maneiras singulares, mas que estão coletivamente conectadas pela experiência cultural e social.

Para essa compreensão, me remeto ao conceito de "capacidade de agir", como um constructo que transmite ideia de atos de resistência ao status quo, mas também podem ser atos de reforço a ele, conforme 
apresentou Ahearn, (2001). Segundo essa autora, longe de ser uma prática de livre arbítrio, estas ações são descritas como parte da capacidade humana de agir, tendo origem na sobreposição de vínculos sociais, culturais e linguísticos que precedem essas ações. Pode ser descrita de maneira coletiva, se referindo a ações de grupos, comunidades e instituições, mas também ao nível individual, do qual participam diálogos interiores e a subjetividade vista como fragmentada e complexa, a autora ressalva que o que se propõe como capacidade de agir parece ser orientado a ligar experiências singulares a contextos e discursos mais amplos, como por exemplo, a questões relativas ao gênero, etnia e classe social.

Portanto, para Ahearn, (2001), mais do que colocar rótulos, deve-se valorizar a análise das ações humanas como uma linguagem, sendo tomadas como uma prática social. Assim, a capacidade de agir se manifestaria por meio da linguagem. (Pizza, 2005) se utilizou dessa leitura, considerando que a noção de capacidade de agir influencia e modifica relações sociais e políticas instituídas. Ao mesmo tempo, essas mesmas relações influenciam e circunscrevem a capacidade de agir dos sujeitos, numa via de mão dupla. Ele considera que a noção de capacidade de agir humana para além de se submeter a um determinismo social e cultural, impulsiona processos de transformação da cultura e da sociedade. Esse autor coloca foco no sujeito “encarnado". E nesse sentido, a capacidade de agir não seria só resistir, mas também orientar-se em ações não conformistas por meio da vontade de transformação.

Sobre isso, o foco preferido por Pizza (2005) foi o da experiência, inserida no cotidiano. Ele explica, que transformações no modo de pensar e agir são não só situacionais, como também são políticas, sendo o corpo um terreno de conflito. Assim, o sofrimento psíquico poderia ser interpretado como o resultado de processos de encorporação ${ }^{1}$ de conflitos atuantes nas relações de poder que regulam a experiência humana. Minelli (2006) se utilizou dessas compreensões para falar que quando usuários de serviços de saúde mental

\footnotetext{
Utilizei da expressão encorporar como foi trabalhada por (Vargas 2001) como sinônimo de embodiment, conceito que está relacionado ao processo de transformar e tomar corpo, superando o dualismo mente/corpo.
} 
recebem diagnósticos psiquiátricos e fazem tratamento nesses locais, suas ações cotidianas são limitadas e/ou ampliadas. Argumentou que estas pessoas dinamicamente escolhem e simultaneamente são posicionadas de acordo com suas necessidades e vontades sempre em relação com um entorno que apoia e legitima determinadas práticas e não outras em jogos dinâmicos de figura e fundo (Minelli, 2006). Esse autor (Minelli, 2013), considerou que essas relações estão sempre contextualizadas, cujas consequências influenciam processos de reconhecimento entre profissionais de saúde e pacientes.

Apoiada nessas compreensões e estimulada pelo do discurso psicossocial basagliano (Rovatti, 2013) para que coloquemos a questão da doença mental em suspensão, busquei adotar uma postura crítica com relação ao sofrimento psíquico como sinônimo de diagnóstico psiquiátrico. Considerei que as pessoas participantes deste estudo, na perspectiva delas, compreendiam suas experiências como imersas nos seus cotidianos e sobre as quais em diferentes momentos são atribuídos diferentes sentidos e significados, singulares sim, mas conectados a contextos mais amplos. Importou refletir sobre experiências de sofrimento psíquico quando este estava associado ao consumo de drogas, ao longo das vidas dos participantes. Estes vêm sendo posicionados de determinados modos pelos diversos discursos presentes em contextos de saúde, de acordo com políticas públicas, relações, construindo descrições de si singulares, sobre as quais os participantes deste trabalho agem cotidianamente. A partir dessa compreensão importa introduzir neste trabalho o tema das drogas no contexto de tratamentos de saúde mental, apresentando uma literatura que patológica esse consumo bem como uma literatura que se posiciona de maneira crítica a essa descrição. 


\subsection{O tema das drogas e o contexto de tratamentos de saúde mental}

Atualmente se considera que o consumo de drogas é um problema de ordem social, da saúde e objeto de atenção, classificação e controle, sendo uma questão tomada como desviante de uma norma hegemônica. Apesar disso, o consumo de drogas ao longo da história humana tem sido descrito como presente e disseminado em diferentes culturas e só há pouco mais de um século passou a ser descrito dessa maneira (Fiore, 2013). As drogas têm sido definidas como substâncias psicoativas que promovem, em diferentes graus - dose e tempo dependentes - alterações de senso-percepção e do comportamento seja estimulando, inibindo ou perturbando a consciência, o sentimento e o humor de que as consome. Podem ser diferentes substâncias e compostos, sendo bebidas, inaladas, injetadas, ingeridas ou mesmo consumidas de outras maneiras de acordo com práticas e costumes social e culturalmente definidos (Carneiro,2005).

Por terem práticas de consumo culturalmente construídas, se relaciona que sentidos diversos desse consumo sejam construídos, de acordo com o entorno onde seu consumo se insere e dessa maneira, algumas substâncias são mais legitimadas que outras, sendo algumas reconhecidas como drogas enquanto outras não. Este termo geralmente se refere a substâncias ilícitas, mais que às lícitas (Simões, 2008). Esse consumo vem sendo discutido pelo discurso médico-psiquiátrico, de maneira que pessoas são descritas como portadoras de uma doença mental e recebem diagnósticos psiquiátricos a partir da identificação e descrição de prejuízos relacionados ao comportamento social, interpessoal e mesmo desvios de uma determinada normalidade quanto ao humor ou juízo crítico da realidade, segundo a Classificação Internacional de Doenças em sua décima edição (CID-10) (WHO, 1992).

Deste ponto de vista, o consumo de drogas descrito como doença nasceu da sua compreensão moral como vício, fraqueza de caráter e intemperança associados ao consumo do ópio, do álcool e de outras drogas durante o século XIX, nos Estados Unidos. O status de que o consumo de drogas é uma doença, segundo 
esse discurso, se associava ao apetite mórbido e compulsivo de busca pela intoxicação, associando a questões como vontade descontrolada e irresponsabilidade regidas pela via biológica (Fiore, 2008). Essa compreensão implicaria na elaboração de estratégias de tratamento e cuidado direcionados ao indivíduo. Orientaria intervenções a fim de promover o controle do consumo, como apresentado no capítulo referente à revisão de literatura médico-psiquiátrica do duplo diagnóstico, que se insere nessa lógica. Mas também se pauta na proibição e a criminalização das substâncias consumidas.

O discurso médico-psiquiátrico sobre o consumo de drogas, vem sendo recebendo críticas de que ele vem sendo influenciado pelo sub influência do discurso proibicionista. Este discurso na contemporaneidade, vem sendo visto como atendendo a interesses de mercado no contexto da globalização (Rehm, Taylor, \& Room, 2006). Essa lógica, quando aplicada a determinados contextos, se reverte em práticas de exclusão de certa população e valorização de certos modos de vida em detrimento de outros (Torcato, Soares, CorradiWebster, Carneiro, \& Adorno, 2013) e o aprofundamento de desigualdades sociais (Adorno et al., 2011). A literatura médico-psiquiátrica sobre drogas tem também discutido o consumo caracterizado como doença quando este é feito em um padrão considerado excessivo, promovendo problemas em termos de saúde física, psicológica e relacional (Fiore, 2004).

Foram, portanto, criadas diferentes classificações de padrões de consumo, relacionadas ao tempo de uso e a prejuízos associados, sendo reconhecidos como: uso recreativo, de abuso, nocivo, de dependência; ou uso de baixo, médio e alto risco para desenvolvimento de doenças físicas ou mentais (Zaleski et al., 2006). Para sua classificação ao nível transcultural, têm sido elaborados diversos critérios do que se considera problema relacionado ao consumo de drogas, sendo os mais utilizados aqueles elaborados na CID-10. Essa classificação tem como critérios para a dependência o conjunto de fenômenos comportamentais, cognitivos e fisiológicos que se desenvolvem após o uso repetido de uma droga, associado ao forte desejo de consumir e à dificuldade de seu controle. Refere-se também à utilização persistente desta substância, apesar das suas 
consequências negativas relacionadas, a maior prioridade dada ao uso da droga em detrimento de outras atividades e obrigações, aumento da tolerância pela droga e estado de abstinência física (WHO, 2002).

Com relação aos critérios do Manual Diagnóstico e Estatístico de Doenças Mentais em sua quarta edição revisada (DSM-IV-TR) (APA, 1994), é apontado um padrão mal adaptativo de uso de uma substância. Este é manifestado por consequências adversas recorrentes e significativas relacionadas a seu uso repetido e a um conjunto de sintomas cognitivos, comportamentais e fisiológicos indicando que o indivíduo continua utilizando a droga, apesar de problemas significativos relacionados a ela. A definição de dependência também se relaciona ao desenvolvimento de tolerância, abstinência e comportamento compulsivo de consumo; desejo persistente de reduzir ou regular o uso; e dispensa de muito tempo obtendo, usando ou recuperando-se dos efeitos do uso da droga. Mudanças no sistema de classificação dos manuais diagnósticos do campo da saúde mental têm sido discutidas e o Manual Diagnóstico e Estatístico de Doenças Mentais em sua quinta edição (DSM-V) traz mudanças no sentido de combinar as categorias já existentes na edição anterior em uma única categoria, separada pelo tipo de substância utilizada, mensurada como um contínuo de leve a severo (Mewton,et al., 2011).

Anteriormente o critério diagnóstico se relacionava a um único sintoma, enquanto na edição do DSM-V se considera ser necessário o preenchimento de ao menos três sintomas de uma lista de onze (APA, 2013). Ao introduzir o conceito de "dimensão" do sofrimento psíquico como uma medida da intensidade e gravidade dos sintomas, em que são levados em conta indicadores subjetivos de sofrimento e o grau de prejuízo associados ao transtorno (Mewton et al., 2011). Apesar dessas mudanças nos critérios de classificação do consumo de drogas como problema de saúde mental, ainda persiste a orientação do discurso proibicionista que posiciona o usuário como único responsável pelos problemas com o consumo de drogas. Esses problemas ainda são descritos como tendo origem na constituição das pessoas, necessitando de controle sobre os comportamentos a partir de um referencial externo a pessoa (Carneiro, 2008). 
Sob o ponto de vista do discurso psicossocial, alternativas à compreensão do discurso médicopsiquiátrico vêm sendo discutidas no campo das drogas, associando os problemas com o consumo ao contexto das relações socioculturais onde a pessoa se insere. Essas alternativas, vêm associando estratégias de cuidado por meio de estratégias comunitárias de ação, para além do discurso da doença (Corradi-Webster, 2013). Um exemplo é o caso da estratégia de Redução de Danos, que tem como premissa a assunção de que alguns comportamentos apresentam riscos em que se busca a minimização de danos causados por esses comportamentos (Fiore, 2008). No entanto, ainda assim, se utiliza do discurso médico-psiquiátrico para falar sobre danos e riscos, utilizando de uma estratégia retórica desse discurso que se apropria da experiência humana por meio de técnicas e dispositivos médicos para assegurar a "vida" das pessoas que as consumem, embora por esses métodos, por vezes se reforcem processos de exclusão e dominação (Bourgois \& Schonberg, 2009).

A partir da contribuição de autores das Ciências Humanas de que aspectos históricos e culturais estão envolvidos na relação humana com as drogas (MacRae, 2004), se compreende que consumos de diferentes drogas podem ser vistos ou não como problema em uma determinada cultura ou contexto social (Room, 1969). E nesse sentido, são destacados outros aspectos para além da ação farmacológica das drogas no corpo, importando também atitudes e personalidade do usuário, o ambiente de uso e seu contexto (MacRae, 2010). Alguns autores vêm interpretando que as drogas podem ser utilizadas como um dispositivo de poder. Vargas (2008) explica que essa literatura vem associando o consumo a um contexto mais amplo de discursos de verdade, e nesse sentido, seu uso demarca a capacidade de agir humana diante de certas relações de poder instituídas social e historicamente.

Por essa vertente de pensamento, se compreende que as consequências atribuídas a ele sofrem influência do modo como essa substância é vista socialmente, bem como o contexto onde ela é consumida (Henman, 2008). As legitimidades presentes no consumo de drogas apresentam-se por meio de discursos 
diferentes, mas também contextos sociais e culturais distintos que modificam compreensões e efeitos do consumo. Assim, problemas relacionados ao consumo vêm sendo discutidos como associados a situações de vulnerabilidade para sua existência. Essa questão tem sido tratada por (Silva \& Adorno, 2013) como uma questão que merece atenção, provocando reflexões no sentido de desconstruir o termo vulnerabilidade. Para esses autores, vulnerabilidade é tomada em um sentido mais amplo, considerada como resposta a situações limites, aos agravos e sofrimentos vividos no cotidiano, sendo posicionados em lugares sociais em que passam a viver constrangimentos, doenças, pobrezas, acidentes.

Essa questão vem sendo compreendida em função das respostas adaptativas ou não em que as pessoas descritas como em situação de vulnerabilidade passam a ser dispostas ou tratadas (Silva \& Adorno, 2013). Essas situações vêm sendo atribuídas a relações de violências estruturais existentes na sociedade contexto capitalista (Farmer, 1997). Essas violências, retomando o conceito trazido no capítulo anterior, promoveriam sofrimentos sociais. Assim, alguns tipos de sofrimentos não são resultados acidentais, mas podem ser interpretados como consequências diretas ou indiretas da capacidade de agir humana face a violências estruturais. Assim, fatores como etnia, gênero, status socioeconômico pode cada um demonstrar que participam na construção de indivíduos e grupos vulneráveis para o sofrimento humano extremo de maneira simultânea, como axiais que complexamente contribuem de maneira diferente em cada contexto e época histórica para a construção do sofrimento humano.

A questão das drogas é fortemente influenciada por essas questões de sofrimento social (Malfitano, Adorno \& Lopes, 2011). Além disso, o modo como drogas e seus consumidores são vistos parece influenciar na exposição à vulnerabilidades (David \& Caufield, 2005) estando associadas à classe social pobre, a etnia negra e tendo nuances influenciadas por discursos de gênero, entre outras questões, como por exemplo, processos de patologização da pobreza (Hansen, Bourgois, \& Drucker, 2014). Além disso, vem sendo compreendido como inserido da lógica da globalização e do modo de vida capitalista ocidental, sendo que 
as perspectivas locais são tomadas como fazendo parte de um mosaico que não pode ignorar sua conexão com um cenário internacional (Bourgois, 2012). Embora se possa observar respostas locais a esses processos.

Isso significa dizer que no cenário globalizado internacional, estão presentes ideais de vida hegemônicos ligados ao acesso a bens e consumos e à lógica de mercado sobre os quais se considera que também as drogas fazem parte, porque também passam pelo acesso a determinadas drogas e não outras nos contextos locais (Quesada, Hart, \& Bourgois, 2011). No Brasil, pela vertente crítica ao modelo médicopsiquiátrico sobre essa questão, vêm sendo feitas leituras desde as políticas públicas de tratamento para usuários de drogas (Volcov \& Vasconcellos, 2013), bem como com a produção de pesquisas críticas em relação ao acesso à questões de saúde de qualidade por grupos de pessoas que historicamente são alvo de movimentos repressivos que reforçam processos de violência e exclusão (Adorno, 1999). Dentre essas pesquisas também existem aquelas que se orientam para conhecer a subjetividade da pessoa que faz uso de drogas (Corradi-Webster, 2009).

No que se refere às políticas de atenção ao consumo de drogas, por um lado ela está associada ao discurso proibicionista que no campo da saúde se orienta pela busca da abstinência como objetivo do tratamento, bem como a prevenção do consumo de drogas (Alves, 2009). Historicamente esse foi o modo predominante de tratamento da questão do consumo de drogas, juntamente com a criminalização do tráfico e do consumo (Santos \& Oliveira, 2012). Exemplos foram a criação de centros de tratamento, pesquisas sobre prevenção do consumo, ampliação de comunidades terapêuticas por meio do financiamento pelo SUS de internações nessas comunidades (Volcov \& Vasconcellos, 2013). Faz parte também desse discurso o alarme social sobre o consumo de drogas, de maneira que produz processos de exclusão do usuário, aprofundando processos de vulnerabilidade (Romani \& Roso2014).

Por outro lado, este ligado à questão da saúde do usuário como tema de saúde pública, nos últimos 30 anos, em um movimento concomitante com a Reforma Sanitária, foram criadas algumas iniciativas no 
sentido de atenção ao usuário de drogas (Santos \& Oliveira, 2012). Vem sendo propostas intervenções alternativas ao proibicionismo, como por exemplo, estratégias de redução de danos em grupos sociais considerados de alta vulnerabilidade (Silva \& Adorno, 2013). Exemplos são as políticas direcionadas a usuários de drogas voltadas para a prevenção da infecção da síndrome da imunodeficiência adquirida (AIDS) e iniciativas de redução de danos de problemas relacionados ao consumo, buscando estratégias multiprofissionais de ação junto a populações moradoras de rua. Outras linhas de atenção vem sendo a proposta de trabalhos comunitários de promoção de emancipação por meio de coletivos e movimentos sociais de maneira a promover a discussão sobre o acesso a direitos da população usuária de drogas mais marginalizada (Adorno et al., 2013).

Como dois processos quase paralelos, a política sobre o consumo de drogas, em e as políticas de reforma do modelo asilar de tratamento em saúde mental, ao nível federal, foram assumidas políticas públicas que preconizavam a necessidade de tratamento, recuperação e (re)inserção da pessoa descrita como usuária de drogas (Santos \& Oliveira, 2012). A operacionalização dessas políticas públicas voltadas à saúde vieram a partir da consolidação do SUS e da Reforma Psiquiátrica, anteriormente tratada sob o olhar da saúde mental, passaram a orientar a construção de dispositivos especializados na questão de problemas com o consumo de álcool e drogas ilícitas por meio do Centro de Atenção Psicossocial para problemas relacionados ao consumo de álcool e outras drogas (CAPS-AD) (Santos \& Oliveira, 2012). Este serviço foi criado como parte integrante da Política de Nacional Saúde Mental (São Paulo, 2004) e da RAPS. A rede de atenção a usuários de drogas vem sendo composta por diversos equipamentos públicos da rede de atenção à saúde mental desde os CAPS AD a alas específicas para usuários de drogas em hospitais psiquiátricos públicos e estabelecimentos privados como clínicas particulares especializadas e/ou religiosas. O objetivo desses últimos são em tese o tratamento, a recuperação e reinserção social dos usuários (Martins, 2012).

Essas redes de serviços estão interligadas ao nível estadual (referente ao território onde este estudo foi realizado) e fazem parte da política de atenção à saúde, inserindo-se no Plano Estadual de Saúde. - 2012- 
2015 (vigente na época de realização do estudo). Este plano preconizava em tese, o fortalecimento da rede de saúde mental, com ênfase no enfrentamento da dependência do crack e outras drogas ilícitas. Essa proposta vem recebendo críticas por seu caráter manicomial, contraposto ao preconizado pelo Movimento da Reforma Psiquiátrica. Uma dessas críticas tem sido com relação à facilitação e promoção de políticas voltadas a internações de caráter involuntário e compulsórias. Essa estratégia foi criticada por (Volcov \& Vasconcellos, 2013) por ter seguido a tendência da política de judicialização do cuidado em saúde mental, que não leva em conta aspectos sociais e da subjetividade presentes na problemática do consumo. Essa questão, tratada dessa maneira comprometeria a condição de cuidado de profissionais de saúde mental por produzir situações de que propiciariam maior vulnerabilidade às pessoas que usam drogas (Vieira, Caldana, \& Corradi-Webster, 2013).

Considera-se que pessoas em tratamento em serviços de saúde mental são figuras chave que exemplificam isso, mas para além delas, todo um entorno se configura para sustentar esse status quo (Rauter \& Peixoto, 2009). Há vários discursos dentro do campo das drogas que buscam entender a razão para o consumo. Essa literatura permite trazer compreensões interessantes para a reflexão questões do consumo de drogas em relação ao campo da saúde pública e saúde mental de maneira mais abrangente e contextualizada social e historicamente, conectada a outras localidades de uma maneira global. Essa perspectiva no que se referiu a este trabalho, ofereceu uma perspectiva para além do discurso médico-psiquiátrico, promovendo a construção de novas possibilidades de ação e reflexão crítica sobre o consumo considerado problemático de drogas apresentado na realidade clínica cotidiana de serviços de tratamento em saúde mental e de drogas por pessoas identificadas como em sofrimento psíquico. 


\subsection{Justificativa}

O discurso médico-psiquiátrico discute a questão do diagnóstico duplo, por meio de estudos quantitativos e epidemiológicos. Percebi que essas pesquisas vêm construindo descrições de pessoas incapazes de dizer sobre si mesmas, em situação de vida degradante, necessitando de ajuda de outras pessoas para cuidar de si mesmos. Estudos realizados na abordagem qualitativa vêm buscando conhecer sentidos e significados e razões relatadas para o consumo de drogas entre pessoas que receberam diagnósticos psiquiátricos, sendo muitas vezes orientadas pelo discurso proibicionista da abstinência.

Autores do campo da saúde mental vêm problematizando a questão do sofrimento psíquico como doença mental e alinhar críticas com relação a necessidade de considerar o impacto do diagnóstico psiquiátrico na subjetividade de quem o recebe. Outros autores vem trabalhando para legitimar e dar voz a movimentos criativos próprios dessas pessoas, percebendo sua capacidade de agir diante das diversas situações de vida, contextualizadas de maneira mais ampla.

Com relação ao tema das drogas, boa parte da literatura se utilize do discurso médico-psiquiátrico e proibicionista. Outros autores vêm procurando levar em conta o contexto onde o consumo de drogas é realizado e os sentidos desse consumo, considerando que são social e historicamente circunscritos. Nesse sentido, discutem a necessidade de levar em conta que muitas vezes o consumo de drogas é uma estratégia de ação diante violências com relação ao gênero, etnia e à dificuldade de acesso a bens de consumo e direitos.

Essas violências impactam a subjetividade levando a sofrimentos socialmente compartilhados. Estes podem ser de ordem psíquica ou não, de qualquer forma se discute que o discurso médico-psiquiátrico pode contribuir para processos de exclusão, promovendo aprofundamento do sofrimento social no grupo de 
pessoas descritas com diagnóstico psiquiátrico e no grupo de pessoas que fazem uso de drogas de maneira considerada problemática.

Este trabalho, portanto, foi construído levando em consideração a literatura do discurso médicopsiquiátrico sobre o tema do diagnóstico duplo. No entanto, ele se posiciona em alinhamento com autores que têm criticado a estratégia desse discurso de adotar uma postura reducionista centralizada na figura do especialista. Busquei, em vez disso, valorizar a legitimidade das experiências vividas em primeira pessoa e sua potencialidade de criar conhecimentos sobre isso.

Além disso, como apontado em publicações anteriores (Vieira, 2012; Vieira et al., 2013), muitos dos profissionais de saúde têm dificuldade de aproximação com pessoas que fazem uso de drogas, dificultando formação de vínculos e tratamento destes pacientes. Nesse sentido, considero importante produzir pesquisas que emprestem da legitimidade do discurso científico e permitam aproximações entre profissionais das pessoas que eles atendem.

No encontro com potencialidades das pessoas estudadas, procurei construir um texto que se aproximasse delas, dando ouvidos à maneira como compreendem a própria experiência. Em tempos de busca por desinstitucionalização, essa perspectiva de pesquisa pode propiciar reflexões que abarcam a complexidade associada à experiência das pessoas que recebem duplo diagnóstico. Para compreender melhor sentidos e significados do consumo é necessário olhar criticamente sobre suas narrativas quando inseridas em serviços de saúde mental e de tratamento para problemas decorrentes do consumo de drogas. Este estudo propõe complementar essa discussão no campo 
2 Objetivos 


\subsection{Objetivo Geral}

Como objetivo geral pretendi conhecer sentidos e significados do consumo de drogas a partir de narrativas de história de vida de pessoas descritas com duplo diagnóstico.

\subsection{Objetivos Específicos}

Como objetivos específicos, procura-se com esse estudo conhecer descrições sobre a experiência de sofrimento psíquico ao longo da vida; conhecer descrições sobre a experiência de consumo de drogas ao longo da vida; e conhecer descrições sobre experiências em que o consumo de drogas esteja associado a sofrimentos psíquicos. 
Método 


\subsection{Tipo de Estudo}

Este trabalho está inserido no projeto "Consumo de Substâncias Psicoativas entre Pacientes Psiquiátricos: Identificação e Compreensão da Comorbidade", coordenado pela Prof. ${ }^{\text {a }}$ Dr. ${ }^{\text {a }}$ Clarissa Mendonça Corradi-Webster, do grupo de pesquisa Laboratório de Ensino e Pesquisa em Psicopatologia, Drogas e Sociedade - LePsis. Ele visou responder à necessidade crescente de conhecer e construir reflexões sobre práticas assistenciais e políticas públicas voltadas às pessoas que usam os serviços públicos de saúde mental e consomem substâncias psicoativas não prescritas, chamadas no presente trabalho de "drogas", bem como compreender como se dá o consumo dessas substâncias entre usuários de serviços de saúde mental. Este projeto maior foi dividido em duas etapas: uma quantitativa, de levantamento do consumo de drogas em serviços de saúde mental e outra qualitativa, em que este estudo está inserido.

O presente estudo se caracteriza como estudo exploratório, no qual se propõe conhecer diferentes histórias de vida que pudessem ilustrar possibilidades de situações encontradas entre usuários de serviços comunitários secundários de saúde mental e de tratamento para problemas relacionados ao consumo de drogas. Neste estudo, parti em busca de diferentes construções de sentido e significados sobre o consumo de drogas entre pessoas portadoras de sofrimento psíquico entendidas aqui como sinônimo de diagnósticos psiquiátricos, situação esta descrita pelo discurso médico-psiquiátrico como diagnóstico duplo ou comorbidades. Orientada pelas considerações de MacRae (2004) sobre metodologias qualitativas sobre o tema drogas, busquei adotar o foco de atenção de pesquisa em informantes-chave. Procurei valorizar a experiência narrada em primeira pessoa, sem, no entanto, desconectá-la do contexto onde se inserem. Dessa maneira, interessaram mais as percepções sobre o vivido do que a realidade como uma totalidade concreta. Em resposta ao contato com o campo, próprio da perspectiva de pesquisa qualitativa adotada, o percurso de pesquisa foi desenvolvido ao longo do andamento do projeto, que permitiu ampliar locais de coleta de dados a fim de responder aos objetivos do estudo 


\subsection{Locais de Estudo}

Para responder às necessidades já apresentadas no capítulo introdutório e nos objetivos, os locais de pesquisa procurados foram aqueles que pudessem oferecer encontros com pessoas identificadas como fazendo consumo problemático de drogas e diagnosticadas com transtorno mental. Turato (2005) ressalta que é útil buscar por tais locais de estudo por possibilitarem a observação em ambientes onde há a produção de processos de cuidado à saúde, viabilizando acesso a questões pertinentes à problemática do estudo para além dos relatos dos participantes. Por isso foi importante entrar em contato com pessoas que estivessem inseridas na RAPS, foco do estudo. Em um primeiro momento, a coleta de dados ocorreu no CAPS II da região central de um município de médio porte do estado de São Paulo.

Este serviço participou também do estudo maior em que este e insere. Ao longo do andamento do projeto, percebemos que o trabalho ficaria mais enriquecido com a participação também de usuários do CAPS-AD do município, já que este atende a demanda da cidade relacionada a problemas com o consumo de drogas. A região central foi selecionada, pois conta com duas unidades de serviços de saúde mental, sob a responsabilidade da Secretaria da Saúde da prefeitura do município estudado. Uma característica da região central é a concentração de estabelecimentos de prestação de serviços e comércio, sendo uma região de grande circulação de pessoas tanto da cidade como pessoas de fora dela. O CAPS II está próximo a estabelecimentos comerciais mais utilizados por pessoas da classe trabalhadora urbana. Os locais onde funcionam estes serviços já foram residências, sendo alugados pela prefeitura com a finalidade, também dentro da proposta do discurso psicossocial, de integrar espaços da cidade e promoção de cidadania como a atenção e cuidado em saúde mental. 
O CAPS-AD foi selecionado por atender a todo o município onde se realizou a pesquisa, sendo administrado por uma organização sem fins lucrativos, fazendo parte da RAPS. O serviço se caracteriza por atendimentos para problemas de saúde relacionados ao consumo de drogas, tendo como área de abrangência todo o município de Ribeirão Preto, sendo administrado pela organização sem fins lucrativos "Sanatório Espírita Vicente de Paulo", fazendo parte da rede municipal de atenção em saúde mental. Localiza-se em uma região periférica da cidade, também marcada por grande circulação de pessoas por conta de estabelecimentos de prestação de serviços. Apesar disso, as condições de vida do bairro eram diferentes daquela encontrada na região central da cidade, cujo padrão de vida também estava presente entre as pessoas atendidas no serviço. Este dispositivo de saúde, juntamente com outro que tem função de internação breve, se localizavam onde antigamente era um hospital psiquiátrico. Esses espaços, por terem histórico de serem no lugar onde já foi um hospital psiquiátrico, ainda eram referenciados dessa maneira pelas pessoas que moram na cidade estudada.

O CAPS II é organizado em atendimentos em saúde mental em regime de semi-intensivo e ambulatório, para pessoas a partir de 18 anos residentes no distrito central, encaminhadas por meio do ambulatório do Distrito Central, hospitais geral e especializado em psiquiatria. Atendia pessoas com transtornos mentais severos, incluindo transtornos bipolares, esquizoafetivos, esquizofrenia e depressão com sintomas psicóticos, funcionando de segunda a sexta-feira em horário comercial. O serviço tem equipe multiprofissional de saúde mental, que conta com psiquiatras, equipe de enfermagem, assistente social, psicólogos, arte-terapeuta, terapeuta ocupacional, auxiliares administrativos e de limpeza. As atividades desenvolvidas nesse local são atendimentos individuais e em grupo de psicoterapia, oficinas terapêuticas e de cunho intersetorial, administração e entrega de medicamentos aos usuários do serviço, tendo também a inserção de estagiários de diferentes cursos de graduação e pós-graduação da área da saúde.

O CAPS $\mathrm{AD}$ atende pessoas adultas, identificadas com consumo problemático de drogas, funcionando por demanda espontânea - ou seja, sem a necessidade de indicação médica para o tratamento - 
ou por encaminhamento de serviços de saúde, assistência social e judicial do município estudado. O perfil principal dos usuários é de pessoas com consumo problemático de álcool, cocaína/crack, bem como o consumo de múltiplas drogas. Essas pessoas passam por um processo de triagem, sendo encaminhadas para consulta psiquiátrica e atendimentos individuais e em grupo. Esse serviço conta com equipe multidisciplinar formada por profissionais médicos, psicólogos, terapeutas ocupacionais, enfermeiros, educador físico, auxiliares de enfermagem e técnico-administrativos, estagiários de cursos de graduação e de pós-graduação.

$\mathrm{O}$ atendimento no CAPS AD funciona de maneira ambulatorial e como semi-intensivo, variando de acordo com o projeto terapêutico de cada usuário. São oferecidos grupos de acolhimento e atendimentos psicológicos, médicos, de enfermagem e de terapia ocupacional. O serviço também disponibiliza dois leitos para usuários que estejam em período de abstinência ou com necessidade de serem medicados, precisando ficar em observação durante o período de estada no serviço. Era responsável também pelo encaminhamento a serviços de internação para desintoxicação em hospital psiquiátrico ou comunidades terapêuticas conveniadas à RAPS do município, recebendo também destes, pessoas que neles haviam iniciado o tratamento para o consumo de drogas. Estas internações são feitas a pedido do paciente, de sua família, de serviços de saúde ou por mandatos judiciais.

\subsection{Participantes}

O conjunto de participantes deste estudo foi construído a partir de critérios de seleção criados ao longo do processo de pesquisa. Os participantes do CAPS II foram selecionados a partir de consulta no banco de dados do levantamento quantitativo. Deste banco foram extraídas informações relacionadas ao nível educacional, ocupação, tempo de tratamento e o diagnóstico dado pelo serviço de saúde mental 
(retirado de prontuários dos participantes). Como primeiros critérios de seleção dos participantes, procurei por pessoas com diagnósticos de transtornos psicóticos, de humor e de ansiedade e que no momento da coleta de dados, faziam tratamento no serviço.

Outro critério que contou nesse primeiro momento foi ter tido uso de drogas considerado problemático ao longo da vida, identificado a partir instrumento Alcohol, Smoking and Substance Involvement Screening Test (ASSIST) (WHO, 2002), no estudo quantitativo. Este instrumento foi desenvolvido pela Organização Mundial da Saúde (OMS), traduzido e validado para o Brasil (Henrique et al., 2004). Ele foi proposto para identificar o consumo de nove classes de substâncias, sendo elas: tabaco, álcool, maconha, cocaína, estimulantes, sedativos, alucinógenos, inalantes, opióides e a categoria “outras drogas”, podendo ser identificadas outras substâncias além dessas. Dessa maneira, foi possível obter informações sobre o uso de substâncias e padrão de consumo ao longo da vida, avaliadas anteriormente às entrevistas. Foi considerado foco de atenção o consumo identificado pelo instrumento ASSIST em padrões de uso moderado e de alto risco, que foram tomados como um único grupo, chamado de "padrão de consumo problemático".

No segundo momento de coleta de dados, busquei pessoas em tratamento de transtornos relacionados ao uso de drogas no CAPS AD. O perfil de participantes procurado foi de pessoas com os mesmos diagnósticos que os dos serviços de saúde mental. Estes foram indicados pela equipe do serviço, sendo convidados a colaborar com a pesquisa. Como critério de seleção, além dos já descritos (uso problemático, diagnósticos psiquiátricos, estar em atendimento no serviço estudado), foi pedido também que os gêneros dos participantes fossem igualmente distribuídos, permitindo conhecer a perspectiva das mulheres frequentadoras do serviço. Isso porque percebi que os usuários do CAPS AD eram em sua maioria homens. Foram também anotadas informações contidas nos prontuários dos entrevistados, como diagnósticos 
psiquiátricos, histórico de internação e do tratamento para o consumo de drogas. Esses dados complementaram as informações obtidas nas entrevistas.

Foi composto, portanto, um grupo de participantes selecionados a partir das diferentes possibilidades de associação entre diagnósticos de transtornos mentais. As pessoas selecionadas receberam diagnósticos de transtornos psicóticos, de ansiedade e de humor, segundo critérios da CID-10 (WHO, 1992). Foi proposta a busca por diversificação do tipo de drogas consumidas em padrão identificado como problemático longo da vida: tabaco, álcool, maconha, cocaína/crack entre outras drogas. Também foi critério de inclusão dos participantes ter dados de acesso disponíveis ou disponibilizados pela equipe do serviço, ter condições, no momento da entrevista, de fornecer informações, permanecer, no momento da coleta de dados, em tratamento em algum dos locais de estudo e concordar em participar formalmente dele.

O foco dado na construção do conjunto de participantes foi a busca por informações que permitissem compor um quadro de múltiplas apresentações de quadros de diagnóstico duplo ou comorbidades, sendo limitada pela qualidade das informações coletadas em termos de multiplicidade de experiências. O limite de participantes foi dado pelas possibilidades do trabalho de campo e pelos critérios de inclusão deste estudo, procurando ser coerente como o modelo exploratório de pesquisa adotado.

Foram, portanto, entrevistadas dez pessoas (homens e mulheres) em um primeiro momento de coleta de dados, no serviço de saúde mental. No entanto, dentre estes participantes, foram selecionados para o corpus de análise oito dos entrevistados. Isso se deveu por erro na computação do escore do ASSIST, em um momento em que a coleta de dados se deu concomitante com a pré-análise do material e seleção dos participantes seguintes. O percurso de construção do conjunto dos participantes desse primeiro momento de coleta de dados foi descrito na Tabela 1.

Tabela 1: Processo de construção do conjunto de participantes do CAPS II

\begin{tabular}{ll}
\hline Características & $\mathbf{N}$ \\
\hline Total de participantes do estudo quantitativo & 243 \\
\hline
\end{tabular}




\begin{tabular}{ll}
\hline Excluídos por não serem identificados como fazendo uso problemático de drogas & 129 \\
\hline Excluídos por não serem identificados com o perfil diagnóstico delineado & 24 \\
\hline Excluídos por dificuldades de acesso aos pacientes & 33 \\
\hline Excluídos por não terem condições de fornecer informações & 2 \\
\hline Excluídos por apresentarem perfil repetido & 37 \\
\hline Excluídos por não estarem mais sendo atendidos no serviço & 3 \\
\hline Foram convidados & 18 \\
\hline Excluídos por se recusarem a participar, por não quererem conversar ou não comparecer ao encontro combinado & 5 \\
\hline Foram entrevistados & 10 \\
\hline Excluídos do corpus por erro na avaliação do score do ASSIST & 2 \\
\hline Selecionados para o corpus do estudo & 8 \\
\hline
\end{tabular}

No segundo momento de coleta de dados foram entrevistadas dez pessoas, entre homens e mulheres,

apontadas pela equipe do CAPS AD como também diagnosticadas com transtorno mental, conforme descrito

na Tabela 2.

Tabela 2: Processo de construção do conjunto de participantes do CAPS AD

\begin{tabular}{lll}
\hline Características & $\mathbf{N}$ \\
\hline Indicação, pela equipe, para serem entrevistados & 12 \\
\hline Recusaram participar por não comparecer ao encontro combinado ou não estarem interessadas na participação & \\
\hline Foram entrevistados e selecionados para compor o corpus do estudo & 2 \\
\hline
\end{tabular}

Foram, portanto, selecionados para análise das entrevistas dezoito participantes, compreendidos

como um grupo único de pessoas que receberam diagnósticos psiquiátricos e que foram identificados como

fazendo uso de drogas de maneira problemática.

Descrição dos Participantes

Dentre os dezoito participantes selecionados para análise das entrevistas, oito $(44,4 \%)$ eram usuários do CAPS II e dez $(55,5 \%)$ eram usuários do CAPSAD. Onze $(61,1 \%)$ participantes eram homens, as idades variaram entre 25 e 63 anos, sendo que treze $(72,2 \%)$ estavam na faixa etária entre 35 e 55 anos. Treze $(72,2 \%)$ participantes não tinham companheiros fixos, quinze $(83,3 \%)$ eram cristãos. Oito $(44,4 \%)$ tinham 
até o primeiro grau completo, sete $(38,8 \%)$ recebiam aposentadoria e oito $(44,4 \%)$ dependiam da renda da família, sendo que apenas uma (5\%) participante disse nunca ter trabalhado. Sete $(38,8 \%)$ dos participantes não souberam dizer a própria renda. Entre os onze $(61,1 \%)$ que sabiam dizer a renda, esta variou entre $\mathrm{R} \$ 500,00$ e $\mathrm{R} \$ 5000,00$, embora destes, sete $(38,8 \%)$ tinham renda entre $\mathrm{R} \$ 500,00$ e $\mathrm{R} \$ 1500,00$.

As características dos entrevistados selecionados para análise das entrevistas dos três serviços como um conjunto único estão apresentadas no Tabela 3.

Tabela 3: Características sociodemográficas e clínicas dos participantes selecionados para análise

\begin{tabular}{|c|c|c|c|c|}
\hline Características & & & $\mathbf{N}$ & $\%$ \\
\hline \multirow{9}{*}{$\begin{array}{l}\text { Características } \\
\text { Sociodemográficas }\end{array}$} & Gênero & Masculino & 11 & 61,1 \\
\hline & Idade & $30-55$ anos & 13 & $\overline{72,2}$ \\
\hline & Estado Civil & Sem companheiro fixo & 13 & 72,2 \\
\hline & Religião & Cristãos praticantes ou não & 15 & 83,3 \\
\hline & Estudo & $1^{\circ}$ grau incompleto & 8 & 44,4 \\
\hline & \multirow{2}{*}{ Trabalho } & Aposentadoria & 7 & 38,8 \\
\hline & & Depende da renda da família & 8 & 44,4 \\
\hline & \multirow{2}{*}{ Renda } & $\mathrm{R} \$ 500,00$ a $\mathrm{R} \$ 1500,00$ & 7 & 38,8 \\
\hline & & Não souberam responder sobre o valor da renda & 7 & 44,4 \\
\hline \multirow{14}{*}{$\begin{array}{l}\text { Características } \\
\text { Clínicas }\end{array}$} & \multirow{7}{*}{ Diagnósticos } & Transtornos Psicóticos & 10 & 55,5 \\
\hline & & Transtornos do Humor & 8 & 44,4 \\
\hline & & Transtornos de Ansiedade & 2 & 11,1 \\
\hline & & Retardo & 3 & 16,6 \\
\hline & & Transtornos por Uso de Substâncias & 10 & 55,5 \\
\hline & & Mais de um diagnóstico psiquiátrico exceto transtorno por uso de substâncias & 4 & 22,2 \\
\hline & & $\begin{array}{l}\text { Sem Diagnóstico Psiquiátrico, mas apontado pela equipe como tendo } \\
\text { diagnóstico duplo }\end{array}$ & 2 & 11,1 \\
\hline & \multirow{7}{*}{ Drogas } & Tabaco & 12 & 66,6 \\
\hline & & Álcool & 16 & 88,8 \\
\hline & & Maconha & 12 & 66,6 \\
\hline & & Cocaína / Crack & 8 & 44,4 \\
\hline & & Estimulantes & 1 & 5,5 \\
\hline & & Inalantes & 2 & 11,1 \\
\hline & & Consumo de mais de uma Droga & 13 & 72,2 \\
\hline
\end{tabular}

Outros dados dos entrevistados foram descritos e discutidos no capítulo referente ao Encontro com o Campo e o Tema de Pesquisa, na seção Resultados e Discussão, sendo compreendidos como parte dos resultados deste trabalho. 


\subsection{Instrumentos}

A coleta de dados ocorreu por meio de Entrevistas de História de Vida Temática e observações anotadas em caderno de campo.

\section{Entrevista de história de vida temática}

Parte da coleta de dados foi feita por meio de entrevistas de história de vida temática, em conformidade com a estratégia de aproximação das experiências dos participantes da pesquisa. A modalidade de entrevista de história de vida se insere no grupo de histórias orais, que se caracterizam por um relato capaz de contar situações vividas associadas a acontecimentos, a partir da perspectiva dos participantes na relação com o pesquisador/entrevistador (Plano \& Querzoli, 2003). As histórias de vida, segundo MacRae (2004), podem ser vistas como peças de um mosaico de informações levantadas, enfatizando percepções e interpretações em primeira pessoa de determinados comportamentos. Esse autor enfatiza que por meio dessa modalidade de entrevista são facilitadas compreensões dos impactos do comportamento para os participantes e do contexto onde eles se inserem.

Como outras variedades de história oral, a entrevista de história de vida apresenta-se como uma valiosa contribuição, já que as pesquisas no campo têm exigido um "novo olhar" sobre a problemática das drogas, segundo discutiu (Gonçalves \& Lisboa, 2007). Autores consideram que para além de demarcar situações cotidianas, o uso dessa modalidade de entrevista no contexto de pessoas em situação de estigma e processos de exclusão, favorece a construção de versões próprias e atualizadas da história de vida dos participantes (Plano \& Querzoli, 2003). Para (Caldana, 1998), a modalidade de entrevista de história de vida temática é uma estratégia de entrevista que se caracteriza por ser semi-estruturada, permitindo delinear 
relações de sentido de acontecimentos pelos participantes, orientadas pela entrevistadora de acordo com os objetivos e pesquisa. $\mathrm{O}$ foco é dado às experiências vividas que são contadas a partir da orientação de disparadores temáticos, propostos como perguntas ou estímulos de continuação da conversa.

Considerei que a entrevista é produzida como uma narrativa, no momento de sua realização. Por essa perspectiva, entrevistador e entrevistado se encontram, e se posicionam de maneira distinta, formando uma relação colaborativa (Bruner, 1991). Por isso, a narrativa construída não versaria sobre uma realidade generalizável, mas é co-construída na interação com a pesquisadora/entrevistadora num contexto particular que influencia no que será conversado ou não (Georgakopoulou, 2006). A narrativa também se configura a partir do contexto onde a pessoa entrevistada se insere, possibilitando conhecer aspectos sociais e culturais envolvidos nos eventos relatados, servindo também como articulação para o entendimento da temática em estudo. Portanto, parafraseando Fonseca (1999), cada narrativa não é uma narrativa, pois versa sobre experiências localmente construídas, singularmente experimentadas, mas cujos circunscritores eram compartilhados.

Neste trabalho, portanto, a entrevista de história de vida temática utilizada como fonte de dados para a pesquisa estruturou-se em quatro momentos principais, interligados entre si: estabelecimento de rapport e convite à pesquisa; focalização em dados pessoais do entrevistado que permitem sua caracterização; construção livre da história pessoal do entrevistado, apresentando sua perspectiva própria e particular ao momento do encontro de entrevista; esclarecimento de determinados pontos, marcados por meio de um roteiro de tópicos a serem explorados, orientado pelos objetivos da pesquisa (Anexo 1. Roteiro de Entrevista). Os temas da entrevista foram compostos por tópicos para direcionamento para os objetivos da pesquisa, abordando aspectos que porventura não tivessem sido abordados espontaneamente pelo participante: trajetória dos sofrimentos e história do diagnóstico; trajetória do tratamento; trajetória do consumo de drogas; relação entre os sofrimentos e o consumo de drogas; conformação da rede social; rotina e perspectivas futuras. Foram investigados, portanto, aspectos de interesse específico sobre o sofrimento 
psíquico e o consumo de drogas, seus aspectos em termos da história de vida, significados pessoais e sentidos percebidos sobre como era o contexto do entrevistado.

\section{Observações anotadas em caderno de campo}

Segundo considerações de MacRae (2004), a entrevista de história de vida deve ser complementada e contextualizada por outros tipos de materiais como, por exemplo, observações vindas do trabalho de campo onde foram desenvolvidas as entrevistas e todo o processo de pesquisa. Portanto, a coleta dos dados também foi realizada por meio de anotações de observações em caderno de campo, que consistiu na produção permanente de ideias em relação ao tema de estudo. O caderno de campo foi criado como instrumento de coleta de dados para o processo de observação participante no campo da etnografia. A observação participante foi apontada como técnica mais emblemática da metodologia qualitativa. Ela pressupõe a ida do pesquisador ao campo e o estabelecimento de relações, dando mais atenção a comportamentos e à contextualização das verbalizações. Para esse autor, o ato de anotar as observações feitas em campo, além da utilidade de registro, funciona como uma estratégia de ordenação inicial ao material e ajuda na reflexão sobre o tema proposto.

Spink (2003) discute que a construção do campo se dá em concomitância com a construção do tema, considerando que não existe campo sem tema Para ele, o campo não precisa ser considerado apenas como um espaço específico, mas como construído nos diferentes encontros e lugares onde se constroem sentidos sobre determinada temática. $\mathrm{O}$ autor destaca que quando o pesquisador está inserido em determinado tema, este passa a ser construído em suas múltiplas interações. Quando se utiliza a observação do campo anotada, pesquisadores se esforçam para desenvolver um sentido teórico para suas pesquisas, apesar de admitirem $a$ priori não conhecer suficientemente o tema em estudo, que só surgiria no decorrer da pesquisa (MacRae, 
2004). Nesse sentido, a imersão em determinado campo e dessa maneira em um determinado tema pode contribuir para conectá-lo com outros saberes e ideias, construindo sentidos e realidades sociais ao ampliar as vozes e perspectivas sobre determinado assunto (Spink, 2003).

Com essa perspectiva, no primeiro momento de coleta, foram retiradas informações do banco de dados. No segundo momento de coleta de dados, as informações dos participantes foram consultadas diretamente em seus prontuários, disponibilizados pela equipe do serviço estudado. Portanto, as informações dos participantes anotadas em caderno de campo foram: diagnósticos psiquiátricos, histórico de internação e tratamento para o consumo de drogas, complementando as informações obtidas nas entrevistas. Outras anotações relacionadas às entrevistas também foram descritas como a interação dos participantes comigo. Além delas, foram anotadas situações de interação com funcionários e profissionais de saúde dos serviços pesquisados e situações prévias ao desenvolvimento da pesquisa. Essas anotações fizeram referência às conversas informais e percursos no campo, bem como o desenvolvimento de ideias sobre questões do tema pesquisado e mesmo questionamentos teóricos, filosóficos, práticos, éticos e políticos, conforme apresentado por Magnani (1997). Fizeram parte também discussões e questionamentos ocorridos em orientação de pesquisa e conversas com outros pesquisadores, inclusive durante o período de estágio no exterior, além de situações cotidianas consideradas importantes ao processo de construção do campo e do tema de pesquisa, sendo levados em conta no momento de análise das entrevistas.

\subsection{Coleta de dados}

Em um primeiro momento de coleta de dados, os participantes foram acessados por meio do banco de dados, conforme descrito no capítulo de caraterização dos participantes. Isto ocorreu por meio do serviço onde eles faziam tratamento, cujo contato foi feito diretamente por telefone, no próprio serviço. Foi feito um 
primeiro convite à participação no estudo, sendo marcado um encontro no próprio serviço para a realização do rapport e da entrevista. Entre aqueles que concordaram em participar, a entrevista foi realizada no mesmo dia do rapport, quando possível, quando não era possível, foi negociado um dia e horário específicos para a realização das entrevistas. No segundo momento de coleta de dados, as pessoas candidatas à entrevista foram selecionadas pela equipe, como descrito no capítulo de construção do perfil dos participantes. Fui apresentada pela equipe a eles, e em seguida, fiz o convite à participação na pesquisa, apresentando-a em linhas gerais. Aqueles que concordaram em participar foram entrevistados no mesmo dia do rapport, quando isso foi possível. Quando não foi possível, eu marquei um dia e horário, negociado com os participantes para a realização da entrevista.

As entrevistas foram realizadas individualmente, em situação face a face, com duração média de uma hora, em horário combinado com os participantes, sendo realizadas em uma sala reservada dos respectivos serviços de saúde, com condições mínimas adequadas de conforto e privacidade. No início da entrevista, para todos os entrevistados, li junto com o participante o termo de consentimento, explicando o objetivo do estudo pela perspectiva da pessoa entrevistada. No início de entrevista, também expliquei seu processo, passos e conteúdos, possibilitando ao entrevistado tomar contato com o percurso delineado para a entrevista. Após sua realização, foi deixada aberta a possibilidade de um segundo encontro que permitisse aprofundar pontos da entrevista que por algum motivo não ficaram claros nessa primeira entrevista. Isso foi realizado com duas participantes no primeiro momento do de coleta de dados. Quanto a isso, uma das participantes, após a primeira entrevista pediu para não ter a segunda conversa, sendo respeitada sua decisão, embora sua entrevista tenha sido considerada como parte do corpus de análise.

\subsection{Reflexividade}


As características pessoais dos entrevistadores/ pesquisadores são considerados como exercendo efeito considerável sobre as respostas dos participantes da pesquisa (MacRae 2004). Nesse sentido, considera-se que essas características têm importância não somente em termos relacionais na interação com os participantes e com o campo de pesquisa, como também políticos em seu posicionamento como pessoa e pesquisador (Pussetti \& Brazzabeni, 2011). Com relação à interação comigo nas situações de entrevistas, de contato com o campo e durante a análise, algumas características minhas me pareceram importantes como circunscritoras de compreensões e conversas. Os participantes entrevistados no CAPS II foram também participantes do estudo quantitativo que identificava o consumo de drogas, já mencionado anteriormente. No entanto, não lhes foi dado o feedback sobre o tipo de consumo identificado, embora tenha sido mencionada a busca por essas pessoas por terem participado do outro estudo. Tanto para estes participantes como para os que eram atendidos no CAPS $\mathrm{AD}$, foi dito que o interesse estava na maneira como contavam sobre sua história A adoção desse posicionamento talvez tenha promovido que outras drogas fossem relatadas além daquelas identificadas antes da entrevista.

Entre essas características, ser mulher influenciou minhas compreensões sobre discursos de gênero relacionados às falas dos entrevistados, identificando elementos de sofrimento que pareceram se relacionar com discursos rígidos sobre a mulher e que talvez se eu não fosse também mulher, que no caso se interessa pelo assunto, eu não me daria conta, dada sua naturalização na nossa sociedade. Além disso, pude identificar também discursos que alguns homens entrevistados traziam subjacentes às suas narrativas, sendo compreendidos como reflexos de discursos rígidos sobre masculinidade e do feminino, impactando em suas vidas em termos de sofrimentos sociais e psíquicos. A questão da idade importou também. Algumas experiências que eram próprias de gerações anteriores me foram contadas como uma novidade ou como um esclarecimento sobre como um determinado aspecto era visto por gerações anteriores. Aqueles participantes que tinham mesma idade ou próxima a mim, no entanto, não tiveram que me explicar elementos que eram compartilhados comigo em termos de geração, por exemplo, expressões e referências. 
Ser psicóloga, entrevistadora/pesquisadora foram diferentes papéis sociais que importaram na conversa. Eles circunscreveram a conversa sobre o consumo de drogas e sobre sofrimentos psíquicos, realizadas em um ambiente de tratamento de saúde mental e para o consumo identificado como problemático de drogas. Ser profissional de saúde, para alguns participantes. Pode ter convidado a que eles se expressassem por meio da linguagem médico-psiquiátrica. Nesse sentido, também participaram como elementos que foram considerados na análise das narrativas, o que Caldana (1998) denominou de "escuta clínica”. Esse tipo de escuta permite valorizar como fundamentais os elementos da experiência de sofrimento psíquico da pessoa dos entrevistados, questão importante para os objetivos deste trabalho (Turato, 2011).

Outra questão que importou foi o papel da entrevista em tornar públicas opiniões e descrições de si possibilitadas pela oportunidade de realização da entrevista. Alguns dos participantes fizeram questão de "deixar claro" alguns posicionamentos e "querer dizer" algumas experiências e impressões e não outras, como por exemplo, falar do consumo de algumas drogas e não de outras ou fazer comentários sobre determinados eventos e observações do ponto de vista de quem recebe a prestação de serviços em saúde. Outra questão que pareceu pesar foram as diferenças sociais entre mim e os entrevistados. Muitas vezes eu não compreendia algumas referências deles e por mais que me esforçasse para compreendê-las, senti dificuldades. Como se compreendessem que eu por vezes não compartilhava dos mesmos valores, eles me explicavam o que queria dizer determinada expressão ou costume.

A conversa sobre drogas entre os participantes do CAPS AD era familiar aos entrevistados, entretanto, mas nem sempre o sofrimento psíquico era algo identificado pelo participante, sendo necessário trazer questionamentos. No CAPS II, ao contrário, a conversa sobre sentimentos e sofrimentos era facilitada, enquanto foi mais difícil a conversa sobre o consumo de drogas. Com os participantes de cada serviço, busquei adequar meu posicionamento, de maneira a propiciar inteligibilidade comum sobre os sofrimentos psíquicos e consumo. Ainda que isso pudesse de alguma forma influenciar na construção dos sentidos sobre 
os sentimentos, foi útil por promover uma atitude de escuta declaradamente não classificatória ou moralista pareceu favorecer a conversa sobre o consumo.

Por esses circunscritores, alguns aspectos de saúde e ou doença foram mais facilmente discutidos em detrimento de questões que poderiam não dizer respeito a esse processo. Isso permitiu a emergência mais facilmente de discursos do sistema de crenças em saúde em detrimento de outros sistemas de crenças como, por exemplo, do trabalho, das relações interpessoais e familiares, embora fosse possível perceber trânsitos entre diferentes sistemas.

Como discutem Pussetti e Brazzabeni (2011), escrever sobre sofrimento, na perspectiva adotada relacionada ao sofrimento psíquico e social, não se limita à subjetividade do pesquisador, mas à sua sensibilidade como questão política e responsabilidade ética com relação à pesquisa. Esses autores enfatizam a necessidade de não só explorar formas de tornar evidente e significativo o sofrimento, mas poder dialogar com as perspectivas e as "possibilidades" dos entrevistados e outras pessoas que participaram da construção do tema de pesquisa e do campo. Nesse sentido, defendem a necessidade de considerar dimensões plurais, contraditórias, paradoxais e burocráticas presentes nos contextos sociais, institucionais onde a pesquisa se desenvolveu. Portanto, procurei considerar "as complexidades dessas experiências da mesma forma que as reconhecemos em nós mesmos", considerando que suas capacidades de agir estão sempre contextualizadas, conforme escreveu Biehl (2011). Esta análise foi balizada pelos dados anotados no caderno de campo não só do percurso de pesquisa, mas também das considerações construídas sob a influência da leitura sobre o diagnóstico duplo pelo discurso médico-psiquiátrico e sobre o sofrimento social. (Magnani, 1997) discute que o caderno de campo pode ser utilizado como instrumento de referência, registrando observações sobre um "mundo" afetado pelo pesquisador, bem como permite ao pesquisador apresentar-se afetado por esse "mundo". 


\subsection{Análise dos dados}

O conjunto das dezoito entrevistas selecionadas e as anotações do caderno de campo compuseram o corpus a ser analisado. Biasoli-Alves e Dias da Silva (1992) propõem como estratégia de análise de dados qualitativos responder à necessidade de conhecer os dados inseridos em um contexto, sistematizá-los e compor os resultados por meio da redação do texto da tese. A análise desse tipo de dado de pesquisa se caracteriza, segundo essas autoras, por um movimento constante, nas várias direções, entrecruzando elementos das falas e do caderno de campo com relação ao contexto de pesquisa e dos entrevistados até que fosse construído "desenho significativo de um quadro, multifacetado sim, mas passível de visões compreensíveis"(p.65). Adotei processos indutivo-dedutivos de análise, permitindo o trânsito entre material teórico, as narrativas e o trabalho de campo, ao longo de todo o seu processo (Turato, 2011). Para isso, parti de transcrições do áudio das entrevistas para que fossem facilitadas as posteriores leituras e releituras flutuantes e repetidas do material selecionado para análise (Fontanella, Campos \& Turato, 2006).

Utilizei a compreensão de Turato (2011) sobre sentidos e significados como elementos que permitem conhecer o que "querem dizer" os entrevistados. Este autor definiu sentidos como aquilo que o entrevistado ou o entrevistador percebe, permitindo reconhecer a orientação para onde essa compreensão aponta. Significados, por sua vez, seriam as diversas maneiras como é compreendida a questão da pesquisa para os entrevistados. Ambos são concebidos de maneira interpretativa, segundo esse autor. Como complemento, utilizei considerações de MacRae (2004) de que por se tratar de uma pesquisa com usuários de drogas, é preciso considerar os distintos usos e expectativas culturais atreladas aos efeitos das drogas e o que se consegue sendo descrito como "dependente". Além disso, outros ângulos não podem ser ignorados como, por exemplo, a participação de instituições, suas práticas e ideologias nas compreensões dos participantes. 
A construção dos resultados e da discussão foi feita de maneira concomitante (Turato, 2011). Ela partiu não só do material colhido no encontro com o campo, mas também da sensibilidade em descrever elementos não verbais observados no encontro de pesquisa, o contato com a literatura e com outros pesquisadores (Adorno \& Castro, 1994). Por isso, procurei trazer para o leitor um texto em sua versão sempre provisória, sobre aquilo que foi dito e pesquisado. A proposta foi descrever sentidos e significados do consumo de drogas, quando associado ao sofrimento psíquico, no contexto dos participantes e da entrevista. Para a redação do texto deste trabalho, aceitei o convite de Young (1981) de colocar a pessoa que vivencia como figura central no processo de produção de conhecimento.

Considerei as entrevistas como narrativas, baseando-me na compreensão de que organizamos nossa experiência por meio de formas convencionadas culturalmente, compreendidas individualmente como versões de realidade, conforme teorizou Burner (1991). Este autor considerou que os participantes selecionaram eventos, vividos ou imaginados, e os reuniram em função da história contada no encontro da entrevista. Para ele, a narrativa não se comportaria como uma representação da realidade, não sendo possível estabelecer uma relação causal entre os acontecimentos narrados. Por essa escolha de perspectiva de análise das entrevistas, embora se refiram a acontecimentos particulares, as narrativas podem ser compreendidas como inseridas no cotidiano do entrevistado e do entrevistador, sendo sempre endereçadas.

Além disso, Young (1995) discute que é possível perceber discursos e ideologias subjacentes presentes nas narrativas de pessoas que estão inseridas em instituições, no caso de seu estudo, de psiquiatria, cujos posicionamentos permitem algumas conversas em detrimento de outras. Neste trabalho atribuí importância ao posicionamento e às descrições que profissionais de saúde dos serviços estudados dirigiam aos participantes, conforme descreveu Corradi-Webster (2014). Essas questões pareceram ser circunscritoras do conteúdo e da forma como as narrativas foram produzidas, segundo Young (1995). Em composição com essa ideia, também considerei que a pessoa se constrói nas conversas cotidianas, a partir da relação com 
outras pessoas e no decorrer de sua vida (Corradi-Webster, 2014). Tomei o consumo de drogas como um dispositivo que permitiria ampliar a capacidade de agir dos entrevistados diante dos sofrimentos psíquicos. Isso poderia acontecer porque assim foram atribuídos sentidos e significados sobre as experiências e não foram expressos de outra maneira, conforme compreendeu Das (1997) sobre processos de construção social de dor e sofrimento. Assim, também considerei que os entrevistados estavam inseridos em outros ambientes além dos serviços de saúde onde ocorreram as entrevistas, compondo com estes um contexto multifacetado. Com essas considerações, compreendi que os participantes narraram experiências que às vezes foram compreendidas por eles como sintomas psiquiátricos ou diagnósticos, como aprenderam ao longo de seus percursos de tratamento em serviços de saúde. Outras vezes suas experiências eram compreendidas como fazendo parte do rol de possibilidades de experiências cotidianas e de interpretações dessas, a depender da legitimidade e da situação em que aconteciam.

Após a transcrição, foram realizadas repetidas leituras, releituras e impregnação com o material, buscando construir compreensões sobre os sentidos e significados percebidos pelo processo de impregnação do material como um todo (Turato, 2011). Durante todo o processo de análise, foram anotados, em caderno de campo, comentários que poderiam auxiliar no processo de discussão da tese. Foi realizado um segundo movimento de análise em que procurei relações envolvidas entre os diversos consumos de drogas, feitos em diferentes situações ao longo da história de vida narrada. Os sentidos e significados do consumo de drogas associados aos sofrimentos psíquicos foram contextualizados quanto às situações de consumo, discursos subjacentes, o território onde situavam os participantes e os trânsitos entre diversas instituições, relações e ambientes feitos pelos participantes nas suas narrativas. Foi importante também a construção que fizeram em relação ao passar do tempo, sem que isso fosse visto como uma procura por causas e efeitos, mas que fosse coerente com a entrevista de história de vida temática realizada. Procurei ilustrar a variedade e o dinamismo que sentidos e significados assumem em diferentes situações e ao longo das narrativas de vida, encontradas nas entrevistas, colocando foco nas compreensões de que as vivenciou, suspendendo diagnósticos. 
A exposição dos resultados, e sua concomitante discussão, foi dividida em duas partes. A primeira foi a narrativa do processo de construção das compreensões sobre o tema estudado pela descrição do percurso de trabalho de campo. Ilustrei com trechos tirados do caderno de campo e das narrativas dos participantes, mostrando não só o percurso de pesquisa, como também o movimento reflexivo durante ele. Outra parte dos resultados e discussão foi feita pela descrição pormenorizada de nove narrativas, discutida com a literatura do campo do diagnóstico duplo e do sofrimento social. A escolha desse modo de construção do texto da tese foi feita a partir da leitura de autores que vêm buscando orientar politicamente a escritura de seus textos, procurando dar ouvidos aos participantes de suas pesquisas (Biehl, 2008).

Considerei como sofrimentos psíquicos a maneira narrada e apresentada em linguagem corporal pelos próprios entrevistados, em um posicionamento de pesquisa em conformidade com o referencial escolhido. Não levei em consideração em especial particularidades relacionadas ao tipo de drogas consumidas, compreendendo que essa foi uma escolha entre outras possíveis. Nesse sentido, diante dos diferentes tipos de drogas identificados, cada uma pareceu assumir sentidos e significados diferentes entre si diante de diferentes situações narradas e entre antes e depois do tratamento de saúde mental e do consumo. Optei, nessa questão, por priorizar o modo como essas pessoas me contaram suas experiências, construídas ao longo da narrativa.

Um argumento que levei em conta foi o de que as experiências de sofrimento social, geralmente são percebidas, mas não efetivamente descritas por meio de métodos que buscam associações quantitativas entre eles, conforme discutiu (Farmer, 1997). Para esse autor, a "textura" da aflição, talvez seja melhor detalhada em estudos de caso, em que as biografias estão sempre localizadas em contextos sociais e históricos préexistentes. Assim, a singularidade se conecta pelo contexto a muitas outras. Procurei, então, descrever os resultados procurando apresentar as narrativas de história de vida dos participantes de maneira a expor a "textura" do seu sofrimento psíquico, em que o consumo de drogas, seus sentidos e significados estavam 
presentes. Isso ajudou a mostrar não só os sentidos e significados do consumo associado ao sofrimento psíquico como também evidenciar elementos de contexto que circunscreveram essas compreensões.

Para isso, foram selecionadas dez narrativas para serem apresentadas. Estas foram divididas em três grandes grupos de diagnósticos, descritas em três subcapítulos, em que as narrativas apresentavam experiências mais proeminentes relacionadas aos sintomas desses diagnósticos. Os critérios de seleção destas narrativas foram: grupo diagnóstico e sintomas mais proeminentemente apresentados na narrativa; a diversidade quanto ao gênero; ao serviço onde faziam tratamento; e a variedade de tipos de drogas consumidos. Ou seja, busquei apresentar variedade de expressões de sentidos e significados por meio da ilustração de narrativas. A escolha de quais narrativas seriam apresentadas foi feita, inicialmente, a partir dos três grupos diagnósticos escolhidos como critérios de seleção dos participantes (transtornos psicóticos, transtornos do humor e de ansiedade). Para cada grupo diagnóstico a seleção foi orientada pela proeminência na narrativa de características desses diagnósticos e a riqueza como que foram retratadas as experiências de sofrimento e de consumo de drogas nas entrevistas. Foi importante também discutir os elementos quanto ao gênero dos participantes e a sua participação nos diferentes serviços estudados. Essa seleção permitiu construir um panorama diverso de elementos presentes nas narrativas, sendo coerente com o modelo exploratório de pesquisa adotado. Foi levada em consideração também a condição de exequibilidade do texto da tese, não sendo possível trazer todas as narrativas de maneira pormenorizada.

Dez participantes receberam diagnósticos de transtornos psicóticos, destes, três não apresentaram nas suas narrativas experiências de ouvir vozes ou alterações da percepção da realidade, característicos desses transtornos associados com o consumo de drogas de maneira clara. Dos seis restantes, foram apresentadas quatro narrativas, três de homens e de uma mulher, sendo um deles do CAPS II e três do CAPS AD. Entre as oito pessoas que receberam o diagnóstico de transtornos de humor e apresentaram na narrativa características mais proeminentes relacionadas a ele, escolhi apresentar três narrativas sendo de uma mulher, atendida no CAPS AD e de dois homens, vindos do CAPS II. Com relação ao diagnóstico de transtorno de 
ansiedade, a doze participantes deste estudo de alguma maneira apresentaram experiências em que a ansiedade pareceu ser uma experiência significativa e passível de diagnóstico, embora não tenha sido formalmente diagnosticada. No entanto, somente duas mulheres receberam esse diagnóstico, sendo apresentada apenas uma narrativa. Esta tinha, comparativamente à outra narrativa, elementos mais ricos para a reflexão sobre esse diagnóstico com relação ao consumo de drogas, sendo ela pertencente ao CAPS AD.

Em complementação, procurei compor com o quadro apresentado pela literatura sobre o diagnóstico duplo de que algumas pessoas apresentam características subclínicas desse transtorno ou apresentam grande sensibilidade a ansiedade (Stewart, Karp, Pihl \& Peterson, 1997). Além disso, essas pessoas também são descritas como argumento recorrente associado ao consumo de drogas por pessoas que receberam outros diagnósticos de transtornos mentais graves. Para a composição dessa diversidade de apresentações encontrada na coleta e na literatura pesquisada do campo, escolhi apresentar duas narrativas de homens, que também faziam tratamento no CAPS AD. Foram, portanto, apresentadas nove das dezoito narrativas selecionadas para análise. Todos esses participantes foram selecionados também em termos de diversidade de histórias que compuseram o mosaico de possibilidades de apresentação restrita aos locais onde o estudo foi feito. Os outros nove participantes que também compuseram o material analisado, tiveram suas narrativas mencionadas no capítulo "Encontro com o campo e o tema de pesquisa". Essas outras narrativas trouxeram elementos importantes a serem refletidos em termos de processo de trabalho de campo, de pesquisa e de construção do tema pesquisado. Os critérios de seleção das narrativas a serem descritas estão resumidos na Figura 1. 


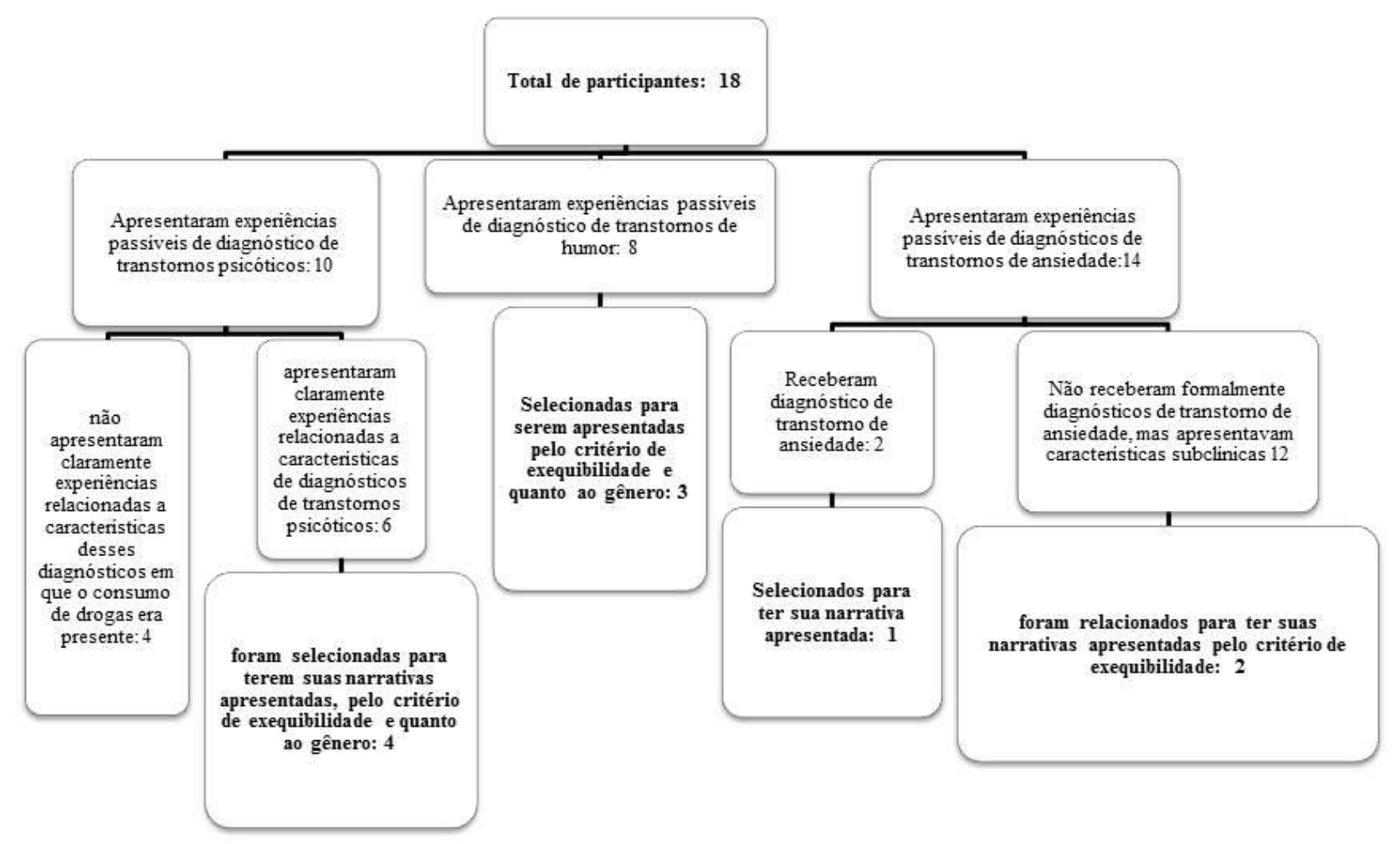

MacRae (2004) discute que a apresentação dos resultados deve ser orientada de modo a descrever o processo de pesquisa, facilitando ao leitor seu próprio julgamento quanto à adequação e ao grau de confiança a ser atribuído ao trabalho. Assim, foi organizada uma linha argumentativa orientada pelos objetivos da pesquisa, mas também pelas experiências encontradas no trabalho de campo, na literatura do discurso médico sobre o diagnóstico duplo, mas também nas narrativas dos participantes. Por essa estratégia procurei mostrar a emergência de sentidos e significados do consumo de drogas, sendo apresentados trechos de falas que ilustrassem esses argumentos. Não tive a pretensão de esgotar a questão pesquisada, mas circunscrevê-la às narrativas descritas e ao universo desta pesquisa. Assim, os resultados foram discutidos juntamente com sua apresentação de maneira a fomentar a discussão sobre o que se compreende como experiência de uso de 
drogas ao longo da vida por pessoas que apresentam sofrimento psíquico, descritas por diagnóstico psiquiátrico e que fazem tratamentos em serviços de saúde mental e de drogas.

\subsection{Aspectos Éticos}

O presente estudo foi aprovado pelo Comitê de Ética em Pesquisa da Faculdade de Filosofia, Ciências e Letras de Ribeirão Preto-USP em 30 de maio de 2012 (Anexo 2. Aprovação no Comitê de Ética em Pesquisa). Para a realização das entrevistas foram respeitados os critérios éticos da resolução n. ${ }^{\circ} 196$ de 10 de outubro de 1996, vigente na época da aprovação no Comitê. Além disso, para a consecução do segundo momento de coleta de dados do estudo, foi anexado um adendo ao projeto, incluindo o CAPS-AD como local de coleta, o que foi aprovado no mesmo comitê. Assim, foi formalizada a anuência da participação mediante a assinatura do Termo de Consentimento Livre e Esclarecido (Anexo 3. Termo de Consentimento), no qual se explicitam os objetivos e a natureza da pesquisa.

Ao longo do trabalho, procurei adotar uma postura no campo de modo a construir vínculos de confiança com os profissionais, em constante atenção aos elementos do campo presentes não somente nas observações como também nas conversas informais com estes. Com isso, por uma escolha ética, e condizente com o foco da pesquisa, escolhi neste trabalho não discriminar o cargo e as profissões dos profissionais de mencionados na tese. Portanto, suas falas e interações informais foram consideradas como parte dos elementos observados e registrados no caderno de campo, não sendo trazidas de maneira literal, embora eu tenha usado algumas expressões deles que eram interessantes para interpretação dos dados. Os profissionais foram, portanto, caracterizados sempre no gênero masculino e de acordo com os serviços onde as conversas aconteceram. 
Nas entrevistas, estas sim foco do trabalho busquei adotar uma postura que percebesse o entrevistado como pessoa, para além de seu diagnóstico e dos sintomas que apresentava ou contava. Coerente com essa atitude, por se configurar um grupo de pessoas conhecido pela equipe dos serviços onde foram realizadas as conversas, tive um cuidado especial no sentido da escolha de como e quais informações a respeito dos participantes seria apresentada tanto para a equipe na hora da coleta como na construção da tese, para que fosse minimizada a possibilidade de identificação. Além disso, pedi que os participantes escolhessem seus nomes fictícios usados nesse trabalho. Fiz isso pensando no incômodo que tive em não atribuir a eles a assinatura de co-autoria nesse trabalho. Encontrei eco desse incômodo nos comentários de Fonseca (2013) de que o uso de pseudônimos em nossos textos é uma maneira de lembrar a nossos leitores e a nós mesmos que não temos a pretensão de restituir a realidade bruta, mas assumir a responsabilidade autoral vis a vis das pessoas que colaboram na pesquisa. Dessa maneira o trabalho versou sobre suas vidas e compreendi que minha leitura dessa conversa foi influenciada por escolhas narrativas deles e dessa maneira, eles foram também co-autores desse trabalho. 
4 Resultados e Discussão 


\subsection{Encontro com o campo e o tema de pesquisa}

Perfil dos participantes

O perfil construído no CAPS II, entre os oito selecionados para o corpus do estudo foi de cinco $(62,5 \%)$ homens, seis $(75 \%)$ participantes não tinham parceria fixa, as idades variaram entre 32 e 63 anos e apenas um $(12,5 \%)$ não tinha religião, embora cinco $(62,5 \%)$ dos que tinham religião não as praticavam. Quanto à escolaridade, três $(37,5 \%)$ participantes tinham o primeiro grau incompleto e apenas um $(12,5 \%)$ tinha o segundo grau completo. Apenas um $(12,5 \%)$ dos participantes trabalhava, sendo que quatro (50\%) recebiam auxílios previdenciários e três (37,5\%) tinham renda acima de um salário mínimo, como apresentado na Tabela 4.

Tabela 4: Características sociodemográficas dos participantes do CAPS II

\begin{tabular}{|c|c|c|c|}
\hline Características & & $\mathbf{N}$ & $\%$ \\
\hline \multirow{2}{*}{ Gênero } & Masculino & 5 & 62,5 \\
\hline & Feminino & 3 & 37,5 \\
\hline \multirow{2}{*}{ Estado Civil } & Solteiros & 4 & 50 \\
\hline & Divorciados & 2 & 25 \\
\hline Idade & $32-63$ anos & & \\
\hline \multirow{2}{*}{ Religiosidade } & Cristãos & 7 & 87,5 \\
\hline & Não praticantes & 5 & 62,5 \\
\hline \multirow{4}{*}{ Escolaridade } & $1^{\circ}$ Incompleto & 3 & 37,5 \\
\hline & $1^{\circ}$ completo & 2 & 25 \\
\hline & $2^{\circ}$ Incomplento & 2 & 25 \\
\hline & $2^{\circ}$ Completo & 1 & 12,5 \\
\hline \multirow{4}{*}{ Trabalho } & Recebem aposentadoria / Auxílio doença & 4 & 50 \\
\hline & Nunca trabalhou & 1 & 12,5 \\
\hline & Dependem da renda da família & 3 & 37,5 \\
\hline & Autônomo & 1 & 12,5 \\
\hline \multirow{2}{*}{ Renda } & Renda acima de 1 salário mínimo & 3 & 37,5 \\
\hline & Não souberam dizer a renda & 2 & 25 \\
\hline
\end{tabular}

Cinco $(62,5 \%)$ entrevistados desse primeiro momento do estudo tiveram diagnóstico de transtornos psicóticos, quatro (50\%) tiveram diagnósticos de transtornos do humor e um $(12,5 \%)$ entrevistado tinha 
transtorno de ansiedade, sendo que quatro (50\%) tinham mais de um diagnóstico. Nenhuma tinha diagnóstico formal de transtorno por uso de substância. Cinco $(62,5 \%)$ entrevistados faziam tratamento do tipo ambulatorial e o tempo de tratamento variou entre um ano e meio e quarenta e seis anos. Cinco (62,5\%) participantes faziam tratamento ambulatorial e três $(42,8 \%)$ faziam tratamento de semi-intensivo. $\mathrm{O}$ consumo problemático de drogas identificado ou mencionado foi principalmente de cigarro e álcool, ambos nomeados por sete $(87,5 \%)$ participantes desse primeiro momento do estudo. O uso do cigarro foi identificado como atual em seis (75\%), enquanto quatro (50\%) participantes tiveram uso de maconha e seis (75\%) fizeram uso de mais de uma droga de maneira problemática na vida. Essas características estão apresentadas na Tabela 5.

Tabela 5: Características clinicas dos participantes do CAPS II

\begin{tabular}{|c|c|c|c|}
\hline Características & & $\mathbf{N}$ & $\%$ \\
\hline \multirow{5}{*}{ Diagnóstico Psiquiátrico } & Transtornos Psicóticos & 5 & 62,5 \\
\hline & Transtornos do Humor & 4 & 50 \\
\hline & Transtornos de Ansiedade & 1 & 12,5 \\
\hline & Outros diagnósticos presentes no prontuário & 1 & 12,5 \\
\hline & Mais de um diagnóstico & 2 & 12,5 \\
\hline \multirow{2}{*}{ Tipo de tratamento } & Ambulatorial & 5 & 62,5 \\
\hline & Semiintensivo & 3 & 37,5 \\
\hline \multirow{7}{*}{ Drogas Identificadas/ mencionadas } & Cigarro & 7 & 87,5 \\
\hline & Álcool & 7 & 87,5 \\
\hline & Maconha & 4 & 50 \\
\hline & Cocaína & 1 & 12,5 \\
\hline & Crack & - & - \\
\hline & Outras & 1 & 12,5 \\
\hline & Mais de uma droga & 6 & 75 \\
\hline
\end{tabular}

Pela pré-análise das entrevistas, foi possível notar que nem sempre o consumo de drogas foi percebido de maneira problemática pelos entrevistados. Apesar disso, foi identificado pelo instrumento o consumo problemático. Mara, por exemplo, disse não fazer uso problemático de álcool, considerando que as drogas que consumia eram as medicações prescritas para seu tratamento em saúde mental.

"F: Deixa eu te perguntar. Você alguma vez já usou... Você falou que nunca fumou cigarro, você já usou álcool? Você já bebeu cerveja...Tomou cerveja?

Mr: Eu tomo, mas não exagerado. Não passa de um, dois copos... E também não é todo dia... Não é sempre não... Muito de vez em quando.

F: E você já experimentou alguma droga, alguma outra coisa? 
Mr: Não. Não.

F: Maconha.

Mr: Não. As únicas drogas que eu já usei são as drogas que eu tomava que eram os remédios que os psicólogos, psiquiatras passavam pra mim... Só isso só... Essa droga do mundão aí não.”

Outra questão que apareceu na pré-análise das entrevistas era que nem sempre o consumo problemático de drogas era atual. Isso foi apresentado, por exemplo, na narrativa de Paulo, que apesar de ter sido identificado com consumo problemático de maconha e álcool, havia deixado de fazer uso e estava abstinente no momento da entrevista, mas persistia no consumo de cigarro de maneira moderada, como apresentado na fala dele, sobre a maconha.

"Pa: eu comecei a fumar maconha eu tinha 16 anos... eu fumava e sentia normal... quer dizer, chapado, mas me sentia normal... fumei maconha com o que... desde os 16, até os 30... [fica pensando] é... comecei com 16 anos. Faz 2 anos que eu parei de fumar, né... maconha."

A fala sobre o consumo nesse serviço, além de não ser atual pareceu ser atravessada pela dificuldade em recontar as experiências, não deixando claro elementos da interrelação entre sofrimento e consumo. Dois entrevistados foram identificados com dependência pelo instrumento, sendo um relativo ao álcool, Israel, e um relativo ao tabaco, Carmen. Israel também já havia feito uso de cigarro e não lembrava bem se já tinha usado cocaína e maconha. Na entrevista já estava abstinente dessas drogas.

"F: E você já cheirou cocaína? Experimentou?

Is: Oh! É... Lá... Assim... (fala gaguejada). Lá onde que eu moro os outros falou pra eu conversar com um, falar com o outro, fazer assim... Ainda to tentando me...(Pausa)

F: Descobrir.

Is: Descobrir. Porque eu não posso falar uma coisa, as vezes, que eu não fiz, ou falar uma coisa que eu já fiz. Se eu falar uma coisa que eu já fiz, e eu não sei, comigo mesmo... porque eu não tenho memória”.

Carmen, por sua vez, no momento da entrevista narrou que o consumo de álcool era visto como problemático pela família e era compreendido por ela pelo discurso proibicionista de que esse consumo interferiria em seu tratamento medicamentoso, mantendo-se abstinente, não deixando claro sobre como era esse consumo.

"C: Eu tomava vinho.

F: Vinho? Você gosta de tomar vinho?

C: Gosto.

F: Você toma ainda?

C: Mas eu não bebo... Não, agora não...

F: Por quê?

C: Porque eu tomo remédio.

F: Por causa da medicação... Mas o cigarro, você não parou.

C: Não.

F: Ele não interage com a medicação? Foi por isso que você parou de beber vinho... Por que ele interage com a medicação...

C: Não... Eu fiquei doente, aí eu parei! 
F: É? Como que era?

C: Eu tomava só um pouquinho assim, ó [mostra a quantidade pequena com os dedos indicador e polegar].”

Emergiu da pré-analise das entrevistas feitas no CAPS II que os participantes não apresentaram consumo atual de substâncias ilícitas. Com essa configuração de participantes, a sensação a foi de que era divergente o modo como profissionais descreviam o diagnóstico duplo e ele como era encontrado na realidade cotidiana. Nas entrevistas, os participantes relataram que o consumo de cigarro era o mais frequente, embora não fosse considerado droga pelos profissionais do serviço. Entretanto, entre aqueles que foram identificados com uso problemático de outras drogas além do cigarro, o consumo relatado nas entrevistas tinha sido feito no passado, sendo principalmente o álcool e a maconha. Sobre o primeiro, os participantes do CAPS II se descreveram como abstinentes ou fazendo consumo ocasional ou recreativo de álcool. A exceção foi Jorge, que fazia consumo atual de maconha, cuja narrativa foi apresentada no capítulo "Variações Emocionais e o consumo de drogas".

Ao longo das entrevistas, percebi que, embora as narrativas fossem múltiplas, encontravam alguma repetição quanto ao tipo e padrão de consumo de drogas e sua associação com o diagnóstico. Achamos, eu e minhas orientadoras na época, que procurar pessoas no CAPS AD seria enriquecedor, pois permitiria encontrar pessoas identificadas com consumo problemático de drogas atual, principalmente as ilegais. Por esse motivo, o processo de pesquisa foi ampliado.

No CAPS AD, foram entrevistadas dez pessoas. A distribuição entre os gêneros foi equitativa propositadamente, por eu buscar também a perspectiva de mulheres que faziam uso de drogas e tinham diagnósticos psiquiátricos. Entre os entrevistados, sete (70\%) eram solteiros e a idade variou entre 25 e 52 anos, sendo, portanto, mais novos que os entrevistados no CAPS II. Sete (70\%) eram cristãos e entre eles, seis $(60 \%)$ eram praticantes, tendo uma prática religiosa mais frequente que no CAPS II. Cinco (50\%) tinham primeiro grau incompleto e dois (20\%) tinham o segundo grau completo. Quanto ao trabalho, apenas dois (20\%) faziam bicos ou pediam dinheiro na rua, enquanto três (30\%) tinham benefícios previdenciários e cinco (50\%) dependiam da família. Cinco (50\%) não souberam dizer a própria renda e dois (20\%) tinham 
renda acima de um salário mínimo. Eles tinham, portanto, um perfil socioeconômico parecido com os participantes do CAPS II, embora relatassem viver em condições de vida mais precárias, como é possível identificar na Tabela 6.

Tabela 6: Características sociodemográficas dos participantes do CAPS AD

\begin{tabular}{|c|c|c|c|}
\hline Características & & $\mathbf{N}$ & $\%$ \\
\hline \multirow{2}{*}{ Gênero } & Masculino & 5 & 50 \\
\hline & Feminino & 5 & 50 \\
\hline \multirow{2}{*}{ Estado Civil } & Solteiros & 7 & 70 \\
\hline & Casados/ morando junto & 3 & 30 \\
\hline Idade & $25-52$ anos & & \\
\hline \multirow{2}{*}{ Religiosidade } & Cristãos & 7 & 70 \\
\hline & Praticantes & 6 & 60 \\
\hline \multirow{4}{*}{ Escolaridade } & $1^{\circ}$ Incompleto & 5 & 50 \\
\hline & $1^{\circ}$ completo & 1 & 10 \\
\hline & $2^{\circ}$ Incompleto & 2 & 20 \\
\hline & $2^{\circ}$ Completo & 2 & 20 \\
\hline \multirow{3}{*}{ Trabalho } & Recebem aposentadoria / auxílio doença / LOAS & 3 & 30 \\
\hline & Fazem bicos / pede dinheiro na rua & 2 & 20 \\
\hline & Dependem da renda da família & 5 & 50 \\
\hline \multirow{2}{*}{ Renda } & Renda acima de 1 salário mínimo & 2 & 20 \\
\hline & Não souberam dizer a renda & 5 & 50 \\
\hline
\end{tabular}

Seis $(60 \%)$ dos participantes vindos do CAPS AD tinham diagnóstico de transtornos psicóticos e quatro (40\%) de transtornos do humor, um (10\%) tinha diagnóstico de transtorno de ansiedade e nove (90\%) tinham mais de um diagnóstico. Cinco (50\%) participantes do CAPS AD tinham diagnósticos interrogados nos prontuários, pois segundo o psiquiatra, eram diagnósticos que ainda estavam sob investigação clínica. O tempo de tratamento variou entre três meses a doze anos, sendo menor que a variação de tempo de tratamento encontrada no CAPS II. O tipo de tratamento foi ambulatorial para dois (20\%) dos participantes, semi-intensivo para seis $(60 \%)$ deles e dois $(20 \%)$ estavam internados e oportunamente estavam no CAPS AD para consulta psiquiátrica na ocasião da entrevista.

O consumo de drogas identificado entre os participantes vindos do CAPS AD variou muito, sendo que oito (80\%) faziam uso de mais de uma droga, sendo as mais frequentes o álcool, a maconha e o crack, presentes em oito (80\%). Seguido dessas drogas, o consumo do cigarro e a cocaína foram encontrados em 
seis $(60 \%)$ participantes. No CAPS $\mathrm{AD}$, o padrão de consumo problemático de drogas encontrado era geralmente descrito pelos profissionais e pelos usuários do serviço como atual e muitas vezes eram múltiplas as drogas consumidas. Também foi possível encontrar com pessoas que estavam em processo de diminuição e mesmo de abstinência de algumas das drogas consumidas. Esse perfil clínico se apresentou diverso, compondo com aquele encontrado no CAPS II. As características clínicas dos participantes do CAPS AD estão apresentadas na Tabela 7.

Tabela 7: Características clínicas dos participantes do CAPS AD

\begin{tabular}{|c|c|c|c|}
\hline Características & & $\mathbf{N}$ & $\%$ \\
\hline \multirow{7}{*}{ Diagnóstico Psiquiátrico } & Transtornos Psicóticos & 6 & 60 \\
\hline & Transtornos do Humor & 4 & 40 \\
\hline & Transtornos de Ansiedade & 1 & 10 \\
\hline & Transtornos por Uso de Substancias & 10 & 100 \\
\hline & Outros diagnósticos presentes no prontuário & 3 & 30 \\
\hline & Mais de um diagnóstico & 9 & 90 \\
\hline & Diagnósticos interrogados & 5 & 50 \\
\hline Tempo de Tratamento & 3 meses a doze anos & & \\
\hline \multirow{3}{*}{ Tipo de tratamento } & Ambulatorial & 2 & 20 \\
\hline & Semiintensivo & 6 & 60 \\
\hline & Internação & 2 & 20 \\
\hline \multirow{7}{*}{ Drogas Identificadas/ mencionadas } & Cigarro & 6 & 60 \\
\hline & Álcool & 8 & 80 \\
\hline & Maconha & 8 & 80 \\
\hline & Cocaína & 6 & 60 \\
\hline & Crack & 8 & 80 \\
\hline & Outras & 2 & 20 \\
\hline & Mais de uma droga & 8 & 80 \\
\hline
\end{tabular}

Foi possível perceber que somente no CAPS AD os diagnósticos de transtornos mentais estavam associados ao transtorno por uso de substâncias, com exceção de Flora e Bruno, que não receberam diagnóstico de transtorno psiquiátrico formal em seu prontuário, embora tenham sido apontados pela equipe do serviço como portadores de um diagnóstico duplo. Suas narrativas foram, respectivamente, apresentadas no capítulo "Outras percepções da realidade e o consumo de drogas" e "A vida nervosa e o consumo de drogas".

Para apresentar os participantes que foram escolhidos para fazer parte do corpus, agrupei por participante suas características na Tabela 8. Foi possível perceber um perfil sócio demográfico semelhante 
entre os serviços estudados, embora clinicamente diversificado por tipo de diagnóstico e substâncias consumidas. 
Tabela 8: Características por participante

\begin{tabular}{|c|c|c|c|c|c|c|c|c|c|c|c|c|c|}
\hline \multirow[b]{2}{*}{ Nome } & \multicolumn{7}{|c|}{ Características Sociodemográficas } & \multirow{2}{*}{$\begin{array}{c}\text { Renda } \\
\text { Fonte de } \\
\text { renda } \\
\text { Renda }\end{array}$} & \multicolumn{5}{|c|}{ Características Clínicas } \\
\hline & Gên & Anos & $\begin{array}{c}\text { Estado } \\
\text { Civil }\end{array}$ & $\begin{array}{r}\text { Religião / } \\
\text { Pratica (S/1 }\end{array}$ & & Escolaridade & $\begin{array}{c}\begin{array}{c}\text { Trabalhos na } \\
\text { vida }\end{array} \\
\end{array}$ & & $\begin{array}{l}\text { Diagnósticos } \\
\text { Psiquiátricos }\end{array}$ & Tipo de droga & $\begin{array}{c}\text { Tempo de } \\
\text { Tratamento }\end{array}$ & Serviço & Tratamento \\
\hline Maria & $\mathrm{F}$ & 63 & Solteira & Católica (N & & $\begin{array}{c}1^{\circ} \\
\text { incompleto } \\
\end{array}$ & Balconista & $\begin{array}{c}\text { Aposentadoria } \\
\mathrm{R} \$ 600,00 \\
\end{array}$ & F. 20.5 & Tabaco & 46 anos & $\begin{array}{c}\text { CAPS } \\
\text { II }\end{array}$ & $\begin{array}{c}\text { Semi- } \\
\text { intensivo }\end{array}$ \\
\hline Paulo & M & 32 & Solteiro & Mórmon (S & & $1^{\circ}$ completo & $\begin{array}{c}\text { Garçom, } \\
\text { serviços gerais }\end{array}$ & $\begin{array}{c}\text { Aposentadoria } \\
\text { R\$1500,00 }\end{array}$ & F. 20.0 & $\begin{array}{l}\text { Tabaco, álcool, } \\
\text { cannabis, } \\
\text { cocaína }\end{array}$ & $\begin{array}{l}1 \text { ano e meio } \\
\text { (nesse caps) }\end{array}$ & $\begin{array}{c}\text { CAPS } \\
\text { II }\end{array}$ & $\begin{array}{c}\text { Semi- } \\
\text { intensivo }\end{array}$ \\
\hline Carmen & $\mathrm{F}$ & 39 & Divorciada & Católica (N & & $\begin{array}{c}1^{\circ} \\
\text { incompleto }\end{array}$ & - & $\begin{array}{c}\text { Renda da } \\
\text { família } \\
\mathrm{R} \$ 500,00\end{array}$ & $\begin{array}{l}\text { F. } 25.0, \text { F.70.0, } \\
\text { F. } 25.2\end{array}$ & Tabaco, álcool & 15 anos & $\begin{array}{c}\text { CAPS } \\
\text { II }\end{array}$ & $\begin{array}{c}\text { Semi- } \\
\text { intensivo }\end{array}$ \\
\hline Mara & $\mathrm{F}$ & 60 & Casada & Espírita (N & & $\begin{array}{c}1^{\circ} \\
\text { incompleto }\end{array}$ & Doméstica & $\begin{array}{c}\text { Renda da } \\
\text { família } \\
\text { Não soube } \\
\text { dizer }\end{array}$ & F. 33.1, F.41.2 & Álcool & 9 anos & $\begin{array}{l}\text { CAPS } \\
\text { II }\end{array}$ & Ambulatorial \\
\hline Israel & M & 32 & Solteiro & Cristão (N & & $\begin{array}{c}2^{\circ} \\
\text { incompleto }\end{array}$ & $\begin{array}{c}\text { Auxiliar de alta } \\
\text { pressão e } \\
\text { leitorista }\end{array}$ & $\begin{array}{c}\text { Auxílio } \\
\text { doença } \\
\mathrm{R} \$ 724,00\end{array}$ & F. 20.0 , F. 32.0 & Tabaco, álcool & 2 anos & $\begin{array}{c}\text { CAPS } \\
\text { II }\end{array}$ & Ambulatorial \\
\hline Pedro & M & 34 & Solteiro & Católico (N & & $\begin{array}{c}2^{\circ} \\
\text { incompleto }\end{array}$ & Panfletista & $\begin{array}{c}\text { Renda da } \\
\text { família } \\
\text { Não soube } \\
\text { dizer }\end{array}$ & F. 20.0 & $\begin{array}{c}\text { Tabaco, álcool, } \\
\text { cannabis, lança- } \\
\text { perfume }\end{array}$ & 7 anos & $\begin{array}{c}\text { CAPS } \\
\text { II }\end{array}$ & Ambulatorial \\
\hline George & M & 50 & Casado & Não tem relig & & $2^{\circ}$ completo & Programador & $\begin{array}{l}\text { Autônomo } \\
\mathrm{R} \$ 5000,00\end{array}$ & F31.1 & $\begin{array}{l}\text { Tabaco, Álcool, } \\
\text { Cannabis }\end{array}$ & $\begin{array}{c}21 \text { anos }(10 \\
\text { anos no } \\
\text { CAPS })\end{array}$ & $\begin{array}{c}\text { CAPS } \\
\text { II }\end{array}$ & Ambulatorial \\
\hline Vitor & M & 54 & Divorciado & $\begin{array}{r}\text { Igreja da } \\
\text { Congregação } \\
\end{array}$ & & $1^{\circ}$ completo & $\begin{array}{r}\text { Eletricista } \\
\text { ferroviário }\end{array}$ & $\begin{array}{c}\text { Aposentadoria } \\
\mathrm{R} \$ 3100,00 \\
\end{array}$ & F. 31.0 & $\begin{array}{c}\text { Tabaco, Álcool, } \\
\text { cannabis }\end{array}$ & 12 anos & $\begin{array}{c}\text { CAPS } \\
\text { II } \\
\end{array}$ & Ambulatorial \\
\hline Bruno & M & 33 & Solteiro & $\begin{array}{l}\text { Vai à vária } \\
\text { igrejas }(\mathrm{N})\end{array}$ & & $\begin{array}{c}1^{\circ} \\
\text { incompleto }\end{array}$ & $\begin{array}{l}\text { Servente de } \\
\text { pedreiro, } \\
\text { catador, } \\
\text { limpador de } \\
\text { fossas, bicos } \\
\end{array}$ & $\begin{array}{c}\text { bicos, sem } \\
\text { renda fixa } \\
\text { Não soube } \\
\text { dizer }\end{array}$ & $\begin{array}{c}\text { F.19.5, F.19.2 } \\
\text { F. } 70\end{array}$ & $\begin{array}{c}\text { Álcool, } \\
\text { cannabis, } \\
\text { cocaíina, crack, } \\
\text { Tabaco }\end{array}$ & $\begin{array}{l}12 \text { anos (idas } \\
\text { e vindas) }\end{array}$ & $\begin{array}{l}\text { CAPS } \\
\text { AD }\end{array}$ & Internação \\
\hline $\begin{array}{l}\text { José } \\
\text { Carlos }\end{array}$ & M & 32 & Solteiro & Não tem relig & & $2^{\circ}$ completo & Panfletista & $\begin{array}{c}\text { Renda da } \\
\text { família } \\
\text { Não soube } \\
\text { dizer } \\
\end{array}$ & $\begin{array}{l}\text { F. 19.2, F.70, } \\
\text { F14.2, F.20, } \\
\text { F31 (?) }\end{array}$ & $\begin{array}{c}\text { Cannabis, } \\
\text { inalante (CO e- } \\
\text { ou CR) }\end{array}$ & 3 meses & $\begin{array}{l}\text { CAPS } \\
\text { AD }\end{array}$ & $\begin{array}{c}\text { Semi- } \\
\text { intensivo }\end{array}$ \\
\hline Igor & M & 37 & Solteiro & Evangélico & & $\begin{array}{c}1^{\circ} \\
\text { incompleto }\end{array}$ & Sapateiro & $\begin{array}{c}\text { Renda da } \\
\text { família } \\
\text { Não soube } \\
\text { dizer }\end{array}$ & $\begin{array}{c}\text { F. 19.2, F. } 29.0, \\
\text { F } 19.5(?), \\
\text { G.40, F. } 20(?)\end{array}$ & $\begin{array}{l}\text { Álcool, tabaco, } \\
\text { crack, cocáńna, } \\
\text { cannabis }\end{array}$ & 1 ano & $\begin{array}{l}\text { CAPS } \\
\text { AD }\end{array}$ & $\begin{array}{c}\text { Semi- } \\
\text { intensivo }\end{array}$ \\
\hline Rogério & M & 37 & Solteiro & Católico & $\mathrm{N}$ & $\begin{array}{c}2^{\circ} \\
\text { incompleto }\end{array}$ & $\begin{array}{c}\text { Sufrassagista, } \\
\text { estoquista, } \\
\text { motoboy }\end{array}$ & $\begin{array}{c}\text { Auxílio } \\
\text { doença } \\
\mathrm{R} \$ 724,00\end{array}$ & $\begin{array}{c}\text { F. } 14.5, \text { F.29.0, } \\
\text { F. } 20 \text { (?), F. } \\
32.2(\mathrm{em} \\
\text { remissão) }\end{array}$ & $\begin{array}{l}\text { Álcool, } \\
\text { cannabis, } \\
\text { alucinógenos, } \\
\text { cocaína, crack, } \\
\text { solventes }\end{array}$ & 5 anos & $\begin{array}{l}\text { CAPS } \\
\text { AD }\end{array}$ & $\begin{array}{c}\text { Semi- } \\
\text { intensivo }\end{array}$ \\
\hline Fabiano & M & 25 & Solteiro & Cristão & $\mathrm{S}$ & $\begin{array}{c}1^{\circ} \\
\text { incompleto }\end{array}$ & $\begin{array}{c}\text { Marceneiro, } \\
\text { bicos como } \\
\text { catador }\end{array}$ & $\begin{array}{c}\text { Renda da } \\
\text { família } \\
\text { Não soube } \\
\text { dizer } \\
\end{array}$ & F. 20 , F. 19.2 & $\begin{array}{c}\text { Tabaco, } \\
\text { cannabis, } \\
\text { cocaína, crack, } \\
\text { extasy }\end{array}$ & 3 anos & $\begin{array}{c}\text { CAPS } \\
\mathrm{AD}\end{array}$ & Internação \\
\hline Juliana & $\mathrm{F}$ & 31 & Casada & Evangélica & $\mathrm{S}$ & $2^{\circ}$ completo & Faxineira & $\begin{array}{c}\text { Renda do } \\
\text { marido } \\
\mathrm{R} \$ 1300,00\end{array}$ & F. 19.2, F.41.1 & $\begin{array}{c}\text { Tabaco, álcool, } \\
\text { cocaína, crack, } \\
\text { cannabis }\end{array}$ & 7 anos & $\begin{array}{c}\text { CAPS } \\
\mathrm{AD}\end{array}$ & $\begin{array}{c}\text { Semi- } \\
\text { intensivo }\end{array}$ \\
\hline Flora & $\mathrm{F}$ & 33 & $\begin{array}{l}\text { Morando } \\
\text { junto }\end{array}$ & $\begin{array}{c}\text { Igreja } \\
\text { Universal }\end{array}$ & $\mathrm{S}$ & $\begin{array}{c}1^{\circ} \\
\text { incompleto }\end{array}$ & Faxineira & $\begin{array}{c}\text { Pede dinheiro } \\
\text { na rua } \\
\mathrm{R} \$ 240,00 \\
\end{array}$ & F. 19.2 & $\begin{array}{c}\text { Crack, álcool, } \\
\text { cannabis, } \\
\text { tabaco }\end{array}$ & 1 ano & $\begin{array}{c}\text { CAPS } \\
\mathrm{AD}\end{array}$ & Ambulatorial \\
\hline Nicodemos & M & 42 & Solteiro & - & - & $\begin{array}{c}1^{\circ} \\
\text { incompleto }\end{array}$ & $\begin{array}{l}\text { Faxineiro, } \\
\text { padeiro }\end{array}$ & $\begin{array}{c}\text { Renda da } \\
\text { família } \\
\text { Não soube } \\
\text { dizer } \\
\end{array}$ & $\begin{array}{l}\text { F.31.7, F10.3, } \\
\text { F.10.2 }\end{array}$ & Álcool & $\begin{array}{l}4 \text { anos- longo } \\
\text { histórico de } \\
\text { internação }\end{array}$ & $\begin{array}{l}\text { CAPS } \\
\text { AD }\end{array}$ & $\begin{array}{c}\text { Semi- } \\
\text { intensivo }\end{array}$ \\
\hline Aline & $\mathrm{F}$ & 39 & Solteira & Católica & $\mathrm{s}$ & $\begin{array}{c}2^{\circ} \\
\text { incompleto }\end{array}$ & Venderora & $\begin{array}{c}\text { Aposentadoria } \\
\text { R } \$ 724,00 \\
\end{array}$ & $\begin{array}{l}\text { F.19.2, F.20, } \\
\text { F25 (?) }\end{array}$ & $\begin{array}{c}\text { Álcool, cocaína, } \\
\text { cannabis, crack, } \\
\text { cigarro }\end{array}$ & 1 ano & $\begin{array}{c}\text { CAPS } \\
\mathrm{AD}\end{array}$ & Ambulatorial \\
\hline Marli & $\mathrm{F}$ & 52 & Casada & Católica & $\mathrm{S}$ & $1^{\circ}$ completo & $\begin{array}{c}\text { Cozinheira, } \\
\text { babá, faxineira }\end{array}$ & $\begin{array}{c}\text { Faxina, auxílio } \\
\text { doença } \\
\mathrm{R} \$ 2000,00\end{array}$ & $\begin{array}{c}\text { F.31, F.10.1, } \\
\text { F.10.2 (?), } \\
\text { F.10.3, F. } 10.5\end{array}$ & Álcool & 5 anos & $\begin{array}{l}\text { CAPS } \\
\mathrm{AD}\end{array}$ & $\begin{array}{c}\text { Semi- } \\
\text { intensivo }\end{array}$ \\
\hline
\end{tabular}


Esse perfil clínico de participantes foi condizente com o caráter exploratório da pesquisa, que teve como características clínicas uma variedade de diagnósticos e de tipos de drogas consumidas de maneira considerada problemática. A questão do duplo diagnóstico apresentou-se em uma população frequentemente heterogênea pela variedade de diagnósticos e tipos de drogas consumidos de maneira problemática (Zaleski et al., 2006). Pelo caminho tomado no trabalho de campo, a conformação do desenho de pesquisa permitiu que fossem agrupadas pessoas que foram identificadas como fazendo uso de drogas e estavam em tratamento em serviços de saúde mental, bem como as que receberam diagnósticos de transtornos mentais e faziam tratamento para o consumo de drogas. Foram, porém, vitualmente as mesmas pessoas, embora sejam descritas e posicionadas de maneiras diferentes, sendo oferecidos tratamentos diferentes diante da oferta de serviços disponível na RAPS estudada.

Estudos apontam que a busca por serviços de saúde é feita mais frequentemente por mulheres, que por homens (Mello, Mello, \& Kohn, 2007). No entanto, estudos no campo das drogas apontam que o consumo de drogas está mais relacionado aos homens, que às mulheres (United Nations Office on Drugs and Crime [UNODOC], 2010). Coerente com esse quadro, o perfil de participantes se distribuiu entre aos serviços ofertados, tendo um perfil masculinizado, pelas características de serem pessoas usuárias de drogas, embora eu tenha também procurado mulheres para compor com o quadro de participantes desse estudo. Em complementação, Marsiglia, Silveira \& Carneiro Junior (2007) discutem nos últimos 30 anos, o grupo de pessoas com as características sociais apresentadas tiveram maior acesso à serviços públicos de saúde, embora esses autores destaquem a importância da pobreza e da desigualdade social e do processo de urbanização como barreiras na promoção de saúde e à saúde mental de maneira integral.

Ribeiro, Barata, Almeida e Silva(2006) estudaram o perfil de pessoas atendidas pelo SUS, rede do qual os serviços estudados fazem parte, e perceberam que eram em sua maioria caracterizados com poucos anos de estudo, com renda mais baixa que aquela encontrada entre usuários de sistemas privados, cujo uso era principalmente de serviços ambulatoriais. Pareceu que o perfil social dos participantes desse estudo foi 
coerente com o de pessoas atendidas em serviços da rede pública, sendo levado em conta também características econômicas e culturais desse grupo (Almeida, D’Andrea, \& De Lucca, 2008). Esse quadro descrito como "amalgamático" de características de pessoas que habitam a cidade, para Adorno (1999), promoveria a condição de existência de formas de vida que dividiriam espaço com tradições, conformando diferentes formas de sociabilidade. Este autor refletiu que instituições sanitárias localizavam na cidade a centralidade de suas intervenções, preocupando-se com a organização da sanidade de pessoas descritas como "pobres", “doentes” e "desocupadas". Características que pode-se dizer, fazem parte do perfil foi encontrado entre os participantes desse estudo.

Duarte (1986), em consonância com outros autores, classificou esse grupo de pessoas como classes trabalhadoras urbanas, buscando diferenciar esse grupo da classe média e da população rural. Esse grupo, segundo o autor, compartilharia características gerais como a falta de recursos financeiros, a centralidade da questão do trabalho nos ideais de vida e serem moradoras de áreas urbanas. Essa classe seria, segundo esse autor, pertencente à sociedade brasileira e mais amplamente, seria participante das sociedades ocidentais que compartilhariam ideais ditos "modernos" de vida. Ou seja, partilhariam da compreensão de indivíduo como unidade social em que são estabelecidas relações fundamentadas em instituições como a família, o trabalho, sendo organizados pelo Estado em ações e discursos rígidos sobre a divisão hierárquica de papéis de gênero acesso a bens e ao consumo em termos de valores de superioridade e inferioridade social. No entanto as classes trabalhadoras urbanas, por suas particularidades, formariam subsistemas de valores locais, conformando subculturas das classes trabalhadoras urbanas brasileiras. Nesse grupo, existiriam compreensões ligadas ao não acesso a bens e direitos, tendo como referência, no caso brasileiro, passados rurais e ações de resistência a condições precárias de vida (Duarte, 1986).

Apesar das mudanças ocorridas no Brasil nos últimos 30 anos, algumas configurações simbólicas foram atualizadas para um contexto globalizado. Isso quer dizer que no atual momento, para autores como Adorno (2011), emergem com ainda mais evidência, diversidades de formas de vida. Segundo esse autor, 
elas anteriormente eram colocadas às margens do mundo ocidental. A questão do diagnóstico duplo, cada vez mais presente na prática cotidiana de serviços da RAPS estudada, pareceu ser um exemplo disso e vem sendo sentida pelos profissionais dos serviços como mudanças no perfil de pessoas levadas para internação em hospitais psiquiátricos (Vieira, 2012) e mesmo nas unidades de internação breve, como o CAPS III (Leão, 2016).

Os nós da rede

Diante da configuração dos serviços descrita no capítulo Método, pude perceber que o CAPS II e o CAPS AD foram serviços, cujas características condiziam com a orientação dos princípios da Reforma Psiquiátrica por serem comunitários, inter-relacionados a outros serviços da RAPS e a outros serviços da rede pública de saúde. No entanto, pude notar no trabalho de campo, que apesar dessas transformações, os usuários desses serviços ainda eram alvo estigma e institucionalização. Andreoli et al. (2007) afirmaram que o processo de desinstitucionalização proporcionado pela Reforma Psiquiátrica não foi acompanhado por aumento na rede de atenção comunitária. Esses autores perceberam que houve diminuição no financiamento no campo da saúde mental, proporcionalmente ao que era esperado, a partir da observação de processos similares que ocorreram em outros países e isso pôde ser percebido no CAPS AD em que o espaço onde ele se localiza era antigamente um hospital psiquiátrico, ou seja, a rede produzida pela reforma pareceu aproveitar os dispositivos já existentes no território.

Da mesma maneira que a rede foi conformada pelos recursos já existentes no território, também os profissionais de saúde dos serviços se misturavam entre aqueles que participavam ativamente das propostas ligadas aos ideais de Reforma Psiquiátrica e aqueles que menos ativamente participavam dela. As práticas destes, porém, estavam menos ligadas a essas ideias, que aos cânones do discurso médico-psiquiátrico como 
o posicionamento dos usuários do serviço por meio do diagnóstico e a centralidade da medicação e do discurso proibicionista no tratamento proposto, costurando hibridismos entre as práticas propostas pela reforma psiquiátrica e pelo discurso psicossocial e a forma influência histórica do discurso médicopsiquiátrico. Assim, no trabalho de campo percebi que discursos de saúde e sobre drogas eram compartilhados entre participantes e profissionais de saúde que trabalhavam nos serviços estudados, circunscrevendo as relações interpessoais desenvolvidas no cotidiano desses serviços. Nessas relações pesavam posicionamentos dos profissionais de saúde que estabeleciam relações com as pessoas atendidas, fosse como pessoas, como equipe, permitindo-lhes lidar com determinados assuntos e não outros.

Observei no processo de trabalho de campo que entre os entrevistados com longo tempo de tratamento, muitos tinham seus percursos de vida circunscritos ao trajeto casa-CAPS. Maria, por exemplo, narrou um percurso de vida que girou em torno de vários serviços de saúde mental desde antes da Reforma Psiquiátrica. Ela narrou que não tinha autonomia, ficando ainda muito dependente de cuidados fornecidos pelo CAPS e sua família, mantendo, inclusive comigo um posicionamento infantilizado.

"Ma: Ah... nada não, tia! [pausa] se sente mal, né tia? Se a gente não trabalha, não faz as unha! A minha foi já, mas aí a moça não quis fazer. Aqui faz a [fala o nome de uma mulher], aquela morena. Que é da limpeza. Que serve almoço, serve leite... Tá na hora... que hora que é, tia?

F: Agora são 2:44.

Ma: Nossa eu preciso ir lá ligar pro meu irmão, tia!

F: Por que?

Ma: ah, pra vir me buscar, porque ele não sabe onde eu tou! E eu não sei ir embora sozinha, tia. Nem meu primo vem me buscar, porque é aniversário dele... nem sei se ele vai vim não!

F: mas a gente ainda tá no CAPS, não tá?

Ma: Tá.

F: Então ele sabe onde você tá, não sabe?

Ma: Sabe. Mas eu aviso todo dia elas pra falar pra ele. Sabe tia, porque aí ele já sabe... Manda dinheiro, manda cigarro, manda caixa de fósforo...

F: Ele manda cigarro... ele que compra pra senhora?

Ma: Manda, ele que compra. Ele e meus dois irmão.

F: É? A senhora pede ou eles dão?

Ma: Eu peço".

Uma possibilidade de justificativa para a configuração dessas práticas é que a política de saúde mental da maneira como foi implementada propiciou que fossem suprimidas formas de vida e resistências locais em nome de respostas universalizantes a processos de saúde e doença (Biehl, 2011) e essas respostas parecem dificultar o processo de desistitucionalização (Andreoli et al,2007). Outra questão percebida no 
trabalho de campo foi que a identificação com um determinado perfil de pessoas atendidas nos serviços, importou nas relações institucionais existentes nesses serviços e isso foi construído ao longo do tempo.

Estas pessoas, por sua vez, eram posicionadas pelas equipes como usuárias de serviços de "saúde mental" ou de "drogas" de maneira excludente. A legitimidade do consumo de drogas e sua comunicação com os profissionais do serviço pareceram estavam atrelados de maneira complexa à necessidade de tratamento do consumo. Isso aconteceria caso fosse ele identificado strito sensu como problemático ou não a partir de padrões de consumo problemático internacionais (Midanik \& Room, 2005;), ou fossem definidos localmente (Pinho et al., 2008). Nesse sentido, os relatos, quando relacionados ao cotidiano dos serviços pesquisados foram diversos, por vezes contraditórios e evidenciaram nuances do que era considerado consumo problemático de drogas por pessoas descritas por meio de diagnósticos psiquiátricos. Em uma nota no caderno de campo escrevi.

Alguns profissionais do CAPS II disseram eu eram poucos os pacientes dos CAPS "saúde mental" que consumiam drogas, enquanto outros profissionais no serviço disseram que eram muitos nessa condição. Além disso, um profissional do CAPS II contou que "eram poucos os pacientes assumiam o uso de drogas e que desses, poucos aderiam ao tratamento para o consumo".

No CAPS AD, a questão do diagnóstico psiquiátrico foi relatada como uma questão "indissolúvel” do

consumo de drogas para algumas pessoas atendidas no serviço. Nesse sentido, alguns profissionais comentaram que se a questão de saúde mental fosse tratada, alguns usuários do CAPS AD não precisariam estar lá, pois a problemática que apresentavam não parecia decorrer do consumo, mas do sofrimento psíquico diagnosticável como transtorno mental.

Foi recorrente, nas conversas informais com os profissionais, a visão de que eles sentiam que o sofrimento psíquico, descrito como sinônimo de transtorno mental era indissolúvel da vivência de algumas pessoas que fazem uso problemático de drogas. Essa questão foi reiteradamente conversada no CAPS AD, como na fala de um profissional de que "no final, se for ver, todos têm alguma comorbidade psiquiátrica". Outros profissionais do mesmo serviço comentaram que algumas pessoas atendidas não tinham problemas relacionados com o consumo de drogas, apesar de fazerem uso delas. Estas foram descritas como tendo problemas relacionados a transtornos mentais e não ao consumo, sendo, portanto, elegíveis ao atendimento em serviços de saúde mental e não de drogas. Um exemplo da lógica empregada pelos profissionais do CAPS AD pode ser dado com o caso de um dos usuários entrevistados, que chamei Nicodemos. Ele foi descrito pelo diagnóstico de transtorno do humor em remissão e que, por consumir álcool, era atendido no CAPS AD, embora esse consumo não fosse, pelo entendimento da equipe, promotor dos problemas de saúde mental que apresentava. Aliás, ele foi um homem cuja trajetória de institucionalização foi longa, tendo sido internado em hospital psiquiátrico por longo tempo e, quando este foi fechado, foi reencaminhado para outros serviços de atendimento de saúde mental, sendo reinserido na família de origem, com quem até a época da entrevista mantinha contato e relação de apoio.

O consumo de drogas por pessoas com diagnósticos psiquiátricos ou também chamada “comorbidade", como é mais comum no Brasil, por ser uma problemática cada vez mais reconhecida nos 
serviços da RAPS soou, à primeira vista, como um conceito compreendido da mesma maneira pelos diferentes profissionais dos serviços e pela literatura médico-psiquiátrica pesquisada. Pelo trabalho de campo, foi possível refletir sobre o percurso da RAPS estudada, permitindo observar percursos. Essas observações foram discutidas com outros pesquisadores do grupo de pesquisa LePsis e também em diversas oportunidades com outros pesquisadores tanto do campo da saúde mental como das drogas, anotadas em caderno de campo.

Uma reflexão que chegamos sobre o manejo do diagnóstico duplo era que:, por não haver o estabelecimento de um fluxo específico quanto ao seu tratamento, a negociação sobre quem cuidaria dessa demanda era feita na própria rede municipal e entre as equipes. Em vista da conformação da rede de assistência delineada, os profissionais se viram tendo que atuar com relação aos comportamentos descritos pelo discurso médico-psiquiátrico como sintomatologia psicopatológica, quando apareciam nos relatos dos usuários dos serviços posicionados como "usuários de drogas". Atuavam com relação do consumo de drogas, quando relatados por usuários dos serviços posicionados como "de saúde mental".

Essas descrições em conjunto com os posicionamentos dados pelos profissionais convidavam a manejos em abordagens psicoeducacionais e motivacionais que procuravam diminuir o consumo de certas drogas. Entretanto, caso o consumo de certas drogas se intensificasse ou tomasse proporção compreendida como fora do escopo de um dos serviços, esta pessoa era encaminhada para o CAPS AD. Neste serviço era proposto tratamento medicamentoso para manejo de sintomas de abstinência e sintomas psiquiátricos descritos pelo discurso médico-psiquiátrico. E também eram propostas psicoterapias e atividades de reabilitação a partir do discurso psicossocial. Uma vez encaminhadas para o CAPS-AD, as pessoas diagnosticadas com transtornos mentais deixavam de ser atendidas pelo serviço de saúde mental a que eram referência, passando aos cuidados e tratamento, caso aderissem, do serviço de drogas, que deveria cuidar também do tratamento psiquiátrico.

A comunicação do tipo de droga utilizado não era fácil, mesmo no CAPS AD em que alguns entrevistados contaram suas experiências, mas não nomeavam as drogas utilizadas, expressando verbalmente somente aquelas que eram, para eles, socialmente mais aceitas, embora fosse perguntado sobre o uso de outras substâncias. Isso ocorreu na entrevista com José Carlos, que contou que usava "maconha cheirada" e não cocaína, embora fosse costume entre os entrevistados comentar que faziam uso cheirado de cocaína. Com a suspensão do que poderia ser parte dos comportamentos presentes no quadro de esquizofrenia 
atribuído a ele, sua fala foi interpretada como uma escolha dele de construir sua narrativa como pensou ser mais legitimado de ser escutado e compreendido.

"JC: Ah, então... eles ficaram um pouco preocupado comigo e aí me puseram na semi-internação.

F: Que que deu preocupação neles?

JC: Que eles ficaram sabendo que eu tava cheirando.

F: Ah, cocaína?

JC: Maconha. Eles ficavam preocupado, aí eles quiseram me colocar aqui na semi-internação e me colocaram aqui na semiinternação.

F: Entendi... e você já usou outro tipo de droga, tipo cigarro...

JC: Não. Só maconha.

F: Só maconha?

JC: Só maconha.

F: E... loló...

JC:Não só maconha.

F: Já te apresentaram estas outras drogas?

JC: Não. Por enquanto não.

F: Não?

JC:Não por enquanto só maconha eles me venderam."

Essa questão trazida na narrativa de José Carlos pareceu importante no trabalho de campo na realização das entrevistas e sua análise. Autores como (Fiore, 2008) discutem que existem drogas que são mais legitimadas de serem consumidas, enquanto outras drogas são vistas com maior reserva e alarme social. Assim, no caso da narrativa de José Carlos, que era acompanhado no CAPS AD, ainda que a conversa sobre o consumo de drogas fosse mais facilitada nesse serviço, era mais fácil para ele contar para mim que fez uso de maconha cheirada do que de cocaína para mim.

O modo, portanto, como a RAPS do município fazia o encaminhamento entre serviços parecia carecer de conversas claras sobre a questão desse uso de droga e sua relação com o sofrimento psíquico, aqui descrito como sinônimo de transtorno mental. Em uma nota de caderno de campo eu comentei os critérios de observei para a realização do encaminhamento para o CAPS AD e CAPS II.

No CAPS AD, o perfil dos participantes foi construído por outro vértice: a presença de descrições de transtornos mentais por pessoas descritas como "usuárias de drogas", o que diferenciava o perfil de clientela atendido, como somente "usuárias de drogas". Em complementação, um profissional do CAPS AD contou de que "todos os comórbidos são encaminhados para cá". Além disso, os pacientes tinham que ter no mínimo dois anos de abstinência para estar em tratamento em serviços de saúde mental, como o CAPS II. Outro profissional do CAPS AD relatou que, embora encontrassem dificuldades, essa era uma conversa que vinha sendo buscada nas discussões com a RAPS".

Essa configuração da rede, portanto, era localmente organizada, posto que Esdras (2004) comentou que algumas RAPS atendem pessoas identificadas com o diagnóstico duplo nos dois tipos de serviços. Essa organização local construída pela RAPS estudada, portanto, condizia com o perfil de participantes desta 
pesquisa, em que um critério de seleção para estar em atendimento no CAPS II, era que os usuários desses serviços estivessem abstinentes do consumo de drogas como maconha, cocaína e crack, mas não necessariamente cigarro ou o álcool em padrão de consumo não considerado excessivo. Já no CAPS AD, o critério de inclusão era ser descrito como fazendo uso atual de drogas, principalmente as ilícitas e o álcool, apesar de se ter a sensação de que seu consumo teria como base sofrimentos psíquicos entendidos como sinônimo de transtornos mentais.

A base dessa configuração de rede e das práticas de cuidado com relação às pessoas atendidas em serviços de saúde, no caso aquelas identificadas com o diagnóstico duplo foi denominada por Young (1995) como de ideologia clínica, que seriam os modelos sobre os quais se dão relações de cuidado entre profissionais de saúde e pacientes em que pesam compreensões pessoais, treinamentos, relações interpessoais com as pessoas atendidas e as relações institucionais estabelecidas. Assim, partir da ideologia clínica presente nas práticas cotidianas dos profissionais dos serviços estudados, os fluxos entre os serviços pareceram ser estabelecidos na RAPS estudada. No entanto, essa forma de lidar com a questão do duplo diagnóstico não pareceu ser claramente definida nos termos como apresentei, ela era mais possível de ser observada como práticas cotidianas, do que um movimento da rede organizado. Esse jogo pereceu envolver as relações já estabelecidas com determinadas descrições de pacientes, de maneira que eles eram posicionados em relações, de certa maneira, naturalizadas nos serviços, sendo produzidas a partir de ideologias clínicas que descreviam o consumo de drogas como problema a partir do discurso médicopsiquiátrico. Essas relações estabelecidas eram legitimadas pelos demais serviços da RAPS, que embora como um todo, fossem propostas estratégias de intervenção a partir do discurso psicossocial, ainda que estivesse imersas em um processo sociocultural de reconhecimento de demandas de cuidado específicas a partir do discurso médico-psiquiátrico. Assim, pessoas cujos perfis "fugiam" de um determinado perfil do serviço eram encaminhadas para outros serviços ou caiam nos buracos dessa rede de atenção. 
Para Saraceno (1995) essa conformação de práticas se dá nas dinâmicas relacionais estabelecidas onde estão sempre presentes recursos limitados. Em consequência, negociações são feitas entre serviços e estratégias de tratamento que se tornam possíveis em um contexto sempre mais amplo que o campo da saúde mental. As possibilidades de intervenção estão, portanto, conectadas e circunscritas por políticas públicas. Portanto, as ideologias clínicas presentes nos serviços estudados se ligavam a um contexto maior de políticas públicas da cidade, participando localmente do processo de Reforma Psiquiátrica Brasileira. Estavam, por isso, estreitamente ligados ao território onde se localizavam e se percebem práticas de trabalho em saúde frequentemente segmentadas. Elas, por sua vez, são sempre em resposta a novas demandas e urgências, que por sua vez convidam a práticas profissionais em que se perde de vista a relação com o paciente (Minelli, 2006).

Considerei que essa foi a trama possível de ser observada ao longo do trabalho de campo, costurada pelos profissionais da RAPS estudada. Dessa forma, foram possíveis alguns percursos em detrimento de outros, compreendidos como imersos em dinâmicas que os transcenderam. Se por um lado a RAPS pareceu se conformar como descrito, por outro lado, pareceu deixar de fora certos aspectos dessas mesmas pessoas participantes dessas dinâmicas, que se perdiam nos "buracos" na rede de relações institucionais. Pitta (2011) argumenta que o processo de Reforma Psiquiátrica ainda está longe de ser finalizado. Essa afirmação parece importante principalmente no período político-ideológico em que este trabalho foi escrito, no qual se configuram grandes desafios em termos de políticas públicas sobre o tema do consumo de drogas em que se observa paradoxos e contradições que podem ter como consequências movimentos retroativos em relação aos ganhos observados com a Reforma Psiquiátrica.

Os interstícios da rede 
Para Good (1994) descrições médico-psiquiátricas moldam interpretações sobre como são vividas experiências. Por essa perspectiva, quando a pessoa é descrita com diagnóstico de transtorno mental e faz consumo de drogas identificado como problemático é, na experiência vivida em primeira pessoa, uma experiência única de sofrimento e consumo de drogas, contextualizada em sua história de vida e seu contexto sociocultural. Entretanto, isso pareceu ser percebido pelos serviços de saúde estudados de maneira parcial, frequentemente dicotômica. Para exemplificar o modo como essa questão foi tratada, recorri a uma situação encontrada no trabalho de campo.

Nos percursos de construção do campo, eu conversei com profissionais de outros serviços de saúde mental também participantes da RAPS estudada. Em um desses percursos, procurei por um paciente com diagnóstico de depressão, a quem chamei de Fábio, que era seguido há certo tempo por um serviço de saúde mental e que havia sido identificado pelo levantamento quantitativo o consumo de cocaína. Naquela ocasião obtive a informação por um profissional de que não estava mais sendo atendido lá. Ele havia sido encaminhado para o CAPS AD por ter sido identificado com uso problemático de cocaína pela equipe. Perguntei o porquê desse encaminhamento. A resposta foi que ele fugia do perfil atendido no serviço de saúde mental por ter uso de drogas, que não poderia ser acompanhado no serviço por seu escopo. Como desdobramento dessa busca, tive notícia de que ele tinha ido até o CAPS AD, como lhe havia sido recomendado, mas que depois, havia procurado novamente o serviço de origem para continuar o tratamento medicamentoso, o que não foi correspondido pela equipe do serviço. A equipe refez o discurso de que seria melhor atendido no CAPS AD. Até onde tive notícias, ele não foi mais atendido nem no serviço de origem, nem no CAPS AD.

Os profissionais que seguiam Fábio o encaminharam para o CAPS AD quando identificaram seu consumo de cocaína. Por outro lado, Fábio, que se identificava com diagnóstico de transtorno depressivo, por descrever vivências relacionadas a comportamentos passíveis desse diagnóstico pelo discurso médicopsiquiátrico, aderiu ao tratamento no serviço de saúde mental por identificar que este era capaz de responder a sua queixa. Ao ser identificado com o consumo de cocaína, a equipe deixou de posicioná-lo como um "usuário de serviço de saúde mental", passando a ser identificado como "usuário de drogas", portanto, um paciente mais adequado ao CAPS AD. No serviço de drogas, Fábio não se identificou com o perfil do serviço ou com o posicionamento como usuário de drogas dado pelos serviços da RAPS.

Talvez isso acontecesse por que Fábio não descrevia sua experiência como um usuário de drogas, ou uma pessoa que necessitava de tratamento para esse consumo. Esse posicionamento não correspondente entre paciente e equipe se cristalizou e impediu que Fabio se mantivesse em atendimento no serviço de saúde mental onde já tinha vinculo. Apesar de ele querer fazer o tratamento medicamentoso da depressão, não poderia ser seguido nesse mesmo serviço no que se relacionava ao possível tratamento para o consumo de 
drogas. A dinâmica que pareceu estar em jogo emergiu de uma fala trazida por um dos profissionais do próprio serviço de saúde mental onde Fábio fazia tratamento.

O profissional disse que tinha dificuldade em "aceitar o consumo" [de drogas], porque muitas vezes a droga trazia uma questão "diferente" daquela do transtorno mental sem uso de substância. "Aceitar o consumo" seria considerar que essa era uma dentre muitas possibilidades de escolhas na vida do paciente? Uma interpretação para essa fala é que esse profissional aceitava que se fumasse cigarro, mas não que se fizesse consumo da cocaína, ou que consumisse ambos associados à medicação psiquiátrica.

A questão da droga ser "diferente" da questão "mental" foi expressão repetida várias vezes ao longo

do trabalho de campo não só por profissionais de saúde da RAPS, mas também por pessoas que faziam pesquisas no campo da saúde mental ou mesmo participavam deste conjunto de relações estabelecidas nos espaços estudados. Essa forma de discriminar os problemas relacionados ao consumo de drogas daqueles relacionados ao transtorno mental, descrita como "diferente" pareceu aglutinar múltiplos sentidos para a droga e seu caráter problemático, desconectando-a da questão do sofrimento psíquico presente nos discursos sobre transtornos mentais pelo discurso psicossocial.

Esses diferentes posicionamentos produzidos nos serviços de saúde mental pareceram apresentar a dimensão de complexidade envolvida na questão do diagnóstico duplo e por isso só pôde ser interpretada à medida que o trabalho de campo se aprofundou e se adensou na rotina dos serviços. Pude observar como elementos presentes no cotidiano desses locais complementavam o mosaico de elementos da chamada "comorbidade" em termos de dinâmica da rede de serviços. Dessa maneira, pareceram importar nas construções de sentidos e significados sobre o consumo de drogas, presentes nas narrativas dos participantes do estudo. Essa diversidade de descrições presentes nas narrativas de profissionais e pacientes lançou luz sobre a questão da visibilidade e importância dada à questão do consumo de drogas identificado como problemático por pessoas descritas com diagnósticos psiquiátricos.

Ao longo do trabalho observei que muitas vezes o simples consumo de algumas drogas era considerado problemático porque se atribui a deflagração de "crises" e provocariam o "aparecimento dos sintomas", como descreveram alguns profissionais do CAPS II. Apesar disso, caso este consumo só trouxesse vivências ruins, as pessoas teriam mais facilidade em deixar de fazer uso, portanto a experiência 
vivida como de sofrimento psíquico combinada com o consumo de drogas pareceu ir além da promoção de "crises" e "aparecimento de sintomas". Essa perspectiva pareceu ir ao encontro de descrições de senso comum que o consumo de que algumas drogas, aquelas "mais pesadas" e de grande alarme social como o crack tornaria a pessoa tão dependente do consumo que se tornaria um morador de rua (não o contrário!), como comentou Jorge, Dias, Yasui e Alves (2013) . A narrativa de José Carlos foi emblemática quando contou que usara drogas e com o aprofundamento desse uso, foi perdendo trabalho, com isso dinheiro e vendera também os móveis da casa onde morava.

“JC: Ah não, eu nunca agredi ninguém, sabe... mas eu assim, eu sempre lutei pra conseguir a maconha... vendia coisa de casa, mas nunca agredi ninguém... e basicamente é isso.

F: Você falou que trabalhou como panfletista...

JC: É trabalhei, trabalhei já...

$\mathrm{F}:$ Como que foi?

JC: Ah, era bom, era bom... que ganhava dinheiro, ganhava bem. Aí depois eu perdi o serviço, te fala uma coisa, aí eu comecei vender os móveis de casa, vendi tudo, ai com... com o dinheiro eu comprei a droga, aí a droga acabou, aí eu fiquei sem as coisas de casa, fiquei sem a droga, e sem serviço, e sem dinheiro...

F: Como que você se sentia nessa época?

JC: Ah, eu me sentia muito mal. Foi aí que eu fui pro [hospital psiquiátrico]”.

José Carlos contou que nunca agrediu ninguém. Ele se associava a uma descrição de lutador, dizendo que sempre lutou para conseguir maconha. Seu jeito de "lutar" era vendendo inclusive os móveis de sua casa. Diante dessa situação, sua família pediu sua internação em hospital psiquiátrico. Assim, o estado de precariedade concreta com relação aos meios de sobrevida foi interpretado como passível de diagnóstico de transtorno psicótico e retardo mental, presentes em seu prontuário. Provavelmente, outros comportamentos estavam presentes e configuravam um quadro passível de internação psiquiátrica. Mas isso tudo foi feito por outras pessoas que não José Carlos, que, na sua narrativa "se sentia muito mal". No trecho apresentado foi possível perceber que ele foi conciso na descrição de sentimentos, mas foi capaz de dar mais detalhes com relação ao que fez para comprar drogas. Talvez essa tenha sido a forma de José Carlos falar de como se sentia, encorporando isso a sua linguagem na narrativa de sua história de vida.

Também compôs com os interstícios da rede estudada um olhar dos profissionais sobre diferentes discursos presentes no cotidiano e que unem a todos nós como parte de um mesmo tecido social. Os diferentes discursos a que somos expostos permitem que tracemos diferentes descrições de nós mesmos, 
sendo que quando não nos encaixamos neles, somos alvo de processos de exclusão, violência e isso repercute nos diversos modos como nos relacionamos socialmente e sofremos com isso. Exemplo disso pôde ser visto na narrativa de Aline, em que se misturavam situações em que o consumo fazia parte das relações cotidianas, expressão de sofrimentos psíquicos, discursos rígidos sobre o papel de gênero feminino, sendo o discurso médico-psiquiátrico uma via possível de comunicação das experiências de sofrimento.

"F: nesse segundo momento você me conta um pouquinho da tua história... ta bom?

A: tá.

F: é... pode começar do jeito que você achar melhor

Al: Meu namorado me apresentou a maconha quando eu tinha 17 anos. Eu não conhecia (áudio incompreensível). Porque era de toquinho... Fininho como eles falam né... eai tudo bem ficou e tal com a maconha e ai aos 24 eu conheci a cocaína. Ai deu tudo certo também... Me sentia livre comecei a gosta... Ai depois o álcool... Ai veio o álcool ... Ai depois que veio o álcool de verdade eu fui internada em uma clinica na em [uma cidade próxima]... Ai eu comecei a tomar pinga... Você fica me olhando assim ahahahahaha. Ai eu comecei a tomar pinga fiquei internada... Passei por um processo lá muito terrível... Fiquei seis meses... Faziam um monte de coisas em mim... Lavagem estomacal... Lavagem por baixo... O estomago... Eu fiquei enorme de gorda... Pensei que nunca mais eu ia voltar, mas mesmo assim voltando de [da internação] eu passei comprei mais um corote.. Fui pra casa tomei de novo, continuei tomando... Ai eu fui fazer tratamento no [hospital geral]. Ai no [hospital geral] peguei pneumonia, fiquei tuberculosa, ai beira morte né! Se eu não parasse, eu ia morrer... Tudo por causa de pinga... Ai depois eu voltei tratei tuberculose, Tratei pneumonia...Tratei tudo, parei com tudo... E comecei na cerveja de novo, depois que eu tinha sarado... Ai eu comecei na cerveja de novo e peguei na cocaína de novo, peguei a maconha de novo... Ai foi onde eu fui para na clinica particular... Fiquei 7 meses, depois mais 3 em outra... Depois eu sai ai me deu ataque de cabeça la".

Essas experiências vividas em primeira pessoa foram questões inseparáveis e compartilhadas também por pessoas que não recebem diagnósticos psiquiátricos. Não seriam, portanto, diferentes de nós. Embora tenham trajetórias de vida e contexto diferentes, como salientou Biehl (2011) quando orientou que pesquisadores olhassem os participantes das suas pesquisas com as mesmas lentes que usamos para nós mesmos e para as pessoas com quem nos relacionamos. Foi nesse sentido que procurei trazer as narrativas e os sentidos do consumo de drogas associados ao sofrimento psíquico, procurando compor com a literatura pesquisada entendimentos sobre o que foi compreendido como sentidos do consumo de drogas por pessoas com diagnósticos psiquiátricos. 


\subsection{As narrativas e os sentidos do consumo de drogas associados ao sofrimento psíquico}

\subsubsection{Outras percepções da realidade associadas ao consumo de drogas}

Procurei apresentar e discutir experiências de ouvir vozes, gritos, sentir-se perseguido, apresentadas pelos participantes. Foram descritas experiências de ver vultos, fantasmas, entidades espirituais, parentes e amigos mortos em que o consumo de drogas se fazia presente, com seus sentidos e significados situados no contexto dos participantes. A escolha de não chamar essas vivências de sintomas psicóticos ou delírios e alucinações buscou ser condizente com o referencial escolhido, como também considera-las contextualizadas. Adotei uma perspectiva que suspende regimes de verdade e realidade, temporariamente, problematizando-as como experiências e construções próprias sobre a realidade. Fui ao encontro de descrições já existentes sobre o que é ter diagnóstico psiquiátrico e essa postura se apresentou especialmente interessante no tocante ao consumo de drogas. Assim, foi possível aprofundar a reflexão sobre a participação do consumo de drogas no relacionamento da pessoa com as vozes, vultos, organização do pensamento e percepção da realidade como inseridas em um contexto próprio do entrevistado, mas também compartilhado socialmente.

Esta atitude foi influenciada pelo contato com movimentos de usuários de serviços de saúde mental, familiares e pesquisadores do campo da saúde mental sobre pessoas diagnosticadas com transtornos psicóticos (Ruddle, Mason, \& Wykes, 2011). Esses movimentos compreendem que ouvir vozes é uma experiência que faz parte das possibilidades humanas, para além dos julgamentos de que são normais ou patológicas. Além disso, esses movimentos propõem posturas mais abertas relacionadas a outras experiências descritas como delírios, buscando estratégias de compreensão e construção de sentidos que possibilitem às pessoas descritas por diagnósticos de transtornos psiquiátricos possibilidades para além do 
tratamento convencional e da desvalorização de suas versões próprias da realidade em prol de compreensões mainstream sobre a realidade (Woods, Jones, Alderson-Day, Callard, \& Fernihough, 2015). Essa perspectiva é especialmente interessante para o contexto brasileiro por sua diversidade de raízes cultuais, possibilitando legitimar formas locais de resposta ao sofrimento psíquico vindo dessas experiências.

A literatura qualitativa sobre o consumo de drogas lícitas e ilícitas por pessoas que recebem diagnósticos de "transtornos psicóticos" descreve as experiências de ouvir vozes eram consequência do consumo de drogas (Peters et al., 2009). Outras descrições foram de que o consumo de drogas permitia melhora no sofrimento psíquico decorrente das vozes (Asher \& Gask, 2010), mas também poderia piorar o sofrimento psíquico decorrente dessas mesmas experiências (Bradizza \& Stasiewicz, 2003). A literatura médico-psiquiátrica qualitativa estudou principalmente o consumo de maconha e de outras drogas ilegais nos países onde foram realizados os estudos. No presente estudo, os participantes faziam consumo de álcool, maconha, crack, cocaína e lança-perfume, sendo apresentados segundo apareceram nas narrativas. Não importou generalizar como cada droga se relacionava ás experiências descritas como características de diagnósticos de transtornos psicóticos. Ao contrário, preferi destacar sentidos e a usos pessoais atribuídos ao uso das drogas mencionadas. Eles foram entendidos como parte do contexto onde os participantes se inseriam.

Os participantes que foram escolhidas para terem suas narrativas descritas de maneira pormenorizada foram quatro: Fabiano, Pedro, Rogério e Flora. Eles foram selecionados pelos critérios já descritos no capítulo Método de clareza na apresentação de características proeminentes do diagnóstico de transtorno psicótico, diversidade de gênero e serviço onde eram atendidos, permitindo construir um quadro amplo de apresentações encontradas no trabalho de campo. As narrativas dos três primeiros permitiram apresentar diversidade de sentidos e significados do consumo de drogas, ainda que fossem singulares as suas experiências. A narrativa de Flora foi apresentada, tomando-se como justificativa a recomendação de 
(Fontanella, Ricas, \& Turato, 2008) por contar não a repetição de elementos, mas por apresentar elementos novos, cuja riqueza contribuía para a discussão sobre o tema estudado.

\section{Fabiano}

Fabiano entendia o consumo de maconha como um auxílio diante das vozes, diminuindo o volume delas. De maneira confusa, pareceu associar o consumo de maconha como estratégia para não escutar as vozes. Fabiano descreveu que as vozes e os vultos o deixavam agressivo, o que corroborou com os achados de (Thornton et al., 2012) de que o consumo ajudava a sair de padrões de pensamentos problemáticos.

"F: E você fumava maconha pra parar com isso, ou a maconha te deixava vendo mais?

FA: Parar com isso daí... em vez de usar... ver voz... escutar vozes...

F: Como que é isso?

FA: Ah! escutava uma vozes des... estranha... o meu medo era que eu escutasse... vozes, vultos... ouvia..."

Sua experiência de ouvir vozes surgiu ao mesmo tempo em que consumia maconha. Entretanto, atribuiu à "macumba" a experiência de ouvir vozes e vultos a qual teria sido "jogada" nele em decorrência do término de um relacionamento com uma namorada, reiterando achados autores comentaram que algumas pessoas isso não tinha relação com a percepção de que as vozes eram devidas a algum tipo de doença. Esses autores relataram que alguns dos participantes de seu estudo atribuíram que o consumo de drogas diminuía o impacto sobre a experiência de ouvir vozes.

"F: Sempre maconha? E você tinha essa sensação desde pequeno, ou não?

FA: Não.

F: Isso aconteceu quando?

FA: Começou quando eu comecei... quando... larguei dessa menina aí que é a ... que o pessoal dela falava que (trecho inaudível)... $\operatorname{mim} . .$.

F: O que?

FA: Bagulho de macumba assim sabe?

F: Fizeram um trabalho pra você?

FA: É ... uma colega minha quem falou. Uma colega que é parente, não... quase parente... mora lá perto deles lá...

F: E o que você acha desses trabalhos?

FA: Ah, isso daí eu não gosto, porque isso daí faz mal pra todo mundo né... isso daí é pessoa que não quer ver a pessoa bem...”.

A atribuição de que as vozes originaram da "macumba" que "jogaram" nele encontra respaldo em

discursos religiosos afro-brasileiros, em que é comum esse tipo de associação da "macumba" como se fosse 
uma "maldição", geralmente descrita como "trabalho" feito por outra pessoa em direção ao amaldiçoado, imagem que segundo (Goulart, 2008) mobilizavam estigmas de etnia. Para Fabiano isso, fazia parte do contexto onde ele se inseria e que será discutido mais adiante. Portanto, para ele o consumo de maconha não estava associado ao aparecimento das vozes, e sim a uma estratégia para lidar com elas.

$\mathrm{Na}$ entrevista, as vozes pareciam provocar medo em Fabiano, que recorria a ações diversas para se distrair delas e dos sentimentos que elas despertavam. O consumo de maconha estava entre essas ações. Portanto, a maconha, fazia parte do repertório de possibilidades de ação, no momento em que tinha experiências de ouvir vozes. Esse episódio narrado poderia ser uma interpretação do participante sobre uma situação cotidiana de ciúmes, ou também uma experiência de delírio, como descreve o discurso médicopsiquiátrico.

"F: Você só namorou ela?

FA: Só ela. E eu to nesse termo aí até hoje... Se ela vem pra cá ou não... Porque a última vez que nóis se encontrou ela tava descendo duma rua que nóis sempre se trombava... Ela só olhou pra mim, e eu só olhei pra ela. Porque eu tava na neurose por causa dos moleque... Nem parei pra conversar com ela sobre esse negócio... O que ele fez, o que ela fez... Porque ela falou que ele tava dando em cima dela...

F: E essa neurose com esse cara aí... ela vinha quando você tava de boa, ou quando, ou alguém te contou... como que foi essa situação?

FA: Não. Não foi ela que me contou não. Porque ela no mesmo dia tava tendo jogo lá na quadra. Aí ela também jogava lá na quadra. Aí esse moleque pegou o horário na quadra... Aí se ele pegou o horário... Aí no dia que eu fui jogar bola... A bocada é... Tem a bocada ali na quadra... Aí os dois um se olhou pro outro... Daí já achei estranho. Os dois se olhando um pro outro no canto"

A questão foi resolvida e legitimada, segundo ele com, a intervenção de pessoas que como ele,

faziam parte do tráfico de drogas, seus “irmãos". Estes atuaram, na sua narrativa, como mediadores conversando com Fabiano se era o caso de "quebrar as pernas" de seu opositor. Nesse contexto da "bocada" estavam estabelecidas "atitudes" e "procederes", quando determinada regra compartilhada pelo grupo era infringida (Malvasi, 2012).

"F: Não podia?

FA: Podia, podia né! Mas eu achei estranho. Aí eu to vendo os dois indo embora sozinho.

F: E eles não eram amigos?

FA: E eles não eram amigos.

F: Aí você falou que ela também ficou chateada com você porque você ficou com alguém...

FA: É foi... Qque aí eu fiquei com alguém... Aí foi... Aí dev... Deve... Foi nesses dias que ela ficou com ele.

$\mathrm{F}$ : Meio que quis revidar?

FA: Aí fui trocar ideia com os irmão. Sempre na paz né...

F: Como que é isso, trocar ideia com os irmão? 
FA: Ah... trocar ideia com irmão isso daí é assunto sério... Tem que ver se o irmão mandou ir lá e quebrar as pernas dele... Sabe que é isso... É porque perto de nóis quer dizer que é safado... Não pode pegar a namorada, não pode pegar a namorada de um e de outro..."

Ele ainda nutria na época da entrevista sentimentos por essa menina, e narrou que quando ouvia comentários sobre ela se lembrava de que quando estava com ela, “era mais feliz".

"FA: Quando eu tava com a minha namorada eu era mais feliz. Eu ia com ela pra escola, ficava com ela na escola".

Atribuiu à menina com quem namorava ter saído da escola e que, apesar de ficarem anos sem se ver, às vezes tinha notícias dela e ainda pensava nela. Assim, quando conversamos sobre sentimentos relacionados à tristeza. Sobre isso, ele comentou na entrevista que ainda ficava "com agonia no coração" ao pensar nela. Com relação a esses momentos, eu perguntei se ele pensava nela quando fumava maconha, ele respondeu que pensava nela "todas as vezes".

"F: Aí quando você pensa nela você sente tristeza?

FA: Ah! Sinto. Dá uma agonia no coração. Mas a gente tem que esquecer o pesadelo que a gente fez.

F: Como que você lida então com isso? Com essa agonia no coração?

FA: Ah! Lido normal... Tento as vezes procuro uma outra namorada... Os parente dela fala dela, que ela vai vir pra cá... Aí... Não sei se ela vai vir pra cá, se é por causa de mim, se é por causa desse moleque...Não sei né!

F: Fica fazendo isso na tua cabeça?

FA: Fazendo isso...

F: Hum... E quando você fuma... Quando você fuma maconha... Você pensa nela?

FA: Áas vezes... Toda vez...

F: E você se sente bem...

FA: Sinto mais calmo... Sinto... Ela... Mais... Perto.... Sinto ela mais perto de mim, as vezes..."

O efeito da maconha, nessas situações era de promover com que Fabiano se sentisse "mais perto" da

ex-namorada.. Essa fala pareceu estar relacionada ao efeito de alteração do pensamento quando fumava maconha. Asher \& Gask, (2010) também descreveram que alguns dos participantes de seu estuo associaram o consumo de maconha com a lembrança de antigos relacionamentos.

Fabiano narrou ter falado com os amigos sobre a separação dessa namorada com colegas. Ele disse “se eu for falar dos problemas, vamos ficar loucos". Essa fala sugeriu que, no contexto onde ele se inseria, a conversa sobre sentimentos relacionados a problemas era vista como loucura, não sendo prática legitimada naquele grupo. Outros modos de agir diante do sofrimento eram manifestados quando "o bagulho ficava sério".

"FA: As vezes quando eu paro pra conversar com meus colegas sobre alguma coisa assim, o bagulho fica sério. F: É? E você conversa bastante com seus colegas sobre isso?

FA: Humrum. Tem vários colegas meu perto de casa lá que tem umas namoradinha que eu falo, ih! Isso é problema, se for falar dos problemas, vamos ficar loucos". 
Asher \& Gask, (2010) comentaram que os participantes de seu estudo narraram buscar se descreverem como usuários de drogas ao invés de se descreverem como pessoas com problemas emocionais, colocando o foco de atenção na conversa sobre o consumo de drogas, e não deixar evidente o sofrimento psíquico. Na narrativa de Fabiano, outros modos de ação diante do sofrimento precisavam surgir quando "o bagulho ficava sério" e para não "ficar louco". Assim, quando ele fumava maconha, ele era capaz de pensar nessa situação de sofrimento de uma forma mais tolerável.

Os sentidos atribuídos por Fabiano sobre o consumo de drogas foram construídos ao longo de sua história de vida, passando por processos de institucionalização em unidades de encarceramento. Isso se deu na infância em decorrência do envolvimento com o tráfico de drogas, juntamente com outros colegas da "bocada", onde o consumo de drogas era legitimado, como narrou no trecho em que ele falou sobre o início do consumo da maconha.

"F: Você usa maconha desde quando?

FA: Desde os doze anos.

F: Dos doze?

FA: Humrum. (meneia com a cabeça afirmativamente)

F: Você lembra como que foi que te deu curiosidade...

FA: Não. Foi quando eu tinha saído da Ca... Da FEBEM né. Aí um menino queria dar pra mim experimentar. Falei, não, não. To firmão. Aí quando eu ficava lá na bocada com os meus colegas aí eu aprendi fumar ficando perto deles".

Becker (1953) relacionou o aprendizado do consumo de maconha com práticas em que se compartilhavam não só o modo mais apropriado de uso, mas também sentidos atribuídos sobre esse consumo. Construíam também outros significados como os dos efeitos obtidos com o consumo de maconha. O contexto da "bocada", Fabiano, foi construído como uma comunidade onde ele se inseria e se sentia parte, diferentemente do contexto da "FEBEM". Essa interação social auxiliou na construção de sentidos sobre a experiência de consumo, onde ele se sentindo-se legitimado e percebendo que tinha "colegas", onde pôde aprender a fumar maconha, ficando perto deles. Sentia-se diferente no contexto da FEBEM, onde um “menino quis oferecer para ele experimentar", mas ele não aceitou, dizendo “To firmão".

Lobbana et al., (2010) discutiu essa questão em seu estudo, em que a legitimação do consumo passava pelo bairro e comunidades onde os participantes do seu estudo se inseriam, tendo importância 
grande no início do consumo, embora também importassem a escolha pessoal diante desse consumo. Um exemplo disso foi a situação narrada por Fabiano sobre a cocaína e a escolha de não se descrever como usuário dela, destacando que era uma droga "muito pesada", embora em seu prontuário aparecesse que havia feito consumo dessa droga.

A cocaína, dentro de uma construção social das drogas, ficava em um status menos legitimado de ser conversado que a maconha, como já apontado no capítulo referente ao trabalho de campo. Lobbana et al. (2010) complementa a percepção de que existe hierarquia de aceitação desse consumo inclusive entre os pares.

"F: E o álcool? Você falou de tomar uma cerveja de vez em quando. Quando você começou a usar?

FA: Já usava lá na biqueira mesmo.

F: É?

FA: Junto com meus colega.

F: Antes de ir pra FEBEM?

FA: Humrum... Antes de ir pra FEBEM.

F: E você usava todo dia... como que era?

FA: Não. Só final de semana só... Tomava porque nóis tinha o jogo lá... Os campeonato né...

F: De que?

FA: De futebol.

F: Ah! Você gosta de jogar futebol?

FA: Anhrann!

F: Hum... E como que era... Tava todo mundo bebendo e você chegava...

FA: Não, enquanto o jogador jogava, nóis torcia e tava usando a droga. Entendeu dona?

F: Humrum... Entendi... E como que era? Você só usava mais cerveja... Você tomava outras coisas...

FA: Mais cerveja. Só cerveja só. Cerveja e maconha. Pó não. Pó, que eu me lembro, foi uma vez só, que eu me lembro. Uma vez que eu tava descendo de bicicleta e eu achei um tubão, assim, tinha um pouquinho... Aí eu tentei respirar um puoquinho aí subiu um negócio, aí eu falei, nossa que bagulho ruim!

F: Não gostou?

FA: Não gostei.

F: Porque que você não gostou?

FA: Ah, uma droga muito pesada".

O consumo do álcool fazia parte do processo de socialização com os amigos da "bocada/biqueira",

desde antes da internação na FEBEM, o que é corroborado com achados da literatura sobre o diagnóstico duplo que apresentam essa questão (Asher \& Gask, 2010), e mesmo a literatura sobre drogas já vem discutindo essa questão mesmo entre pessoas que não receberam diagnósticos psiquiátricos (Campos \& Ferreira, 2007). O cigarro, por sua vezele disse que aprendera com sua mãe, na época que estava na FEBEM.

"FA: Não. Eu comecei a fumar cigarro também pela FEBEM. Sabe porque? Minha mãe fumava nas antiga e hoje ela parou. Faz não sei quantos anos que ela parou de fumar cigarro. Eu acendia pra ela. Peguei o gosto do cigarro. Só que quando ela saia, depois da visita, eu não fumava não. Comia umas bolacha... Que podia levar ... Lá em [na cidade onde estava internado] podia levar... Aqui não pode... Não entra essas coisas..." 
Eventos geradores de sentimentos de vulnerabilidade aconteceram também com pessoas de sua família, impactando na maneira como viveu suas experiências e as significou. Um exemplo foi o episódio em que sua família foi despejada da casa onde moravam, precisando mudar-se do bairro onde cresceu. Ele, no entanto, manteve laços com pessoas do bairro onde inicialmente morava e essa mudança, para ele, exigiu adaptação.

“FA: Foi lá que nóis foi despejado. Num sei quantos dias de despejamento... Daí nós ganhou uns predinhos aqui no ( Inaudível)... F: Hum... Entendi... O que você achou dessa mudança de casa?

FA: Ah eu achei que não ia ficar muito bom pra cá não... Mas tá bom...

F: Tá bom?

FA: Tá. Eu tenho saudade de lá... Eu vou lá de vez em quando... Conversar com meus colegas... Mas viver lá não..."

Estes acontecimentos pareceram ser elementos importantes para compreender a construção dos sentidos relacionados ao consumo de drogas, às experiências de ouvir vozes para Fabiano. Adotei a perspectiva de que, para ele, o consumo da maconha era uma forma de diminuir as vozes, sendo legitimada pelo seu entorno. Isso possibilitaria a ele se descrever como capaz de agir em um momento em que se sentia que foi atingido por uma "macumba" ou "que o bagulho ficava sério", ou seja, quando enfrentava situações de sofrimento que lhe dava a sensação iminente de enlouquecimento. Tendo vivido desde a infância em um contexto onde violência fazia parte do cotidiano, vivenciava dificuldades de acesso a direitos e a necessidade de sobreviver às violências no seu cotidiano. Diante, inclusive, de experiências de ouvir vozes, o consumo de álcool e maconha parecia fazer parte do repertório presente no contexto onde tráfico de drogas, trabalho, lazer e consumo se misturavam.

Os valores compartilhados pelas pessoas do contexto onde Fabiano se inseria tinha uma organização definida por experiências em que eram estabelecidas regras de convivência e de resolução de determinados conflitos e não outros (Biehl, 2008). Nesse sentido, na narrativa de Fabiano, as maneiras de construir sentidos sobre o consumo de drogas e sua associação com sofrimento psíquico gerado pelas vozes pareceram ser circunscritas a esse contexto. Sua narrativa se assemelhava e se conectava a outras narrativas de outros participantes. Como veremos, quando olhamos para o contexto onde há dificuldades de acesso a direitos, pobreza e uma interação com o Estado de maneira repressiva, como por exemplo, a institucionalização desde 
a infância até o momento da entrevista são marca da importância de lidar com o sofrimento psíquico intenso e sobreviver às violências estruturais sofridas (Farmer, 1997). O pouco espaço nessa comunidade para dar vazão aos sofrimentos psíquicos exigiu de Fabiano lançar mão de outros recursos para se expressar e lidar com eles.

Pedro

Pouco tempo antes de ser internado pela primeira vez, Pedro contou que se sentia "desconfiado". Como estratégia para lidar com esse sentimento, começou a beber muito e a fumar maconha, consumos que ele já fazia, e que se intensificaram.

"P: Ah... Como que eu posso dizer... Ficar meio desconfiado... Aí eu comecei a beber muito... Fumar maconha... Aí eu comecei a ficar ruim... Ficar sem fazer nada...".

Pedro passou a "ficar ruim" e isolado em casa, caracterizando o consumo do álcool como beber algo "mais forte" do que lhe era habitual, o que ele descreveu como "beber pinga mesmo".

"P: Ah, eu bebia cerveja, de vez em quando... Mas eu falo de beber pinga mesmo... Com coca-cola, com fanta... Coisa mais forte. Aí os enfermeiros chegou em casa e me levou pro [hospital psiquiátrico], pro [unidade de internação em hospital geral]... Aí eu fiquei 7 dias lá em observação e depois eu fui pro [hospital psiquiátrico].

F: Mas como você estava se sentindo... O que acontecia na sua vida nessa época?

P: Ah... Não sei te dizer, viu... [pausa] É como se não fosse eu. Agora eu tenho a consciência de que sou eu mesmo... Eu tenho, por exemplo, noção do que eu tô fazendo. Agora... Tá tudo normal, mais claro pra mim”.

Nessa época foi internado em hospital psiquiátrico. Essas internações se repetiram mais duas vezes, nas quais ele não referia consumo de drogas, apesar de apresentar experiências de ficar "desconfiado" e não sair casa. Isso ele descreveu retrospectivamente como a sensação de que ele não se reconhecia.

"P: É, de eu voltar pro [hospital psiquiátrico] de novo. Foi só duas vezes...

F: E como que foi essa situação? Você... Voltou a beber, a ter sensações...

P: Não... A beber não... Eh... Ficava mais desconfiado... Eu não... Saía de casa também... Eh... Foi aí que me levaram de volta pra lá... E depois disso, eu melhorei! Agora faz o que, quase 8 anos que eu não volto pra lá".

Bradizza \& Stasiewicz, (2003) encontraram no seu estudo que o consumo de drogas poderia ser motivado por afetos negativos, o que pareceu se relacionar na narrativa de Pedro que contou ter iniciado consumo mais intenso de álcool quando se decepcionou com uma menina, o que ocorrera 
concomitantemente ao período em que começara a sentir-se "desconfiado". Esse consumo foi complementado com cigarro e maconha.

"F: O que que aconteceu pra você começar [a beber com mais intensidade]...

P: Por causa dessa menina, aí.

F: O que você pensou? Que a pinga podia te ajudar em alguma coisa?

P: Ah, sei lá... Não sei se podia ajudar, ou ajudava a esquecer... Não sei...

F: A cerveja não ajudava a esquecer. Tinha que ser algo mais forte, como você falou.

P: Não. Naquela época eu tava bebendo cerveja também... mas era mais pinga, né? Todo dia era o que eu pegava era cigarro, pinga e refrigerante. Pra ficar... pra ficar só em casa bebendo".

Para ele, o uso do álcool foi narrado como uma estratégia de lidar com as sensações em relação à menina e à decepção diante dela. Esse consumo poderia ter potencializado os efeitos da maconha e desencadeado a perda do controle de experiências descritas pelo discurso médico-psiquiátrico como "sintomas psicóticos", promovendo a situação de crise (Bradizza \& Stasiewicz, 2003). Dizia que o consumo para ele "tinha que ser de algo mais forte", o que fazia diariamente "pra ficar só em casa bebendo", o que ocorreu no período que antecedeu ao momento de internação psiquiátrica.

Em outro momento da entrevista conversamos sobre a experiência de consumo da maconha, que segundo ele, provocava alteração na senso percepção. A partir de elementos presentes no seu cotidiano, explicou essa sensação diante da maconha, por meio de uma metáfora.

"P: Olha, é assim... Deixa eu te explicar... Você já assistiu aquele desenho Cavaleiros do Zodíaco?

F: Ahn

P: Não tem a Ikki de Fênix. Aquele cavaleiro, irmão do da corrente?

F: Tá...

P: Ele tem um golpe que chama golpe fantasma de fênix. Ele dispara um raio na testa do oponente e ele fica ali e vê uma ilusão. Ele tá acordado, mas ele tá paralisado, mas na mente dele ele tá vendo uma ilusão.

F: Sei.

P: Era assim... Eu fumava maconha, e ficava pensando... E nesse pensamento vinha uma ilusão... Ou eu assistia um filme... Ouvia uma música..."

Pedro descreveu que a maconha tinha como efeito inicial provocar "ilusões". A partir da referência de um desenho animado dos anos 90, ele relatou que a sensação era de "estar paralisado", mas "na mente, ele via uma ilusão". Esse efeito, com o tempo, parou e ele acabou por abandonar o consumo. Referia que enquanto a maconha ainda promovia esse efeito, ele sentiu que sua criatividade era aumentada, possibilitando a ele fazer música e filme. Esse efeito também foi relatado por Thornton et al. (2012) que referiu que o consumo da maconha permitia pensar livremente e criativamente. Costain (2008) relatou 
aumento e promoção da criatividade em pessoas com diagnósticos parecidos com o de Pedro quando consumiam maconha.

"F: Te ajudava a pensar?

P: Ajudava. Eu criei música, criei filme

F: É? Sob o efeito da maconha.

P: Sob o efeito. Depois parou de fazer efeito... E não usei mais”.

Quando busquei explorar um pouco dessa sensação, Pedro descreveu com muitos detalhes como era

uma das suas "ilusões", quando estava sob o efeito da maconha.

"P: Ah, lembro muito! Por exemplo, eu criei um filme chamado "A Saga dos Sete Portais". No sétimo portal, é assim... Tá uma... Tá chovendo... Num campo aberto, só tem árvore. Chuva e trovão. Aí aparece uma rosa, uma rosa gigante e ela se abre... E sai uma moça. E conforme a música vai tocando a moça vai dançando.

F: Que música que toca?

P: Eterna lua.

F: Eu não conheço.

P: Fui eu que criei.

F: Ah, você que criou? Ela é de letra ou só instrumental?

P: É de letra, tipo uma poesia. Uma poesia que eu transformei em música. Se você ler ela, é uma poesia.

F: É! E ela sai...

P: É não sei explicar, porque quando eu fumava, você pensava as coisa e as coisa vinha na sua mente. Não era você que ordenava, vinha. As coisas iam acontecendo e você ia passando pro papel".

A sensação que Pedro tinha era que a maconha catalizava a capacidade de percepção. Ele descreveu a cena imaginada por meio de vários estímulos sensoriais como música, promovidos, segundo ele, quando estava que via sob o efeito da maconha e que depois se tornou um filme que ele narra ter escrito. Costain (2008) também comentou que um dos participantes de seu estudo sentia-se mais capaz de compor RAP, se utilizando das rimas que inventava para se expressar. Essa era uma prática legitimada pela mãe do participante que atestava melhora nessa habilidade, embora ela percebesse que com o consumo seu comportamento ficava mais desorganizado.

A maconha auxiliava, para Pedro seu processo criativo, enquanto o cigarro lhe parecia participar do processo produtivo de desenhar.

"F: E hoje você ainda cria vídeos.

P: Hoje eu crio, escrevo roteiro... Desenho gibi...

F: Mas não sob o efeito da maconha...

P: É, não faz mais efeito!

F: E muda a criação?

P: Não, não muda.

F: Você acha que consegue criar do mesmo jeito sem a maconha... [acena positivamente com a cabeça] E o cigarro? Te ajuda a criar?

P: É... Quando eu tou... Pronto para escrever um roteiro eu fumo um cigarro, tomo um suco... Fico lá pensando... E as ideias vêm e eu passo pro papel." 
Apesar de não fazer mais uso da maconha, quando foi entrevistado, pois esta já não fazia o efeito desejado, Pedro narrou alteração em sua percepção descrevendo que era "como se o pensamento se tornasse real". Mas essas sensações, segundo Pedro só aconteciam sob o efeito da maconha. Antes dela, não tinha tido essas experiências as quais chamava de "ilusões". Após interromper o consumo, ele não as tinha mais da mesma maneira, atribuindo essas "ilusões" a "lembranças" da época em que fumava maconha. Essas lembranças o ajudavam também no processo de criação.

"F: ah... Você nunca tinha tido essa experiência antes de fumar maconha?

P: Não.

F: E mesmo depois de parar ela também parou? Essas experiências de sentir aquilo que você tava pensando, mais real?

P: É, eu continuo lembrando, né?

F: Lembrando.

P: Lembrando e passando pro papel. Mas fumando e vendo, eu não tou mais vendo não".

Atribuiu a alteração da percepção a um efeito da maconha. Sem ela, não tinha mais essa sensação, embora ele tenha comentado que com o tempo, os efeitos da maconha já não eram os mesmos. Apesar de ter parado de fazer uso da droga, ele referiu ter mantido a capacidade criativa. Fiore, (2013) comentou que um dos participantes do seu estudo, que usava maconha na época da faculdade, relatou que não teve prejuízos com o consumo no que se refere ao aprendizado do conteúdo ensinado na época, sugeriria que a experiência vivida por pessoas descritas ou não por diagnósticos psiquiátricos pode ser semelhante.

Costain (2008) comentou que, nem sempre essa percepção de não ter prejuízos com a droga era compartilhada por outros que convivem com pessoas em sofrimento psíquico. No caso de Pedro, que dependia da renda do pai, as histórias de quadrinhos foram produzidas, segundo ele, para serem publicadas em um almanaque. No entanto, Pedro passava muito tempo imerso nessas histórias e lançou dúvidas se conseguia colocar em prática essas ideias de publicação, que para ele tinha um sentido produtivo de trabalho.

"P: É eu pretendo começar lá pelo ano que vem. Se eu terminar os "7 Portais". Que agora final de ano eu dei um tempo. Tou mais treinando...

F: Você passa bastante tempo desenhando?

P: Ah, tinha dia que eu ficava bastante tempo. Como se tivesse assim, num horário de serviço mesmo. Só parava pra ir no banheiro, comer e beber água...

[pausa]

F: Como que... Como que você controla esse seu trabalho?

P: Ah, tem que ter muita determinação, viu, tem que ser dedicado... Tem dia que eu tou... Desanimado. Tem dia que eu só desenho duas páginas. Fumo um cigarro, vou deitar, acabo dormindo". 
A construção de suas histórias datava desde a época da primeira internação, o que Pedro associou a momentos em que pensava nessa menina por quem se apaixonou. Ela também, segundo ele, foi objeto de desenhos, sendo uma das personagens principais e representada como companheira do herói de suas histórias que ele atribui a si mesmo, construindo uma imagem idealizada de mulher.

"F: Você consegue fazer alguma relação com o que você estava sentindo... Com a necessidade de você usar alguma droga? Ou você acha que não tem nada a ver...

P: Eu fumava mais pra ver ela, né?

F: Como assim?

P: Porque era ela que dançava. No 'Sétimo Portal'

F: Não entendi.

P: Era a menina. Que eu gostava. Dançava..."

O consumo do álcool e da maconha só se intensificou em um momento mais próximo da época em que teve sua primeira internação psiquiátrica, o que poderia ser interpretado pelo discurso médicopsiquiátrico como parte dos "sintomas" da esquizofrenia, mas na sua experiência, não foi compreendido dessa maneira. Nesse sentido, o consumo da maconha e do álcool pareceu propiciar a sensação de proximidade com a garota por quem se apaixonou, por meio da alteração de percepção de uma experiência que ele chamou de "ilusão". Na época em que tinha sido internado em hospital psiquiátrico "as lembranças" dessa moça também ocorriam e com sua criatividade, construiu histórias nas quais ela participava. Em uma mistura entre o sonho, a imaginação, o efeito da maconha e alterações que poderiam ser chamadas de delírios pelo discurso médico-psiquiátrico, ele construiu uma narrativa própria para contar sua experiência.

"F: Como que foi a situação dessa segunda crise?

P: ... [pausa]... Não sei... [pesaroso] Mas eu chegava e pensar nela, quando eu tava lá no [hospital psiquiátrico].

F: Eh? Como que foi?

P: [pausa breve]... Eh... Enxergando o Sétimo Portal. Tudo aquilo que se passou... [pausa grande]

F: Esse sétimo portal, ele é muito importante pra você.

P: É.

F: o que que é ele?

P: Ah, é uma... A história do Sétimo Portal é uma... Assim... Aa história conta a minha história... Eu sou um homem normal, sem poderes nenhum, que chegou num templo, que quando ele tá bêbado - ele bebe vodka - bebe garrafa de vodka, aí eu, ele se distrai os ninjas estão montando guarda nas estátuas sagradas... eu entro e pego as garras e coloco. Elas dão poder para liberar o poder das garras... Aí dá pra utilizar as técnicas. Aí quando chega nesse sétimo portal, o que acontece, eu tenho a capacidade de virar um homem-leão. Ele chama o Leão da Escuridão. O que acontece. Esse leão separa do meu corpo, aí fica eu e o monstro. Frente a frente".

O período em que interrompeu o consumo da maconha coincidiu com o início de seu tratamento e com o início da administração de medicamentos psiquiátricos no CAPS II. Sob o efeito da maconha nas suas "lembranças", a experiência frustrada de encontro com a menina se transformou em uma experiência 
positiva e fantástica. Na narrativa de Pedro, o consumo da maconha promovia expansão da percepção e da criatividade, permitindo que criasse roteiros de histórias construídas quando ele estava sob o efeito da maconha, além disso, parecia permitir a imaginação de outras saídas possíveis diante de uma situação de sofrimento.

De maneira semelhante a Fabiano, o consumo de maconha pareceu contribuir para a expressão/elaboração do modo como percebia a situação de frustração. No entanto, os circunscritores dessas experiências foram diferentes na narrativa de Pedro. Para ele as referências que tinha eram as histórias de heróis e desenhos animados do anos 1980 e 1990, enquanto para Fabiano, as referências eram relacionadas ao contexto da "bocada".

"P: Começo a desenhar 9:00... Da manha. Eu ponho filme, né... Enquanto o filme rola, eu vou escutando o filme, eu vou desenhando...

F: Que filme você gosta de assistir.

P: Ah, tem vários, vários... Todos os dos anos 80 e 90".

Pedro contava que uma rotina, para ele, era desenhar enquanto assistia a filmes dessa época. Além da construção criativa que pareceu ser fomentada por desenhos animados da sua época de infância e adolescência, na narrativa de Pedro, começara a consumir o álcool aos 16 anos, época em que sua vida mudou muito devido à morte da mãe e à mudança de cidade para viver com o pai.

"F: Álcool você não usa mais... Você começou a beber com quantos anos?

P: Com 16.

F: Com 16 também... Foi mais ou menos na época que a sua mãe morreu?

P: Foi quando eu vim morar aqui em [cidade da pesquisa].

F: Ah, você não morava aqui?

P: Morava em [cidade do litoral]

F: Ah eh? Como foi essa história de você vir pra cá?

P: Foi quando ela morreu. Foi quando eu vim pra cá... Não tinha ninguém pra morar lá comigo!

F: Seus pais eram separados.

P: É. Eles não eram casados. Eles não são casados.

F: Aí você, então veio pra cá, morar com o seu pai. Foi difícil se adaptar, morar com ele?

P: Mais ou menos!"

Nessa época precisou se adaptar à nova vida, fazer novos amigos. Contou que passava os dias jogando videogame, tomando cerveja com os amigos.

"F: Quando você tava com o computador legal, você jogava o quê?

P: The King of Fighters

F: É... Jogo de quê?

P: Jogo de luta. Tipo Street Fighters.

F: Então você ia com os amigos jogar, e aproveitava e tomava uma cervejinha. 
P: Isso.

F: Mas não tomava pinga nessa época.

P: Não. Comecei a tomar pinga no final de 2004. Pra 2005".

O consumo de álcool, ao que pareceu, fazia parte do cotidiano de sua adolescência, sendo algo compartilhado pelos amigos. O consumo da maconha aconteceu um pouco mais tarde, também compartilhado pelos amigos, que o convidaram e o ensinaram a fazer uso dele.

"F: E a maconha, veio quando?

P: 2003 [pausa]

F: Como que foi?

P: Ah, eu tava numa roda de amigos e eles falaram 'ó quer fumar?' Eu falei 'vam'bora!' Aí eu não sabia fumar, aí eles me ensinaram a fumar... pronto".

Como para Fabiano, o consumo de maconha e do álcool foi aprendido entre amigos, tendo circunscritor jogos de videogame, o que permite supor que a família de Pedro podia proporcionar a ele esse tipo de entretenimento, diferentemente de Fabiano. Importa lembrar que Pedro tinha o mesmo diagnóstico de esquizofrenia que Fabiano. O primeiro fazia tratamento no CAPS II, enquanto o segundo era atendido no CAPS AD. Diferentemente de Fabiano, Pedro foi posicionado como paciente psiquiátrico pela equipe de saúde. Além disso, Pedro morava na região central da cidade, tinha maior poder aquisitivo que Fabiano, o qual fora foi institucionalizado desde pequeno, sendo descrito como usuário de drogas, fazendo uso, na época da entrevista, de cocaína e crack, além de maconha e álcool, conforme descrito em seu prontuário, circunscrevendo experiências e sentidos atribuídos a elas diferentes. Parecia esses elementos circunscreveram o modo como Pedro significou o consumo de álcool e maconha diante das suas experiências, ainda que no momento da entrevista já não fizesse mais uso dessas drogas, continuando somente com o cigarro, que era legitimado para ser consumido no CAPS II.

Rogério

Rogério contou que as vozes que sempre ouviu falavam baixinho, dando "conselhos que não eram conselhos bons". 
"R: Ouvir vozes não, porque eles sempre falavam baixinho.

F: Você sempre ouviu vozes?

R: Sempre, sempre ouvi vozes e eles falavam bem baixinho entendeu? Pra gente ficar meio naquele conselho que não era um conselho bom... Ficava falando baixinho pra pessoa pegar , mas não era um conselho bom entendeu?"

$\mathrm{Na}$ época em que aconteceu a entrevista, Rogério narrou que vinha se sentindo pior em relação às

vozes, pois no seu relacionamento com elas disse que pararia de usar drogas, as quais o fizeram "passar mal".

"F: E o que que elas falavam?

R: Ah! ultimamente foi pior né... Depois do... De uma tragédia que aconteceu comigo... Porque pra mim aquilo foi uma tragédia né.

F: O que aconteceu?

R: Foi tipo um prego... Eu usava mais a maconha do que a cocaína... Aí fui falar que parava... Parar de usar... Eles fizeram eu passar mal. Eu fiquei na cama doente, foi onde eu vim parar aqui [CAPS AD]".

$\mathrm{Na}$ sua forma de pensar, as vozes o fizeram passar mal, e teriam provocado a overdose como uma

forma de punição por querer parar de consumir drogas. A sensação de ouvir vozes teria aumentado na época em que teria tentado interromper o consumo, sendo interpretada por Rogério como uma piora no seu estado mental e motivação para ser encaminhado para o CAPS AD. Holt \& Tickle (2013) discutem que entre ouvidores de vozes, como Rogério, elas podem ter características de aumentar a sensação de "fraqueza" e submissão da pessoa que as ouve, dando-lhes a sensação de que sucumbiriam aos comandos das vozes.

"R: Aí que começou mais as vozes... Eu falei pras vozes que ia parar...

F: Você falou para as vozes que ia parar, mas aí elas não deixaram?

R: Elas não deixavam... Vieram me resgatar pro uso de novo. Para o trabalho de novo e para o uso de novo.

F: Que trabalho? Como assim?

R: Porque eu estava trabalhando né, só que depois do acontecido... Depois da overdose que me deu... Foi overdose.

F: Cê teve overdose de cocaína?

R: É... É... Isso ai.. Overdose de cocaína...”

Diante do pensamento de que deveria parar de consumir drogas, Rogério aumentou o consumo da cocaína, o que provocou “overdose”. Entendera essa situação entendeu como uma punição por querer parar de consumir. Esse sentido atribuído ao consumo de drogas também foi encontrado por Asher \& Gask (2010), que encontraram a atribuição de que as vozes, por vezes se apresentavam de maneira negativas e incitavam o uso de drogas nas pessoas que as ouviam. Essa experiência, para Rogério, foi vivida como uma "tragédia", significando-a de maneira diferente dos sentidos atribuídos ao consumo por Pedro e Fabiano, apresentados anteriormente. 
Com a cocaína, apesar de as vozes existirem, sob o efeito dessa droga, Rogério narrou que a substância fazia com que as vozes ficassem "em silêncio, embora elas aumentassem o volume da televisão. O sentido atribuído ao consumo de cocaína por ele era como se o consumo favorecesse a alteração da percepção de seu entorno, que o fazia sofrer, ou como ele comentou "poderia pessoas sofrerem com isso".

"F: E com a cocaína, ela...

R: Ficava todo mundo em silêncio ninguém dava conselho a não ser a televisão que ficava na maior das alturas em casa...E ai eles aproveitavam que tava dando conselho e aumentava a televisão no ultimo e poderia pessoas sofrerem com isso né”.

Ele organizou seu pensamento a partir de uma lógica própria, relacionando que o consumo de maconha ajudava a diminuir o volume e a calar as vozes, de maneira análoga ao sentido atribuído por Fabiano para essa experiência, mas compreendendo-a de maneira diferente, deixando as vozes "em silêncio", como também encontrado por Asher \& Gask (2010).

"F: Uhm... A droga ela te ajudava a controlar essas vozes ou não?

R: Ajudava, ficava todo mundo em silêncio.

F: Quando você usava que tipo de droga?

R: Maconha.

Em outro momento da entrevista, perguntei se, sob o efeito da maconha, as vozes ficavam quietas.

Rogério respondeu afirmativamente.

"F: E... quando você fumava maconha as vozes ficavam quietas?

$\mathrm{R}$ : É as vozes ficavam quietas.

F: O que passava na cabeça?

R: Na minha cabeça?

F: É.

R: Ah! eu ficava tipo esperando uma ajuda... Uma ajuda que nunca vinha.. Eu ficava ali naquela... Pô eu tô fumando maconha aqui... Primeiro começou com cigarro..."

Rogério complementou essa informação dizendo que nessas horas ficava esperando ajuda, sugerindo um sentimento de desamparo e falta de outros recursos para lidar com essa experiência. Com o consumo de maconha, ele tinha a sensação de que as vozes diminuíam, ao mesmo tempo, a maconha também tinha significado de companhia diante experiência.

A partir da compreensão de que ouvir vozes era uma experiência antiga na sua história de vida, Rogério relacionou a origem das vozes aos "ouvidos", dificultando sua audição. (Woods et al., 2015) encontraram pessoas que também atribuíam à origem das vozes em partes do corpo, no entanto, faziam uma separação entre o corpo e o cérebro, o corpo e a percepção de si mesmo. Na narrativa de Rogério, ao 
contrário das compreensões apresentadas por esses mesmos autores, a origem das vozes tinha a ver com a sensação de que seus ouvidos não estavam bem limpos, pois tinha a sensação de que não foi cuidado, quando era pequeno.

"F: E como que... Você sente que sempre escutou essas vozes desde pequeno?

R: Sinto... Porque eles atingiam meus ouvidos... Pra não escutar e não me higienizar direito... Não me ensinavam a me higienizar eu não limpava direito os ouvidos porque eu não tinha cotonetes... E além disso acho que eles atingiam meus ouvidos... Pra não escutar direito... Que era pra que era parar de escutar... Escutava bastante".

O consumo de drogas, para Rogério acontecia como forma de chamar a atenção da família dele. Ele deu como exemplo a narrativa de quando começou a fumar cigarro, sua mãe não respondeu como ele esperava ("com tristeza"), mas com "alegria", segundo ele, legitimando seu consumo.

"F: Ela sabia que você fumava?

R: Sabia. Ela ficou sabendo que eu fumava porque ela pegou os tocos de cigarro dentro do cinzeiro ai a reação dela não foi de tristeza, foi de alegria".

Ele falou em uma grande variedade de vozes presentes e que participavam da experiência de consumir drogas. Algumas vozes ficavam em silêncio, outras vozes o “incitavam” a usar droga, mas também existiam vozes que, na sua compreensão, evidenciavam problemas com consumo do crack, impactando sobre "o psíquico". Holt e Tickle (2013) discutem a importância de reconhecer as diferentes identidades das vozes presentes e de dar atenção ao relacionamento entre ouvidores e vozes, possibilitando conhecer o "poder" das vozes sobre as pessoas que as escutam. Rogério retomou que apesar de todas essas experiências, sentia prazer com o consumo dessa droga e por isso, apesar dos problemas apresentados pelas vozes, ainda tinha vontade de consumir.

"R: Ai eles atingiam de novo... O psíquico da gente pra gente poder correr da droga;

F: Então tinha...

R: Tinha sempre um que me atingia pra eu correr da droga. Pra eu sentir o problema da droga, não a sensação de gosto de bom. F: hã.

R: A sensação de gosto ruim, não de gosto bom da droga.

F: Então o que você está me contando é que tinham vozes que te incitavam a usar e tinham vozes que te incitavam a parar [de usar]?

R: A parar e eu virava alvo de alguma coisa que.. Pra mim sentir o horror da droga.

F: O que você sentia...

R: Só que ai, a sensação era maior né... Como você experimentou, você quis sentir... Como eu já tinha experimentado, quis sentir de novo aquele prazer".

Nessas experiências, ao crack foi atribuída uma sensação de grande prazer, a qual era maior que "a sensação de gosto ruim" provocada pelas vozes que ouvia e o "atingiam para correr da droga", para "sentir o horror da droga”. Esse sentido negativo do consumo atribuído às vozes diante do consumo de crack, talvez 
tenha sido influenciado pelo discurso médico-psiquiátrico, que faz críticas ao consumo ressaltando mais seus aspectos negativos, inclusive diante das experiências de ouvir vozes (Costain, 2008).

Essas construções de sentido pareceram ser circunscritas, na narrativa de Rogério, por experiências do passado infantil descrito como "não muito bom não". Ele narrou ter presenciado cenas de violência do pai contra sua mãe, o que para ele teve um impacto negativo. Buadze et al., (2010) encontrou em seu estudo participantes que atribuíram às suas famílias aos problemas de criação a promoção de problemas mentais que experienciavam.

“R: (...) Meus pais estão casado desde 1976. Estava casados desde 1976, houve a separação quando eu tinha 4 anos de idade. Por motivos de brigas que eles brigavam tal.

F: Como que foi pra você?

R: Ah! Foi meio esquecido... Assim, porque eu era uma criança, mas não foi muito bom não porque eu já vi relatos de que eu vi eles brigando, meu pai enforcando minha mãe, um tipo de brincadeira assim... Era agressão de brincadeira, mas tinha agressão".

Essas experiências, para Rogério, o marcaram muito e ele pareceu refletir sobre isso, não concordando em ter sido exposto a esse tipo de situação. Rogério qualificou a educação oferecida pela família como "não muito inteligente", tendo sido criado pela avó que era semianalfabeta, quando a mãe mudou de país para trabalhar. Ele relatou que nessa época a família passou por dificuldades financeiras.

"R: Ah! dificuldade financeiras, dificuldades de convivência né... Esses tipos de coisas. Então eles entravam em conflito também e eu ficava vendo aquilo lá né... Eu sempre olhava aquilo lá.

Dai minha mãe se formou jovem... Ela se formou pra cabelereira aos 17 anos e foi [para outro país] trabalhar lá. Me deixou com minha vó, então minha criação foi de vó e ela é semianalfabeta não foi uma criação muito inteligente entre aspas assim né. Não foi uma criação muito inteligente"

Além disso, Rogério tinha a sensação de que lhe faltava apoio familiar diante de problemas que enfrentava, como por exemplo, na escola. Deixou de frequentar a escola, momento que coincidiu com o início do consumo de drogas.

"R: Então na hora das reuniões... Não tinham que ir na reuniões... Reuniões de pais e mestres.

F: Sua vó não ia?

R: Minha vó ia de vez em quando. Quando não ia... Uma vez minha prima e minha mãe estavam [fora do país] trabalhando, meu pai nas drogas e no álcool e não ia.

F: Hum... Você sentiu falta.

$\mathrm{R}$ : Eu senti falta da família essa hora, nas reuniões de pais e mestres".

Rogério pareceu usar drogas como uma estratégia dele para chamar atenção da família para algo que se passava emocionalmente com ele. Era como se o cigarro e depois a maconha, a cocaína e o crack 
assumissem papeis de linguagem para transmitir algum sentimento que ele pareceu não saber exprimir de outra forma ou que foi legitimado pelo seu entorno para ser expresso daquela maneira.

"F: Como que foi essa situação que cê parou de estudar?

$\mathrm{R}: \mathrm{Ah}$ ! Eu parei e voltei 3 vezes. Parei na 7 serie que eu repeti.

F: Ai você saiu?

R: Ai eu sai... Acho que era o começo das drogas.

F: Como foi isso?

R:Ah! Isso foi terrível também pra mim... Eu achava que não precisava daquilo entendeu? As pessoas faziam a gente achar que... Não sei se eles catavam baixo ou que eu achava que não precisava do colégio.

F: Ai você usava o que?

R: Na porta do colégio primeiro nós começamos a fumar cigarro. Depois passou pra maconha, depois cocaína, crack... usava crack dentro do banheiro do colégio".

Diante do consumo, as experiências de sofrimento acerca das vozes foram transformadas e puderam ser vividas a partir de seu silenciamento. Essa estratégia foi compartilhada por outras pessoas da família, como a mãe e o pai, o qual também tinha problemas relacionados ao consumo de drogas. Diante da sensação de precariedade que sentia viver, os sentidos e significados do consumo de drogas sofreram influência de seu entorno, que os legitimou. Fabiano, Pedro e Rogério, , embora estivessem em situações de vida diferentes receberam diagnósticos psiquiátricos, sendo atendidos em serviços de saúde, os quais contribuíram para complementar com outras referências as construções de sentidos sobre suas experiências.

A partir do discurso médico-psiquiátrico sobre o consumo de drogas e sobre ouvir vozes, essas experiências foram compreendidas como problema. No caso de Rogério, elas foram compreendidas como assustadoras e tinham grande poder sobre ele. O consumo de drogas pareceu compor com outros repertórios presentes no seu cotidiano para expressar sofrimentos psíquicos, diminui-los. No entanto, em seu relacionamento com as vozes, elas pareceram reagir de diferentes maneiras diante do consumo ou da vontade de parar com ele. 
Flora, iniciou o consumo de crack com 21 anos, sob a forma de pedra e descreveu essa experiência como "fumando uma atrás da outra".

"F: O que você já usou?

FL: Pedra.

F: Só pedra? Com que idade você começou a usar?

FL: Eu tinha21... 21 ano.

F: O que aconteceu antes dos 21 anos.

FL: É que [tava] só pegando dinheiro, só pegando dinheiro... Não vinha aqui mais... Só pegando dinheiro... Fuma. Aqui no [bairro onde fica o CAPS AD] só pegando dinheiro pra fumar... Aí um dia peguei de encontro... Ganhei 15 reais... Fui... Fumando uma atrás da outra... pegava 4 [pedras]".

Este foi seu modo próprio de apresentar sua história de vida, em que reconstruiu o sentido do consumo como uma fala sobre a compulsão em consumir o crack, medida em reais. Atribuiu como motivo para consumir a s momentos em que "ficava nervosa". Alguns estudos sobre o sentido do consumo de drogas ilícitas, descrevem que essa é uma atribuição comum entre pessoas diagnosticadas com transtornos psicóticos (Asher \& Gask, 2010; Bradizza \& Stasiewicz, 2003), entendendo nervosismo como tradução de estresse e ansiedade. Essa categoria será estudada mais adiante, mas é interessante notar essa associação.

"F: Porquê. O que te motivava? O que fazia você querer...[usar crack]

FL: Passar nervoso... Ficava nervosa... Passava nervoso... Falei o quê?”

Flora também falou do consumo do cigarro e o descreveu como vício, "porque eu não paro" e cuja vontade de fazer uso "vai e volta", enquanto o consumo do crack, segundo ela já havia sido interrompido, não sendo, portanto, um problema para ela.

"F: Você falou que você usa cigarro...

FL: Cigarro tenho vicio, porque eu não paro.

F: Como que é isso?

FL: O cigarro ele é (áudio incompreensível) na hora que você tá assim... Eu fumei 3 cigarro na hora que eu tô vindo. Aí você tá fumando cigarro até chegar aqui. Aí eu tô assim, beleza. Tô aqui... Aí depois volta de novo... Vai e volta".

Flora narrou uma cena em que ela interagia com o marido e um traficante, pessoas de seu entorno que a convidaram a ir na "bocada", escolhendo se apresentar dessa maneira para mim, no momento de entrevista. Em continuação a sua fala, narrou como se saiu da situação em que o crack lhe foi oferecido, expresso pela locução “o pai quer te ver", respondendo também por meio da locução "meu marido não quer que eu saia... peguei, disse essas".

"F:... Você tava me contando da tua história.

FL: Ah não! Aí eu... Aí o povo vai... Ai José, o que é o Ronaldinho lá no prédio lá... 'Aí, pai quer te ver...' F: Quem é o pai? 
FL: O José e o Ronaldinho lá do Beco.. aí ...Aí ele, do... Ele vende pedra, vende maconha.Aí, ele falou: 'Vou falar pro pai', 'Vou manda um abraço'... Porque ia perto do meu marido, vai falar... 'Aí o pai quer te ver'.

F: Ele era seu ex?

FL: Não.

F: Ele era só traficante".

Na entrevista e na transcrição do áudio da conversa com Flora foi possível perceber uma modulação da voz, em volume alto, que permitia menor compreensão do que ela falava. Além disso, sua conversa se apresentou entrecortada de falas de outras pessoas de seu entorno que conversavam com ela e que se misturavam às suas ideias, compondo seu fluxo de pensamento.

"FL: Aí ele fala assim ó... Não porque a minha vó, à minha vó teve casa e ele com a casa da minha tia. Ele fala 'o pai quer te ver'... E começa 'aí o pai quer te ver'... Tem dia que eu falo 'fala pro pai que eu mandei um abraço, porque não tem agora...' 'O meu marido não quer que eu saia'. Peguei, disse essas... Bem, eu posso descer lá embaixo... Aí foi que foi ele começou a brigar comigo ontem".

Na sequência dessa fala, Flora contou que estava querendo parar de usar crack, descrevendo-o como “o capeta”, cujo consumo vinha sendo promovido pelas pessoas ao seu redor, na sua perspectiva.

“FL: ... Ele só falou 'Você quer ir você, quer ficar então'. Aí eu falei ‘Aí então...' 'EU, sou seu marido... Você quer ir, você quer ficar então?' Você quer lá no Ronaldinho? Ele chama Ronaldinho... 'Você quer ir lá?' Falei 'não, não vou...' Aí veiote falou 'ou vamo c'a motinha, vamo deixar ela no beco'. Eu falei 'quê? O capeta tava falando pra eu... que?' (áudio incompreensível) 'O pai que te vê...' 'Eu vou te dar um teco'. Eu falei 'fi... tsc tsc. (faz o som como uma negativa) quero nem pensar! Tô lá dentro [do abrigo municipal] essa roupa que eu tenho a eles que doam'. É isso aí nem pensar que eu não quero... Nada de drogas”.

Bradizza \& Stasiewicz (2003) relataram que estar próximo de certas pessoas e em ambientes associados ao consumo de drogas eram elementos que se apresentavam como motivadores e uma barreira para a diminuição do consumo dessas drogas. Flora apresentou na sua narrativa um sentido semelhante àquele encontrado por esses autores quando narrou que naquela situação em que foi convidada para ir ao "beco", estava implícito que o traficante "Ronaldinho" estava oferecendo "um teco" da droga para que ela consumisse. E o marido dela que foi apresentado como alguém que não queria que ela fizesse esse consumo, foi descrito por meio da fala para o traficante que o "marido não quer que eu saia". No entanto, esse mesmo companheiro oferecia levá-la "lá no beco". Essas falas se fizeram presentes na sua narrativa e se apresentaram para ela como sendo a presentificação do diabo.

Flora se utilizou do discurso religioso para falar sobre o consumo do crack, discurso que, na cultura ocidental, vem associando o consumo de drogas à contraposição entre o "bem e o mal” (Souza, 2013), na narrativa de Flora foi chamado de "o capeta". Esse discurso no nosso país vem sendo utilizado por religiões 
cristãs como um discurso por vezes alternativo, por vezes complementar ao discurso médico-psiquiátrico (Sanchez \& Nappo, 2008). O significado demoníaco atribuído ao crack juntamente com o oferecimento do consumo foram sentidos por Flora como tentações, cujo desfecho seria negativo na sua opinião.

Ela escolheu, diante dessa situação narrada, se descrever a partir dos prejuízos e dificuldades que experienciava naquele momento. Preferiu narrar que não aceitou a oferta, procurando o pastor que já vinha lhe ajudando oferecendo recursos básicos para a manutenção da sua sobrevivência como "sabonete". Com ele, ela mantinha alguma identificação porque ele também tinha sido "viciado", tendo vivido uma situação de vida parecida com a dela, tendo compartilhado com ela sua história.

"FL:Aí foi que foi pastor da igreja que também era viciado... Ele falou a história dele. 'Traz a meia...' Ele viu a meia minha... Aí ele falou que vem uma só meia... Eu levei uma pra ele. Ele me dava sabonete... Aquele sabonete que eu tomava banho, pegava um pra mim, um pra ele... Ele tomava banho também aí começou né.... Conhecendo ali mesmo... Eu também..."

Esse discurso religioso foi atualizado nos últimos anos no Brasil com o advento de uma política de drogas que utiliza de comunidades terapêuticas comandadas por instituições religiosas como estratégia de tratamento do consumo de drogas, cuja normativa é a busca pela abstinência (Souza, 2013). Por um lado, pela utilização desse discurso, Flora pôde visualizar a possibilidade de salvação da zona de abandono social, onde se encontrava. Por outro, ela se dava conta da sua precariedade, sentindo concretamente que não tinha recursos nem "pra tomar banho", recebendo "sabonete" do pastor. A precariedade em que se encontrava dizia respeito à necessidade de morar em um abrigo municipal e usar roupas que lhe foram doadas pela instituição onde morava. Além disso, estava no momento da entrevista, grávida.

Sua narrativa pareceu ser construída com a precariedade do ambiente em que ela se encontrava. Como reflexo, o discurso religioso pareceu servir como alento para o sofrimento e alternativa ao "povo" com quem convivia. Esse "povo", diferentemente do modo como descreveu Fabiano em relação aos traficantes com que mantinha contato. A "biqueira"/"bocada" não era vista por Flora como uma referência valorizada, sendo descrito como "o capetinha", igualando à droga.

“FL: Aquele povo que é o capetinha. Parece isso aqui oh... Você tá assim lá e na biqueria lá tem um negocinho igualzinho ao seu celular [pega meu celular, que uso como gravador da conversa, e o manuseia]... Se você pegar 10 real ele aperta aqui balança [mexe no celular como se fosse uma balança] faz de conta que isso aqui é balança... Dai ele pega... Aí ele faz assim... Isso aqui é a 
pedra [pega uma caneta que estava na mesa a sua frente] faz assim oh... Ele não vai ligar [falando sobre o manuseio do meu celular e da minha reação diante desse manuseio] Oh...

F: Ele pesa.

FL: Pesa... Ai ele fala quanto você quer? Tó".

Talvez, como uma estratégia de ultrapassar barreiras sociais e culturais entre mim e ela, Flora descreveu, como era para ela o contexto onde ela fazia consumo do crack por meio do manuseio do meu celular, usando-o como metáfora de de balança e cachimbo, durante o encontro de entrevista. A cena que pareceu muito com elementos descritos por (Jorge et al., 2013) que associaram o consumo do crack como não desconectado do contexto social e econômico em que todos estamos inseridos. Estes autores consideraram que o crack, tornava-se símbolo das camadas "mais populares". Ou seja, ao mesmo tempo que o crack simbolizava mercadoria de péssima qualidade, originado do que sobrou de uma droga mais limpa e associada às camadas empresariais, era símbolo de ostentação e poder, como foi demonstrado na performance de Flora.

Como fez durante toda a entrevista, Flora me convidou para experimentar com ela a sensação onírica do consumo, em um caminho imaginário e inverso. Do mesmo jeito que ela agia com resistência diante da “opressão conjugada", termo usado por Bourgois \& Schonberg (2009) para falar de um conjunto de dificuldades e negações de direitos, imputação violências e de discursos de exclusão, Flora atualizava isso comigo na entrevista no manuseio do celular, que me levou a compreender mais vivamente sua experiência. Essa forma de construir sua narrativa, partiu de um contexto diferente daquele apresentado por Pedro, mas guardava semelhança com as histórias, músicas e filmes que ele escrevia. Flora ofereceu uma descrição de si e de suas experiências de uma maneira que lhe era própria, mas igualmente mantinha ligação com conteúdos de seu contexto e das diferenças concretas presentes entre ela e eu, em que o consumo do qual ela queria se livrar pareceu ser compreendido como recurso de resistência e linguagem. Essa compreensão encontrou eco ao retomar a narrativa de Flora, quando perguntei a ela se sentia tristeza. Ela respondeu contando o sonho de não ter vontade de usar crack.

"F: Você sente tristeza?

FL: Nossa eu sonhava com a pessoa livre assim oh... As pedras nem, nem começa pegar nimim mais. Eu posso andar aqui no[bairro] aqui ó... Posso andar na calçada na feira (áudio incompreensível). 
F: Entendi.

FL: Adianta eu parar de fumar a pedra, e os outro fumando hahahaha.

F: E aí como é que faz?

FL: Adianta que você tá aqui com esse papel aqui [pega o termo de consentimento e o manuseia], esse papel aqui você vai pegar o visto dele de assinar é igual a isso aqui... É igual esse celular cê tá gravando, mas e se ele não tivesse essa bateria aqui... Pessoa que, quer dizer, tem um vício... Por mais que você tem 10 real... Você pegou dois papel. Aí você quer fazer mais corre... Aí vai começa, vai começa, vai começa... Faz de conta que você fez 10, 15 reais. Você vai e pega 15 tem 3 ... Ai o vício começa".

Flora disse que sonhava poder ser livre e andar pelo bairro, "na calçada na feira" e "as pedras nem

pegar em mim mais". Nessa fala, parecia que o consumo se tornou uma linguagem para falar dela mesma, de maneira análoga ao modo como as histórias criadas por Pedro foram formas de falar sobre ele mesmo. Perguntei se sentia tristeza e então me contou sobre o processo do "vício" de consumir crack.

Na sua narrativa, o consumo da droga se apresentava como estratégia de (r)existência na relação com o traficante, com profissionais do CAPS AD e comigo. Por essa via, com essa organização de fala, que Flora conseguiu ser legitimada para contar suas experiências e obter ajuda diante de sua condição social e de saúde, encontrando moradia no abrigo, cuidados em saúde, no CAPS AD. Da mesma maneira que Biehl (2008) narrou a história de Catarina e seu processo de resistência aos diversos abandonos sofridos ao longo da vida, também Flora encontrou abandonos. Ela perdeu sua casa e os filhos quando sua avó adoeceu, passando a viver no abrigo.

"FL:... Eu grávida ainda [filhos gêmeos mais novos] nóis foi para o [abrigo municipal], minha vó me chamou 'filha vamo lá pro [abrigo municipal]... Ela fechou a casa e foi... Chegou lá [no abrigo municipal], a minha vó ficou lá... Aí deu diabete nela, que ela come muito doce, ficou lá no [hospital geral], eu assinei a minha voz ficou daquele jeito, um jeito esquisito, visitava minha vó... Foi que foi que foi [que ela] morreu... Um derrame".

No relato de Flora, dificilmente se percebia sua modulação emocional. Entretanto, por meio de metáforas e das associações com elementos do seu próprio "mundo", foi possível identificar como ela construía seu modo de expressar suas emoções. Flora se utilizou do discurso negativo relacionado ao crack, presentificado pelo discurso religioso e do fantástico para descrever sua narrativa e os sentidos atribuídos ao consumo do "capeta" do crack. Na narrativa de suas experiências, viveu situações que podem ter sido alvo de sofrimento psíquico intenso. Para além deles, a maneira como Flora construiu sua narrativa comigo pareceu ser uma forma de apresentar uma realidade parecida com a de Fabiano, mas sob outro vértice, de uma mulher. A narrativa de Flora se apresentou de maneira diferente do modo como outros participantes apresentaram suas experiências. A narrativa de Flora apresentou algo de diferente do que vem sendo 
publicado na literatura sobre o consumo de drogas por pessoas com diagnósticos psiquiátricos e percebi diante de outros participantes deste estudo. Ela não se apresentou por meio de uma narrativa "pasteurizada", mas por meio de uma construção própria de si mesma, ela apresentou elementos de seu mundo por meio de performances e expressões do que compreendia ser o crack para ela.

Além disso, Flora é mulher, dar ouvidos a ela nesse capítulo foi especialmente importante. Neste capítulo, a proposta foi suspender momentaneamente o rótulo do diagnóstico e procurar a experiência narrada, na maneira como foi narrada, acerca de sentidos relacionados ao consumo de drogas e de sofrimento psíquico. Ao invés de narrar ouvir vozes, foi muito presente a desorganização do discurso e do pensamento em sua conversa. Flora misturou suas ideias com as falas de outras pessoas e com performances que no conjunto construíram uma descrição dela mesma. Essa desorganização vem sendo chamada pelo discurso médico-psiquiátrico como parte dos sintomas que caracterizam o quadro psicótico e frequentemente é um modo como caricaturalmente nos utilizamos para falar sobre "pacientes psiquiátricos" e "usuários de drogas".

\section{Um resumo}

Os participantes deste estudo apresentados neste capítulo e eu vivenciamos uma relação que no campo da intervenção sobre o consumo de drogas pode ser uma experiência cotidiana, em que profissionais de saúde são de "mundos diferentes" daquelas pessoas descritas como "usuários de drogas" e "pacientes psiquiátricos", principalmente aqueles que receberam diagnósticos de transtornos psicóticos, sendo difícil (mas não impossível) a compreensão mútua. Para o grupo de profissionais de saúde, historicamente tem sido mais comum empregar o discurso médico-psiquiátrico que se aproximar da experiência das pessoas que 
ouvem vozes e apresentam compreensões da realidade que a maioria das pessoas ao seu redor não têm ou não compreendem.

Corin (2007) discute que a principal alteração das pessoas descritas por meio de diagnósticos de transtornos psicóticos é a perda da habilidade de situar-se em um mundo onde as coisas são compreendidas como senso comum., Segundo essa autora, a literatura produzida para compreender essa experiência é distante da realidade de quem recebe esses diagnósticos, ficando restrita às descrições do discurso médicopsiquiátrico em que regimes de verdade e legitimidade da sociedade ocidental são reproduzidos e as experiências em primeira pessoa são colocadas em xeque. O diagnóstico de transtornos psicóticos parecem resistir de maneira ambígua nas culturas ocidentais. Por um lado, continua a autora, pessoas que recebem esse diagnóstico são como um corpo estranho nessa cultura, por outro, se reconhece que essa mesma pessoa é permeada e construída a partir do contexto onde ela se insere.

Lovell (2007) discute que, na incerteza e intersticialidade da existência, pessoas que recebem diagnósticos psiquiátricos, que vivem em contextos de extrema vulnerabilidade, elas constantemente precisam negociar suas identidades, à medida que sofrem antipatia generalizada nos meios sociais onde estão. Esse processo produz possibilidades de descrições de si mesmas, circunscritas pelo contexto onde essas pessoas se inserem. Acredito que o mesmo acontece com os participantes que foram retratados neste capítulo e mesmo outros participantes que receberam diagnóstico de transtorno psicótico, mas não foram retratados pelos motivos já citados. Essa circunscrição atua sobre a capacidade de agir dessas pessoas, interagindo com mecanismos de exclusão social. Como um emaranhado complexo, procurei evidenciar que as experiências de ouvir vozes e ver vultos e alterações da construção e da percepção da realidade apareceram em algumas situações anteriores, em outras durante e também depois do consumo de diferentes drogas. Foram atribuídos sentidos sempre circunscritos ao tipo de droga utilizada, à situação e ao contexto em que foi construído esse consumo. 
Entre os participantes deste estudo, o consumo de drogas fazia parte do contexto e do repertório presente nas relações sociais deles. Isso pareceu circunscrever sentidos desse consumo como o auxílio na diminuição do sofrimento psíquico, diminuição da interação com as vozes, mas também favorecendo socialização, a facilitação de processos criativos e comunicativos. Ao longo desse capítulo procurei apresentar versões presentes nas narrativas dos participantes sobre as experiências, para além do discurso médico-psiquiátrico, mas também influenciadas por ele. 


\subsubsection{Variações emocionais e o consumo de drogas}

Este capítulo engloba experiências que vêm sendo descritas pelo discurso médico-psiquiátrico como humor deprimido, humor maníaco ou eufórico, relacionados a diagnósticos de transtornos do humor. Foram apresentadas experiências descritas como depressão, crise, mania, euforia, tentativas de suicídio, vontade de morrer, vontade de sumir, mas também expressões relacionadas a sentimentos de tristeza e sofrimento intensos vistos, no contexto da entrevista como passíveis de caracterização de sintomas de humor pelo discurso médico-psiquiátrico. A literatura qualitativa faz relação entre experiências descritas como depressão e mania/euforia o consumo de drogas como estratégia de lidar com sentimentos de isolamento, raiva e tristeza (Bradizza \& Stasiewicz, 2003). Autores também associam o consumo de drogas como uma estratégia de mudança no foco e fuga de sentimentos ligados a situações indesejadas (Pettersen et al., 2013). Esses estudos geralmente não separaram a apresentação dos resultados entre aqueles que receberam diagnósticos de transtornos do humor e outros transtornos mentais graves.

Até o momento da confecção do presente capítulo foram encontrados muitos estudos qualitativos sobre os sentidos do consumo de drogas específicos sobre o diagnóstico de transtornos do humor. No único estudo encontrado, realizado especificamente com pessoas que receberam diagnóstico de transtorno bipolar, saber do diagnóstico psiquiátrico impactava no manejo do consumo de drogas e na percepção do impacto deste sobre o estado emocional (Healey et al., 2009). Um exemplo citado foi buscar alívio de experiências descritas como sintomas depressivos e a promoção de estados emocionais descritos como maníacos pelo discurso médico-psiquiátrico.

No presente capítulo, foram mencionados consumos de drogas como o álcool, a maconha, o cigarro e a cocaína, também compreendidos como elementos presentes no contexto dos participantes, que podiam também ser utilizados como dispositivos que permitiam agir diante do sofrimento. Da mesma maneira que no capítulo anterior, as experiências ultrapassaram o diagnóstico recebido e dessa maneira, eu considerei o 
modo como os participantes narraram suas experiências. As narrativas apresentadas foram três: Marli, Jorge e Vitor. Suas narrativas foram selecionadas como descrito no capítulo método, ou seja, por apresentarem clareza de características desse grupo de transtornos, diversidade de sentidos do consumo de drogas presentes também em outras narrativas, mas também quanto ao gênero e aos serviços onde faziam tratamento. Elas compuseram com outras narrativas aqui apresentadas e inseridas no contexto descrito no capítulo de trabalho de campo, formando um mosaico de experiências compartilhadas socialmente, permitindo evidenciar contextos e discursos presentes nas vidas dos participantes desse estudo como promotores de sofrimentos psíquicos e sociais onde o consumo de drogas participava.

Marli

Marli tinha mais de quarenta anos quando passou a consumir álcool de maneira intensa, o que a levou a emagrecer muito. A centralidade do álcool em sua vida levou a família a procurar uma clínica de desintoxicação, onde ficou internada por nove meses.

“M: Eu comecei a beber né... Não bebia cerveja essas coisas... Eu bebia uísque essas coisa forte e... Comecei a tomar muita pinga. F: Mas como que começou?

M: Ah! eu comecei assim que eu fiquei muito revoltada por causa do meu filho ter ido preso... Ai eu fiquei nervosa e comecei a tomar sem parar.

F: Você tinha quantos anos?

M: Hã? Eu tava com uns quarenta e pouco... Ai comecei a tomar... Demais... Ai cheguei a pesar trinta quilos. Fiquei uma pele e osso... ai meu marido falou assim eu vou te internar se não você vai morrer... Ai ele conseguiu uma clinica... Ai ele levou eu pra la e fiquei nove meses".

Narrou que sofreu muito nessa época de recuperação, sendo um período muito difícil para ela.

Descreveu que "chorava” por ver a filha grávida estando ela impossibilitada de acompanhar essa gravidez, por estar "doente e internada".

"M: Eu fedia pinga pura. Tanto que eu ( áudio incompreensível) agora... Nossa senhora... Eu sofri pra me recuperar. F: Foi difícil...

M: Foi difícil... Eu falei agora que tenho que conseguir... Agora eu tenho que conseguir que eu tenho meus filhos... essa minha filha que tem essas duas crianças ela... Desse menino mais veio, de 9 ano, quando eu tava internada ela pegou e engravidou... Nossa e eu lá doente e internada.... Ela aparece lá com um barrigona, nossa mais eu chorava e não podia sair ainda da clinica pra cumprir direitinho. 
Narrou que esse consumo de álcool ocorreu como uma forma de lidar com o sofrimento, descrito como sentimento de "muita revolta" em relação ao episódio em que o filho foi preso. Sentia-se "revoltada" e bebia "sem parar".

“M: Eu comecei a beber né... Não bebia cerveja essas coisas... Eu bebia uísque essas coisa forte e... Comecei a tomar muita pinga. F: Mas como que começou?

$\mathrm{M}$ : Ah! Eu comecei assim, [porque] eu fiquei muito revoltada por causa do meu filho ter ido preso... Ai eu fiquei nervosa e comecei a tomar sem parar"

Descreveu a si mesma como "assustada", porque naquela época, seu filho tinha 12 anos. Diante dessa situação, sentiu que "tinha que beber". A intensidade desse consumo que fazia, ela descreveu por meio dos problemas que ele causava, disse que ia às visitas "bebinha", de tal maneira que chegava a "queimar a perna" na moto que a levava para a instituição. Fez uma autocrítica sobre seu comportamento nesse período, dizendo que era de fazer "o escarcéu" quando lhe era negado ver o filho, descrevendo-se como "louca", naquela época.

"M: E nóis ficava tudo assustada.

F: Com doze ano né.

M: Então, ficava tudo assustada... Cumpri FEBEM com ele.. Tadinho eu ia pra FEBEM bebinha... Olha o tanto que eu era louca. F: E como que foi isso?

M: Eu tinha que beber, eu ia de moto taxi queimava a perna... Chegava la bêbada, eles deixava eu entrar.. Olha se não deixasse o escarcéu que eu fizesse la na porta".

Essa situação em que Marli se encontrava também foi relatada por Bradizza \& Stasiewicz (2003) e Compton, Simmons, Weiss, \& West (2011) que relataram que a sobrecarga e o estresse diante de relações familiares conflituosas e problemas legais estavam entre as motivações para o consumo de drogas. Estes pareceram ser circundantes não só à narrativa de Marli, mas também da maioria dos entrevistados do presente estudo.

Na entrevista Marli pareceu se sentir também culpa pelo envolvimento do filho com drogas, sendo este o motivo para sua internação na unidade socioeducativa, que ela chamou de FEBEM. Descreveu-se como "buchinha de mão cheia", sentindo-se impotente em mudar sua realidade e a do filho.

"M: É droga. O problema dele é esse.

F: Tráfico?

M: Isso. O que eu posso fazer? Eu ensinei! Não fiz nada, disso pra ele virar uma pinga... Uma buchinha de mão cheia, mas sarei agora. Quando eu fui internada todo mundo falou que eu ia voltar num caixão... A hora que eles viu eu voltando interinha... E o marido chatiadinho em casa sem mulher... A minha filha disse que ele chorava... Ele falou que não ia me abandonar.. Tem homem que abandona". 
Sua narrativa se conectou com a de Rogério, se descrevendo como alguém que "ensinou errado" o filho, favorecendo com que ele se aproximasse das drogas, como se tivesse falhado no papel de mãe que cuida dos filhos. Marli partiu de um discurso que posicionava a mulher que não falha, não sofre, não tem problemas emocionais. No seu modo de compreender, era como se isso fosse possível em meio a um cotidiano atravessado por questões sociais que geram dificuldades e violências que vão além do controle e da experiência individual.

Recompôs-se dessa sensação de culpa, escolhendo um caminho narrativo, no momento seguinte à sua fala, que a descrevia pelo discurso da superação, por meio da internação para tratamento do consumo e escolha em manter esse tratamento. Descreveu que "bebia, ficava bêbada e ia pra cama", "acordava e bebia de novo, ficava bêbada e ia para a cama". sua rotina da época e, com isso aparentou afastamento emocional dessa situação e da própria condição emocional.

"M: Mas eu nunca andava errado. Eu bebia dentro de casa... Eu bebia, ficava bêbada e ia pra cama. Ai, acordava e bebia de novo, ficava bêbada, ia pra cama... Era assim, dentro de casa, eu nunca ia em bar tomar".

A sensação que Marli tinha era de que precisava "beber até morrer". Como se beber descontroladamente fosse, para ela, uma forma de se matar. Esse comportamento pareceu evidenciar não só descontrole do consumo, mas também um estado emocional de sofrimento psíquico intenso que poderia coincidir com um estado depressivo, a partir do discurso médico-psiquiátrico. Essa vontade de morrer, ela não atribuiu a si mesma, mas a algo externo a ela, como se nem da própria vida ou da vonta de viver, ela tivesse controle.

“M: Não. Não conseguia parar. parecia que era uma coisa falando beber até morrer, bebe até morrer...”.

Esse sentido atribuído ao álcool foi apresentado no estudo de (Healey, Peters, Kinderman, McCracken, et al., 2009), em que alguns participantes de seu estudo usaram a expressão "beber até morrer" relacionada ao estado emocional descrito como maníaco pelo discurso médico-psiquiátrico. Os participantes que tiveram essa experiência descreveram que tinham a percepção de que algo "estava errado", mas que segundo os autores do estudo, não era acompanhada pela sensação de que fossem capazes de fazer algo para controlar esse sentimento. 
Em outro momento narrou como o consumo fazia parte da cultura e dos costumes de sua família, em que as mulheres se reuniam para beber, exemplificando com a experiência de beber com a cunhada, que morava nos fundos de sua casa.

“M: A mãe dessa sobrinha morava no fundo e ela era alcoólatra todo dia ela tinha um litro... Ai eu ia lá no fundo escondido do meu marido e tomava.

F: Então junto com ela, você tomava...

M: Junto com ela. E ela morreu de cirrose. Tadinha não teve cura... Eu internei na frente dela. Era pra ela internar, pra ela se salvar ai ela não quis... Ela preferiu morrer. Ai eu me internei... Ai ela faleceu, nós ficou tudo chateado... Ai a filha dela estava grávida e ficou comigo até hoje. E o irmão dela também, só que agora ele casou e foi embora".

Afirmou que bebia com a cunhada escondida do marido. Esta foi descrita como "alcoólatra" e havia desenvolvido "cirrose" por tomar pinga em excesso. Atribuiu seu falecimento como em decorrência do consumo, tendo "preferido morrer" a ser "internada". Como um contraponto ao desfecho da cunhada, Marli preferiu se descrever a partir da perspectiva de ser "internada pra se salvar".

Ao conversar sobre esse momento, Marli disse que as duas se encontravam "pra encher cara", ficavam rindo e conversando, remetendo-se a sentimentos agradáveis dessa experiência de encontro, momentos que permitiam "esquecer um pouco" seus problemas. (Pettersen et al., 2013) comentou que entre os participantes de seu estudo, alguns relataram que "estar bêbado levava a outro lugar, onde poderia ser feliz".

"M: Ah! Nós bebia.. Era só isso mesmo... Encher a cara. Bebia ficava rindo conversando.

F: Era um momento gostoso...

M: Era... Nós gostava de beber.

F: Você acha que te ajudava a esquecer problemas, dificuldade?

M: hum?

F: Beber te ajudava a esquecer?

M: Ah! Você ficava bêbada, você esquecia um pouco né".

Quando foi perguntada sobre outros tratamentos, contou que fizera perícia no "INSS" para conseguir benefício previdenciário, passando a receber o diagnóstico de "epilepsia", o que não constava em seu prontuário, mas que Marli atribuiu seu desenvolvimento ao álcool.

"F: Foi direto você nunca fez outro tratamento?

M: Ai, da pinga deu epilepsia, ai...

F: Como assim?

M: Passei no INSS, passei na pericia... Epilepsia na cabeça, por causa do álcool que eu bebia”. 
Esse diagnóstico permitiu a Marli receber algum dinheiro, que complementava a renda da família, mas que não era suficiente, tendo que trabalhar como faxineira, às vezes, como comentou na fase de identificação, na entrevista.

"M: E todo bem... E esse do INSS esse salarinho Pra mim me faz bem... É pouquinho... Mas dá pra mim comprar minhas coisas certinho".

Essa é uma questão antiga no Brasil, discutida por Duarte (1986), em que pessoas da classe trabalhadora urbana obtinham auxílio-doença pelo que agentes da instituição previdenciária qualificariam como "doença de nervos", comentando que esse diagnóstico encobria uma série de questões referentes a "condições de vida".

As descrições diagnósticas, inseridas nessas relações entre Marli e o Estado, pareceram impactar nas descrições de si mesma. Marli se apropriou do discurso médico-psiquiátrico de tratamento do consumo de drogas, que significou para ela a "salvação" da vida dela. Essa questão pareceu se aproximar da narrativa de Flora, ambas aderiram ao tratamento médico-psiquiátrico como uma escolha entre viver e morrer, como discutido por (Fassin, 2015) sobre a influência desse discurso médico-psiquiátrico sobre as "políticas da vida".

Essa questão surgiu como discurso subjacente à narrativa de Marli, como se fosse uma escolha individual dela ou da cunhada. A perspectiva adotada neste trabalho foi de que apesar de parecerem questões individuais, essas questões são circunscritas por discursos sobre saúde e doença, vida e morte que fazem parte de um contexto político-social mais amplo. Ao conectar a singularidade da narrativa de Marli ao esse contexto ampliado, ser "enquadrada" em um diagnóstico relacionado a problemas com o consumo do álcool, no seu caso, era uma alternativa não aleatoriamente escolhida de não se descrever como pessoa em sofrimento psíquico, como ter o diagnóstico de transtorno bipolar, presente em seu prontuário, pouco visível na sua narrativa, em termos do discurso médico-psiquiátrico.

Isso foi apontado por Biehl (2011) em sua etnografia sobre respostas terapêuticas brasileiras ao HIV/AIDS como uma forma de política das "balas mágicas", em que a entrega de tecnologias de saúde são 
dirigidas a uma doença específica, apesar da diversidade de fatores sociais, políticos e econômicos que influenciam a saúde, que são deixados de lado. Essa política, segundo esse autor, teria impacto importante nas subjetividades das pessoas atendidas. Marli teve experiências de ouvir vozes, que atribuiu serem decorrentes do consumo do álcool, mas que só apareceram depois que ela já havia parado de fazer uso. Ela narrou que "sofreu bastante" com "os gritos" e "bichos", tendo ficado "louquinha", não querendo falar sobre esse assunto.

"F: E você já teve situação de você escutar vozes.

M: Já, sofri bastante.

F: Como que foi isso ai?

M: Ah! Eu nem gosto de falar isso.

F: Não?

M: Não. Muito ruim demais. Nossa! Eu fiquei louquinha.

F: Mas era na situação que você bebia? Ou..

M: É claro.

F: Fora dela?

M: Não, eu não tava bebendo mais, mas já tava muito tempo alcoolizada.

F: Ah! Só aconteceu depois que cê começou a beber.

M: É ai depois começava os grito.

F: Grito?

M: É... Um monte de coisa... Via bicho, eu via tudo... Luci... Alucinação... Sofri bastante”.

Passou a se apropriar do discurso médico-psiquiátrico para falar sobre essas experiências de ouvir vozes, possibilitando a construção de sentidos sobre ela. Como consequência do consumo prolongado, atribuiu a essa experiência sentidos diferentes daqueles descritos por Rogério e Fabiano no capítulo anterior, culpando a bebida pelo seu aparecimento.

A entrada no tratamento do consumo do álcool no CAPS AD promoveu, na maneira como Marli narrou, a possibilidade de lidar com as experiências negativas de ouvir vozes, o que atribuía a consequências do consumo intenso do álcool. Essa explicação encontra respaldo na literatura sobre consequências do consumo problemático de drogas, em que experiências de sofrimento psíquico estão associadas à sintomatologia de problemas relacionados com o consumo e à síndrome de abstinência (Alves, Kessler, \& Ratto, 2004), a partir do discurso médico-psiquiátrico. Em consonância com esse discurso, no tratamento feito no CAPS AD, ela passou a fazer uso de medicações psiquiátricas para diminuir essas experiências de “ouvir vozes". 
"F: Mas é difícil lembrar disso...

M: É... Difícil...

F:Uhum... E no tratamento cê foi tranquilo? Você foi...

M: Fui bem...

F: Você tava querendo...

M: Me dava vários remédios.. Aqui também pra parar as vozes... Eu sofri bastante tempo. Consegui

F: Quanto tempo?

M: Consegui, mas não sei faz tempo... Ai fui tomando os remédios certinho que tem que tomar mesmo ai parou".

Estas pareceram mais assustadoras e de maior sofrimento para Marli que outras situações também

experienciadas ao longo de sua vida, como por exemplo, situações em que teve perdas de pessoas da sua

família de maneira violenta. Isso pareceu ser mais fácil de ser discutido na entrevista porque, na sua

narrativa, era situações vividas como cotidianas.

"F: Como que era o clima em casa?

M: Ah! Era bom, como que fala assim..

F: Tinha briga?

M: Não... No começo tinha muita brigaiada Depois o irmão dele [do marido] morreu, eles mataram o irmão dele... Agora é só ele e duas irmã, duas cunhada que eu tenho. Mataram o irmão dele mais velho por causa de mulher. Engraçadinho, por causa de bobeira tinha a mulher dele, casado, com um monte de filho... Foi no bar passar a mão na bunda da mulher do homem. O homem tava no bar tava armado meteu um tiro no coração dele matou na hora... Ai chegou o primo do meu marido, meu marido era açougueiro, a faca do meu marido tava em cima da minha mesa... Uma peixeira grandona. Esse primo do meu marido de [outra cidade] chegou em casa, pegou a faca e subiu no bar. Chegou lá e matou o cara também! Morreu os dois um de cá, outro de lá. Matou meu cunhado, mais foi pro inferno também! Duas mortes, nossa senhora, sofri aquele dia. Chorava".

Ao contar da morte do cunhado, e retomando a fala apresentada anteriormente de que bebia "dentro

de casa", Marli narrou seu consumo pautando-se por construções culturais de papéis de gênero que restringem o trânsito entre os espaços da rua e a casa às mulheres, como discutido por Duarte (1986). Entretanto, resistiu a esse discurso bebendo "escondida do marido", sendo esta uma forma de agir sobre esse discurso rígido sobre o papel feminino. Marli foi capaz de se encaixar nesse discurso bebendo "em casa", assegurando que isso era mais apropriado para uma mulher com marido, ainda que tomar bebidas alcoólicas fosse uma prática escondida dele e pouco legitimada no contexto onde ela se encontrava.

Dalmolin (2006) argumentou que pessoas, supostamente alcoolistas, procuram manter sua integridade simbólica em relação às regras do bairro onde estão inseridas. Marli se preocupava bastante com essas regras e expectativas das pessoas que estavam no seu entorno, e respondendo a elas com sua adesão ao tratamento para o consumo quando este deixou de ser legitimado. De maneira diferente ao modo como a autora descreveu os percursos de Pomba-Rola, uma mulher em sofrimento psíquico participante de sua pesquisa, Marli pareceu circular um pouco mais por papéis instituídos sobre o gênero feminino, transitando, 
à sua maneira, entre o ambiente privado da casa, como "esposa" e "a mãe", mas também no ambiente público de trabalho como "cozinheira" e "faxineira". Pomba-Rola ficava mais restrita ao espaço de sua casa, onde interagia com sua família, em um universo mais restrito que o dos outros participantes homens de sua pesquisa, mantendo aspirações relacionadas ao desempenho do papel de gênero como mulher.

Marli, foi descrita como "usuária de álcool” no CAPS AD, por fazer um consumo considerado problemático construído a partir de uma cultura familiar e social, ainda que também tenha sido diagnosticada com transtorno de humor. Essa descrição pareceu circunscrever o modo como ela narrou sua história de vida. O consumo do álcool foi intensificado, segundo ela mesma, em resposta a situações de sofrimento psíquico intenso, permitindo-lhe ser capaz de encorporar no seu dia a dia, tarefas atribuídas ao papel de gênero feminino instituído, mas não sem prejuízos.

Na continuação da sua fala, comentou que pessoas da sua família passaram mal com o episódio de adoecimento do marido, , sendo ela quem ficou com a responsabilidade de cuidar da família, apesar do sofrimento gerado pela morte do cunhado.

"M...Meu marido passou mau, minha sogra... Ai depois minha sogra ficou doente foi pra cadeira de roda... Eu cuidei dela até o fim também ela morava comigo... Comigo na casa dela né eu que morava lá com ela cuidei dela até o fim até a morte dela. Ai ela morreu... Ai a casa ficou pra ele, porque as irmã dele tudo tem casa. Elas falou assim nós não quis repartir... Vender a casa pra repartir, "não fica procê e sua família”. Tem minha mãe, minha mãe tem a casinha dela também”.

Em meio ao tumulto gerado com o assassinato do cunhado, Marli se descreveu como sendo uma mulher que cuidava da família, deixando pouco espaço na sua rotina para lidar com seus sofrimentos psíquicos, que parecera se organizar como uma continuidade em meio a muitos sofrimentos sociais que faziam parte do seu cotidiano.

Marli, preferiu se descrever como "usuária de álcool”, encorporando experiências de perdas e violências vividas no seu entorno como parte do seu cotidiano, deixando de lado aspectos sobre o diagnóstico de transtorno do humor, que apresentava em seu prontuário. Ela contou em vários momentos sobre seu sofrimento, ligados a perdas e a situações de violência, mas era possível perceber que tinha dificuldades em entrar em contato emocionalmente com essa questão. (Healey et al., 2009) discutiram que 
alguns dos participantes de seu estudo receberam diagnóstico de transtorno do humor depois que estavam em tratamento para o consumo de drogas, outros participantes passaram a receber esse diagnóstico, pois passaram apresentar sinais deste a partir do tratamento para o consumo. Entre esses participantes, os autores discutiram que por vezes eles não associavam ou não entendiam os efeitos das substâncias sobre o humor. Foi o que pareceu acontecer com Marli, na sua narrativa.

"F: E me conta assim do sofrimento... Você me contou que teve varias situações que cê teve perdas né? Decepções...Você falou do seu pai, do seu filho...

M: Minha irmão também faleceu.

F: Da sua irmã.

M: Meu sobrinho também morreu matado... O filho dela, no portão da casa da minha mãe... Morreu nos braço da avô".

Essa escolha de narrativa condiz com o argumento de Das e Das (2007), de que o sofrimento era visto, por um lado, como um desvio que era facilmente absorvido como parte do fluxo normal da vida. Essas autoras discutiram que essas experiências podem parecer desviantes, inclusive alvo de diagnósticos a partir do discurso médico-psiquiátrico para pessoas que não convivem com o contexto onde pessoas "que estão ás margens" se inserem. Ao retomar a fala de um de seus participantes, "Z", as autoras expuseram que o consumo, por exemplo, inserido no contexto de pobreza, permitia agir diante dele. Durante seu trabalho de campo, aas autorasperceberam que " $Z$ ” havia faltado ao trabalho e estava sob o efeito do álcool, fazendo um comentário que o posicionava como faltante porque estava bêbado. "Z”, no entanto, ofereceu outra interpretação para essa experiência. Ele disse que, como outras pessoas ao seu redor, as autoras não o entendiam. Ele trabalhava todos os dias levantando objetos pesados e com isso, sentia seu corpo colapsar. Sua forma de lidar com esse sentimento de colapso era bebendo.

A reflexão que as autoras fizeram foi de que precisamos compreender a complexidade do ambiente onde os participantes de nossas pesquisas vivem (Das \& Das, 2007). Essa reflexão pode ser estendida aos usuários de serviços de saúde que nós, como profissionais de saúde, propomos a atender. Essa compreensão da complexidade do ambiente de pessoas que recebem diagnósticos psiquiátricos e fazem consumo de drogas que identificamos como problemáticos permitiria, segundo elas, autorizar o real diante da 
precariedade do cotidiano, comprometendo-se com explicações que partem da economia política, bem como da cultura dessas pessoas, ampliando nossas capacidades de agir sobre essas problemáticas.

Para compreender um pouco do contexto de Marli, retomo um pouco da sua história. Na infância já trabalhava aos dez anos no campo com os pais e posteriormente veio morar na cidade com a mãe.

"F: Que interessante! E você trabalhou no pau de arara desde criança?

M: Aham... É e... Com meu pai... Meu pai morreu novo... Minha mãe ficou sozinha.

F: Ai você veio pra cá.

M: Ele morreu aqui, nós veio pra cá, eu tava com dez ano. E eu era novata aqui... Novinha. Nós não conhecia nada, estranhou aqui. E depois foi acostumando..."

$\mathrm{Na}$ sequência da conversa, Marli disse que todas as pessoas da sua família bebiam, usavam ou usaram drogas, descrevendo sua família como "droguera". Um dos irmãos, inclusive, fizera consumo problemático de drogas, mas estaria abstinente na época da entrevista, tendo se tornado pastor evangélico.

"F: E... Tinha alguém da sua família que bebia.

M: Toda...

F: Que usava droga...

M: Então tem meu filho, tem os meus parente... Tudo mexe com essas coisas, né?

F: É?

M: É a familia é drogueira... Meus irmão... Meu irmão era também, agora ele é pastor".

A narrativa de Marli tinha aspectos que se conectavam às histórias de Fabiano, Flora e Rogério. É possível evidenciar elementos presentes no contexto onde se inseriam alguns dos participantes do estudo. Esses elementos, circunscreveram a construção de sentidos sobre o consumo de álcool e a associação dele com seu sofrimento psíquico, descrito nesse capítulo como características proeminentes do diagnóstico de transtorno do humor. Foi possível perceber que Marli fazia do consumo do álcool uma forma de continuar agindo no seu cotidiano, apesar do sofrimento relacionado a violências sofridas, como por exemplo situações de institucionalização do filho, ao discurso rígido sobre o gênero feminino de que deveria ser uma "boa" esposa e uma "boa" mãe. Essas violências provocavam sofrimentos, que individualmente eram traduzidos em sofrimentos psíquicos passíveis de diagnóstico, pelo discurso médico-psiquiátrico, embora tenham sido compreendidos por ela como "revolta", "loucura", "nervoso". A prática de fazer uso de álcool foi aprendida com a família e compartilhada por outras mulheres que era parentes suas. Marli apresentou experiências que provocavam grande desorganização psíquica e efeitos negativos sobre ela, dando a sensação de que queria morrer ou deveria consumir álcool até que isso provocasse sua morte. A aderência ao 
tratamento pareceu significar, para Marli, uma "escolha de vida", compreensão que foi promovida pela apropriação do discurso médico-psiquiátrico sobre suas experiências.

Jorge

Jorge relatou ter bebido "bastante até os vinte e sete anos", época em que bebia "por causa da depressão". Ele associou à “depressão" com a “timidez”, atribuindo ao álcool o sentido de que este o ajudava a "quebrar" sua dificuldade em "se manter perto das pessoas". Bradizza \& Stasiewicz (2003) relataram que entre as motivações para o consumo de drogas estavam as dificuldades de socialização e os sentimentos de isolamento.

"J: Então. Eu bebia bastante até os vinte e sete. Aí eu parei. Tchufff (faz movimento com as mãos para baixo)!

F: Como que foi?

J: Então eu fiquei uns quinze anos sem beber.

F: Uns quinze anos sem beber.

J: Ah!? Não sei.

F: Você bebia muito?

J: Ah. Bebia por causa da depressão (Fala gaguejada). Muita timidez, sabe.”

"J: Eu tentava beber pra quebrar isso né. Mas não quebrava não. Nem com bebida... Não quebrava minha timidez, né. Quebrou no começo, né (risos). Mas depois você acostuma, né. Não adiantava mais. Aí eu bebia, mais... Eu bebia também pra me manter perto das pessoas, porque você vai... Meus amigos tava... Ia em bar...(fala picotada)".

Com o álcool, ele sentia capaz de agir socialmente mesmo que nem sempre essa estratégia

funcionasse como ele queria. Jorge narrou que esse consumo era restrito a ambientes em que o álcool "fazia parte" do contexto.

“J: Numa festa as pessoas só estavam bebendo. Então eu bebia também pra me manter perto. Mas eu não bebia assim fora de festa. Nem bebia assim... Saía todo dia pra ir em boteco beber. Não é assim... Mas agora, agora, agora (fala gaguejada)... Por exemplo, ontem foi sexta-feira já não... Porque não é só a bebida, você vai num bar, você vê os amigos, você conversa... Aí você bebe também, faz parte... Então..."

Esta atividade era compartilhada pelas pessoas de seu entorno, retomando na sua experiência singular o aspecto cultural do consumo do álcool em situações sociais (Fiore, 2004). Costain (2008), em estudo realizado na Austrália discutiu que o consumo de álcool nesse país era expressivo e impactava nas 
construções de sentido dos participantes, sendo uma prática não só legitimada como também desejada no desempenho social.

Jorge interrompeu o consumo do álcool por ter contraído hepatite. Atribuiu prejuízo na sua habilidade de socialização, pois precisando parar de beber, voltou a sentir dificuldade em participar ativamente de situações sociais em que a bebida se fazia presente. Jorge, referindo-se à depressão, comentou que "por mais mal que estivesse", quando estava sob o efeito do álcool sentia que "estava bem". quando fazia uso do álcool, referindo-se à situações sociais.

"J: Era cerveja. Teve um tempo que eu tomei Whisky também. Mas aí eu comecei a ficar ruim do fígado, sabe. Eu comecei a sentir, assim... Ficava mal muito rápido. Passava muito mal com pouca cerveja, aí já... Tem coisa errada... Aí já...

F: Não era por ai?

J: É aí depois descobri que era Hepatite... Aí já... Aí interrompeu, né. Mas isso aí não é questão da cerveja. Isso aí é questão de que isso me prejudicou socialmente, assim... Prejudicou assim eu me aproximar das pessoas, porque... Por exemplo, uma vez por mês eu ia na festa do meu cunhado. Sabe? Por mais mal que eu tivesse eu tava indo bem. Mas agora sem beber eu não conseguia".

Jorge também consumia cigarro. Para ele, nas situações de "crise", geralmente perdia o emprego, ficando "arrasado" com isso, e tentava parar de fumar, pensando na possibilidade de a família "passar fome" em decorrência da falta de emprego.

“J: Não. Aí quando teve a crise eu já queria cigarro. Aí eu falei, não tem jeito. Aí eu... Tive quatro crises recentemente, né. Então eu tinha a crise, voltava, ficava mal pra caramba. Eu ficava arrasado de ter tido crise. Porque toda vez que eu tinha a crise perdia o emprego, ou era rebaixado no emprego, ou entrava ganhando menos. Quer dizer eu só tomava, né. Aí fui ficando mal, tentava parar de fumar. Ficava arrasado... falava assim, e agora, minha família, vou deixar minha família cair. Quer dizer... Eu via minha família passando fo... Assim no futuro próximo, passar fome, (Palavra ininteligível), sabe? Um inferno".

O consumo de cigarro, em um primeiro momento, se relacionava com sentimentos de prejuízos e de antecipação de problemas decorrentes das "crises", atribuindo sentidos de contenção de sentimentos relacionados a esse momento. Em um segundo momento da narrativa, Jorge separou os significados associados ao cigarro e ao álcool das suas experiências de "problemas" relacionados ao sofrimento psíquico, tratando-os como questões diferentes. Quando fumava cigarro e bebia álcool, se encontrava diante dos problemas decorrentes das experiências de "crises e "depressões", afirmando que o consumo dessas drogas não eram capazes de diminuir sofrimentos psíquicos decorrentes da sensação de "crise" ou de "depressão", nem tinham relação direta com estas situações. Ao contrário da narrativa de Marli, em que o consumo assumia centralidade diante do sofrimento psíquico.

"F: E como o cigarro entrava nisso? (Fala simultânea a de M.). Te ajudava... 
J: Assim... Nunca uma coisa nunca foi suficientemente grande pra enfrentar os meus problemas. Cigarro, bebida, nunca foi suficiente pra tirar esse... Nunca foi equiparado aos meus problemas. Nem se equipara. Meu problema é meu problema, as coisas são as coisas. Eu não junto as duas coisas

F: Entendi.

J: É. Também não é... Ixi... Uma coisa muito pouca, por que... Tudo bem... ela é refletida o meu problema é... Ela realmente tem um efeito. Mas assim, pra mim, por exemplo, se eu fumar dois ou três cigarros por dia aí começa a sumir o efeito. Eu fumo um por dia pra ter o efeito."

O consumo dessas drogas fazia parte do contexto, bem como se associava ao estado emocional em que Jorge se encontrava, afirmando que o consumo "tinha um efeito" sobre esse estado emocional. No entanto, esse consumo não tinha função de diminuir sofrimentos psíquicos, ao contrário do que vem sendo descrito na literatura sobre o diagnóstico duplo de que o consumo de drogas seria uma estratégia de automedicação (Bizzarri et al., 2009) e que tem encontrado respaldo em teorias psicológicas de que o consumo de drogas seria uma estratégia para suprir "faltas", o que vem recebendo críticas (Vargas, 2001). Para Jorge o consumo de cigarro e álcool influenciavam na experiência da "crise", permitindo que ele agisse socialmente em algumas situações específicas, embora não tivesse papel central nessa experiência de “crise" e "depressão".

A sequência da sua fala, permitiu perceber que Jorge também consumia maconha e que esta droga, tinha sentidos diferentes das outras já citadas. Essa fala permitiu perceber que os sentidos atribuídos aos diversos tipos e usos de drogas eram específicos a elas e a situação de uso. Jorge disse ter fumado maconha durante "toda a vida", entretanto, esse consumo não era contínuo, relatando fumar durante "crises", situações que, segundo ele, "eram curtas" e esse consumo era feito em pouca quantidade. Ele disse interrompia o consumo da maconha nos períodos em que se percebia em "depressão".

“J: Mas então... Eu... Durante toda a minha vida. Durante todo esse tempo... Quarenta anos... Depois da crise... Depois do... Dos sete anos... Eu fumei muito pouco... Porque seu eu fumava nas crise... As crises era curta... Eu só tive dez crises... A décima primeira é essa... Então ficou pouco... Sempre foi pouco... Eu fumava durante um período...”

Esse tipo de manejo de consumo também foi encontrado entre os participantes do estudo de (Healey et al., 2009), que faziam um uso de drogas idiossincrático, baseando-se na própria experiência de uso e aprendizado sobre as cries e as drogas consumidas. Para Jorge, o que pareceu determinar a interrupção do consumo eram as experiências de "depressão", em que "ficava dois a três anos" "sem fumar".

"F: Então, mas ao longo do tempo você foi fumando? 
J: É. Mas nas depressão, nunca! Quando aparecia a depressão ficava dois a três anos sem crise... Eu ficava dois a três anos sem fumar... Eu só fumava nos pico só".

Ele explicou que fumava somente nos momentos de "pico", o que poderia ser chamado pelo discurso médico-psiquiátrico de episódios de humor maníaco. Sob o efeito da maconha, Jorge narrou "ver as coisas", tendo alterações da senso percepção com as quais sentia que precisava lidar nos momentos de "crise" e "depressão" que faziam ele com que "sentisse o peso" dessas emoções e percepções. Esse sentido se assemelhava ao que foi encontrado entre alguns dos participantes do estudo de (Healey et al., 2009) que comentaram que a maconha não ajudava na depressão.

"J: Eu fumava eu sentia muita coisa. Via as coisa. E eu tinha que enfrentar aquilo. Como enfrentar a crise de uma maneira equilibrada sem... Eu só via que podia entrar... Eu só sei que eu posso entrar em crise... Eu conheço minhas crise... Eu sei que é sair fora da realidade, né... E foi essa depressão. Eu enfrentando aquilo lá, tive que enfrentar as duas possibilidades. E eu não queria cair nem subir. Então eu consegui enfrentar. Eu consegui enfrentar a crise. Aquela crise que te põe... Te faz sentir peso".

Explorei que significados a experiência de "ver as coisas", decorrente do uso da maconha, poderiam

ter para Jorge. Ele descreveu como um "transporte para outro lugar", tendo "conversado com Deus", o que, para ele, era "legal", mas também "decepcionante".

“F: O que você via?

J: É... Hum... Transportava pra outro lugar, assim... Era outro lugar. Tinha um pessoal conversando. Eu já vi deus. (riso sarcástico). Conversei com ele. Hum. Ele me mostrou o futuro. (fala com sorriso). De mais, aquilo foi o pico. (riso seco). Foi legal, depois ele me mostrou tudo, depois aí eu saí e ele falou, como é que ele falou... (pausa). Siga o seu caminho. (riso). Eu falei... Eu fiquei decepcionado... (riso). No começo né... Mas depois eu entendi. É legal...

De maneira contraposta a outro momento da entrevista em que dizia que a maconha não interferia na “crise", Jorge atribuiu, que o efeito da maconha mudou ao longo do tempo: "antes acelerava", alterando o “nível de consciência”. Jorge narrou que, na época da entrevista, fazia um uso de maconha todos os dias.

F:Você sempre usou nos momentos de crise e momentos picados, mas faz um ano e meio que você fuma todo dia.

J: Direto. Todo dia. É. Porque eu não to mal. Quer dizer. Eu tive... O que me impedia antes de fumar era a depressão. Mas eu não to em depressão. E é gostoso. É bom, relaxa. Agora eu só relaxo. Eu não vejo mais aquilo... Minha mente não acelera mais... Antes acelerava, eu entrava em outro nível da consciência. Agora não. Acabou. Foi só o começo. Mas é gostoso (fala sorrindo) Eu curto.

Esse consumo tinha o significado de promover relaxamento, tendo a percepção de que esse efeito da maconha era possível por não se encontrar em "depressão". O efeito produzido pela droga não era mais de promover "visões", ainda que pudesse favorecer (teoricamente) o aparecimento de "crises" e "depressões", essa não foi a perspectiva adotada por Jorge.

Relatava que, com o tempo os sentidos e significados do consumo da maconha se transformaram, passando a atribuir à droga o sentido de "expor” a situação em que se encontrava, assumindo o sentido de 
linguagem que a droga poderia assumir. Atribuiu responsabilidade a si mesmo pelo enfrentamento dessa experiência e explicou isso fazendo uma separação entre o controle da "crise" e os efeitos da maconha.

"J: Porque o controle da crise é o controle da crise. A droga é uma coisa assim, que ela é... Hã... É... Ela realmente faz girar mais alto né. Então, por exemplo, uma vez eu tive uma crise, então eu falei, não vou fumar".

Experimentou não consumir maconha durante uma crise. Essa experiência pareceu ocorrer a partir de uma apropriação sua do discurso médico-psiquiátrico corrente no senso comum de que o consumo da maconha pode propiciar crises psiquiátricas, baseada em conhecimentos difundidos pela literatura desse discurso, que versa sobre o desenvolvimento de transtornos mentais associados ao consumo de drogas Mueser, Drake, \& Wallach (1998) e que se posiciona em consonância com o discurso proibicionista. A lógica seguida por Jorge foi se observar diante da "crise", procurando identificar mudanças nela quando estava sem fazer uso da maconha.. Concluiu que ainda assim tinha "crise".

“J: Maconha. Maconha. Aí eu tive a crise. (Fala gaguejada). Porque eu falei assim... Vou fazer uma experiência, né. Se eu não fumar quem sabe não é a maconha que tá me fazendo subir de mais e caí, né. Aí entrei em crise aí não fumei, aí tava em casa, fui caindo e tchufff! (trecho ininteligível). Aí fiquei. (Trecho ininteligível). Então, ajuda meu. Pra mim ajuda, no meu caso específico".

Segundo ele, , no seu caso, o consumo da maconha ajudava a levar sua vida com "mais humor". Esse

sentido do consumo da maconha também foi encontrado por (Pettersen et al., 2013) em que alguns dos participantes de seu estudo se apropriaram do discurso médico-psiquiátrico sobre o prognóstico do transtorno de humor, admitindo que tinham uma "doença que não podia ser curada", e por isso, referiram consumir drogas como uma estratégia de "fazer valer" a experiência de viver.

"F: Te ajuda fumar maconha?

J: Ajuda. Porque faz encarar com mais humor. O que muda é o humor. E assim oh! Eu sem maconha fico pensando... As coisas vão ficando sérias... Sérias, pesadas... Aí já vem o humor já colore. Mas você não pode perder o foco e sair fantasiando. Você tem que aproveitar aquele humor, mas aproveitar o humor pra fazer uma coisa objetiva, assim... Fazer uma coisa que vale a pena. Eu tenho medo de entrar em crise. No começo desse negócio aqui, eu ficava com medo de entrar em crise, então eu me policiava. Mas não pra entrar em crise, me policiava pra não desistir. Assim, pra não falar, isso é uma crise, tchau, to fora disso, que aí é... Eu caía também... Não podia desistir... E também não podia deixar levar."

Nas palavras de Jorge, o consumo ajudava a "colorir" a experiência de sofrimento, permitindo-lhe “encarar com mais humor" as situações vividas. Ainda que com o tempo, ele tenha aprendido a "ter medo de entrar em crise", passando, segundo ele, a "se policiar" para não entrar em "crise" e para "não desistir". Jorge acrescentou ainda a expressão "no meu caso específico", retomando a dimensão singular dos sentidos atribuídos ao consumo. 
Portanto, ele falou que a maconha promovia "ver coisas", mas que elas não eram a experiência de sofrimento. Ao contrário, na sua opinião, a maconha "expunha" a situação de "crise", o que pela sua experiência tinha uma existência autônoma em relação ao consumo da maconha e da sua capacidade de controle, restando a ele manejar prejuízos e habilidades. A partir de uma descrição de si como conhecedor dessa experiência de "crise" e "depressão", pareceu ser capaz de agir sobre essas situações, inclusive com a ajuda da maconha. Na sua maneira de pensar, Jorge tinha duas possibilidades de enfrentamento das "crises" e "depressões": "cair" e "subir".

“J: Não! Não! Não ajuda a enfrentar. Ela expõe... Aí a enfrentação é outra. Ela expõe, mas é legal. Porque ela expõe, e ai? Tem que por a realidade pra mim enfrentar. Você vai ficar sempre escondida. Se ela ficar escondida, como é que eu vou enfrentar?"

Disse que não queria viver nenhuma das duas situações, passando a lidar com elas de maneira a "enfrentar" e "sentir o peso" dessas experiências, buscando uma maneira "equilibrada". Portanto, para ele fumar diariamente não trazia impacto sobre suas emoções, diferentemente da época em que se sentia "mal". Relatou que a primeira vez em que ele "parou para pensar" sobre isso foi com o tratamento psicológico que vinha fazendo no CAPS II um ano e meio antes da entrevista, tendo efeito positivo sobre sua experiência de consumo e de sofrimento psíquico descrito como sinônimo de diagnóstico psiquiátrico, passando a "questionar" essa experiência.

“J: A primeira vez... Isso nunca passou pela minha cabeça antes. Passava... Entrava... Do buraco pra crise direto. Não chegava nem a questionar. (risos). Tchuff! Já ia direto. Esse para pra pensar eu não entendia.

F: Esse parar pra pensar veio agora há um ano e meio?(Interrupção.)

J: É. Acho que aí o tratamento com a psicóloga me ajudou muito a pensar. Ela é uma referencia também. Ela é a... Eu sabia que se eu tivesse flutuando ela ia perceber".

$\mathrm{Na}$ época da entrevista sentia que "pela primeira vez" ele sentia que estava equilibrado, refletindo retrospectivamente sobre momentos de "crise", pensando com base em critérios de tempo de duração e intensidade dos sentimentos que poderiam caracterizar uma "crise", a partir do discurso médico-psiquiátrico.

“J: (... )Faz um ano e meio eu mudei. Assim, que equilibrei, pela primeira vez eu equilibrei...

F: Hum!(surpresa)

J: Então, nem um buraco, nem em cima. No meio assim... (riso).

F: Sei.

J: Então já faz um ano e meio. Quer dizer. Não é uma crise. Porque no começo eu achei que era uma crise.

F: Crise você chama de que?

J: Mas a crise não dura mais que quatro meses e é crise de pico. Eu acho que eu sou um máximo.

F: Ah, entendi.

J: E também não consigo trabalhar, você só a mil né. (trecho inaudível). (risos). Quatro meses, tchulll ! Né! Mas dessa vez faz um ano e meio quer dizer que não é uma crise. Eu acho que eu to equilibrado". 
Valorizou o espaço da terapia promovido pelo CAPS II ao longo do tempo de tratamento, principalmente no ano anterior ao período da pesquisa. Sentia que poderia usar aquele espaço para expressar o que sentia e o impacto disso, na sua opinião, foi que "as coisas começaram a fazer sentido". Interessante lembrar que na época o tratamento de Jorge estava sendo revisto pela equipe. Isso parecia ter a ver com o que foi discutido no capítulo Encontro com o campo e o tema, sobre o escopo, possibilidades e escolhas de manejo feitas na RAPS estudada. A maconha tinha também o sentido de permitir sair do "tédio".

"F: Como você tem feito para controlar? (M. interrompe a fala).

J: Então a terapia eu tive aqui... Eu fiquei um ano e meio ju...Todo processo... (fala picotada). Tudo... Da mudança... Junto com tudo isso... Igualzinho... Começou juntinho a terapia aqui... Eu tinha antes... Com a doutora (fala o nome da pessoa que o acompanhava). Mas...Então... Foi demais... Se eu não tivesse ela pra... Conta... Pra expor tudo que tava acontecendo comigo, não ia dar certo. Porque eu sozinho ia explodir. Sim. Ia explodir uma crise. Eu pondo pra fora, as coisas começavam a fazer sentido, porque só dentro de mim tava de mais. (pausa). Aí... Ajudou demais. Mas acabou".

Jorge narrou que essas experiências não eram novas, tendo início quando tinha sete anos, quando foi

exposto, segundo ele, a um "trauma muito forte".

“J: Então... Com sete anos eu tive um trauma. Muito forte. Foi imediatamente depois disso que começou.

F: Sete anos?

J: É. Uma exposição ridícula. Uma exposição pública. Ao ridículo. E... Assim oh... Na hora meu... Eu mudei...Uma mudança (pausa). Foi imediatamente. Depois que aconteceu aquilo que eu já saí dali arrasado eu já senti a diferença. Então aquela criança de sete anos é um moleque peralta. Falante pra caramba, curtia pra caramba, aí depois disso acabou. Pufff! Zerou. Fiquei vazio. Não conseguia sair daquilo. Não conseguia encarar as pessoas. Não conseguia modificar a situação. Aí comecei a tentar de tudo. Ai tentava de tudo pra dentro de mim. Aí..."

Jorge se apropriou da forma como o discurso médico-psiquiátrico classificava suas experiências,

usando a expressão "bipolar" para falar da descrição que recebera no CAPS II, , embora não se sentisse satisfeito com ela.

“J: E... Bom o diagnóstico aqui é bipolar. Sei lá. Acho isso aí muito vago, né. Mas, o diagnóstico é esse... Pra mim é a mesma coisa que falar assim, coisa e tal... Tem um problema de febre... É que não consegue ir mais além então fica no superficial.

F: E o que seria ir mais profundo?

J: Ah! Bipolar é um...ah... um efeito secundário ao negócio. Cada um tem um problema e às vezes o problema... Se mostra assim. (Fala difícil e pausada).

F: Hum.

J: Essa bipolaridade. Depressão e euforia".

Para ele, o diagnóstico é secundário à experiência, explicando que "crise" e "depressão" são antigas e anteriores ao diagnóstico. Ele caracterizou com as próprias palavras "crise" e "depressão", dizendo já ter pensado em "suicídio" várias vezes e tendo se exposto ao risco de morte duas vezes.

“J: Não, faz tempo que eu sinto isso, né. O diagnóstico veio depois.

F: Veio depois.

J: Mas o problema não mudou. Quer dizer... Eu acho...É... E... (pausa). Mas ai, então... Nas crise, quando eu tenho crise eu tenho pico mesmo, de sentir que sou Deus. É pico mesmo. E quando é depressão minha é muito profunda. Eu me sinto um nada, eu me 
sinto um verme, uma coisa desprezível. Que tinha que morrer. Depois que eu tive meu filho, eu tive... Eu tenho pensado muito em suicídio. Até tentei... Mas eu não conseguia tentar comigo mesmo, mas eu tentei provocar com um pessoal da pesada assim, pra ver se alguém me matava. Tentei duas vezes. (Fala sorrindo)"

Para ele, ter diagnóstico não mudou seu "problema". O que mudou para ele com o diagnóstico foi o modo com as pessoas do seu círculo social lidavam com ele, ou seja impactou na sua relação com o a família. Jorge narrou, que a partir do diagnóstico, ele foi "rebaixado" enquanto "ser normal", passando a ser “inferior”, de maneira análoga ao que Aragaki (2006) o diagnóstico impactava também no modo como eram vistas socialmente e como se relacionavam e passavam a dar descrições de si nessas relações, muitas vezes limitando capacidades de ação.

“J: (...) Eu depois de diagnosticado com bipolar, eu fui rebaixado a uma condição de um ser humano normal, inferior né... Então era assim que eles me tratavam... Como um... Inferior... Mas não inferior com maldade, inferior assim... Fazer o que inferior... Até com um pouco de piedade... Até com piedade... Até com bondade... Mas inferior né... E eu acreditei também. Mas isso ai passou. Passou... (fala sem entonação)...”

No entanto, essa percepção de inferioridade ficava suspensa quando fazia uso da maconha, permitindo alterar a percepção diante de situações que ele descreveu como "você tem que trabalhar, porque você tem família, você tem que ganhar dinheiro". Situações essas que eram sentidas como se fosse "escravão" do sistema capitalista ocidental que orienta modos de vida para a produtividade, organizando também descrições de si em torno de marcadores identitários (Duarte, 1986).

"F: O que é tédio, que você chama de tédio?

J: Tédio é assim, você ficar na mesma. Não vê saída pra aquilo. Querer sair daquilo e não vê saída e não tirar daquilo. Aquilo lá vai dando uma coisa né. E as minhas depressão era só isso, né. É puro isso.

F: É o tédio.

J: Tédio total. Ow! (Fala eufórica in terrompendo F.). Você tem que trabalhar, porque você tem que trabalhar, porque você tem família, você tem que ganhar dinheiro. Eu viro um escravo, só falta por as correntes, sabe. Fica puxando... Escravão".

Oscilar diante da realidade cotidiana vivida tinha a ver com permitir-se sair do "aqui-agora" e deixar “o pensamento levar”. Jorge utilizou da metáfora mergulho-respiração para falar sobre essa oscilação da percepção da realidade, permitindo-lhe agir e lidar com demandas cotidianas. Essa imagem também foi utilizada pelos participantes do estudo de Thornton et al. (2012) atribuindo esse sentido devido ao ritual de respiração associado ao uso fumado da maconha.

"J: Eu tenho, porque eu tenho.

F: E o equilíbrio é uma sensação de não tédio?

J: É o equilíbrio é. Então aí tem que ficar respirando, né. Então... Mergulho um pouco, saio um pouco. É, mas olha só... Então, geralmente eu saio um pouco quando eu fumo. Aí eu tchuff!... Começo a subir... Os pensamento começam a levar. Começa a acontecer umas coisas mais alto. Mas se eu continuar fumando, estabiliza lá, e fica lá... Não, não gosto... Aí quando eu to sem 
fumar, sem nada, eu penso no real, no aqui e agora, no serviço, na minha mulher... Quer dizer.... Sem a maconha eu fico mais... Com a maconha eu fico mais alto, vejo as coisas mais de cima, observo mais. E eu não consigo fazer isso sem ela".

Esse sentido de oscilação da percepção da realidade também foi atribuído por Pedro, anteriormente apresentado, embora de maneira diferente. Jorge lidava com esse mergulho, "observando" "as coisas mais de cima", mas ainda conectado com questões e demandas e responsabilidades cotidianas, sendo capaz sustentar sua família, ainda que nos momentos de "crise" isso fosse dificultado. Pedro, por sua vez, verteu-se para a criação de histórias em quadrinhos talvez pela sua habilidade criativa, encontrando dificuldades em ter autonomia para sustentar-se. Essa diferença talvez se dê por conta das características que Pedro e Jorge apresentavam e que permitiam diferentes descrições diagnósticas pelo discurso médico-psiquiátrico, ainda que atribuíssem sentidos e significados, nestes momento específico da narrativa em termos semelhantes.Nesse sentido Jorge enfatizou a necessidade do controle da quantidade de consumo da maconha, pois esse controle permitia que este efeito desejado perdurasse. Ele não sentia que era capaz de simular essa sensação sem a maconha.

J: É um ângulo que eu não consigo simular fora dela. É como se eu me visse de outro ângulo, assim. Eu fumo, mudo de ângulo. (Riso). Aí tudo aquilo que você tava fazendo antes, você fala, nossa! Que eu fiz? Mas é gostoso, porque... É... Gosto de mudar o ponto sem sair do lugar. (Riso).É interessante vê... É... Pelo menos no meu caso... Todo mundo fala que isso não é uma religião (fala sem entonação) Isso não é uma religião! Mas é que no meu caso faz sentido".

Essa experiência, para ele, era singular, privada. Singular porque importavam crenças e rituais na construção de sentidos, que Jorge sintetizou como se fosse uma religião. Diferentemente do álcool, que é droga lícita, e cujo consumo Jorge apreciava quando era compartilhado com outras pessoas.. Da mesma maneira que pareceu ter acontecido com Fabiano, Rogério, Pedro e Flora, a ilegalidade de algumas das drogas consumidas não pareceu ser barreira para o consumo. No entanto, na narrativa de Jorge, pareceu existir uma tensão relacionada à moralidade de promover o consumo diante da família e dos amigos (Lobbana et al., 2010).

“J: Mas ilícita assim... Eu respeito que seja ilícita... Mas no interior...Mas aqui dentro pra mim não tem nada a ver. Na minha cabeça, não. Mas eu respeito. Mas também não faço nada pra desrespeitar.

F: Entendi.

J: Essas coisas é bom não mexer, né

F: O que seria fazer alguma coisa pra desrespeitar?

J: Sair no meio da cidade fumando, né.

F: Ah, entendi. 
J: Ou na frente de mulher e de criança, assim... Tem que ter privacidade... Uma coisa mais afastado né... Mais longe, é uma coisa particular. É uma coisa privada. Inclusive não gosto de sai com alguém assim, que não...”

Nesse sentido, a partir da sua apropriação do discurso proibicionista, Jorge narrou sobre seu consumo de maconha como algo "privado", "particular". Ainda que Jorge, apresentasse uma visão crítica à proibição do consumo da maconha, ele não se engajavam publicamente no discurso anti-proibicionista, ao contrário, parecia reforçá-lo (Fiore, 2013) considerou que a droga, entendida como um dispositivo, atravessava as práticas de seus entrevistados por meio da contradição e da resistência. No entanto, a partir do discurso proibicionista é criada uma visão binária sobre drogas, como legais e ilegais, criando uma visão de que Estado deveria ser o organizador daquilo que cidadãos podem ou não fazer.

Essa apropriação de discursos, no modo como Jorge descreveu suas experiências, lhe permitiu fazer um uso próprio dos recursos que entendeu como disponíveis, agindo em seu cotidiano de maneira a dissociar suas experiências do impacto do consumo da maconha sobre elas. Nesse sentido, talvez o consumo de drogas e o uso do diagnóstico foram linguagens usadas para expressar diferentes modos de agir diante do sofrimento, sendo mais ou menos legitimados pelo contexto onde ele se inseria.

Jorge, diferentemente dos participantes apresentados até o momento, teve mais anos de estudo, trabalhava para sustentar a família, mantinha renda bem mais alta que a maioria, como foi possível perceber na Tabela 4 de caracterização dos participantes, no capítulo Encontro com o campo e o tema de pesquisa. Seu trabalho era no campo da informática, facilitando acesso a informações sobre diversas áreas do conhecimento e isso pareceu influenciar no repertório cultural a que ele teve acesso, influenciando sua construção de sentidos e significados sobre o consumo de drogas.

Foi possível perceber que os sentidos atribuídos ao consumo foi sempre situacional. Jorge, na entrevista, se expressou por meio de termos do discurso médico-psiquiátrico para falar sobre seu sofrimento psíquico, apropriando-se dele de maneira particular. Aproveitou-se do aprendizado da experiência de sofrimento psíquico, dos impactos do diagnóstico, mas também das contribuições da terapia psicológica realizada no CAPS II, adotando a perspectiva de "enfrentar" os sentimentos e pensamentos relativos às 
diversas situações "expostas" pela maconha, diferentemente do modo como fez com o consumo de álcool e de cigarro. No entanto, apesar de ter um perfil socioeconômico um pouco diferente dos demais participantes destes estudo, com eles compartilhou dos reflexos impacto do diagnóstico, que neste trabalho também considerei como sofrimento social. Além disso, de maneira semelhante a Marli, Jorge agiu diante do discurso machista sobre o gênero masculino de que o homem deve ser provedor, por meio do consumo de maconha, que para ele, era uma experiência privada de oscilação da realidade.. Ao contrario dessa participante, porém, ele não viu problemas com esse consumo.

Vitor

Vitor narrou que gostava de tomar destilados. Iniciou o consumo do álcool na época do serviço militar obrigatório, quando tinha o hábito de beber com amigos e com o sogro. Segundo ele, esse consumo lhe “fazia mal” devido ao calor da região onde morava e porque não se alimentava adequadamente.

"V: Eu aprendi no tiro de guerra. E depois com meu primeiro sogro, polícia né... Bebia bastante a gente saia pra ir pros rancho e aí foi onde que eu tomei o destilado né...

F: Vodka, whisky...

V: É...

F; Você gostava de beber o que?

V: Whisky. E a nossa região aqui é calor né. Whisky fazia mal. E eu não me alimentava”.

Descrevia essa época como muito "desconfortável", oferecendo uma narrativa que minimizava os problemas que tinha com consumo do álcool. Descreveu que nessa época não se sentia confiante "em seu potencial", atribuindo à bebida os problemas que tinha com o trabalho e no relacionamento com a primeira esposa.

"V: Era uma época bastante desconfortável, tanto no emprego quanto dentro de casa, né.

F: Como assim?

V: Eu vivia como uma pessoa desconfiada... Talvez eu tinha... Não confiava no meu potencial, né... Por causa da bebida... As vezes eles passavam um serviço da locomotiva pra mim e eu ficava com medo pensando que não ia dar contar de ler... O esquema o sistema a chegar num (Trecho inaudível)... Da locomotiva é grande né... é 600 volts... Aí eu ficava um pouco assustado, pedia ajuda... Cheguei a faltar bastante né..." 
Diferentemente de Jorge, Vitor construiu sentidos de que a bebida era uma entidade autônoma, como o sentido atribuído ao crack por Flora. Portanto, atribuiu ao consumo do álcool aumento da capacidade de agir diante do "desconforto", o que lhe parecia promover "emoção espontânea" de "alegria", no confronto com o sentimento de medo das responsabilidades cotidianas. Esse sentido também foi encontrado entre participantes do estudo de (Bizzarri et al., 2009), que relataram que o consumo de drogas teria propriedades de diminuir estados subjetivos de sofrimento. Esses efeitos sobre os sentimentos, porém não duravam mais que "os primeiros trinta minutos", segundo sua própria narrativa, "a partir daí, ele passava a se sentir alcoolizado". Essa questão também foi discutida por Pettersen et al. (2013), cujos sentidos atribuídos ao consumo de drogas foram compreendidos também como capazes de melhorar os afetos momentaneamente, tendo efeitos de curto prazo.

"F: Você achava que o álcool em algum momento te ajudava a vencer esse medo? [pausa e silêncio profundo] V: Ele ajudava, vamos supôr, nos primeiros trinta minutos... Que vinha aquela alegria aquela emoção espontânea logo já passava, né... Logo já caía meu semblante de novo e já tava alcoolizado, já não conversava mais..."

Diante dos efeitos da intoxicação pela bebida, sentia que precisava "outra dose para suportar o dia". Essa afirmação estava relacionada não só aos efeitos físicos do consumo, mas também estava relacionado ao seu estado emocional, que descreveu como "difícil" de ser suportado e momentos em que se sentia "assustado". Para além de experiências "desconfortáveis", ele também tinha experiências emocionais “insuportáveis".

"V: ... A gente percebe talvez... O cara chega em casa o cara não chega naquela alegria não... Que tava na lanchonete... Ele chega ruim... O que me assustava muito era o amanhecer, o acordar...

F: Te assustava?

V: Assustava. Medo de encarar o dia, do jeito que eu tava eu sabia que eu precisava de outra dose pra mim suportar o dia... Enfrentar..."

Para lidar com a "ressaca", fumava cigarro, que servia como auxílio diante dos efeitos físicos, enquanto a dose de álcool no dia seguinte servia para dar "suporte" à experiência de viver "o acordar". Asher \& Gask (2010) descreveram que entre os participantes de seu estudo o uso de algumas drogas contrabalanceava efeitos negativos do consumo de outras drogas, compondo efeitos desejados e indesejados.

O consumo de álcool se intensificou quando Vitor se separou da primeira esposa, aumentando também os prejuízos causados por ele, como por exemplo, a "falta de responsabilidade com emprego". Isso 
foi encontrado no estudo de Lobbana et al. (2010), em que alguns participantes referiram mudanças no padrão de consumo, ocasionadas por eventos significativos da vida, o que no caso de Vitor pareceu também acarretar mudanças nas consequências desse consumo.

"V: Sim. Quando eu perdi o primeiro casamento dobrou o excesso de bebida. E a falta de responsabilidade com emprego".

Com a primeira ex-esposa, narrou que "deixou a desejar" como marido, atribuindo a causa disso ao consumo do álcool. Exemplificou com algumas situações em que atribuía ao álcool o poder de "fazer você mentir bastante", de maneira que ele "mentia tanto que o álcool fazia eu mesmo acreditar na minha mentira", retomando o sentido atribuído à bebida como entidade autônoma, trazido nas narrativas de Flora e Jorge.

"F: Como que eram esses relacionamentos com as suas esposas?

V: Era legal. Era normal.

F: Como que é normal?

V: Viver bem. Passear. Sorrir. Dividir o serviço de casa... A [primeira esposa] teve menos sorte, porque foi a época que eu bebia. Com a [segunda esposa] não usei bebida, não tive bebida alcoólica, elas nunca viram eu beber. Então elas foi melhor, né. Com o álcool eu deixei um pouco a desejar com a [primeira esposa]. Foi meu primeiro casamento.

F: O que você fazia?

V: Eu não aparecia pra almoçar e falava que ia jogar bola em outros lugares e não ia. Falava que tinha um acidente na rodovia e que precisava fazer parte do socorro, do SOS e ia pro carnaval, ia pra festa ia pro show de rock... Essas coisas... O álcool faz você mentir bastante. Mentia tanto que o álcool fazia até eu mesmo acreditar na minha mentira".

$\mathrm{Na}$ divisão sexual dos papéis de gênero entre homens da classe trabalhadora urbana, descritos por

Duarte (1986), era legitimado aos homens transitar pelos ambientes internos e externos à casa. O consumo de álcool fazia parte do repertório disponível a Vitor para agir diante do discurso de que deveria ser "um bom marido", responsabilizando o álcool pelas consequências negativas dessa ação. Isso reafirmava sua compreensão de que o álcool era uma entidade autônoma e que tinha poderes sobre ele. Essa compreensão é legitimada socialmente no contexto onde ele se inseria (Zanella, 2010). Esse mesmo discurso legitimava trânsitos mais restritos para as mulheres, o que, na narrativa de Marli pareceu ser vivido com a mediação do consumo do álcool. Ouso sugerir que talvez por essa restrição de espaços legitimados de transito para as mulheres, Marli tenha sido posicionada como "usuária de álcool", o que, na narrativa de Vitor, isso não aconteceu, apesar dos problemas que ele parecia apresentar.

O posicionamento como "bom marido" compôs-se com a narrativa de que por vezes não "aparecia para almoçar" mediado pelo consumo do álcool sobre Vitor, de maneira que foi possível perceber crenças sobre as relações de gênero presentes no contexto onde ele se inseria, por exemplo, quando ele falou que a 
primeira esposa, que "teve menos sorte" que as outras. As narrativas de Marli, Jorge e Vitor, entre outros participantes, pareceram manter paralelismo no que se referia ao modo como o sofrimento psíquico associados a determinados comportamentos vêm sendo compreendidos como características passíveis de diagnósticos de transtornos do humor, pelo discurso médico-psiquiátrico. No entanto, a partir de suas narrativas, é possível perceber que também se faziam presentes sofrimentos sociais, compartilhados e inseridos em um contexto social e histórico circunscrito por discursos rígidos sobre papéis de gênero e divisão sexual das tarefas familiares e do trabalho, que participavam de construções sociais de valores e práticas sociais, impactando nas suas subjetividades.

Historicamente, no Brasil, o gênero feminino tem sido construído como subordinado ao masculino, o que favoreceu aos homens uma situação de prestígio, privilégio e poder, por outro lado são incumbidos de deveres como manter a autoridade e a sustentação da renda familiar (Duarte, 1986). Porém, nas últimas décadas, esses papéis de gênero vêm se transformando, modificando padrões de relacionamento e de organizações doméstico-familiar (Santana 2010).

No modo de narrar sua história, Vitor, de um lado se posicionou diante das situações "das responsabilidades" como "marido" ora respeitando a ordem instituída, ora transgredindo. Por outro lado, quando colocamos em suspensão o diagnóstico e assumimos que relações de gênero são construídas social e historicamente de maneira dinâmica em relações interpessoais cotidianas, o sentido atribuído ao consumo do álcool como uma droga que permitia "suportar o dia", permitia também "mentir", agindo sobre essas "responsabilidades" socialmente e culturalmente atribuídas a ele como homem. Esse entendimento veio da narrativa de Vitor sobre seus três casamentos: em todas as separações "foram elas mesmas que erraram", sendo eventos que o "abalaram bastante", se descrevendo nessas relações como "bastante prestativo" como marido. Entretanto, quando consideramos seu discurso sob o aspecto de que nos últimos anos, as relações de gênero vêm se transformando, essa descrição parece anacrônica.

"V: Três casamentos. Geralmente é o homem que falha né. Geralmente é a mulher que larga do homem né. Eles falam, Hã ela largou dele, né. Mas no meu caso não, foi elas mesmas que erraram. Me abalou bastante, sabe? Eu era bastante prestativo". 
$\mathrm{Na}$ época em que a entrevista ocorreu, Vitor já havia interrompido o consumo de álcool. Complementou que esse consumo poderia ter interação com a medicação psiquiátrica prescrita para seu tratamento em saúde mental no CAPS II, aderindo ao discurso médico-psiquiátrico.

"V: Não me perdi. Entro em bar assim, porque tem necessidade, né. Não tive medo não... Entrei peguei meu salgado, minha cocacola. As vezes paro levo a cerveja pro pessoal... Oh, leva a cerveja pro pessoal lá... As vezes vão comprar pergunto se eles querem levar alguma bebida né... Mas eu mesmo perdi o tesão... he he (risos). Quero mais não. Eu vivo sem melhor... Eu tenho que tomar os medicamentos também, é forte né..."

Além do consumo do álcool, Vítor narrou que fez consumo de maconha. Atribuía a essa droga, a qualidade de lhe deixar "um cara verdadeiro", contrapondo com o sentido atribuído ao consumo do álcool, que foi de fazê-lo "mentir", aspecto da personalidade que, segundo sua narrativa, Vitor valorizava, de maneira semelhante a Jorge.

"V: (risos). A maconha não. A maconha você fica um cara verdadeiro, estampado.

$\mathrm{F}: \mathrm{Ah}$ ! É!

$\mathrm{V}$ : Os engenheiros da ferrovia sabia que eu fumava.

F: Não tinha problema?

V: Eu nunca deixei falta nada... Desejar nada... E os serviços que eles passavam a tarefa era cumprida. Tinha um tempo... E eu nunca deixei ela sair... Atrasada... A não ser quando desse um defeito com ela...”

$\mathrm{Na}$ comparação entre o consumo do álcool com o consumo da maconha, relatou que não tinha problemas com o consumo desta droga, por exemplo, com relação ao desempenho no trabalho ou aos seus relacionamentos. Vitor atribuiu a esta substância o sentido de deixá-lo mais "amoroso", "tolerante", "trabalhador" e "paciente", contrapondo os sentidos atribuídos ao álcool.

"F: Mas elas [as ex-esposas] não ligavam que você fumava?

V: Não, não ligava porque eu ficava amoroso, prestativo e trabalhador, né.

F: É?

V: É.

F: A maconha fazia isso com você?

V: Fazia.

F: E com relação a sua cabeça?

$\mathrm{V}$ : Eu ficava mais calmo mais paciente mais tolerante. Gostava de viajar, passear...

F: Isso te deixava mais tranquilo...

V: Mais tranquilo... Se eu entrasse na marginal (fala um nome) e estivesse congestionada eu tava... De boa... (fala simultânea) Eu não me preocupava com nada."

Segundo Vitor, esses aspectos propiciados pelo consumo da maconha eram valorizados pelas suas ex-esposas, mas elas também pediam para que ele parasse de fazer esse consumo, argumentando que "mais tarde podia prejudicar minha mente".

"F: E elas gostavam disso?

$\mathrm{V}$ : Elas falavam pra mim parar

F: Porque? 
V: Elas falavam que talvez mais tarde podia prejudicar minha mente né...”

$\mathrm{O}$ início do consumo da maconha ocorreu na adolescência e perdurou até pouco tempo antes do início do tratamento no CAPS II. Afirmava que consumia a droga junto com colegas do seu bairro, em uma praça da cidade que na época era uma área nobre.

"F: E como que foi fumar maconha?

$\mathrm{V}$ : Eu comecei no tiro de guerra também.

F: Ah! É! Também...

V: É. No exército... Conheci bastante cara assim... Era até uns caras que moravam aqui na (avenida do centro da cidade)... De primeiro a (avenida do centro da cidade) era a parte mais nobre de (fala o nome da cidade), tipo (Fala o nome de outra avenida de alta classe para comparação). (risos). É... Era eu o pessoal da (fala o nome de um bairro), a gente fumava na praça (fala o nome) onde tem a (fala uma referência), a gente fumava lá..."

O contexto em que se desenvolveu a interrupção do consumo da "maconha", época em que passou a se descrever como sentindo "insuportável" consigo mesmo, coincidiu com a experiência vivida de trauma decorrente de um assalto, problemas com a terceira esposa e consequente separação dela, problemas no trabalho e consequente aposentadoria.

"V: Eu comecei a ficar... (Fala longa, pensativa). Insuportável comigo mesmo. Um pouco grosseiro, não recebia conselho de ninguém, palpite de ninguém. O Não tava na minha boca. Qualquer coisa era não e pronto. Dentro da empresa mesmo; precisa fazer tal coisa, não! Eu não respeitei a hierarquia. Aí foi indo até eles me darem a aposentadoria.

F: A aposentadoria veio quando?

V: A aposentadoria veio em 2004.Privatizou a ferrovia e eles queriam até dispensar eu. Eu já tava tendo problema... E o pessoal tava, né... Aí eu tive um acidente de trabalho. Aí eu esperei durante dois anos e oito meses e a aposentadoria veio. Mas completou 30 anos de carteira. Registrei em 74, em 2004 me aposentaram".

Essa questão da aposentadoria e da necessidade de manutenção ou obtenção de alguma renda diante da dificuldade de trabalhar em momentos de grande sofrimento psíquico teve grande impacto na construção de descrições sobre si mesmo na narrativa deVitor, como também esteve presente em narrativas de outros participantes, como foi possível perceber na narrativa de Marli e Jorge.

"V: Isso... Isso... Eu creio que agora eu vou passar por outra perícia... Deles porque a carteira tá aberta ainda. É dez anos né. Então eu acho que agora logo eles me chamam pra passar. Eu era um funcionário bastante exemplar, sabe, assim... Bastante prestativo pra ferrovia. E eu comecei a faltar. Devido a perca das menina. Devido ter sido assaltado. Eu fiquei com medo a noite. Eu pedia pro segurança pra trabalhar comigo na estação; eles não mandavam, né. Eu fechava o ponto e ia embora. Quase fui mandado por justa causa. Aí foi onde que eu procurei o CAPS".

Vitor passou a perceber prejuízos relacionados à sua saúde mental quando parou de consumir a maconha, sentindo-se "bastante triste". Para além dos efeitos que a droga poderia causar sobre suas emoções, Vitor vivia uma situação de vida que provocava importantes sofrimentos psíquicos e para enfrentá-los descreveu que preferiu buscar ajuda no CAPS, encorporando nessa prática o poder do discurso médico- 
psiquiátrico sobre questões de sofrimento psíquico que até então ele lidava por meio do consumo de álcool, cigarro, maconha.

"V: Eu acho que prejudicou um pouco quando eu parei.

F: Porque?

$\mathrm{V}$ : eu fiquei bastante triste.

F: E a maconha não deixava você triste?

V: Não, de jeito nenhum. Nem desanimado... eu sou animado até hoje... A maconha era um... Reati... Era um (fala o nome de um energético). Eu trabalhava eu gostava de ler de estudar, essas coisas... Com ela..."

Segundo sua narrativa, a "maconha" o deixava "animado", aumentando níveis de energia (Costain,

2008). Vitor parou de usar "maconha" e a ter "medo demais das coisas", após o assalto. "Achou melhor" parar o consumo, porque costumava fumar sozinho, ficando com medo de "um dia faltar [droga] e eu ter que fazer o que os caras fizeram comigo".

"V: É porque depois do assalto que eu tive eu vi que (pausa)... Eu comecei a ficar com medo demais das coisas... Então eu achei melhor tirar aquele... Porque a gente fuma sozinho, eu posso fumar sozinho, mas tem vários amigos, né... a gente chegava a comprar junto e eu fiquei com medo de um dia faltar e eu ter que fazer os que os caras fizeram comigo. Assaltaram dinheiro pra poder comprar droga".

$\mathrm{O}$ assalto, em conjunto com outras situações e experiências vividas na época provocou em Vitor, diferentes descrições de si mesmo. Passou a se descrever como alguém que potencialmente poderia ter comportamentos como descontrole e uso de violência para conseguir meios de obtenção da droga, o que ele identificou como realizados pelas pessoas que o assaltaram. Construiu sentidos para essas experiências a partir do discurso proibicionista, que posiciona o usuário de drogas como delinquente e marginal (Simões, 2008).

"V: É... Na falta. Porque enquanto uma pessoa tem ela é ótima, mas quando ela não tem ela é ruim né... Enquanto eu posse de comprar eu sou bom... E quando eu não tenho posse de comprar eu posso pegar o dinheiro da esposa, do meu pai ou de alguém...

F: Você já sentiu vontade de fazer isso por causa da maconha?

V: Eu pedia pra minha mãe.

F: Dinheiro?

V: Dinheiro. Eu tava na (Fala o nome da empresa), tava pagando a pensão das minhas filhas pra ajudar elas a formar. Então eu pedia... eu falava pra ela se tava triste no telefone, mãe eu to triste, ela já sabia que era falta. Aí ela depositava no banco (fala o nome) eu ia lá já tirava e já comprava".

Por não se identificar com essa descrição de "usuário de drogas", sua reflexão contribuiu para mudança no seu comportamento de usar maconha e buscar atendimento em saúde mental. Procurou, portanto, se afastar ainda mais da descrição como "usuário de drogas", passando a se descrever como "usuário de serviço de saúde mental". 
Segundo sua narrativa, refletiu que poderia chegar a ser capaz de "pegar o dinheiro da esposa, do pai ou de alguém”, pois já teve ocasiões em que pediu dinheiro para a mãe dele para comprar droga. Narrou uma situação em que falava no telefone para a mãe, se dizendo "triste", o que foi entendida pela mãe como sendo a "falta" de droga, o que, segundo ele, a levou a depositar dinheiro em sua conta no banco para comprar "maconha". Em contraposição, com relação ao consumo do álcool, a resposta da família não foi a mesma. Ele sentia que a família o "descartou bastante", exemplificando que o pai "não queria ver eu nem na rua de casa".

"F: Com o álcool não era assim?

$\mathrm{V}:$ Não!

F: E como que era?

V: Com o álcool a família descartou eu bastante. A ponto do meu pai falar que não queria ver eu nem na rua de casa. Meu carro vivia com a lanterna quebrada... E..."

A legitimidade e a escolha pela mudança no comportamento de consumir drogas pareceu se dar, na narrativa de Vitor, por um lado em conformação com compreensões presentes também na organização da RAPS da cidade, descrita no capítulo inicial, apresentando-se abstinente no CAPS II. Por outro lado, contribuiu para a busca por outras descrições de si, baseadas em experiências anteriores com o consumo de álcool e regimes de legitimidades presentes nos discursos hegemônicos sobre gênero masculino, entre outros discursos que apresentam versões rígidas sobre o papel social de um homem de classes trabalhadoras urbanas. No exemplo citado por Vitor, ele preferiu se descrever como um homem que tinha já alguma autonomia em relação aos pais, tendo filhos e os sustentando por meio de "pensão", mas ainda sim precisava de dinheiro para comprar "maconha”! Na sua narrativa, sua mãe legitimou esse consumo ao ponto de financiar o consumo do filho.

Nesse jogo de legitimidades, Vitor pareceu preferir se descrever com sofrimento psíquico passível de diagnóstico psiquiátrico, retomando a escolha de deixar o consumo de maconha e passar a se descrever como alguém que precisava de tratamento de saúde mental. Vitor já apresentava experiências, que antes de fazer o tratamento em saúde mental, eram "acobertadas" pelo consumo de drogas. O consumo de algumas drogas, por exemplo, parecia funcionar como uma "válvula de escape". A partir de uma situação ocorrida antes da 
entrevista, em que nos desencontramos e ele ficou me esperando, ele deu exemplos sobre como lidava com pensamentos que lhe ocorriam, em situações cotidianas quando usava diferentes drogas, atribuindo a elas diferentes sentidos para a mesma situação.

"V: Isso. O cigarro se torna uma válvula de escape. Vamos supor se eu chegasse aqui e você falou que ia me atender 8 horas e falariam pra mim e você chegaria 9:30... Talvez eu estaria fumando um, dois, três...

F: Mas vamos pensar nessa situação... Mas não... Assim... Se eu tivesse feito isso com você que sentimento você teria? Fiquei pensando que talvez ficaria frustrado, com raiva...

V: Hum... Não... Acharia que você não foi pontual que...

F: Ficaria bravo...

V: Comigo mesmo porque sem mostrar pro próximo que eu to passando por aquele problema...

F: Hum... Então o cigarro acoberta essa sensação?

V: Isso, acoberta. É...”

Diante da situação de espera, sob o efeito do cigarropensaria que "não fui pontual", sentindo-se "bravo consigo mesmo", sem, no entanto, "mostrar pro próximo que eu estou passando por aquele problema". Sob o efeito da maconha, ele pensaria que "não tinha problema" em esperar e com o consumo de álcool, segundo ele, talvez nem viesse na entrevista.

"F: E a maconha numa situação dessa? Como seria essa situação se você estivesse fumando maconha?

V: Ah, vamos supor se eu tivesse fumado de manhã e você chegasse pra mim e falasse que ia me atender as $9 \mathrm{~h}$ eu ia falar, de boa...

F: Não tinha problema.

V: Não tinha problema. Durante quatro horas.

F: Ah, você tinha o efeito...

V: Durante quatro horas. Quatro horas mais ou menos...

F: Aí acabava o efeito você fumava de novo.

V: É.

F: Você falou que fumava três cigarros né...

V: É... Aí eu faria de novo...

F: E sob efeito do álcool?

V: Sob efeito do álcool talvez nem estaria aqui.

F: Não tinha nem...

V:Não consegue efetuar os problemas, começar a falhar um pouco. Começa a correr da sociedade. A sociedade te leva a bebida né. Aniversário de quinze anos, formatura... E depois se você vira alcoólatra a sociedade te joga na calçada".

Diante de situações cotidianas sob o efeito de diferentes drogas, evidenciou que, além de serem atribuídos diferentes significados a elas, como se pôde perceber ao longo das narrativas até aqui apresentadas. Seu uso era também uma reação às situações, como se pôde perceber na narrativa de Jorge, mas também dependia do tipo de substância consumida e relacionada a essas situações, como evidenciado no trecho apresentado. A construção de sentidos sobre o consumo de drogas nas narrativas deste trabalho pareceram serem formados em uma rede complexa de relações, de sociabilidade e significação, que poderia 
mudar com o tempo, ao longo do aprendizado do uso, das experiências ao longo da vida e de autoobservações a respeito dos efeitos desse consumo.

Um exemplo pode ser dado referente ao consumo do cigarro, em que Vitor achava que consumir cigarro o deixava menos ansioso. No exemplo que deu, ao esperar no ponto de ônibus, ele "percebia que fumava mais".

"V: Eu cheguei pensar que o cigarro me acalmava me tirava a ansiedade, mas de um seis meses pra cá eu to vendo que ele me traz ansiedade.

F: Como assim, o que te fez pensar isso?

$\mathrm{V}$ : Se eu estou no ponto do ônibus e ele começa a demorar eu percebo que eu fumo mais. Eu quero que as coisas acontece mais rápido então me dá ansiedade então eu desabafo no cigarro então eu percebi isso".

No entanto, ele reconstruiu esse sentido, relatando que na época da entrevista, passou a pensar que o cigarro "trazia ansiedade". Portanto, diante da sensação de ter esperar, ele "desabafava" no cigarro, retomando o significado de que o consumo de cigarro para ele, seria uma forma de comunicar seu desconforto. Os sentidos eram atribuídos ao consumo de drogas dinamicamente, variando de acordo também com a reflexão que Vitor fazia sobre esse consumo, sendo influenciados também pelo modo como essas drogas vinha sendo vistas socialmente. Vitor evidenciou a aparente distinção de classes sociais entre "beber socialmente" na "alta sociedade" e "ficar de fogo", que era como pessoas como ele, de classes trabalhadoras urbanas, ficavam quando bebiam em quantidade considerada excessiva. Apesar dessa distinção no modo de descrever, ele percebeu essas experiências como iguais, embora se distinguissem em hierarquias sociais diferentes. Essa visão foi influenciada também pelo discurso proibicionista de que o consumo de drogas revelava uma "degenerecência" em que eram vinculados grupos sociais marginais (Rodrigues, 2008) aos quais, Vitor também não se identificava.

Essas compreensões pareceram remeter à noção de Pessoa-Indivíduo descrita por autores como Duarte (1986), como se existisse um self construído a partir de compreensões difundidas na nossa cultura como única cultura "moderna" em que importam valores, como no caso de Jorge e Vitor, serem "homens de família", serem "trabalhadores" e a "dona de casa", evidenciada pela narrativa de Marli. Eram também entremeadas por complexos contrastes a esse ideal, em uma composição própria, o que influenciava na 
maneira de compreender "nervoso", no caso do trabalho do autor e consumo de drogas, no caso da presente tese. Assim, os significados e os sentidos sobre o consumo de drogas emergem através das experiências e das narrativas, sendo circunscritos por compreensões localizadas de tempo e espaço, sendo produto de trocas discursivas situadas. No caso de Jorge, as experiências tinham a ver com o sofrimento diante de não sentir-se capaz de ocupar o papel social de "homem" definido como "pai de família, trabalhador, responsável”. Essa rigidez na compreensão de papéis sociais pareceu ser motivo para a busca pelo cigarro quando se encontrada diante das consequências das "crises" e "depressões” descritas a partir do discurso médico-psiquiátrico. Este mesmo participante também da maconha, que lhe permitia oscilar entre diferentes percepções da realidade, permitindo-lhe sair da descrição de "escravão" dessas obrigações sociais.

A questão do sofrimento psíquico também se relacionou, nna narrativa de Vitor, com o posicionamento social "desconfortável" promovido pelo que ele entendia como "sociedade". Na opinião dele, a mesma "sociedade" "te leva à bebida", promovendo e legitimando o consumo em situações sociais e "te joga na calçada" quando a pessoa que consome o álcool em uma quantidade considerada como excessiva, passando a descrever essa pessoa como "alcoólatra".

"V: (risos)... (Trecho inaudível)... Então eram uns amigos diferentes né... Eu não sei como que na alta sociedade eles falam beber socialmente né, mas o socialmente deles, eles ficam de fogo também".

Essa compreensão compunha com percepções vindas do trabalho de campo, com relação às maneiras como profissionais de saúde dos serviços estudados percebiam o consumo de drogas, como apresentado em capítulo anterior. Portanto, é possível compreender que esse tipo de discurso se insere em um contexto mais amplo que liga compreensões de profissionais e pacientes, apesar de muitas vezes, eles não pertencerem às mesmas classes sociais e terem referências culturais diferentes.

O consumo de drogas, na narrativa de história de vida de Vitor, se iniciou na época do serviço militar obrigatório, em meio a amigos, momento que ele começou a "tomar social e o social foi até o fundo do poço". Vitor se apropriou do discurso de que o consumo é legitimado na classe social em que ele participava na época, compartilhando essa experiência com colegas que dividiam um espaço social obrigatório para 
homens jovens brasileiros. Pela sua idade foi possível identificar o período histórico porque o Brasil passava, que coincidiu com o final da ditadura militar no país. Embora o serviço militar unisse virtualmente pessoas de classes sociais diferentes, existiam ainda sim divisões de classe nesse grupo. Vitor, diante desse paradoxo, pareceu sustentar o status de igualdade virtual pelo consumo de álcool, cuja consequência para ele foi o "fundo do poço".

"V: Eu comecei a beber quando eu fiz o exército. Tiro de guerra. Com 18.

F: Foi no tiro?

V: No tiro de guerra. Eu saia com os amigos e na nossa formatura mesmo foi o primeiro porre que eu tomei. Depois eu achei que era melhor tomar social e o social foi até no fundo do poço. Com bebida alcoólica”.

De maneira análoga, foi possível perceber em seu discurso que Vitor compactuava com visões de mundo relacionadas aos ideais "modernos", caracterizando a classe social a que Vitor, Jorge, Marli e outros participantes deste estudo como grupo social que se situam em uma posição subordinada dentro das chamadas "sociedades modernas", situando-se em uma posição fronteiriça baseada em gradações morais que separam em "nós" e "eles", como Vitor comentou.

Ele narrou que chegou a "pensar" em iniciar o consumo de cocaína, na época em que decidiu deixar de fazer uso da maconha e também passou a procurar o tratamento de saúde mental. Disse sentir medo desse consumo que poderia ter consequências negativas, refletindo sobre o consumo que teve do álcool e da maconha.

"F: Que substância química?

V: Cocaína, e eu já estava bem próximo ao...

F: E você nunca usou?

V: Não.

F: Nunca experimentou?

V: Não, ficava com medo.

F: Ficava com medo?

V: É, tinha medo. E eu já tinha passado pelo álcool e eu vi que já foi difícil largar, né?

F: Foi difícil largar a maconha?

V: Foi um pouco.

F: Foi um pouco? Mais difícil que o álcool?

V: Eu acho que sim... Porque o álcool você fica ruim e todo mundo percebe e a maconha ninguém percebia. Eu fumava no meio do serviço, dirigia, viajava... O comando parava e eu não tinha medo.

F: E aí ficou com medo de usar a cocaína?

V: Fiquei com medo de usar a cocaína. Eu achei que levaria à morte muito rápido".

A legitimidade do consumo da maconha era maior que a da cocaína e, na narrativa de Vitor, do álcool, além disso, os problemas que teve com o consumo do álcool promoveram que refletisse sobre o 
consumo da cocaína. Contou nessa construção não só o aspecto da legalidade apontado na narrativa de Jorge, mas também o acesso e o custo relacionado com essa droga. Imaginava "se o cara tem pouco dinheiro", "talvez ele use só uma cota", mas se "tem um pouco mais de dinheiro, a gente vai além". A partir dos significados que a disponibilidade de dinheiro tinha com relação ao consumo de cocaína, talvez, o sofrimento psíquico apresentado por Vitor narrou ao falar de si mesmo, estivesse ligado ao desejo de ascender socialmente. No entanto, ele não podia concretamente sustentar isso.

O consumo de drogas fez parte dos repertórios presentes nesse cenário social, permitindo "desabafar" "sem que ninguém percebesse" o "desconforto" que ele sentia. Vitor se identificou com uma classe social mais alta. Ele, como também Jorge, destoou em termos de renda da maioria dos participantes entrevistados, como apresentado na tabela referente às características individuais dos participantes. Isso pareceu refletir o que já foi apontado anteriormente sobre o território onde ele fazia tratamento e a distribuição das pessoas atendidas na RAPS da cidade estudada.

"V: Não. Eu imagino assim, se o cara tem pouco dinheiro, né... Talvez ele use só uma cota né... Só aquela cotinha... Agora quando tem um pouco mais de dinheiro a gente vai além, né. Porque nos bares quando eu tava queimando... Se eu tivesse que gastar cem reais, trezentos quatrocentos... Tinha mais dinheiro...

F: Tinha mais dinheiro e se sentia mais no direito de gastar mais...

V: E de beber mais... Os caras falavam pra eu ir embora eu falava abre mais umas duas, três ai... Entendeu... Não tinha como né... Aí passei por isso... então hoje eu tenho medo de voltar pra chácara e a cidade é muito pequena... Mas meu desejo era voltar pra lá... Pra trabalhar no meu quintal e tudo..."

Ele também compactuava com os ideais da classe que geralmente frequenta serviços de saúde mental públicos, uma classe social mais empobrecida (Ribeiro et al. 2006), como por exemplo Flora, Rogério, Fabiano, entre outros participantes do estudo. Essa não identificação poderia ser descrita pelo discurso médico-psiquiátrico como um aspecto maníaco da sua narrativa, respaldando um discurso de classe que subjaz às políticas públicas relacionadas ao sistema público de saúde, relacionado ao sub-financiamento e a precarização da atenção a essa população, como evidenciado por (Andreoli et al, 2007). Vitor partilhava de um transito "desconfortável" entre os ideais da classe social mais rica e as limitações financeiras de uma classe social mais pobre. Essa questão ficou evidente na passagem em que ele narrou que antes da aposentadoria tinha maior disponibilidade de recursos financeiros. 
"V: Porque o povo da cidade ficou com inveja. Eu arrumei muito a chácara, eu plantava eu colhia eu levava as coisas pra creche né... Mandioca, abóbora, laranja, limão... Eu levava pra creche da escola lá... No entando quando eu larguei da [terceira esposa] comecei a namorar a diretora da creche. Mas eu terminei com ela. Dessa vez eu chamei ela e falei, o (nome da terceira esposa) você vai me perdoar mas... ela falou, é porque você não esquece a (nome da segunda esposa)! Eu falei, também... Mas eu estou com medo de estragar a sua vida. Eu viajei muito quando eu trabalhava, mas quando aposentei eu me perdi de novo..."

A interpretação que fez dessa situação foi de que "o povo da cidade ficou com inveja" dele. Essa visibilidade diante da vizinhança era um marco importante e que depois de ter se aposentado, na sua narrativa ele a perdeu. Com menos recursos financeiros, o consumo de drogas pareceu menos viável financeiramente, para ele, e isso pareceu ser suficiente para, na sua narrativa, deixar de fazer uso naquele momento de vida.

Os problemas com o consumo não foram vistos por ele como relacionados a aspectos afetivos ou dificuldade emocional vivida na época em que fazia uso problemático de álcool. Vitor os atribuiu a eventos relacionados ao descontrole do consumo, como descreveu (Fiore, 2013) sobre a importância do contexto e da situação onde o consumo era feito, como circunscritora de sentidos atribuídos ao consumo. Por causa dessa dificuldade com o controle do consumo do álcool, ele narrou ter "pedido para ser internado", ficando em uma clínica de recuperação vinte anos antes de iniciar tratamento em saúde mental.

"V: Quando eu cheguei na minha mãe e no meu pai e disse que queria parar de beber mas não conseguia parar... Que eu tinha um salário e que eles podiam arrumar um lugar pra mim ficar.

F: Você foi internado então?

$\mathrm{V}$ : Eu fui internado.

F: Quanto tempo você lembra?

V: Quinze dias.

F: Quinze dias...

V: Era pra ficar mais, mais eu não resisti muito lá dentro. Foi lá em (fala o nome da cidade) em (fala o nome do estado). Aí eles foram visitar eu... Eu falei que se eles não fossem me buscar na segunda feira eu ia fugir... (risos)... Aí buscaram eu na segunda feira..."

A partir dessa narrativa, da mesma maneira que "pediu para ser internado", "pediu" também para sair da internação, negociando essa saída por meio de ameaça de fuga da instituição. Vitor também minimizou os problemas que teve com o consumo do álcool, dando uma versão própria sobre o momento em que foi internado pela segunda vez. Desta vez, em decorrência da separação da segunda ex-esposa.

"F: Quando você tava com problema com a [ex mulher], você pediu ajuda e se internou... Você consegue fazer essa relação... Existe essa relação?

V: Existe... Existe sim... Existe porque eu fiz um círculo de amizade de novo e tinha psicólogo, terapeuta, e nós tinha (trecho inaudível), nós tinha academia, piscina, eu fui chefe de cozinha lá... eles queria que eu ficasse trabalhando lá.

F: E você não quis ficar? 
V: Eu fiquei quatro meses era o... Eu fiquei seis. Fiquei seis meses. Depois eu sai e voltei par lá de novo. Voltei... eu não conseguia ficar na casa do meu pai, aí eu liguei pra ele lá de [cidade de médio porte paulista] e falei assim, liga lá em [cidade satélite da cidade citada anteriormente] quero ficar lá... Aí eles fizeram um preço mais razoável pra mim...”

Esta internação durou seis meses e foi narrada com certo glamour. Contou que voltou para a internação porque "não conseguia ficar na casa do meu pai”, onde passou a morar após sua separação com a primeira das ex-esposas.

"V: E tinha umas regalias lá... Eu pagava um bom preço mensal. Trabalhava no portão pra eles sabe no dia de visita. Eu recebia as visitas... (trecho inaudível)... (risos). Combinava de fugir... (risos)... Combinamos várias fugas... Eu ajudava a planejar a fuga mas nunca tive coragem não... eu queria me bem estar... Falei pro cara, não. Eu tenho cama, tenho comida, tenho roupa minhas irmãs que estão contando comigo. Aí parei. Peguei medo de ladrão da bebida de tudo né... Vou falar pra você, ficar sozinho é ruim. Viver sozinho não é bom não. O ser masculino ele é homem enquanto ele tem a esposa a hora que ele perde ele não é..."

Vitor descreveu que gostava de estar internado na comunidade terapêutica, tendo feito amizades nesse local, ora se descrevendo como um paciente do lugar, ora como "trabalhador" do lugar. Na narrativa que construiu, importava a questão "desconfortável” de pertencer às classes que usam como referência os ideais ditos "modernos" de sociedade, baseados no discurso rígido sobre o gênero masculino, na valorização da família e do trabalho. Essa questão foi vivida com sofrimento psíquico e o consumo de drogas que ele fazia era de certa forma parte do contexto onde ele se inseria. Vitor contou que já havia feito consumo problemático de álcool e de maconha, estando abstinente no momento da entrevista. Ainda fazia consumo de cigarro e estava "próximo" de iniciar o consumo de cocaína, na época em que procurou tratamento no CAPS II.

O consumo dessas drogas pareceu permitir a ele exprimir de uma forma própria e necessariamente incompreensível ao outro, que ele vivenciava sofrimentos de ordem psíquica, mas também social. Essas experiências foram sentidas como "desconfortos", por vezes "insuportáveis", em uma maneira muito semelhante à narrativa de Marli, servindo como ampliação da sua capacidade de agir. O consumo de drogas foi o modo como ele agiu sobre o "desconforto" social até ser aposentado, quando sua compreensão sobre o papel do consumo de drogas sobre a capacidade de agir foi alterada também pela diminuição dos ganhos financeiros e pela mudança de posicionamento de "trabalhador" para "aposentado", passando a descrever seu "desconforto" em termos de problemas psíquicos passíveis de diagnóstico psiquiátrico, procurando tratamento psiquiátrico. 


\section{Um resumo}

As experiências e histórias narradas por cada um dos entrevistados, estão todas conectadas a um contexto global mais amplo, sendo interpretadas como vivências de violências estruturais geradoras de sofrimento social (Paul Farmer, 1997). No caso dos participantes, foram apresentados como sofrimentos sociais a influência da questão de classe e da possibilidade financeira de acesso ao consumo, discursos rígidos sobre os gêneros, e do discurso médico-psiquiátrico sobre as descrições das experiências de sofrimento psíquico.

O consumo de drogas possibilitou agir diante de variações emocionais relacionadas ao sofrimento psíquico e que foram descritas pelo discurso médico-psiquiátrico por meio de diagnósticos de transtornos do humor, expressando seus sofrimentos psíquicos em uma linguagem que lhes era própria, sendo uma vivência singular compartilhada socialmente. Assim, participavam da construção de sentidos e significados dessas experiências a busca por inibição de sentimentos ditos "ruins", em que os participantes narraram estar "mal", "ter crise", "ter depressão", estar "desconfortável”, "sofrer, mas aguentar", "suportar". Experiências que foram possíveis de serem vividas também tendo o consumo de drogas como dispositivo que possibilitou a essas pessoas lidar com essa situação de precariedade e paradoxo entre ideais sociais e a realidade vivida, não sem prejuízos. 


\subsubsection{A vida nervosa e o consumo de drogas}

Neste capítulo procurei discutir sentidos atribuídos ao consumo de drogas diante de experiências descritas como nervosismo, agitação, irritação e necessidade de se acalmar, conforme foram relatadas pelos participantes e que podem ser agrupados e descritos como sintomas de transtornos de ansiedade pelo discurso médico-psiquiátrico. Foram também aqui agrupadas experiências que estiveram associadas a outras como, por exemplo, vivência de violências, enfrentamento de responsabilidades e de questões referentes ao contato social, sentimentos vindos de ouvir vozes, ou mesmo diante de emoções como tristeza, que poderiam ser descritas por esse discurso como transtornos de ansiedade. Procurei refletir sobre a questão da ansiedade, que no nosso país vem sendo tratada como sinônimo de "nervoso". No entanto, essa questão foi discutida por Duarte (1986) como uma grande categoria sobre a qual o discurso médico-psiquiátrico busca se debruçar, mas que não cabe estritamente em uma categoria diagnóstica, senão em várias e as ultrapassa, tomando contornos culturais relacionadas a condições de vida das pessoas descritas como "nervosas" (Duarte, 1993).

Dialoguei ao longo dos capítulos com esse autor porque encontrei nas narrativas e na literatura sobre o diagnóstico duplo variadas vezes em que a expressão "nervosismo" estava entre as motivações para o consumo. Além disso, alguns participantes se descreveram "nervosos". A literatura qualitativa sobre esse campo vem principalmente estudando a questão referente aos diagnósticos de transtornos mentais ditos graves e descreve que o consumo de drogas parece estar ligado à diminuição da ansiedade e do nervosismo (Bradizza \& Stasiewicz, 2003), alívio do estresse e relaxamento (Charles \& Weaver, 2010). Associa também a influência da ansiedade no funcionamento social, em que o consumo de drogas facilitaria o desempenho em situações sociais (Asher \& Gask, 2010), mas também o consumo de drogas poderia ser motivado como estratégia de lidar com sentimentos de ansiedade associados com o estigma de receber diagnóstico psiquiátrico (Lobbana et al., 2010). 
Autores discutem que algumas pessoas podem apresentar traços de personalidade ligados à ansiedade, tendo sensibilidade maior a esses sentimentos (Stewart et al., 1997). Essas pessoas poderiam apresentar quadros subclínicos de transtornos de ansiedade que, dependendo da cultura de consumo de drogas presente no contexto onde essas pessoas se inseriam, consumir drogas poderia ser uma forma de automedicação legitimada (Canet, Ortiz, \& Marquez, 2003). Caso esse consumo não fosse visto como legítimo no contexto local ou fosse necessária abstinência desse consumo, seria possível que alguns comportamentos apresentados por pessoas que usam drogas fossem clinicamente descritos como característicos de sintomas de transtornos de ansiedade (Robinson, Sareen, Cox, \& Bolton, 2013) pelo discurso médico-psiquiátrico.

No presente capítulo foram apresentadas experiências com drogas lícitas, como o álcool e o cigarro, e também ilícitas, como a maconha, cola de sapateiro e cocaína. A maioria dos participantes deste estudo, em alguma medida, narraram experiências em que o consumo de drogas fazia parte de estratégias de lidar com sentimentos que poderiam ser classificados como de ansiedade passíveis de diagnóstico pelo discurso médico-psiquiátrico. Para aprofundar nas narrativas escolhi pormenorizar a narrativa de Juliana, que recebeu formalmente este diagnóstico, mas também selecionei as narrativas de Bruno e Igor. Estes dois participantes, embora não tenham sido diagnosticados com transtorno de ansiedade de maneira formal, apresentaram elementos ricos para refletir sobre o que a literatura discute sobre características descritas como subclínicas de ansiedade pelo discurso médico-psiquiátrico, discutidas por alguns autores como presente entre pessoas que fazem consumo de drogas.

\section{Juliana}

$\mathrm{Na}$ adolescência, Juliana se sentia "uma pessoa extrovertida" e mais capaz de se enturmar com seus pares quando fazia uso da maconha, o que parecia mediar essa relação com os amigos, como estava presente 
também nas narrativas de Fabiano, Pedro, Jorge e Vitor e muito comumente citada em estudos sobre o diagnóstico duplo, como o estudo de Asher \& Gask (2010). Isso parece acontecer porque esse vem sendo o motivo do consumo também de pessoas que não receberam diagnósticos psiquiátricos.

"F: E como que você se sentia quando fumava maconha?

$\mathrm{J}$ : Ah! Eu me sentia feliz.. Eu ria de qualquer coisa... Ficava uma pessoa extrovertida... Eu ia conversando conseguia me aproximar das pessoas..."

O consumo facilitava a interação social, que ela narrou como "conseguia me aproximar das pessoas", também relatado por Jorge com relação ao consumo do álcool, mesmo em momentos em que se encontrava em “depressão". Bradizza \& Stasiewicz (2003) encontraram que pessoas diagnosticadas com transtornos mentais graves usam drogas como uma motivação de diminuir emoções negativas. Isso também foi compartilhado por Vitor e Fabiano no início do consumo de maconha, sendo uma estratégia de entrosamento utilizada no grupo de pares.

Lobbana et al. (2010) comentaram que os participantes de seu estudo também atribuíam ao uso de drogas uma ampliação da capacidade de agir diante da vontade de fazer parte do grupo social onde se inseriam. O consumo de maconha, pareceu ajudar na aproximação com outras pessoas, promovendo a sensação de que estava "feliz". No entanto, autores argumento que a questão da socialização também é o motivo pelo qual outras pessoas, que não receberam diagnósticos psiquiátricos também os consumem. Isso se dá porque se considera que as pessoas que recebem diagnósticos psiquiátricos têm as mesmas necessidades que as outras pessoas, pois não são pessoas diferentes, pois a consideração de que são doentes por usarem drogas parte de uma construção social datada e localizada pelo discurso médico-psiquiátrico (Fiore, 2008).

Juliana, por um certo período da sua vida, fez uso de cola de sapateiro e com essa droga, narrou ter tido sensações de "perder a noção". Caracterizou essa sensação "como se a mente adormecesse", suspendendo a "sensação de ficar sozinha”. Sensações essas também descritas por participantes do estudo de Asher \& Gask (2010) como a tentativa de "shut down for a while" ou seja, tomar uma atitude introspectiva momentânea. 
“J: Não, direto na cola. Ai quando fazia o efeito na mente é como se você adormecesse entendeu? E... Na hora que passa o efeito é como se você acordasse do nada assim. E não sei na hora que eu acordava eu não lembrava de nada do que eu tinha feito, nada. F: O que você gostava?

J: Eu acho que eu gostava também de... Dessa questão de parecer... Como se eu tivesse dormindo.. Como se eu tivesse... É... Como se eu não tivesse ali... Como se eu tivesse em outro plano sei lá... E.... Entendeu? Era dessa sensação de ficar sozinha".

Diante do desamparo, a cola de sapateiro teve o efeito de suspender essa sensação, pelo menos no momento em que estava sob o efeito da droga (Thornton et al., 2012).

Outro sentido que apareceu, na narrativa de Juliana teve a ver com a morte do irmão dela, que suscitou aumento do consumo de álcool e cocaína e uma tentativa de suicídio. O impacto da morte violenta do irmão, envolvido com o tráfico de drogas a deixou muito triste.

“J: Meu irmão foi assassinado (fala simultânea a anterior)... Meu irmão se envolveu com tráfico, com... Morreu assassinado... De forma cruel..."

Juliana narrou essa passagem de maneira que era possível perceber não só a tristeza, mas também o sentimento de culpa por não ter visitado o irmão, pouco tempo antes de sua morte, conforme ele pedira a ela. Esse sentimento, ainda no momento da entrevista era presente e se apresentava de maneira forte. Achava que se tivesse visitado o irmão, teria impedido sua morte do irmão.

“J: (...) Aí naquele ano ele me ligou... Ele pediu que eu fosse pra lá que ele queria que eu fosse pra lá... Passar o final do ano com ele... Mas eu não podia, porque eu tava trabalhando (voz embargada)... Então eu me sinto culpada... (Choro) Eu sinto que se eu tivesse ido lá (pausa)... Ele tava aqui... (choro) Eu poderia ter feito algo por ele... Acho que essa culpa que (pausa)... Que me corrói hoje por dentro, entendeu... Eu sinto que se eu tivesse lá ele não ia morrer...'

Narrou ter lidado com essa situação aumentando o consumo dessas drogas, o que julgava ser uma estratégia de "não pensar em nada dessas coisas”.

"F: Hum... E nessa época que você perdeu seu irmão... Você... Que... Como você lidou com isso?

J: Na verdade até hoje é difícil... Eu ... No começo eu fiquei desnorteada né... Eu comecei a usar droga pra que... Quando a gente tá sob o efeito da droga a gente não pensa em nada dessas coisas... Agora, hoje não... hoje eu penso que... Como eu não vi né... Não fui pro velório, pro enterro..."

Juliana explicou que nessa época tentou suicídio por ingestão de veneno. Conectada a essa experiência, sentia dificuldade de expor seus sentimentos. Isso adicionou carga ao sofrimento pela sensação de impotência no controle do consumo de cocaína e álcool, como se o consumo fosse a comunicação do sofrimento. Mas Juliana denominou isso como "recaída", se apropriando do discurso médico-psiquiátrico sobre o consumo de drogas. De maneira análoga, Bradizza \& Stasiewicz (2003) encontrou entre os participantes de seu estudo motivações de que não tinham nada a perder com o consumo, o que alimentava, ambiguamente sentimentos de culpa neles. 
"J.... Ai aos 23 anos eu tive uma outra recaída... Porque eu voltei a usar muito mesmo... Né? Que eu tive vários problemas... Eu me separei de uma pessoa que eu vivia 7 anos e a gente pretendia casar... Mas já não dava mais pra mim conviver com ele... Ai veio a separação, veio a morte do meu irmão. Então eu voltei a usar cocaína e álcool... E ai foi que aconteceu a minha primeira tentativa de suicídio... Porque eu não via outra forma de me livrar disso eu não sabia que existia o tratamento. Então eu achava que eu não conseguia parar... E eu achava que a única forma de eu parar, de eu me livra disso era morrendo.... Ai então eu tomei veneno pra me matar, mas ai meu primo viu eu lá no quarto eu já tava desmaiada... E me levou pro posto..."

Todos esses sofrimentos psíquicos foram retroalimentados entre si. Segundo Juliana geraram tentativas de suicídio, vistas como a "única forma de se livrar disso".

Sobre os sentidos relacionados à cocaína, afirmava que sem a droga ficava "pelos cantos". A sensação que atribuiu à cocaína foi a de "poder tudo". Sem a droga, no entanto, sentia "depressão", apropriando-se do discurso médico-psiquiátrico sobre suas emoções, apesar de não ter recebido da equipe do CAPS AD o diagnóstico de depressão. Ela pareceu narrar esse sentido da droga de uma maneira muito próxima à narrativa de Jorge com relação à maconha, que, ao contrário dela, recebeu esse diagnóstico no CAPS AD. Sobre isso, (Santos, Nakamura, \& Martin, 2007) discutem que a apreensão do diagnóstico de depressão por pessoas atendidas em serviços públicos de saúde mental, pertencentes à classes populares, nem sempre condiz com o diagnóstico recebido ou presente no prontuário, sendo mais uma apropriação particular do discurso médico-psiquiátrico sobre as experiências.

“J: Na verdade a sensação de poder que a cocaína traz. Te deixa com a sensação de como se você pudesse tudo.

F: É diferente da sensação que você sente quando você está sem?

J: É.

F: E como que é?

J: Porque quando eu estou sem, aí bate a depressão. Entendeu. Aí só choro. Fico pelos cantos (...)”.

Segundo Juliana, ela também lidou com esse sentimento de vontade de morrer tentando ignorar o que estava sentindo. E nessa tentativa, que ela chamou de "lutando contra si mesma", ela continuava usando cocaína, cujos efeitos "subiam com mais força”, também de uma maneira parecida com o que Jorge narrou sobre suas experiências de "depressão" relacionadas ao consumo da maconha.

"F: E como que você lidava com essa sensação?

J: Ah! Muitas vezes eu tentava ignorar o que eu estava sentindo...

F: É...

J: É, ficava numa luta contra mim mesma. Lutando contra eu mesma, contra essa vontade de... Tentava não pensar mais ai quando eu fazia alguma droga aí droga subia com mais força"

Healey et al. (2009) encontraram entre os participantes de seu estudo relatos de que o consumo era uma forma de tentar ignorar sentimentos descritos por eles como depressivos, na esperança de que eles 
fossem embora, como Juliana narrou. Nesses momentos, os sentidos relacionados à intensidade do efeito da droga consumida foram influenciados por suas emoções, o que foi uma questão também compartilhada pelos outros participantes deste estudo, como discutido na narrativa de Vitor.

Juliana narrou uma mudança nos sentidos atribuídos aos efeitos do consumo de drogas ao longo do tempo vivido na narrativa construída na entrevista. "No começo", pensava que a cocaína ajudava a “esquecer" situações que a deixavam "pra baixo", também encontrado entre os participantes do estudo de Healey et al. (2009), que relataram que o consumo da cocaína ajudava a manter a alegria.

“J: É! Exatamente. No começo ela ajudava a esquecer. Hoje ela [cocaína] faz o efeito contrário. Entendeu? Hoje ela me põe em depressão. Hoje ela me traz os problemas com mais força, me põe pra baixo, me faz eu querer sumir... Às vezes eu sentava no sofá, eu ficava encolhida, encolhida no sofá assim... Com a sensação de que quanto mais eu me escolhesse mais eu diminuía, como se eu fosse desaparecer... (choro)"

A menção ao "hoje", referente ao momento da entrevista compreendido como "depois" da percepção dos prejuízos com o consumo e aderência ao tratamento deste, o significado do consumo da cocaína passou a ser associado com sentimentos de "querer sumir" e a sensação de que "fosse desaparecer", expondo seus "problemas com mais força", de maneira muito próxima ao que Jorge falou sobre o consumo da maconha. No caso deste, ele falava de uma necessidade sua de enfrentamento dos problemas que tinha, enquanto Juliana se descreveu como incapaz de lidar com estes problemas.

Juliana localizou o momento do início do consumo quando atribuiu significados de que a cocaína promovia a sensação de se sentir "livre de tudo". Localizou como "depois" o momento em que já estava em tratamento no CAPS AD, atribuindo sentidos ao consumo em que "o poder acabou" "porque eu vejo que hoje sou dependente".

“J: Não sei te explicar exatamente. É como se eu me sentisse livre de tudo. De todas essas sensações. Mas isso era no começo. Mas hoje não. Hoje eu me sinto presa.

F: Mesmo estando sob o efeito.

J: Mesmo sob o efeito. O poder acabou. Eu me sinto fraca. Eu me sinto pequena. Porque eu vejo que hoje eu sou dependente. Ela me domina hoje".

As sensações de "antes" e "depois" referentes a sentidos construídos sobre o consumo de drogas tiveram a ver, na sua narrativa, com um marco que foi o tratamento no CAPS AD, quando ela passou a ser posicionada como "dependente". Esse posicionamento mudou o modo como ela passou a significar seu 
consumo de drogas e a si mesma. Inicialmente, Juliana não se posicionava dessa maneira, ainda que fizesse uso problemático de drogas e atribuía a essas drogas o sentido de "poder" agir sobre os sofrimentos psíquicos. Com essa nova descrição, passou a ter outra compreensão de si mesma como alguém "pequena" e "dominada" pela substância. Ela ainda atribuiu ao consumo "poder" sobre ela, de maneira semelhante a Vitor e Flora, descrevendo a droga como se fosse uma entidade autônoma.

Essa nova descrição de si mesma atribuída na ocasião do tratamento, ao invés de psíquico, a fazia sentir diminuída, aumentando esse sentimento. Dessa maneira, na sua narrativa, os sentidos atribuídos à cocaína não mudaram: a cocaína continuou a ter um sentido de entidade autônoma e tendo "poder" sobre ela. Um sentido muito próximo ao encontrado por pessoas de classes sociais mais altas que consomem cocaína e associavam a essa droga aumento da "potencia" financeira e aumento da produtividade, proporcionados pelo custo dessa droga e pelo status social do consumidor (Jorge et al., 2013).

Importa lembrar que Juliana conversou comigo no CAPS AD, já tendo tido várias experiências ruins com o consumo como, por exemplo, ouvir vozes e ter sentimentos que ela chamou de "mania de perseguição". Na época em que ocorreu a entrevista, estava fazendo um consumo mais controlado de cocaína e não estava mais consumindo álcool, relatando ter "crises de abstinência".

"J: Eu sinto muitas dores de cabeça. Eu sinto um frio... Parece que eu tô com febre, mas eu não tô com febre... Eu tremo muito, eu sinto náusea, eu tenho nojo da comida, eu tenho sudorese... E... Só que essa vez foi a pior porque eu passei a ter alucinação... Eu tive mania de perseguição... Achei que tinha alguém me seguindo... Eu vi escorpião na minha casa, aí quando eu usava, eu achava que tinha bichos andando em mim ... Aí eu saia na rua porque tinha medo que ficar em dentro de casa... Só que aí na rua eu tinha mais medo ai... Porque eu achava que tinha uma pessoa me seguindo e que a qualquer momento ia aparecer um escorpião e ia me picar... Sabe eu sentia ele andando no meu corpo... E foi aí que eu pedi ajuda porque eu não aguentava mais essa visão... Tava achando eu tava enlouquecendo, mas ainda sim... Mesmo sabendo que eu ia passar por tudo isso... Eu não conseguia não usar a droga [cocaína]".

Juliana narrou que nessas crises teve "alucinações" e "mania de perseguição" em meio a sensações físicas relacionadas à falta da droga. Essas experiências foram descritas como "bichos andando em mim" e a sensação de achar que "alguém a estava seguindo". Essas experiências foram narradas com muita aflição e sensação de enlouquecimento, em uma experiência que pareceu análoga à de Marli com relação ao uso intenso e prolongado do álcool. Juliana atribuiu todas essa sensações ao consumo de cocaína, que apesar de ter vontade parar de consumi-la, não se sentia capaz de fazê-lo. 
“J: A cocaína... Eu não conseguia não usar... Eu sabia que eu ia ter essa crise de perseguição, de alucinação... Mas eu não conseguia não usar. E ai foi... Agora eu to aguardando uma internação numa clinica pra desintoxicação".

A mudança no modo como Juliana sentia em relação à cocaína "antes" e "depois" de aderir ao

tratamento no CAPS AD influenciou nessa mudança de compreensão sobre o consumo de drogas, influenciando também seu vocabulário a respeito de suas emoções, de maneira a se apropriar do discurso médico-psiquiátrico. A influência desse discurso sobre as experiências de Juliana agregaram sofrimento a ela, de maneira que "antes", a droga era vista como um recurso para lidar com sofrimentos psíquicos intensos relacionados às suas emoções, ampliando sua capacidade de agir diante deles. "Depois", ela passou a ter descrições circunscritas pelo discurso médico-psiquiátrico, enfraquecendo a versão de que esse consumo era um recurso que ela tinha. De maneira contrária ao que foi narrado por Marli, em que o discurso médicopsiquiátrico não foi para ela motivo de aumento de sofrimento, mas de reorganização das possibilidades de ação. Para Juliana, a consequência desse novo posicionamento, para Juliana, foi a intensificação de sentimentos de desvalorização da própria experiência, que passou a ser descrita como uma "dependência" pelo discurso médico-psiquiátrico. Assim, para ambas as participantes, esse discurso significou uma redução das possibilidades de descrição de suas próprias experiências, "antes" indicavam alguma autonomia e “depois" passaram a indicar uma diminuição da capacidade de agir, sendo essa autonomia substituída pelo discurso prescritivo do tratamento.

$\mathrm{Na}$ sua construção narrativa, também esteve em jogo a questão da disponibilidade de dinheiro compra de cocaína, que era visto como um limite ao consumo da droga, ainda que um limite precário e insuficiente.

“J: (...) É como se você... É como quando você tá com fome que você quer comer... É isso...

F: E aí você para pra pensar... Você fica na dúvida...

J: Não... Eu não penso...

F: To com fome, quero comer, vou comer...

J: Só que também só se eu tiver o dinheiro... Se eu não tiver o dinheiro eu controlo. Porque eu não peço fiado... Porque eu não acho certo isso. Porque eu não to indo comprar doce na padaria. Entendeu? Eu não compro fiado. Eu não vendo nada meu pra poder usar. Eu nunca tirei nada de dentro de casa meu pra poder usar. Dessa fissura da droga..."

Ao mesmo tempo em que a cocaína tinha um sentido de "poder" não se sentir sem valor e triste, ela também tinha como sentido o "poder" do dinheiro ou da disponibilidade de dinheiro para comprar droga e o 
controle sobre ela, numa relação de reciprocidade que não sentia ter em outras relações, como por exemplo, com o irmão. Embora essas relações não se equiparem, para Juliana, simbolicamente pareceram manter relações de sentido com o controle dos sofrimentos psíquicos e a sensação de impotência.

A partir de uma rede de relações mediada pelo consumo de drogas, o sentido atribuído à cocaína "antes", era de emprestar "poder" à Juliana, ainda que ilusório. Como ela mesma disse, "não estava indo comprar doce na padaria”, evidenciando que não era uma atividade ordinária e feita por todos de seu círculo social. Esse sentido pareceu análogo ao que Jorge falou sobre o consumo de maconha, como algo "particular". Em um jogo simbólico, Juliana se posicionou a partir do discurso proibicionista, tendo a percepção de que o consumo de drogas não era amplamente legitimado, posto que era ilegal, envolvia riscos, diferentemente de ir à padaria, o que era uma atividade ordinária e amplamente legitimada socialmente. Ela se descreveu como não podendo ter "dinheiro na mão". A partir do posicionamento como "dependente", a capacidade que ela tinha de agir passou a ser tutorado pelo marido, e pelo cartão de crédito. Passou a se descrever como não tendo controle sobre o gasto do seu dinheiro com o consumo.

"J: Precisa ter o dinheiro pra isso. Tanto que eu combinei com meu marido, não deixar dinheiro comigo mais. F: E ele?

J: E ele concordou. Só com cartão de crédito".

Interessante o papel do cartão de crédito nesse campo, porque ele é um método cada vez mais usado para fazer compras, mas como o uso de cocaína é proibido, ela não pode ser comprada com este cartão, o que pareceu retornar em parte a capacidade de controle do consumo à Juliana, mas que talvez. Se o consumo da cocaína fosse uma prática legalizada, essa estratégia não funcionaria. Apesar de poder ser uma estratégia eficaz de redução de danos, pelo menos no caso da narrativa de Juliana, em conjunto com o tratamento orientado para a abstinência fornecido pelo CAPS AD, não pareceu que esse serviço problematizasse os modos de vida baseados no consumo crescente e seu como impactando no modo como Juliana constrói seu consumo de cocaína. Bourgois \& Schonberg (2009) discutem que o discurso médicopsiquiátrico se utiliza de uma lógica neoliberal relativa ao tratamento do consumo, que se apropria de formas de vida e passa a descrevê-los como "doentes". Esses autores discutiram que simultaneamente esse discurso 
gera um "poder" e uma "violência simbólica" nas subjetividades das pessoas atendidas nessa lógica de tratamento, porque persuade os indivíduos a culparem-se a si mesmos por sua vulnerabilidade e sofrimento encorporados, impostos política e institucionalmente.

Esse autor (Bourgois, 2000) discute sobre os modos muitas vezes contraditórios com que as relações de poder operam nas ciências da saúde, refletindo ainda que esse campo parece adotar a perspectiva da redução de danos e riscos por meio de técnicas específicas. Argumenta que, por vezes, essa perspectiva parece camuflar julgamentos morais por trás da objetividade médica, alertando para o potencial dessas práticas em que se perde de vista um quadro mais amplo e complexo relacionado ao modo multifacetado são operados e reproduzidos sofrimentos sociais. Para ilustrar uma versão de quadros mais amplos que parecem circunscrever os sentidos do consumo de Juliana, interessa retomar acontecimentos anteriores ao período de tratamento. Lidava com um sentimento muito forte de desvalorização e solidão já presentes "antes" do tratamento, sentimentos que ela disse sentir "desde sempre", buscando diferentes drogas ao longo do seu percurso de vida para lidar com ele, segundo a sua narrativa.

Juliana contou que sempre se sentiu "excluída" das rodas de amigos e também em relação à família e durante a adolescência apresentou sentimentos de vergonha com relação ao corpo, que nesse período se modificava. Narrou isso de maneira emocionada.

“J: Muito... Uma amiga só eu tinha...Você vê, eu era excluída... Eu era excluída das brincadeiras... Dentro de casa estavam sempre me cha... Me colocando apelido. No começo porque eu era magra... Depois eu engordei... Aí era porque eu estava gorda. (choro). F: Mas era algo de brincadeira? Se sentia que era algo de brincadeira ou não?

J: É... Faziam brincando, mas me machucava... (choro). Me fazia mal”.

O sentimento de inferioridade vivido na adolescência vinha de apelidos criados a partir de discursos sobre o gênero feminino e ideais de corpo difundidos na cultura ocidental, com grande repercussão na cultura brasileira, reproduzida por veículos midiáticos (Goldenberg, 2005). Eles provocavam sentimentos, na sua adolescência de não conformação consigo mesma para além daqueles próprios da fase de adolescência, sentidos como uma carga a mais, que ela descreveu como "um pouquinho de vergonha de tudo". Esse momento coincidiu com o início do consumo de drogas. 
“J: (...) Ai quando eu entrei na minha adolescência...Eu tinha um pouquinho de vergonha de tudo... Eu tinha vergonha que as pessoa notassem... Porque as pessoas notassem que meu corpo estava mudando e isso virava motivo pra piada, como sempre. Então eu não usava roupa de menina... Eu me vestia como moleque... Eu usava bermudão camiseta.. Pra esconder meu corpo que eu tinha vergonha. Eu tinha medo que alguém percebesse e fizesse piada... Sabe, virasse motivo de piada. E foi ai que eu comecei a usar droga pra me socializar... (choro)..."

Diante de expressões da família e amigos apoiadas em discursos rígidos sobre o gênero feminino correntes, o consumo de drogas funcionou, não só como estratégia de socialização, mas também linguagem do corpo em transformação na adolescência. Na narrativa de Juliana, seu corpo foi alvo de provocações, ainda que "brincando". Foram reproduzidos discursos sobre gênero e corpo que desviavam da norma idealizada (primeiramente Juliana era magra demais, depois gorda demais), tendo impacto negativo na sua subjetividade. Isso dificultou a construção de descrições de si mesma como digna de valor. Essa questão, em sua narrativa, pareceu circunscrever não somente as compreensões sobre si mesma, mas também a sua relação com outras pessoas, de maneira a sentir "vergonha" de si mesma diante dos outros. O consumo de drogas, nessas relações, pareceu participar também como uma forma de lidar com esse sofrimento psíquico e social como discutido por (Vargas, 2001) "não é apenas a dor que deve se calar" com o consumo, "mas também, e principalmente o próprio corpo", referindo-se ao processo de medicalização dos corpos que tem implicações na subjetividade e nas construções sociais sobre corpo "saudável" e por extensão, "bonito".

Juliana lidava com a desvalorização de si mesma mediando suas relações com descrições de si e com outras pessoas pelo consumo de drogas. O consumo de drogas pareceu ser para ela a ação e a linguagem possíveis diante do paradoxo em que se encontrava. As drogas que consumia pareceram funcionar como dispositivos por meio dos quais ela era capaz de agir no contexto onde se encontrava. Sua narrativa pode ser conectada à de Marli e à Flora por diferentes perspectivas, por exemplo, quando interpretei que elas pareceram sofrer com discursos rígidos sobre gênero feminino, onde o consumo de drogas pareceu ser o meio pelo qual foram capazes de agir diante do sofrimento psíquico e social, submetendo-se por um lado a esses discursos e resistindo a eles, por outro lado, por meio do consumo de drogas. Marli e Juliana pertenciam a gerações diferentes, enquanto Flora se distanciava das duas em termos econômicos e sociais. As três participavam do mesmo serviço de tratamento, o CAPS AD, embora fizessem usos de drogas 
diferentes, sendo alvo também das mesmas descrições :eram usuárias de álcool e drogas, o faziam de maneira considerada problemática e necessitavam de intervenções em serviço especializado e público, no sentido de diminuir os problemas que apresentavam, sendo estes de ordem psíquica, mas também social.

Os impactos dos discursos sobre o gênero feminino nas subjetividades das três mulheres também foram diferentes. Em relação à entrada no tratamento, para Marli, ter sido posicionada como "dependente" do consumo do álcool, significou para ela uma "salvação", se apropriando do discurso médico-psiquiátrico como possibilidade de viver e superar o sofrimento vindo, segundo ela, do consumo excessivo de álcool. Para Flora, a entrada no tratamento foi uma das poucas possibilidades oferecidas a ela de acesso a direitos e reconhecimento social, estando imersa em uma zona de abandono da qual seia muito difícil sair sozinha. Para Juliana, o impacto de ser posicionada como usuária do CAPS AD foi de reforçar crenças de incapacidade e desvalorização de si mesma. Para as três, o discurso médico-psiquiátrico pareceu circunscrever possibilidades de vida (Biehl, 2008), centralizando o problema em aspectos mentais, individuais, substituindo, inclusive, o modo como expressavam as próprias experiências e resistiam ao sofrimento psíquico e social, sendo oferecidas as mesmas respostas institucionais, ainda que apresentassem demandas diferentes.

Bruno

Bruno desde a infância fazia uso de álcool, comprando bebida com o tio, padrasto e amigos, fazendo uso compartilhado com eles. Essa situação também foi encontrada nas narrativas de Fabiano e Rogério entre outros participantes em que, grande parte dos familiares das pessoas que receberam o diagnóstico duplo faziam uso de drogas (Bradizza \& Stasiewicz, 2003). Pela centralidade do consumo do álcool nas relações sociais da cultura brasileira, e porque não latina, mundial, fazer consumo desde a infância e início da 
adolescência dos participantes fazia parte de práticas familiares comuns nos meios em que frequentavam (Canet et al., 2003).

"F: Nessa época você já fumava?

B: Ouch... Já... Isso...

F: E também já bebia na cerveja do padrasto...

B: É... Sim...Cerveja... Aí num... Aí tem meu tio (fala um nome)... Faleceu também...

F: Também era um tio legal?

B: Isso! Ele pedia pra eu buscar uma corote... Nóis comprava e bebia junto... Nói...

F: Então era gostoso?

B: É, nós tomava, fazia caipirinha...

F: Era um momento gostoso de estar com o tio?

B: É... Tinha os amigos também... Conversava... Ouch... Aí ficava querendo dormir...."

Como discutido na narrativa de Fabiano, o aprendizado desse uso também passou pela

experimentação de diferentes subtipos de bebida. Bruno consumiu álcool de diferentes maneiras em diferentes momentos da sua infância e adolescência. Inicialmente consumia sob uma forma palatável a uma criança, como a caipirinha, depois passou a beber cerveja e pinga pura, cujos sabores são diferentes, mas que foram sendo encorporados (embodied) ao paladar de Bruno e às suas práticas de consumo. Os aprendizados sobre os efeitos produzidos pela droga construíram e redefiniram os efeitos como prazerosos e também o manejo do consumo de maneira a alcançar efeitos desejados e diminuir efeitos indesejados, ainda que no longo prazo, o consumo fosse prejudicial.

Esse consumo inicial de álcool, além de ter aspectos afetivos envolvidos nas conversas com o tio em termos de socialização, provocavam sono em Bruno. Segundo Bruno, as situações por que ele passava o deixavam nervoso, sendo uma característica que pareceu acompanhá-lo por toda a sua trajetória de vida narrada na entrevista. Ele contou várias situações geradoras de sofrimentos psíquicos que chamou de "nervoso" como presença de brigas na família, perdas de pessoas afetivamente importantes para ele, experiência de assaltos e tiros quando trabalhava.

"Eu já trabalhei de farmácia...

F: De farmácia o quê?

E: De farmácia que atende...

F: Ah! Atendente de farmácia.

E: Aí só que era lá no Jandaia era muito assalto. Aí não sei se é bala... Num... (voz embargada)... Aí num dia eu tive uma briga feia em casa, Ouch... O namorado da minha mãe também não gosta de mim, eu também odeio ele... Ouch... Ouch..." 
No entanto, pareceu que o consumo do álcool foi transformado não somente pela associação ao gosto dessas bebidas, ao aprendizado do uso ou por causa da legitimidade desse consumo perante as relações familiares e sociais dele e na cultura Brasileira. Bruno disse que se qualquer coisa o deixava "nervoso", ele "já tomava uma dose" ou tinha vontade de fazê-lo.

"B: Aí depois nós começou a tomar caipirinha... Com limão... Aí eu fui crescendo assim... Aí esse vício do álcool pegou eu dum tal jeito que eu até tento lutar contra, mas se por alguma coisa me deixa eu nervoso e eu tiver um real eu já tomo uma dose de um real... E... Ouch... Muita briga, briga com irmão e... Confusão... Muitas... Sei lá... Medo de alguém querer me matar...

F: Vem na cabeça isso aí? Ou você já foi ameaçado?

B: Ah, na escola uma vez o menino falou que ia puxar o revólver pra mim..."

Nesses momentos, falou que tentava lutar contra a vontade de beber, mas não conseguia, sentindo-se confuso no ambiente onde se encontrava. Ambiente esse que associou a situações de violência, que misturavam brigas com o irmão, o medo de sofrer violências e lembranças da infância que o faziam sofrer. Todas essas sensações se misturam em imagens violentas, construídas em um contexto social em que o consumo fazia parte, de maneira análoga á narrativa de Fabiano, mas também Rogério, Flora e Marli.

Ao falar sobre a sensação de beber, Bruno contou que ela não era boa, embora persistisse no consumo porque se sentia mais "calmo" sob o efeito da bebida. Era como se ao beber ele fosse capaz de transformar o modo como via as situações enfrentadas, dando leveza a essa experiência, misturando realidade e fantasia. Isso também foi narrado por Flora em relação ao crack e também por Jorge diante da “depressão", em ocasiões sociais em que o consumo tinha o papel de suspender o sofrimento vivido.

"F: E o álcool o que você sente quando você bebe?

B: Ah! Eu falar assim sensação boa não tem nenhuma.

F: Não?

B: Não. Eu fico calmo quando bebo. Aí quando eu não bebo eu sou uma pessoa mais calma, mais inteligente, eu gosto de brincar com criança... A gente acha os beija flor tudo bonitinho... Anjinho... Os anjinho vende por dois reais. Falei vou comprar um corote... Vou tomar uma dose, vou tomar um corote... Mas agora eu estou diminuindo..."

Bruno também contou que tinha sentimentos de "nervoso" que "vinham de dentro", "vem do nada" e

o deixavam "agressivo" e "sem saber como conversar com as pessoas". Nesses momentos pareceu que ele perdia o controle sobre suas ações.

"B: Ah só se for esse nervosismo que me dá tem hora que eu fico muito bravo... Sei lá o que é...

F: Como que é isso?

B: Ah eu... É uma coisa que dá por dentro assim e eu não sei como conversar com as pessoas. Porque eu já bebi um outro dia ai... Não sei se é vontade de beber no dia... Sei lá fico meio agressivo... Mais (Bocejo)... (trecho inaudível). Aí manda eu ir embora eu vou embora... Mas sei dizer que é uma coisa...

F: Sobe uma coisa, uma raiva? Não precisa ninguém te provocar. Ela... Já é seu assim... 
B: Vem de dentro... Normal... Não sei... Ontem eu cheguei eu fui no bar do... Era umas duas horas...

F: Pra dar uma...

B: É antes... Antes... Ai ontem eu já fiquei agressivo... Ai dei murro na parede...

F: Porque as ideias na cabeça começam a ficar confusas ou é alguma coisa de fora que faz...

B: Não sei... Vem do nada..."

Esse descontrole vinha em um contexto em que pessoas ao seu redor também estavam fazendo uso de

drogas. No entanto, na sua narrativa, o que pareceu diferenciar seu modo de perceber o impacto da droga

foram, por exemplo interpretações que fazia de falas de familiares, de maneira a se tornar agressivo. E em

uma narrativa sequencial à apresentada acima, ele ilustrou isso por meio de uma cena em que a mãe queria

jogar fora a pinga dele, mas ela também fazia uso de cerveja. Também o namorado dela, segundo ele, fazia

uso de "farinha"[cocaína]. Como reação à intervenção da mãe, ele falou de uma maneira indignada, mas

também em meio a bocejos, e "deu um murro que estourou todo guarda roupa", respondendo não somente a

essa intervenção, mas ao pensamento de que talvez a mãe quisesse que ele "sumisse", para que ela ficasse

com seu namorado.

"F: Entendi... E isso sempre foi assim?

B: Sempre.

F:Vamos supor, você bebeu ontem foi bastante mais, de certa maneira você esta acostumado. Aí essa sensação...

B: (bocejo)... (trecho inaudível)... Eu tava nervoso já. Ela [mãe] falou, vou jogar essa pinga fora, eu falei, eu jogo a cerveja de vocês fora? Não jogo. Aí ela falou alguma coisa pra mim, eu dei um murro que estourou todo guarda roupa. Ele ficou quebrado, acho que ela quer que eu sumo pra ela ficar com a cervejaiada dela e com o namoradinho dela que usa farinha. Nem sei se ela tá usando, mas eu acho que não. Porque só se for pessoa burra porque uma pessoa que usa e ter relação com outra pessoa dá na mesma..."

Seu irmão também bebia, sendo descrito na narrativa de Bruno que ele e a mãe eram pessoas que também faziam uso de drogas em grande quantidade. No entanto, eles não se identificavam como fazendo uso problemático delas, diferentemente do modo como percebiam o consumo de Bruno.

"E: Meu amigo é meu irmão gêmeos. Mas ele não sabe se controlar, ele quer me bater. Aí eu tenho que bater nele.

F: E você fica agressivo quando você bebe?

B: Não. Fico calmo, mas aí meu irmão que bebe não sabe se controlar. Aí ou é ele ou é eu que apanho. Que ele já bebeu eu já bebi né...

F: Entendi. E ele também faz tratamento?

B: Não, ele diz que tá trabalhando, agora não sei do que.

F: Só você da sua família que faz tratamento com drogas?

B: Aqui é.

F: Porque fazia em outro lugar?

B: não.

F: E outras pessoas você identifica que tem problemas com drogas na sua família?

B: Minha mãe... Deve ser de família...

Por um lado os familiares pareceram recriminar o consumo de drogas de Bruno. Por outro, eles

pareceram agir como ele, fortalecendo aspectos que legitimam a manutenção do consumo e da dificuldade 
de cuidar de si. Um exemplo foi a situação em que a mãe bateu nele e ele não respondeu, por sentir respeito por ela. Ao contrário, em outra situação, ele se sentiu desrespeitado, tornando-se "agressivo", "nervoso" e com vontade de beber.

"B: Eu (bocejo). As vezes eu fico o dia inteiro dentro de casa, na rua ,sem comer nada... Só espero minha mãe chegar... Fico com saudade esperando ela chegar...

F: Tirando essa briga com o namorado dela, você se dá bem com ela?

B: Dou. Respeito.

F: É? Sempre foi assim?

B: Sempre... Ela me bate eu não reajo... Me dá vassourada... Não reajo..

F: Mas ela faz porque isso?

B: Porque eu as vezes eu to bêbado... 'Eu falei pra você não beber!' [imita a voz da mãe]... 'Tá bom mãe, tá bom!' [respondendo ao pedido da mãe]... Ela me dá tapa na cara... Aí ela fala assim, que foi? Ai eu falo, dá do outro também... (risos)... Aí ontem ela me jogou na cama, vai dormir, vai dormir... Aí eu tentei dormir, mas não consegui.

F: Então vocês se estranham um pouco, mas se dão bem... Conseguem conviver?

B: É com a minha mãe. Agora se aquele... Se o namorado dela tentar alguma coisa, eu já estava pensando em pedir o revolver pro (fala um nome)..."

A vontade de beber muitas vezes vinha como urgência e um forte sentimento de "nervoso" também na presença de crianças no bar. Ele explicou que existiam, para ele, "jeitos certos" de brincar com crianças.

Exemplificou um “jeito certo", falando de brincadeiras onde regras eram respeitadas.

"B: Aí eu não gosto que criança vem brincar comigo, porque dá vontade de querer tomar um...

F: Qual é a relação entre criança e tomar uma...

B: Porque criança tem que brincar com criança. Eu brinco com criança, mas sabendo brincar certo.

F: Como que é brincar errado?

B: Meu irmão tava ensinando uns golpes de capoeira pra ele, aí ele mandou um... Aí eu falei, então vai outro... Cinco minuto ... Ouch ...aí eu dei um nele aí ele me deu um monte... (risos). Aí eu falei, parou, parou... (risos)

F: É isso que é brincar errado... (risos)

B: Os meninos brincam até certo porque eu falo, na cara não vale".

Brincar "errado", no entanto, foi uma questão de difícil abordagem com Bruno, sobre o que, eu perguntei se tinha a ver com situações de abuso, me referindo a abuso sexual, além dos abusos físicos que sofria. Ele respondeu que "não se lembrava", "sentindo vergonha" em conversar sobre isso.

"F: Era muito criança? Você já teve... Você falou que... Me deu aqui a... Fiquei pensando... Você falou de brincar certo e brincar errado com criança, brincar errado é abusar?

B: Isso.

F: Você já foi abusado?

B: Acho que não lembro.

F: Não.

B: (bocejo). A gente, falar assim, sente vergonha em dizer né...”

Bruno sentiu vergonha em dizer se já fora vítima de abuso, mas a cena narrada anteriormente sugeriu que o consumo de álcool poderia estar relacionado a lembranças dessa experiência. Essa questão foi abordada por participantes do estudo de Thornton et al. (2012) como uma estratégia de "esquecer" situações 
de abuso, e no estudo de Charles \& Weaver (2010) como estratégia de lidar com situações de violência. Percebi na entrevista que Bruno não estava à vontade para contar sobre essa experiência, portanto, não explorei mais, de acordo com o compromisso ético combinado no rapport da entrevista.

Essas experiências de "nervoso" poderiam ser descritas pelo discurso médico-psiquiátrico como elementos que se relacionavam a lembranças de violências sofridas, descritas como estresse pós-traumático (Sou \& Dantas, 2009). A partir de uma leitura pela ótica do discurso médico-psiquiátrico, pode-se dizer que Bruno apresentou experiências como esquiva e distanciamento emocional. Narrou sua experiência em meio a bocejos e atribuía a lembranças e sensações corporais o que chamou de "nervosismo", estas sensações foram relacionadas como motivação para o consumo intenso de álcool.

Ao invés de me orientar por esse diagnóstico, que ele não recebeu, nesse trabalho preferi me verter para compreensões sobre violências presentes no nosso cotidiano e que circunscrevem formas de vida, provocando sofrimentos sociais. Essa escolha de não problematizar o diagnóstico, mas oferecer outras opções interpretativas, inclusive por meio dele, foi feita no sentido de colocar em evidência um ciclo de eventos em que sentimentos descritos pelo discurso médico-psiquiátrico como ansiedade, pareceram fazer parte das motivações relacionadas ao contexto e das construções de sentido do consumo, na narrativa de Bruno, em que a agressividade e a irritabilidade passaram a ser um motivo de estigma e potencialização do e pelo consumo, em um ciclo retroalimentado.

Da mesma maneira que venho colocando diagnósticos psiquiátricos em suspensão, focalizando a discussão nas experiências vividas pelos participantes deste estudo, também senti que era importante oferecer outras opções interpretativas relacionadas aos sentidos e significados do consumo de drogas, suspendendo o status de "doente mental" e de "usuário de drogas". Talvez, como na narrativa de Vitor, se Bruno fosse visto por outro lado do prisma, outras possibilidades e descrições de si poderiam emergir.

A partir da análise de sua narrativa foi possível perceber que Bruno se encontrava em um ambiente agressivo e o consumo compulsivo de álcool narrado por ele, assim como Fabiano, Rogério, Marli e Juliana 
pareceu ser uma possibilidade de resistência à violência encontrada por eles em seus cotidianos. Estes participantes, ao longo do tempo e de suas experiências, aprenderam a lidar com essas situações e as emoções vindas deleas, que poderiam ser descritas pelo discurso médico-psiquiátrico como fóbicas, agindo sobre elas a partir do consumo de drogas, como encontrado no estudo de Canet et al., (2003) de que características sub-clínicas relacionadas a ansiedade importariam na compreensão do quadro apresentado, em termos do discurso médico-psiquiátrico.

De maneira análoga a Fabiano, Bruno estava inserido em um ambiente que reservava pouco espaço para a expressão do sofrimento e o consumo pareceu linguagem possível para dar voz a ele, sendo essa, aquela escutada pela equipe do CAPS AD. Figueira \& Mendlowicz (2003) comentaram que transtorno de estresse pós-traumático vem sendo pouco diagnosticado aqui no Brasil, sendo um diagnóstico mais comum nos Estados Unidos, embora o Brasil apresente números expressivos de violência. (Young, 1995), por outra perspectiva, comentou que a construção social deste diagnóstico remetia a um momento específico na história dos Estados Unidos, estando relacionado ao tratamento de ex-soldados de guerra no país, que são pessoas atendidas por sistemas públicos de saúde, tendo importância também em termos previdenciários. Este autor considera que essa questão social contribuiu para que esse diagnóstico fosse incluído em manuais de psiquiatria. Com essa reflexão importaria discutir que implicações podem existir quando se coloca em evidência a valorização, na RAPS, do consumo de drogas sobre os sofrimentos psíquicos quando tomados como sinônimos de transtornos mentais nessa população estudada. Como foi possível perceber, entre os participantes, estes guardavam características sociodemográficas semelhantes, embora tivesse características clínicas relativamente distintas, sendo vistos pelos diversos serviços da RAPS de maneiras também diversas.

$\mathrm{Na}$ experiência de Bruno, beber estava presente também nos contextos de trabalho. Ele narrou queteve trabalhos que caracterizou como aqueles que "ninguém queria", inclusive de limpar "caixa de gordura" e "matar insetos". Trabalhos como esses foram também discutidos no estudo de Duarte (1986) como tendo importantes repercussões sobre as descrições de si, nas pessoas que desempenham atividades, 
como Bruno disse "que ninguém queria", construindo sentidos também sobre o sentimento de "nervoso", descrito por Bruno como motivação para beber.

"F: E aí você trabalho catando papel e depois você trabalhou de que?

B: Eu trabalhei matando inseto ali nos [bairro próximo ao CAPS AD]...

F: Matando inseto?

B: De... Za... (Gaguejo)...

F: Dedetizando? [meneia afirmativamente]

B: Aí, começaram a colocar eu pra limpar caixa de gordura. Aquelas caixa de gordura funda que ninguém queria... Eu não conseguia... As vezes eu bebia e tinha que subir num prédio muito alto... Pra limpar as caixas... Ouch... As caixas d'água...”

Era uma época, segundo ele não tinha muito controle sobre o dinheiro e costumava beber só aos

finais de semana, quando pegava parte do salário para gastar com o consumo. Essa era uma estratégia que usava para se controlar, que ele retomou como buscando "pegar o controle" a partir da entrada no tratamento no CAPS AD. Embora Bruno tenha narrado fazer uso de uma estratégia de redução de danos, análoga ao que Juliana narrou, seu posicionamento quando fazia isso era oposto ao dela. Quero ressaltar o que Bourgois (2000) discutiu sobre o paradigma da redução de danos, como um terreno limítrofe entre o Estado e os aparatos médicos se interpõem à autonomia do sujeito. Ressalto a importância de olhar para essas atitudes cotidianas de redução de danos, problematizando não a aplicação das técnicas, mas discursos e práticas que estão por trás deles e se eles não são novos modos de buscar o controle do discurso sobre as experiências.

"F: Esse de limpar a caixa de gordura você bebia pra dar conta do cheiro? Pra dar conta do serviço, ou não era uma coisa que você gostava de fazer?

B: Assim, eu trabalhava a semana inteira mas acho que eu não bebia eu bebia só no final de semana. Aí chegava na sexta feira eu fala pra chefe... 'Ow pode fazer um vale pra nóis?' 'Quanto você quer?'.... Eu não lembro quanto eu pegava... Acho que era 40... Aí ela dava... Agora eu to pegando o controle..."

Outro aspecto que pareceu relevante explorar foi o consumo do cigarro quando Bruno, e também outros participantes narraram sentirem-se "nervosos".

"B: Ah, o cigarro eu (bocejo)... quando eu ficava nervos eu fumo um cigarro (bocejo)... (trecho inaudível)..."

Lembrou que com os avós aprendeu a fumar cigarro e essa foi uma lembrança para ele importante,

em que associou o consumo aos avós desde pequeno.

"B: Ouch... Ele fumava aquele... Ouch... Fumo de corda... Ouch... Eu ia quando eu tinha dez... Doze... Ouch... Eu ia comprava um pouquinho com ele e começava a fumar. A primeira vez que a (Fala o nome da mãe) viu eu tava fumando um cigarro dela, o (fala a marca) ela me deu um tapa na oreia... Ouch... Mas a minha avó não deixava ela me bater...

F: Era uma forma de você lembrar do seu avô?

B: Era... (voz embargada)...

F: Fumar fumo de corda? Então era gostoso?

B: Eu gostava de fumar causo que eu fumava desde pequeno... Ouch... (suspiro)..." 
Quando se lembrou dos avós, pessoas que eram referência para ele na infância, contou que sentia muita falta deles e que tinham morrido há algum tempo. Nesse momento da entrevista ele se entristeceu, dizendo que tinha dificuldades de dormir à noite, pensando neles.

"B: Ela morreu já faz tempo... (pausa)... Eu... (voz embargada)... Sinto muita falta dela... Saudade... (Choro)...

F: Ela era uma boa vó? Te dava carinho?

B: Ouch... (Choro)...

F: Você era muito próximo dela?

B: Hã?

F: Você era muito próximo dela?

B: Era... (voz embargada; trecho incompreensível)...

F: Cuidava de você? (pausa)... Lembrança boa de você então...

B: Eu não consigo dormir pensando nela... (choro)... No meu vô... Eu não consigo dormir... (Choro)... Ouch..."

Ele fez uma comparação entre os sentidos atribuídos aos efeitos da maconha e do cigarro, contando

que preferia a maconha, precisando de menos quantidade para alcançar efeitos desejados, enquanto o cigarro, segundo ele, "dá câncer depois de estourar o pulmão", se remetendo ao discurso médico sobre saúde física e vida saudável corrente e que associa o consumo de cigarro a estilos de vida de risco(Spink, Lisboa, \& Ribeiro, 2009).

“B: Não sei cigarro dá câncer depois de estourar o pulmão... A maconha não é só um traguinho e pronto... (bocejo)...

F: Dura bastante o barato?

B: A sensação é bastante demorada. É um lance de meia hora mais ou menos”.

Bruno gostava de fumar maconha, que, para ele, se fosse possível deixaria de fumar até o cigarro, valorizando aspectos da personalidade que ficavam alterados quando ele fumava maconha, como comentado por Jorge e Vitor.

"F: E o que te dá vontade de fumar maconha?

B: Isso eu não sei responder...

F: aparece você fuma.

B: É, ás vezes tá... To passando assim, aí to tomando uma pinga e falo, o (Fala um nome) posso dá um trago, só um trago? Aí eu do um trago e já...

F: Só um trago e já dá barato?

B: É já... Parece que a gente muda...

F: E fumar só maconha... Você fumaria só a maconha?

B: Se você o caso seria... Largava até do cigarro".

Bruno descreveu o consumo do cigarro como o "vício" que não o levaria a lugar nenhum, pois ele foi perdendo ao longo do tempo a condição de cuidar de si, misturando compreensões sobre o consumo de várias drogas, desde o cigarro, o álcool e o crack.

"F: E aí... Sempre foi assim ou você foi perdendo essa condição de cuidar do seu dinheiro a medida do tempo?

B: Fui perdendo... Fui perdendo porque eu comecei a tomar álcool né... Aí eu comecei com o crack. Aí eu fui perdendo o controle. Se eu pegava 50 reais eu já comprava três. 
F: E você conseguia guardar? Por exemplo, pegava o sei lá... trê, quatro pedras e sei lá... Fuma uma...

B: Não...

F: Tudo na hora...

B: Na hora que você fuma você consegue fumar dez".

Ele encorporou o discurso médico-psiquiátrico sobre a abstinência como meta para atingir resultados satisfatórios com o tratamento, assim, o importante para ele era "não usar", ficando ainda insatisfeito em ter “apenas” diminuído o consumo das drogas que fazia uso. Essa desvalorização do discurso sobre a redução do consumo como um resultado positivo do tratamento, de certa maneira encobria ganhos com a redução de danos decorrente dessa diminuição do consumo, posto que desejava "parar de uma vez" com esse consumo.

“B: É o problema é você num usar... Porque se você usar, perde o controle. Porque eu catei quatro reais, deu cinco aí comprei um (trecho inaudível)... Aí peguei cinco reais, comprei um maço de cigarro e dei o dinheiro pra minha mãe.

F: E então você falou, pera aí, vou devagar aí...

B: É eu... Se controlei... Porque se eu catasse quatro reais eu ia pegar mais um pra usar, mais aí eu pensei não, ela perguntou se eu queria jantar eu falei, põe pouco, aí eu só comi a carne e as batatas que tava na vasilhinha lá. Ela põe pra mim, 'você não vai comer?' Eu falei, 'só quero isso só, tá bom vou dormir'.

F: E como você se sentiu controlando?

B: Controlando. Eu não queria nem controlar...

F: Não queria ter que controlar...

B: Parar de uma vez..."

Bruno, no momento da entrevista, se apresentou entristecido com a internação decorrente do consumo de drogas que fazia.

“B: Eu não queria ter ficado internado no [hospital psiquiátrico]. Eu queria continuar fazendo esse tratamento... Não consigo ficar o dia inteiro sem (voz embargada; trecho incompreensível)... Eu chego na rua e fico nervoso, tomo uma dose de pinga, fumo o meu cigarrinho aí hoje meu irmão foi lá conversou muito comigo me xingou foi embora..."

Essa internação pareceu reforçar o ciclo de desvalorização dos esforços que vinha fazendo para controlar o consumo, ainda que fossem insuficientes para que ele retomasse o controle sobre a própria vida, motivo que o levava a permanecer em tratamento no CAPS AD. O CAPS AD, ao contrário da internação, pareceu ser para ele uma alternativa à rua, onde sentia que estava mais exposto e vulnerável.

"F: Você gosta de vir aqui [no CAPS AD]?

B: Adoro. Aí quando sai pra rua... Não sei que... Hum... Sabe... Dá uma coisa... Que sei lá... O... Eu fico olhando esses carros andando de luz acesa de dia quase atropelando a gente... eu ando nessa [nome de uma rua] aí óh... quase perigo de ser atropelado... Ouch..."

Pareceu que por toda sua trajetória de vida, o álcool pareceu ser um ponto de sustentação, ainda que problemático, diante das dificuldades. Também influenciou na construção de sentidos sobre o consumo de drogas, que estavam relacionados ao sentimento de "nervoso" diante o ambiente social onde Bruno se inseria e também ao sentimento de sentir-se muito mal ao estar diante de crianças, tendo desejo forte de beber 
nesses momentos. Bruno morava em uma favela, vivenciava a falta de dinheiro, o que influenciou na escolha do consumo de crack no lugar da cocaína. Isso também influenciou na construção de sentidos das suas experiências de "alucinações" a partir do tratamento religioso do terror noturno. A narrativa do uso de droga girava em torno das diversas experiências de consumo e nesse sentido, trouxe um repertório de possibilidades de sentidos do consumo e não das vivências de sofrimentos psíquicos.

Igor

Igor começou sua narrativa dizendo que iniciou o consumo de cigarro de tabaco e a maconha com 12 anos, sentindo que era "gostoso", "legal".

"F: Você fuma desde que idade?

I: Desde os doze.

F: Desde os doze? Como foi começar?

I: Maconha também...

F: Maconha também? Começou na mesma época?

I: Mesma época.

Ele iniciou o consumo na escola, afirmando que não foi por influência de seus familiares, que usavam cigarro ou outras drogas, embora seu pai também fumasse, mas foi por uma experiência entre amigos, o que também foi relatado por outros participantes. Lobbana et al. (2010) discutiram que fatores influenciadores no consumo de drogas entre pessoas com diagnósticos de transtornos psicóticos como a disponibilidade dessas drogas no meio social frequentado.

"I: Meu pai sempre fumou.

F: Fumou?

I: Meu pai fuma até hoje.... Mas foi na escola que a gente aprendeu a fumar".

Nesse mesmo estudo, estes autores comentaram que as visões sobre normalidade e legitimidade das drogas se contrapunham entre usar e não usar drogas. Como uma questão compartilhada também por outras pessoas e mesmo aquelas que não receberam diagnósticos psiquiátricos, também Hart (2013) contou que na sua infância costumava fumar cigarro escondido, roubado de pessoas mais velhas que faziam parte de seu 
círculo social. Para esse autor, o que importava naquela experiência era parecer mais velho e impressionar as meninas.

Em uma mistura entre o que é sentido atribuído à maconha e o que é atribuído ao cigarro, Igor contou que sempre teve "prazer, uai!". Afirmava que no início do consumo do cigarro, ele tinha uma "tonteira". (Hart, 2013) também comentou que na sua infância, quando experimentava o cigarro, este o fazia sentir-se “dizzy”, que poderia ser traduzido como tonto, enjoado, referindo-se a essa experiência. Igor, no entanto, como outros entrevistados deste estudo, sentiu que com o tempo, esse efeito foi passando.

"F: Não? E que cê sente quando cê fuma?

I: Ah... Eu sinto prazer uai.

F: É? Dá tonteira ou já não dá mais?

I: Já não da mais a aquela tonteira não".

Para ele, "maconha é da hora!", sentido prazeroso com o consumo também encontrado por (Healey et al., 2009) que comentaram que essa atividade era uma parte importante da vida. Essa compreensão também é comum entre pessoas sem o diagnóstico do psiquiátrico, o que conecta Igor, que teve diagnóstico de transtorno psicótico às pessoas sem diagnóstico algum. A ideia do uso recreativo de drogas parece geralmente negada a pessoas que fazem tratamento de saúde mental.

"I: A maconha é da hora!

F: É da hora? Cê curti? Ah! Ah! Ah!

I: Eu gosto... Eu fumo ainda.

F: Fuma ainda? Quantos cigarros por dia?

I: Um cigarro... Uma maconha.

F: Dá barato?

I: Dá...

F: Demora bastante...

I: Dá um sono...

F: Dá um sono? Dá fome?

I: Da um sono, dá fome... Parece que acostumou.

F: Como assim?

I: O organismo acostumou.

F: Hum... E que hora que cê gosta de fumar?

I: A noite.

F: É? Pra ajudar a dormi ou não?

I: Pra ajudar a dormir também.

F: Também...

I: É porque eu já tomo uns remédios né?

F: E cê toma remédio pra que?

I: Pra dormir.

F: Só durante a noite?

I: Dormir e Ritalina... Pra parar de tremer de manhã... Pra não tomar pinga”. 
Igor atribuiu à maconha, complementando o uso recreativo, a a qualidade de auxiliar no efeito da medicação psiquiátrica prescrita para promover o sono, além do efeito de promover fome. Fumava um cigarro por dia e afirmava que "o organismo acostumou" com a droga, aludindo a uma diminuição dos efeitos da maconha ao longo do tempo de consumo. Também se medicava para diminuir os efeitos da experiência de "parar de tremer de manhã", descrita pelo discurso médico-psiquiátrico como síndrome de abstinência, associado ao efeito do consumo excessivo do álcool. Esse consumo de álcool também se iniciou aos 12 anos, quando ia para a escola e, com os amigos, tomava bebidas alcoólicas. Estar com os amigos pareceu ser atrativo para que frequentasse a escola, pois não gostava de estudar. Entre os entrevistados deste estudo, foi possível perceber que Fabiano vendia drogas na escola, sendo preso por isso, Juliana consumia várias drogas já na época escolar, assim como Bruno, Pedro e Rogério. Entre os entrevistados mais velhos, como Vitor, pareceu que o consumo iniciou após a idade escolar. Embora de gerações diferentes, cujo contexto escolar era diferente, interessa perguntar que alternativas vêm sendo propostas para esse ambiente além do proibicionismo e a culpabilização do indivíduo pelo consumo de drogas? A questão do consumo de drogas na escola vem sendo uma questão bastante debatida entre educadores e profissionais de saúde que trabalham com prevenção do uso nesse ambiente (Ministério da Justiça, 2013).

"F: Tudo foi, mais ou menos, a mesma idade?

I: Tudo aos doze.

F: Doze? E que que aconteceu aos doze... Que que... Como que era aos doze... A vida?

I: Ah! eu comecei a estudar a noite... Ai um monte de gente ia.

F: Hum... Você fumava com os amigos?

I: Fuma com os amigos.

F: Bebia também?

I: Também.

F: Era a mesma turma?

I: Era a mesma turma.

F: Hum... Você curtia estudar?

I: Tsc tsc (som negativo)

F: Não? Ou mais ou menos[meneia negativamente]... Não?

I: Não, nem gostava”.

Igor narrou que o consumo não se iniciou pela pinga, mas pela menta. Como comentado também por outros participantes, como Bruno, esse consumo se construiu ao longo do tempo em decorrência da relação entre o custo financeiro e a relação efeito/dose consumida. 
“I: É... Ah!.. Não começo não era pinga não. No começo era menta... Batida essas coisa.

F: Hm... O que que fez mudar?

I: Ah! É... O... O preço...

F: Que é caro?

I: Sei lá. Foi ficando cada vez mais fraca a menta, a batida... Ai pinga é mais forte né”.

Esse foi um elemento importante para entender o sentido do consumo do álcool para Igor, que passou

buscar uma bebida que lhe oferecesse o que desejava, dentro de suas possibilidades de pagamento. Essa foi uma resposta de Igor, assim como Bruno, Fabiano, Rogério e Flora para com a falta de dinheiro. Como para qualquer pessoa que vive dificuldades financeiras, uma alternativa oferecida pela dita "sociedade de consumo" é a busca por um consumo mais acessível (Jorge et al., 2013).

Igor narrou que iniciara a cocaína mais tarde, aos dezoito anos, com o mesmo grupo de amigos com quem iniciou o consumo das outras drogas.

"F: Quando que você começou a cheirar?

I: Aos dezoito.

F: Aos dezoito? Como que foi essa sensação?

I: É, foi uma sensação diferente né, uma droga mais forte".

Qualificava a cocaína como mais forte que as outras drogas que consumia, e como motivação para o consumo, não soube afirmar porque ficou com vontade de cheirar, embora ao ser perguntado, concordou que poderia ter sido levado pelo grupo para consumir "também".

"F: Mais forte que o que?

I: Que o que eu usava, por exemplo, pinga, batida e maconha.... Era uma outra sensação

F: Hum... Quem te apresentou?

I: Hã... A mesma banca de amigos.

F: A mesma? Todos estavam juntos. Entendi... E que que te deu curiosidade de cheirar?

I: Não sei.

F: Hum... Estava todo mundo lá fazendo e você fez também?

I: Também".

Fiore (2013) fala sobre o consumo na adolescência de seus entrevistados e discutiu sobre o uso como uma forma não só de socialização, mas também de construção desse uso como um evento. Além disso, a motivação para o consumo nem sempre foi uma questão já pensada, em que os sentidos desse consumo já haviam sido construídos, sendo apenas relatados na entrevista (Lobbana et al., 2010).

O consumo de crack também se iniciou em torno dos 18 anos, mas ao contrário de outras drogas, a busca pelo crack, narrada na entrevista foi do próprio Igor, pois ele soube que o consumo dava sensação de 
que “o baguio era bão!", o que o motivou a buscar a droga, mas que não encontrou respaldo na experiência própria, atribuindo efeitos negativos com esse consumo.

"I: O crack fui eu... Eu fiquei sabendo que baguio era bão... Ai eu mesmo fui atrás... E não é bom nada.

F: Não? E com que idade você... Já tava mais velho quando você experimentou o crack?

I: Foi... Mais ou menos quase com dezoito também".

O consumo de crack começou, segundo Igor "chutando o barde", ou seja, com um consumo maior que o experimental, em que a dose vai sendo aumentada ao longo do tempo. Esse início do uso da droga coincidiu com a entrada dela na região onde morava, em que contou que a venda era feita por "pedaço". O status de novidade da droga foi um dos pontos levantados como motivação para o consumo de drogas, segundo apontado por (Jorge, 2013).

I: Não... Quando eu comecei, eu comecei chutando o barde.

F: Aé? Quantas pedras?

I: Ah! Na minha época não vendia por pedra vendia solta.

F: Aé? Como que era como que você fazia?

I: Vendia assim... Por pedaço... Você chegava com 5, com 3, com 10, com 20...

Igor relatou que na época da Copa do Mundo, quando ele já estava fazendo tratamento no CAPS

AD, ele "deslanchou" novamente no consumo do crack. Essa experiência poderia ser chamada de recaída pelo discurso médico-psiquiátrico e que vem sendo considerada como uma parte do processo de tratamento da dependência de drogas (Carvalho, Brusamarello, Guimarães, Paes, \& Maftum, 2011), a partir da lógica adotada por esse discurso.

"I: Na copa do mundo que eu deslanchei... Que usei crack (emburrado, irritado).

F: É? Porque... O que que... Que situação foi essa?

I: Eu ganhei.

F:Você ganhou?

I: Eu ganhei um pedaço bom... Ai fumei”.

Na narrativa de Igor, no entanto, ele a usou porque ganhou a droga de um amigo que "faz" crack, o que ele narrou com certa irritação. Bradizza \& Stasiewicz, (2003) relatou que alguns dos participantes, mesmo depois de abstinentes, tinham dificuldade de evitar o consumo, quando a droga era oferecida.

"I: Foi um colega meu que eu conheço... Ele faz... Crack. ... Ai ele chegou e me deu um pedaço.

F: Hum... Ai você fumou só o pedaço, ou você foi fumando mais?

I: Fumei tudo ué! (irritado)".

Era um "pedaço bom", segundo Igor, pontuando que era um pedaço grande, que ele "fumou tudo, ué!”, considerando a obviedade sobre o comportamento adotado diante da porção de crack que tinha. A 
irritação de Igor destoou do restante da entrevista, pois ele se mostrava bastante tranquilo em relação às perguntas feitas por mim na entrevista. Essa irritação apareceu nas interjeições, no seu modo próprio de contar sua narrativa. Sob o efeito do crack, segundo ele, ele ficava "normal", "parado na minha", mas também com uma "sensação estranha”, de "nóia” após o consumo.

"F: Como que você ficava?

I: Fico normal.

F: Normal. Quieto parado.

I: Parado na minha... Tenho até mais medo da população do que a população deve ter de mim.

F: Porque que você fala isso?

I: Porque eu fico com medo sei lá".

Adicionou um elemento interessante para refletir sobre o significado do consumo de crack para ele.

Sentia "até mais medo da população, do que a população deve ter dele", em uma interpretação própria do sentido que a "nóia" tinha para ele, aludiu ao medo demonstrado pelas pessoas nas ruas onde usuários de drogas fazem consumo. Essa interpretação sobre como vem sendo visto socialmente o "usuário de drogas" apresentou uma dimensão de sofrimento social experimentada por Igor, por assim descrevê-la. Fiquei me perguntando se não seria também aquilo que Bradizza \& Stasiewicz (2003) nomeou como "piora nos sintomas psicológicos como a paranoia, a ansiedade e o nervosismo", como sentidos do consumo de drogas para seus participantes.

"F: Você sempre sentiu esse medo? [menenia afirmativamente] É? Ou é só sobre o efeito de alguma droga?

I: É.. Só é... É nóia, é a nóia.

F: É a nóia, mas assim isso vem de antes de você usar droga ou...

I: Não, vem depois que usei a droga.

F: No que que você fica pensando? Quando você tá na nóia?

I: Que nego quer me pegar... Que nego quer me matar. É uma sensação estranha".

Ao retomar a ideia de que é necessário adotar uma perspectiva de análise que permita conhecer aspectos para além do discurso médico psiquiátrico das pessoas que são atendidas nas RAPS do município estudado, pareceu importar a reflexão sobre impactos do discurso proibicionista para a experiência de "noia". O estudo de (Childs et al., 2011), com relação à maconha, levantou essa questão, discutindo que talvez a ilegalidade de certas drogas poderia contribuir para a sensação de paranoia experimentada por pessoas que usam drogas, que na narrativa de Igor, ele descreveu como a sensação "que nego quer me pegar". Ou seja, não como um efeito do crack, ou de aspectos seus de alteração da percepção da realidade, mas pela alteração 
sensorial ficariam exacerbados pensamentos relacionados a não legitimidade desse consumo. Além disso, Igor contou que se descrevia como uma pessoa ansiosa, se apropriando do discurso médico-psiquiátrico. O consumo de drogas, para ele, parecia ajudar nesse manejo da ansiedade, juntamente com o consumo da medicação prescrita no tratamento no CAPS AD.

"F: Você teve alguma situação que cê já se sentiu muito triste, ou muito ansioso? [meneia negativamente] Não?

I: Ansioso sim.

F: Ansioso sim.

I: Ansioso eu sou.

F: Você é?

I: Eu sou ansioso.

F: Hum... Mesmo sem a droga? A droga te ajuda a manejar?

I: Mesmo sem a droga.

F: Hum... A droga te ajuda a cuidar da ansiedade?

I: Ajuda... Os remédios também, que eu ando tomando".

Esse parece ser um ponto importante na narrativa de Igor, que comentou que já usou "todas as

drogas", exceto "tacar na veia", referindo-se ao uso de drogas injetáveis.

"F: Você falou que já usou de tudo, o que mais que você já usou?

I: Tudo que é toxico eu acho que eu já usei, menos taca na veia"

Entre as drogas que usou, Igor posicionou o uso de medicamentos psiquiátricos, descritos como "tarja preta" como as drogas sintéticas das quais fez uso em certa época da sua vida, quando chegou a fazer uso não prescrito de medicação psiquiátrica misturando com álcool e buscando a sensação de "ficar louco".

"I: Não. Sintética nenhuma.

F: Nenhuma? Anfetamina?

I: Só remédio".

F: Remédio pra dormir?

I: Misturava com álcool.

F: Também com os amigos? Pra vê se era bom?

I: Não isso ai eu já aprendi comigo memo.

F: Como que foi?

I: É porque eu já sabia o que era remédio tarja preta e depois eu tomava conhaque... Deixa louco.

F: Deixa louco?

I: Deixa.

F: O que você gostava da sensação?

I: De ficar louco uai”.

Interessante Igor colocar o uso de medicações psiquiátricas como sintéticas, remetendo que elas eram drogas encapsuladas. Biehl (2011), inclusive, discutiu sobre isso em relação a políticas públicas que reduzem a promoção de saúde ao acesso apenas medicamentoso de tratamento, negligenciando a atenção a condições de vida que levam à vulnerabilidade dos problemas apresentados. Na fala de Igor, isso ficou evidente ao considerar que as medicações psiquiátricas eram drogas como todas as outras que já usou. Em um segundo 
momento eu retomei com ele essa fala e ele disse que não fazia mais esse tipo de uso, narrando que fazia uso de um conjunto de medicações prescritas que incluía antipsicótico e benzodiazepínico usados para o tratamento realizado no CAPS AD.

"F: Você falou que misturava conhaque com remédio tarja preta. Pra ficar loucão.

I: É.

F: Hum... Você us...

I: Não to fazendo mais isso.

F: Não? É um remé... É o mesmo remédio que você toma hoje?

I: É o diazepam, haldol.

F: Hum... Você costuma ficar agressivo?

I: Tsc tsc (som negativo).

F: Não? Agitado?

I: Agitado sim... Agressivo não".

De todas as drogas, ele não usou aquelas que comumente são agrupadas como drogas sintéticas, drogas que vêm sendo consumidas no Brasil por pessoas com maior poder aquisitivo que ele (Jorge et al., 2013). Chamou a atenção o modo como ele escolheu se descrever, narrando que já havia consumido "todas as drogas". Ao contrário de outros entrevistados que buscaram se descrever por meio da nomeação de drogas mais legitimadas, Igor preferiu se descrever como "usuário de 'todas' as drogas". Embora não tenha consumido "todas" as disponíveis no mercado, ele consumiu "todas" aquelas que estavam disponíveis no contexto onde se inseria. Essa descrição de si permitia um posicionamento quanto ao modo como narrava descrições de si e do próprio consumo, como alguém que se reconhece nessa experiência e a percebe como óbvia.

"F: Ah! A história da sua vida? De onde Você quiser começar.

I: Ah! Eu... Eu trabalhava de sapateiro... Até eu conhecer as drogas, depois que conheci as drogas...

F: Quais drogas são essas?

I: Ah!!! Todas".

Asher \& Gask (2010) discutem que entre o participantes de seu estudo, o consumo de drogas tinha como significado ser uma parte importante da identidade, associando o uso de drogas com pessoas conhecedoras desse tipo de prática. Igor se descreveu como trabalhador, como sapateiro, características que o descreveram "até conhecer as drogas". Essa mudança de descrição de si pareceu ocorrer como se depois disso, só fosse possível a descrição de “drogado". É possível, no entanto, que na época em que iniciou o consumo ele não se descrevesse como uma pessoa que usava droga, mas alguém que tinha uma turma de 
amigos com os quais se divertia. O posicionamento como "drogado" foi fixado também pelo tratamento realizado no CAPS AD, onde Igor era descrito como "paciente psiquiátrico" além de "usuário de drogas". Para Igor, parecia não haver problema em "ficar louco" quando estava sob o efeito das drogas que consumia. Além disso, como encontrado na narrativa de Flora, eram limitadas as ações do Estado direcionadas a pessoas com a sua história, cujo acesso a serviços e direitos parecia limitado a serviços de saúde e assistência social, e não ao lazer, por exemplo. Restava a Igor aderir ao tratamento medicamentoso prescrito como uma das poucas opções de cuidado oferecidas pelo Estado.

Esse tratamento oferecido não era suficiente para ele, que complementava a ação da medicação psiquiátrica com o consumo da maconha na busca por sedação, como ele mesmo disse em sua narrativa. Em uma fala sequencial, apresentou rapidamente sentidos que ele atribuiu ao consumo de diferentes drogas, sem muitas palavras, de maneira análoga ao modo como apresentou Vitor, ampliando o rol de possibilidades interpretativas dos significados atribuídos às drogas. Nessa fala, os significados do consumo das drogas que fazia uso já estavam encorporados como parte de quem ele "era", assumindo esse consumo, também aspectos identitários.

"F: É? Mas cada droga deixa louco de um jeito?

I: Sim.

F: O que você gosta, por exemplo, da sensação de ficar louco de maconha?

I: Pra dormir.

F: E do álcool?

I: Do álcool? De ficar no bar conversando com os amigos.

F: Você se sente mais solto? Quando você bebe?

I: Aham. (meneia afirmativamente)

F: Você tem mais facilidade de conversar ou não?

I: É...

F: É? Ou depende da dose.

I: Não... Eu me sinto mais a vontade conversar.

F: E o crack?

I: O crack é... Problema.

F: Mas e a sensação de ficar louco? O que é gostoso?

I: Ah! O gostoso é que.. Você quer sempre mais né... É difícil falar sobre o crack...

F: É?

I: É bom e é ruim.

F: É diferente da cocaína?

I: Bem.

F: É? A loucura da cocaína é como?

I: Ah! É... Sei lá... É diferente... O crack você que quer cada vez mais e efeito passa mais rápido.

F: E... Você já cheiro cola?

I: Já. 
F: Você sendo sapateiro, você tinha facilidade de acesso?

I: Ah! Ah! Ah! Aham...

F: É?

I: É bom hein?

F: É? Você gosta?

I: Gost... Gosto.

F: Cê usa ainda?

I: Eu ia falar que gostava, mas se véi, eu gosto, gosto".

Não pareceu, na narrativa de Igor, haver a possibilidade de construção de outros sentidos do consumo que não aqueles já descritos, aliás, esse pareceu ser o motivo de sua irritação, Canet et al. (2003) escreveu sobre a questão da necessidade de diminuir o consumo de drogas como situação que poderia promover comportamentos descritos pelo discurso médico-psiquiátrico de ansiedade. Somente em um momento posterior na entrevista, ele maneirasse apresentou mais flexível, podendo, inclusive me pedir que não risse dele ao dizer que esse era seu prazer. Ele parecia buscar ouvir vozes e ver elementos que geralmente não faziam parte da percepção do cotidiano e sem a droga. Descreveu que "queria ter" essas experiências, por exemplo, sob o efeito de cheirar cola, de ver "coisas nada a ver".

"F: Ouve vozes? Não?

I: Não. Ah! Ah! Ah! (fala com expressão entristecida)

F: O que te deixa triste?

I: Queria ter... Ah! Ah! Ah!

F: Queria ter? Ah! Ah! Ah! Você já experimentou ter (Ah! Ah! Ah!) Essa sensação?

I: Eu queria ter... Quando eu cheirava cola no começo era assim... Via umas coisa que nada a ver.

F: Tipo o que?

I: Tipo caveira, via fantasma".

Falar sobre essa vontade de ter essas experiências de ouvir vozes não pareceu ser legitimada no contexto nem de saúde, nem daquele em que se inseria fora do tratamento. No entanto, esse era o prazer que encontrava no consumo.

"I: Não ri de mim não hein... Ah! Ah! Ah!

F: Não vou rir...

I: Ah! Ah! Ah!

F: Não vou rir não.

I: É o barato era desse jeito.

Ao longo do tempo ele parou de ter alterações da sua percepção, justificando que "o organismo vai acostumando" com a droga, diminuindo os efeitos que ele tinha prazer em ter.

"F: O barato era muito louco?! Mas você começou a sentir isso, mas isso não continuou?

I: Não, conforme o tempo foi parando.

F: Foi parando?

I: Eu acho que o organismo vai acostumando com a droga né... Ai não faz mais todo o mesmo efeito.” 
No entanto, embora Igor tenha falado que buscava nas drogas "ficar louco", em outro momento da entrevista, tentei conhecer se outros sentidos eram atribuídos ao consumo da maconha e do crack que poderiam ir nessa direção de maior espontaneidade na construção de sentidos. Ele foi categórico: "maconha é só pra comer e dormir", demonstrando certa irritação na resposta.

"F: Você já sentiu isso com a maconha?

I: Tsc tsc (Não)

F: Não? Com o crack?

I: Maconha é sempre pra comer e dormir. (irritação)

F: E com o crack?

I: Nem sei porque eu fumo aquilo lá".

Talvez meu jeito de fazer a pergunta o tenha irritado, talvez eu estivesse fazendo uma pergunta sem cabimento, na sua opinião, talvez esse fosse um assunto delicado para Igor. De qualquer maneira, o modo como descreveu os significados do consumo das diferentes drogas foi rígido, de certa maneira rígida. Além disso, como comentou um pesquisador do campo das drogas, algumas experiências não são possíveis de serem ditas em palavras e dizê-las é um esforço inútil porque são corporais. Resta ao observador, no caso pesquisadora, captar nuances e tentar colocar em palavras ou descrições situacionais do que foi captado.

Tentei entender a sua irritação, tentando explorar sentidos do consumo do crack para ele. Sentidos estes que também mudaram ao longo do tempo, conforme apresentou na sua narrativa.

"F: Nunca foi boa ou já foi boa alguma vez?

I: Não, no começo era bom, mas depois num...

F: Tem haver com o preço?

I: Tsc tsc, Acho que não.

F: Não? Você usa droga pela sensação? [meneia positivamente]... Hum... Entendi”.

Igor não queria muita conversa sobre o assunto, como disse antes, era difícil falar sobre o crack.

Tentei, então retornar a algo que pareceu fazer sentido para ele: usar drogas pela sensação, silenciosamente ele encerrou a questão me respondendo com sinais de cabeça. Foi possível compreender essa questão da irritação na sequencia da sua fala, respondendo sobre a legitimidade do consumo e dos sentidos que atribuiu às drogas que fazia uso.

“I: É.. Não é muito bom eu com minha irmã [sobre seu relacionamento com ela]... Com meu pai e com a minha mãe é de boa, mas com a minha irmã, não é legal não.

$\mathrm{F}$ : Sempre foi assim?

I: Não.

F: O que mudou?

I: Mudou porque ela não aceita né... Que eu fumo. 
F: Hum... Você fuma em casa?

I: Fumo em casa, na rua... Qualquer lugar.

F: O fato de ser... Você usar drogas legais e ilegais... O fato de ser ilegal muda alguma coisa?

I: Eu acho que sim".

Igor tinha dificuldades de relacionamento com a irmã. Ela "não aceitava" que Igor consumisse

maconha Essa dificuldade, segundo ele, vinha também da ilegalidade desse consumo e não pela quantidade, ou pelos problemas relacionados ao diagnóstico psiquiátrico. Igor deixou de apresentar irritação, passando a aparentar desconforto com o modo como era visto socialmente.

"I: Na cabeça dela eu acho que é... Porque eu fumo cigarro, ela também fuma.

F: Hum... E beber cerveja ela também bebe? Beber pinga?

I: Não. Acho que não né... Pelo menos nunca vi ela bêbada não".

Essa fala pareceu conectada às observações feitas nos serviços estudados e nas conversas informais com os profissionais de saúde desses serviços sobre a questão da hierarquia de legitimidade relacionada ao consumo de drogas.

"I: Também... Eu gosto dela... Eu sei que eu estou errado.

F: É?

I: É que ela não está errada de não gosta de mim.

F: Ela não gosta de você, ou não...

I: De não aceitar o que eu faço".

Ele tornou evidente que essas compreensões sobre a legitimidade do consumo de crack em comparação com o consumo de cigarro influenciaram a compreensão de suas experiências. Seja pela equipe de profissionais, como apresentado em capítulos iniciais de resultados e discussão, seja pela família e meio social onde ele se inseria essas relações promoveram em Igor sentimentos de irritação e desconforto emocional, que também impactaram no consumo e nos seus sentidos . De maneira análoga à Juliana, pareceu que impactava na sua subjetividade ser identificado como usuário de drogas, ainda que esse era um aspecto de sua identidade que também tinha características positivas.

Igor já tinha um percurso de tratamento para o consumo, tendo sido internado duas vezes em comunidades terapêuticas.

“I: Já... Já me internei, já.

F: Varias vezes ou uma vez só?

I: Duas vez". 
No entanto, na época da entrevista, sentia que era "uma dependência" a relação que tinha com o consumo de drogas, e que este "levava a nada". Sem aprofundar em detalhes, disse que o consumo o prejudicava em "tudo".

I: Hoje já, já não penso assim.

F: Ah é? Porque?

I: Ah! Porque é uma dependência, é um vicio que não leva a nada... Quer dizer nenhum vicio leva a nada, mas esse menos ainda”.

Segundo sua narrativa, Igor já havia conseguido parar de usar várias das drogas que consumia (álcool,

cola, crack, cocaína), permanecendo ainda com a maconha e o cigarro. Desejava conseguir deixar de fazer uso de maconha, embora do cigarro não tivesse a mesma vontade.

"F: Uhum... Você já pensou em algum motivo pelo qual você quer parar?

I: Ah! Eu quero parar porque eu sei que me prejudica em tudo.

F: E você é... Você conseguiu para já varias drogas... Você tem vontade de para de usar maconha?

I: Tenho

F: Tem?

I: Pouco, mas tenho.

F: Pouco, mas tem? Hum... E o cigarro? Você tem vontade de parar? Quem que te...

I: O cigarro nu...

F: O cigarro nu, nu o quê?

I: Acho que não atrapalha nada... A não ser na saúde né... Eu sei que é prejudicial.

F: Qual a diferença do atrapalhar do cigarro e do atrapalhar das outras drogas?

I: As outras drogas mexe com o psicológico da gente.

F: Como assim?

I: Deixa você mei..."

A diferença entre o consumo das outras drogas e do cigarro para ele estava na influência delas em aspectos descritos como "psicológicos" da sua vida. Nesse sentido, por tudo o que foi dito até agora, é possível compreender que, pela apropriação do discurso médico-psiquiátrico sobre suas experiências, Igor pareceu empobrecido em termos de repertórios para lidar com o sofrimento psíquico. Apreendeu a partir do tratamento que "droga prejudica em tudo". No entanto ele pareceu apreender também a diferenciação feita pelos discursos correntes sobre drogas, descrevendo que droga "mexe com o psicológico da gente", diferentemente dos problemas que o cigarro causa, que diria respeito à saúde física, uma questão "óbvia", mas ainda sim pouco explorada.

Essa afirmação, feita no contexto da entrevista, convidou-me à reflexão sobre a que "saúde" nos referimos quando nos apropriamos de diferentes discursos de tratamento do consumo de drogas para pessoas com diagnósticos psiquiátricos, ou mesmo as que não recebem esse diagnóstico? Seja o médico-psiquiático, 
foca essa questão em termos biológicos oferecendo respostas farmacológicas, seja o discurso psicossocial, que na prática pareceu englobar aspectos sociais à questão da saúde, por meio de estratégias de redução de danos. Não creio que seja uma questão de onde deve ser alocado um serviço ou um tipo de tratamento específico para pessoas com diagnósticos duplos, ou que tipos de tratamentos podemos criar para eles. Pois esse foi o caminho oferecido pelas redes de relações pelas quais respondemos social e historicamente diante do "fenômeno das drogas" no Brasil. A entrevista de Igor convidou-me a refletir não só sobre a suspensão do diagnóstico de transtornos mentais, mas também em relação suspensão da visão sobre o consumo de drogas só como promotor de "problemas" psiquiátricos e não parte da rede de relações sociais e culturais em que todos nos inserimos, algumas pessoas mais e outras menos.

\section{Um resumo}

Nas narrativas dos participantes, o consumo de drogas, principalmente as lícitas, pareceu ser um dispositivo usado como estratégia de ação diante das expectativas sociais e das demandas cotidianas de resposta rápida, dinâmica, ainda que de maneira frustrante. Acredito que, em graus variados, essas experiências narradas pelos participantes também podem ser vividas pelas pessoas em geral, e talvez por isso, como já dito, o consumo de algumas drogas seja mais legitimado. Porque sentimentos de ansiedade com relação à interação social ou mesmo em relação às expectativas que temos das nossas relações cotidianas, não são uma experiência que nos diferencia entre pessoas "normais" e "doentes", ao menos em qualidade, posto que é um sentimento básico e compartilhado, não sendo no entanto, experiências focadas por intervenções no cotidiano dos serviços, a menos que fossem experiências consideradas exacerbadas e por isso, passíveis de diagnóstico pelo discurso médico-psiquiátrico. 
O sentimento ao qual chamei ansiedade, emprestando do discurso médico-psiquiátrico essa expressão talvez por falta de outra possível, assim como o "nervoso" de Duarte (1986) pareceu ser um aspecto que liga a experiência cotidiana a contextos mais globais de instabilidade social, precariedade de condições de sobrevivência, dificuldades nas relações interpessoais. Em um mundo cada vez mais excludente e paradoxalmente globalizado, o uso de drogas entre os participantes deste estudo pareceu se relacionar com a capacidade de agir diante de sofrimentos sociais, que podem ter contornos do que o discurso médicopsiquiátrico chamou de transtorno de ansiedade. Com a facilitação de apropriações do discurso médicopsiquiátrico para expressar experiências de sofrimento, como efeito colateral à política de universalização do acesso à saúde praticada desde a criação do SUS, talvez seja necessário (re)pensar as implicações dos diagnósticos psiquiátricos na vida das pessoas atendidas em serviços das RAPS. Não é o caso de negar-lhes acesso ao tratamento para problemas decorrentes do consumo de drogas ou retirar da saúde a atenção sobre esse campo, mas considerar essa questão criticamente, procurando ampliar as possibilidades de ação diante disso. 


\subsection{O mosaico dos Sentidos e Significados do consumo de drogas associados ao sofrimento psíquico}

As experiências de sofrimento psíquico consideradas nesse estudo disseram respeito a sofrimentos vividos individualmente. $\mathrm{O}$ sofrimento psíquico foi tomado como uma continuidade entre eventos do cotidiano e aqueles passíveis de diagnóstico de transtorno mental, pelo sistema de crenças sobre saúde, cunhado como discurso médico-psiquiátrico. Para os entrevistados, no entanto, o sofrimento psíquico nem sempre foi percebido como sinônimo de doença mental, ou seja, por vezes fizeram descrições de que o sofrimento psíquico era a de que ele parte do rol de possibilidades das experiências cotidianas e de múltiplas interpretações sobre elas, sendo compartilhadas pelas pessoas do entorno dos participantes. Dessa maneira, as experiências narradas fizeram parte não só das histórias de vida dos participantes, como também se considera que eram compartilhadas entre os participantes aqui apresentados

Os sentidos e significados atribuídos ao consumo de drogas, quando associados ao sofrimento psíquico foram sempre diversos. Variaram de acordo com situações específicas de cada história de vida, o tipo de droga consumida e a relação estabelecida ou não com o sofrimento psíquico. Os consumos de drogas neste trabalho também tiveram apresentações variadas de acordo com o modo como cada droga era vista nos diversos ambientes por onde transitaram os entrevistados, sendo compreendidos como experiências pessoais, ainda que muitas vezes este fosse compartilhado com pares e/ou familiares dos participantes. Portanto, importou considerar que o consumo de drogas fazia parte dos elementos presentes nos eventos cotidianos onde os participantes se inseriam. Essa percepção foi decorrente do confronto com a literatura sobre o diagnóstico duplo em que procurei apresentar a "textura das aflições" (Farmer, 1997) dos participantes, o que interessava especialmente evidenciar neste trabalho.

Os sentidos e significados estiveram atrelados a eventos vividos pelos participantes, como argumentou Fiore (2013). Quando foram atrelados ao sofrimento psíquico, o consumo de algumas drogas, principalmente as ilícitas, foi compreendido como promotor dessas experiências, repetindo o que tem 
produzido em pesquisas feitas pelo discurso médico-psiquiátrico sobre elas. Mas entre as drogas lícitas o consumo nem sempre era visto como problemático em relação à saúde mental, mas prejudicial em relação à saúde física. Os entrevistados foram posicionados de maneira exclusiva como "doentes mentais" ou "usuários de drogas" pelos profissionais serviços da RAPS onde eram seguidos, onde foram moldadas possibilidades de narração de suas histórias de vida. Talvez essa diferença nas narrativas tenha se dado pelas diferentes demandas passíveis de serem escutadas e manejadas pelos profissionais do CAPS II e do CAPS AD. Portanto, a condição de produção dessas narrativas talvez estivesse ligada ao modo como essas pessoas eram posicionadas pelos serviços e pela rede que se divide e orienta encaminhamentos entre esses serviços. Pedro foi posicionado como "paciente psiquiátrico" diante de crises que apresentava, enquanto Fabiano foi posicionado como "usuário de drogas". Os convites às conversas nos serviços eram mais sobre determinados assuntos em detrimento de outros, em um jogo de legitimidades que abriam possibilidades diferentes de interpretação e de aderência ao tratamento. No entanto, no mesmo serviço também houve diferenças. Marli, por exemplo, no CAPSAD sentiu ter uma segunda oportunidade de vida; enquanto Juliana, no mesmo serviço, se sentia menos capaz, reforçando antigos esquemas de desvalorização de si mesma.

Outra reflexão também emergiu da análise foi: será que esse modo de conversar não é uma apropriação dos entrevistados para falar de experiências emocionais em que o consumo de drogas como dispositivo serve também para exprimir sofrimentos psíquicos? Isso permitiria à pessoa manter sua capacidade de agir diante das diversas situações vividas e dos sofrimentos vividos nos seus cotidianos e serem atendidos nos serviços estudados. Essa interpretação foi feita na busca pelo afastamento de compreensões de que o consumo de drogas seria uma tentativa de responder a "faltas" sentidas ao longo da vida. Considerei, que na realidade vivida, não existem "faltas" a serem supridas, mas recursos dispostos pelo contexto que podem ser usados para enfrentar o sofrimento. Entre os entrevistados, em termos históricos e sociais, foi possível perceber dificuldades de acesso a direitos e que eles se inserem em contextos com discursos rígidos de gênero e classe social. Assim, os recursos que lhes foram disponíveis para agir diante do 
sofrimento social e psíquico foi, dentre outros, consumir alguns tipos de drogas. Esse consumo muitas vezes trazia, no longo prazo, problemas de saúde física e mental, aprofundando dificuldades que já enfrentavam.

Ao colocar em suspenso o diagnóstico de transtorno mental, também foram possíveis outros modos de descrever o sofrimento psíquico em termos de experiência vivida. Retomei a discussão feita por Morris (2007) de que narrativas de sofrimento, para além da perspectiva individual, se ligariam também a lógicas comunitárias. Fez, então, sentido repensar o consumo de drogas como um dispositivo de ação diante do sofrimento psíquico e sua conexão com sofrimentos sociais, sendo uma condição para o desenvolvimento de experiências de sofrimento psíquico descritas por discursos de saúde como doenças mentais (Corin, 2007). Portanto, a expressão do sofrimento psíquico, nas relações com o entorno social e cultural, pareceram tomar diversas formas nas narrativas, de maneira que não eram generalizáveis.

O entrelaçamento de sentidos do consumo associados a sofrimentos psíquicos apareceu nas entrevistas de maneira muito variada. Em alguns momentos os sofrimentos psíquicos pareceram ser promotores do consumo. Em outros, ele pareceu como decorrente do uso prolongado ou em excesso de drogas. Essas duas compreensões vão ao encontro com a literatura que busca fazer relações de causa e efeito entre o consumo de drogas e o aparecimento de transtornos mentais (Buadze et al. 2010). No entanto, quando levados em consideração os diferentes tipos de drogas, cada uma tinha sentidos e significados diferentes entre si diante de diferentes situações e entre antes e depois do tratamento do consumo. Optei, nessa questão, por priorizar o modo como essas pessoas me contaram suas experiências, construídas ao longo da narrativa. Foi recorrente nas entrevistas a narrativa de experiências chamadas pelo discurso médico-psiquiátrico de estresse precoce, que seriam fatores que essa literatura discute como promotoras tanto de sofrimentos psíquicos e também do consumo de maneira problemática de drogas (Huang et al. 2012). As experiências vividas como abusos e negligências emocionais, físicas e sexuais, a falta de recursos financeiros e eventos traumáticos ocorridos na infância e adolescência, foram lidas pelo vértice de que são experiências individuais de sofrimentos sociais, vindos de processos relacionais mais amplos, sendo o 
consumo de drogas uma das possibilidades de ação e resistência possíveis presentes nos contextos dos participantes.

Como um mosaico complexo, entre idas e vindas dinâmicas, os sentidos e significados do consumo pareceram ser relacionados a essas experiências vividas ao longo de diferentes momentos do desenvolvimento e do momento de entrevista. E nesse sentido, concordo com Lobbana et al. (2010) que descrevem que as motivações para o consumo são dependentes da escolha ativa do indivíduo, mas também há motivações externas como aquelas influenciadas por outras pessoas e pela cultura. Minha escolha em discutir a questão da experiência de sofrimento psíquico foi dar ouvidos ao modo como pessoas descritas por meio do diagnóstico psiquiátrico e que fazem tratamento em serviços comunitários de saúde mental e de drogas construíram sentidos para essa experiência. Assim, escolhi fazer a discussão a partir dessa construção de sentidos e significados de experiências nas entrevistas. Nas narrativas dos participantes, a visão de problema com o consumo, bem como de que ele não era prejudicial pareceram conviver, variando em relação ao momento e ao tipo de droga consumida. A primeira colocava a droga como objeto de tratamento médico psiquiátrico e era motivo pelo qual os participantes procuravam aderir ao tratamento proposto e ao uso de medicação para a diminuição de sintomas descritos como de abstinência ou mesmo comportamentos, pensamentos e vozes compreendidos como decorrentes do consumo considerado problemático das drogas. A outra forma de significar o consumo o considerou como parte da cultura familiar em que diversos tipos de usos era feitos, inclusive diante de sofrimentos psíquicos e sociais, sendo estratégias de ação diante delas.

Quanto ao sofrimento psíquico, este também era compreendido de duas formas que conviviam entre si. Na perspectiva dos participantes, eram vistos como doença mental e como parte das vivências cotidianas mais amplas do que as situações de crise, conforme já descrito por Dalmolin (2006). A análise permitiu aprofundar essa discussão, permitindo refletir que para além das vivências entendidas como sinônimo de transtorno mental existiam outras possiblidades de interpretação para o sofrimento, em que existiam sofrimentos que eram entendidos como parte dos percalços da vida, e aqueles da ordem social vindos de 
discriminações, processos de exclusão e experiências traumáticas vindas de discursos rígidos sobre gênero, etnia e classe social, que eu compreendi como sofrimentos sociais, mas que na experiência vivida em primeira pessoa formavam uma continuidade vista por diferentes lentes interpretativas de acordo com a situação.

Os circunscritores desses sofrimentos no cotidiano dos participantes foram narrados como cenário onde foram pintadas suas histórias de vida e muitas vezes eles mesmos naturalizavam esses sofrimentos como parte da vida. O consumo de drogas entrava nesse aspecto, mediando relações, permitindo agir diante das dificuldades e sendo, por vezes a linguagem para expressar a si mesmo. A questão do diagnóstico duplo, ou melhor dizendo, do uso de drogas por pessoas diagnosticadas com transtornos mentais, era compreendida pelos participantes de três maneiras: a depender do tipo de droga usada, da situação vivida ou de ser antes ou depois da adesão ao tratamento. As experiências de sofrimento poderiam ser descritas por meio do discurso médico-psiquiátrico ou como prática cotidiana. Assim, pelo discurso médico-psiquiátrico, o sofrimento psíquico era visto como sinônimo de doença mental, sendo este alvo de tratamento pelos discursos médicopsiquiátrico e psicossocial, enquanto o consumo de algumas drogas não era visto como problema. O consumo de drogas também poderia ser experimentado como problema, sendo alvo de críticas pelo discurso proibicionista e de tratamento pelo discurso médico-psiquiátrico, mas não era visto como tendo relação com o sofrimento psíquico. Outra forma de compreender o sofrimento psíquico associado ao consumo de drogas narrado pelos participantes foi a de que tanto o consumo, quanto o sofrimento psíquico eram vistos como parte do cotidiano não sendo, portanto, vistos como problema, mas parte de um contexto mais amplo. Neste caso, a resposta construída pela RAPS estudada era inserir essas experiências sob seu controle e atenção. Essa compreensão eu tentei esquematizar na Figura 2.

Portanto, separar a descrições das experiências, poderia dar margem para continuar reificando posicionamentos e descrições que reforçavam discursos de exclusão e exceção, o que não era o meu objetivo com essa tese. Escolhi apresentar os resultados e a discussão a partir de três recortes que fazem eco com as 
categorias diagnósticas escolhidas como critérios de seleção. Nele escolhi pormenorizar aspectos da história de vida trazidos nas narrativas de dez participantes, mas que embora não sejam generalizáveis, encontraram eco nas narrativas dos demais participantes, que compuseram para a compreensão dada às narrativas. Por essa escolha, procurei montar um mosaico de sentidos e significados do consumo de drogas por pessoas com diagnósticos psiquiátricos entrevistados, de maneira que os capítulos não se encerraram em si mesmos, mas cumulativamente, procurei apresentar elementos interessantes para a reflexão sobre o tema de estudo. Essa estratégia de apresentação dos resultados e de discussão foi elaborada em consonância com o referencial de pesquisa adotado, que considera a importância política na produção de pesquisa em dar ouvidos a quem historicamente vem sendo deixado de lado, mas que é alvo de políticas públicas em saúde. 


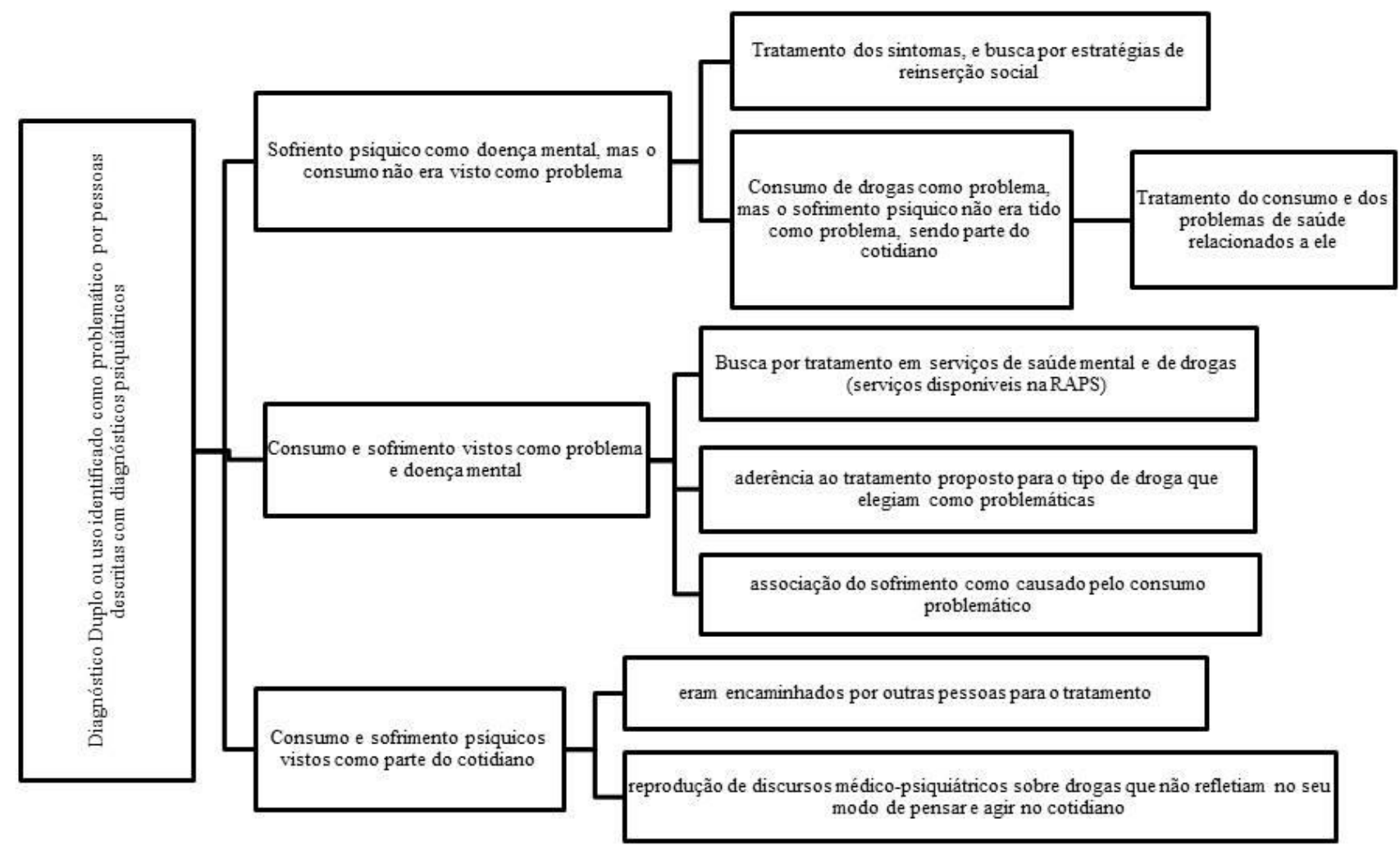




\section{$5 \quad$ Considerações Finais}

Como considerações finais, gostaria de recontar uma das orientações feitas pelo professor Massimiliano Minelli durante o período de estágio no exterior e que eu anotei no caderno de campo. Ele contou que o texto científico poderia ser escrito como um filme, em que o diretor apresenta sua narrativa. Ele joga com planos de câmera diferentes para captar elementos diferentes que só esse jogo de luz e sombra, figuras e fundos é possível transmitir. Assim escolhi compor este trabalho, tentei alinhavar questões que achei importantes por uma linha não ortodoxa de pesquisa qualitativa, me alinhado com alguns autores sem, no entanto, me alinhar com alguma linha teórica em especial. Achei interessante trilhar esse caminho porque penso que o olhar para as pessoas que participaram da construção desse trabalho me ajudaram a olhar para algumas questões de determinados jeitos e, se eu escolhesse uma linha específica ou outra, eu perderia muito do que foi observado e do que escutei nos encontros com os entrevistados.

Procurei transitar em diversos campos de produção de conhecimento sobre saúde, em que diferentes discursos se encontram e se misturam e esse encontro nem sempre precisa ser alvo de críticas, mas de reflexões sobre o fazer em saúde. Aprendi a valorizar o método da narrativa de história de vida como método de apreensão do outro, em um encontro de trocas possíveis. O encontro inusitado com autores que trabalhavam sobre o sofrimento social me ajudou a ver com outros olhos o sofrimento encontrado nas narrativas, destacá-lo do que compreendemos como doença mental, sendo também um conector entre compreensões e formas de vida diversas. Esse olhar alimentou a vontade deixada no mestrado de dar mais espaço no texto de tese para a subjetividade dos participantes. O encontro com a perspectiva que valoriza a capacidade de agir de quem vivencia o sofrimento psíquico em primeira pessoa trouxe um olhar para além de um certo pessimismo que eu lia muito nos textos sobre sofrimento social. Este professor me ensinou, durante o estágio junto a seu departamento, que sempre há soluções e saídas, sutis sim, talvez não tão transformadoras, mas possíveis diante do sofrimento. 
O olhar sobre o consumo de drogas com a perspectiva que procura se afastar do discurso proibicionista, me permitiu abrir os ouvidos para as experiências, sobre as quais procurei trançar conversas entre campos controversos e que muitas vezes não se conversam, complementando a perspectiva de que tanto o conhecimento construído pelo discurso médico-psiquiátrico como o discurso de quem vivencia a experiência são importantes para compor compreensões sobre saúde. O posicionamento propiciado pelo primeiro, porém, vem sendo mais legitimado pelas diversas linhas de produção de conhecimento em saúde que o segundo, dificultando trocas mútuas.

A impressão que tenho é que esse trabalho permite olhar dentro de um caleidoscópio, em que diferentes leituras propiciaram diferentes composições de compreensão do tema do diagnóstico duplo. Assim, foram diversas as possibilidades de sentidos e significados da experiência de usar drogas associadas ao sofrimento psíquico quando estes eram tidos como sinônimos de transtornos mentais. Com a proximidade com o campo, foi possível perceber que os sentidos relatados sobre o consumo de drogas pareceram mudar ao longo das situações, tempo e dose de consumo, bem como das diferentes combinações de drogas e estados emocionais vividos. Os sentidos sobre o consumo de drogas por pessoas descritas com diagnósticos psiquiátricos pareceram ser construídos de acordo com as relações estabelecidas entre a pessoa e a droga usada ao longo da vida, mas também interferiram nessa construção os diversos eventos e situações vividos. Estes circunscreveram significados atribuídos às experiências de sofrimento e consumo. Ao pensar nas narrativas, me remeto à discussão de que estamos acostumados a escutar o sofrimento representam-no como um evento que acontece no meio das ações humanas, sendo menos representado como uma questão sobre a qual é possível agir. A ideia de que o sofrimento não é um assunto individual talvez abra espaço para pensar como pessoas vivenciam sofrimentos e de que maneiras esses são compartilhados. Essa discussão remete que não somos diferentes daqueles que recebem diagnósticos psiquiátricos, como no caso dos participantes, estes vivenciam experiências que a maior parte da população acha difícil de ver e dar conta de estar junto. 
Além disso, vivemos todos imersos em discursos sobre gênero e sobre quem tem acesso a bens e direitos e quem não tem, influenciando na nossa construção subjetiva do sofrimento, conectando-o a uma dimensão compartilhada e social em que também nós estamos inseridos. Essas narrativas apresentadas poderiam ser de qualquer um de nós, ou mesmo de pessoas que conhecemos. No entanto, talvez não sejam por não nos situarmos nesse território ou participarmos como "pacientes" de serviços de saúde mental ou de tratamento de problemas decorrentes do consumo de drogas, onde foi desenvolvido este estudo. Não foram, talvez por não termos sido nós quem narramos nossos sofrimentos psíquicos e nossos consumos de drogas, não sendo nós, aqueles a sofrer com sofrimentos psíquicos e sociais mais intensamente.

Considerei que esses sentidos e significados das experiências narrados foram construídos ao longo da história de vida. Podem ter sido vividos individualmente como sofrimentos psíquicos e descritos como problemas de saúde mental, mas pareceu serem compartilhados também por quem não recebe diagnostico ou não faz atendimento nos serviços de saúde públicos. Coloquei maior enfoque nessa discussão sobre a capacidade de agir compreendida nesse trabalho como aprendida ao longo das experiências de vida para expressar/suprimir sentimentos e responder/resistir a situações de vida que geram sofrimentos psíquicos, mas também são compartilhados socialmente. 


\section{Bibliografia}

Acier, D., Nadeau, L., \& Landry, M. (2011). Influence of the social network on consumption in drug addicts exhibiting psychiatric comorbidity. Encephale-Revue De Psychiatrie Clinique Biologique Et Therapeutique, 37(4), 249-256. http://doi.org/10.1016/j.encep.2010.08.005

Adorno, R. de C. F. (1999). A cidade como construção moderna: um ensaio a respeito de sua relação com a saúde e as "qualidades de vida." Saúde E Sociedade, 8(1), 17-30. http://doi.org/10.1590/S010412901999000100003

Adorno, R. de C. F., \& Castro, A. L. (1994). O exercício da sensibilidade: pesquisa qualitativa e a saúde como qualidade. Saúde E Sociedade, 3(2), 172-185. Retrieved from http://www.scielo.br/scielo.php?pid=S0104-12901994000200009\&script=sci_arttext

Adorno, R. de C. F., Rui, T., Malvasi, P. A., Vasconcellos, M. da P. C., Gomes, B. R., \& Godoi, T. C. (2013). Etnografia da cracolândia: notas sobre uma pesquisa em território urbano. ... Social/Health \& ..., 4(2), 4-13. Retrieved from

http://portal.incubadora.ufsc.br/index.php/saudeetransformacao/article/view/2246

Adorno, R. de C. F., Vasconcellos, M. da P. C., \& Alvarenga, A. T. de. (2011). Para viver e pensar além das margens : perspectivas, agenciamentos e desencaixes no campo da saúde pública. Saúde E Sociedade, 20(1), 86-94.

Ahearn, L. M. (2001). Agentività/Agency. In D. (coord.) (Ed.), Culture e discorso. Un lessico per le scienze umane. (pp. 18-23). Roma - Itália: Meltemi.

Almeida, R. De, D’Andrea, T., \& De Lucca, D. (2008). Situações periféricas: etnografia comparada de pobrezas urbanas. Novos Estudos - CEBRAP, (82), 109-130. http://doi.org/10.1590/S010133002008000300006

Alverga, A. R. De, \& Dimeinstein, M. (2006). A reforma psiquiátrica e os desafios na desinstitucionalização da loucura. Interface Comunicação Saúde Educação, 10(20), 299-316.

Alves, H., Kessler, F., \& Ratto, L. R. C. (2004). Comorbidity: alcohol use and other psychiatric disorders. Revista Brasileira de Psiquiatria (Sao Paulo, Brazil : 1999), 26 Suppl 1, S51-S53.

Alves, V. (2009). Modelos de atenção à saúde de usuários de álcool e outras drogas: discursos politicos, saberes e práticas. Cad. Saude Publica, 25(11), 2309-2319. Retrieved from http://www.scielosp.org/pdf/csp/v25n11/02.pdf

Amarante, P. D. de C. (2007). Saúde Mental e Atenção Psicossocial. Rio de janeiro: Fiocruz. 
Andreoli, S. B., Almeida-Filho, N., Martin, D., Mateus, M. D. M. L., \& Jesus, J. de. (2007). Is psychiatric reform a strategy for reducing the mental health budget? The case of Brazil. Revista Brasileira de Psiquiatria, 22(1). Retrieved from http://dx.doi.org/10.1590/S1516-44462006005000032

Andreoli, S. B., Almeida-Filho, N., Martin, D., Mateus, M. D. M. L., \& Jesus, J. de. (2007). Is psychiatric reform a strategy for reducing the mental health budget? The case of Brazil. Revista Brasileira de PsiquiatriaPsiquiatria, 29(1).

APA, A. P. A. (1994). Diagnostic and Statistical Manual of Mental Disorders DSM-IV-TR Fourth Edition (Text Revision). Jama The Journal Of The American Medical Association (Vol. 285). American Psychiatric Publishing, Inc. http://doi.org/10.1001/jama.285.6.811

APA, A. P. A. (2000). DSM-IV. Diagnostic and Statistical Manual of Mental Disorders 4th edition TR. American Psychological Associaton.

APA, A. P. A. (2013). Diagnostic and Statistical Manual of Mental Disorders: DSM-5. Arlington. Amer Psychiatric Pub Incorporated. Retrieved from http://encore.llu.edu/iii/encore/record/C__Rb1280248__SDSMV_P0,2_Orightresult_X3; jsessionid=ABB7428ECBC4BA66625EDD0E0C5AAFA5?lang=eng\&sui te=cobalt lnhttp://books.google.com/books?id=EIbMlwEACAAJ\&pgis=1

Aragaki, S. S. (2006). O aprisionamento de selves em diagnósticos na área de Saúde Mental. Pontifícia Universidade Católica de São Paulo.

Arias, F., Szerman, N., Vega, P., Mesias, B., Basurte, I., Morant, C., .. Babín, F. (2013). Estudio Madrid sobre prevalencia y características de los pacientes con patología dual en tratameiento en las redes de salud mental y de atención al drogodependiente. Addiciones, 25(2), 118-127.

Asher, C. J., \& Gask, L. (2010). Reasons for illicit drug use in people with schizophrenia: Qualitative study. BMC Psychiatry, 10(1), 94. http://doi.org/10.1186/1471-244X-10-94

Babor, T., \& Caetano, R. (2006). Subtypes of substance dependence and abuse: implications for diagnostic classification and empirical research. Addiction, 101(1), 104-110. Retrieved from http://onlinelibrary.wiley.com/doi/10.1111/j.1360-0443.2006.01595.x/full

Becker, H. S. . (1953). Becoming a Marihuana User. The American Journal of Sociology, 59(3), 235-242.

Biasoli-Alves, Z. M. M., \& Dias da Silva, M. H. G. F. D. (1992). Análise Qualitativa de Dados de Entrevista: Uma Proposta. Paidéia (Ribeirão Preto), 2(Fev/Jul), 61-69.

Biehl, J. (2007). A Life: Between Psychiatric Drugs and Social Abandonment. In Subjectivity: Ethongraphic Investigations. 
Biehl, J. (2008). Antropologia do devir: psicofármacos - abandono social - desejo. Revista de Antropologia, 51(2), 413-449.

Biehl, J. (2011). Antropologia no campo da saúde global. Horizontes Antropológicos, 17(35), 227-256. http://doi.org/10.1590/S0104-71832011000100009

Biehl, J., Good, B., \& Kleinman, A. (2007). Introduction: Rethinkin Subjectivity. In A. Biehl, João; Good, Byron; Kleiman (Ed.), Subjectivity: Ethongraphic Investigations (pp. 1-24). Berkeley and Los Angeles - California: University of California Press.

Bourgois, P. (1998). The moral economies of homeless heroin addicts: confronting ethnography, HIV risk, and everyday violence in San Francisco shooting encampments. Substance Use \& Misuse, 33(11), $2323-2351$.

Bourgois, P. (2000). Disciplining addictions: the bio-politics of methadone and heroin in the United States. Culture, Medicine and Psychiatry, 24(2), 165-195. http://doi.org/10.1023/A:1005574918294

Bourgois, P. (2012). From Jibaro to Crack Dealer: Confronting the Restructing of Capitalism in El Barrio. In R. J. McGee \& R. L. Warms (Eds.), Anthropological Theory: A Brief Introductory History (pp. 587602). McGraw Hill.

Bourgois, P., \& Schonberg, J. (2009). Righteous Dopefiend. Berkeley and Los Angeles - California: University of California Press.

Bradizza, C. M., \& Stasiewicz, P. R. (2003). Qualitative analysis of high-risk drug and alcohol use situations among severely mentally ill substance abusers. Addictive Behaviors, 28(1), 157-169. http://doi.org/10.1016/S0306-4603(01)00272-6

Brasil, M. da S. (2010). Legislação em Saúde Mental 2004 a 2010. (Colegiado de Coordenadores de Saúde Mental, Ed.) (Edição XII). Brasília, DF: Ministério da Saúde.

Brasil, M. da S.-S. executiva de A. à S. (2004). Legislação em Saúde Mental - 1991-2004. (Ministério da

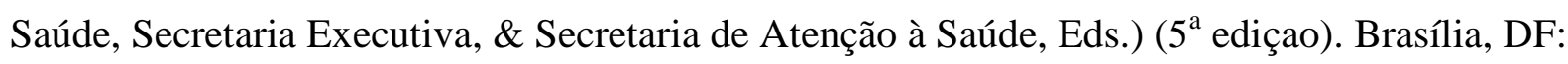
Ministério da Saúde.

Bruner, J. (1991). The Narrative Construction of Reality. Critical Inquiry, 18(1), 1-21.

Caldana, R. H. L. (1998). A criança e sua educação na família no início do século: autoridade, limites e cotidiano. Temas Em Psicologia, 6, 87-103. Retrieved from http://pepsic.bvsalud.org/scielo.php?pid=S1413-389X1998000200002\&script=sci_arttext 
Campos, G. M. de, \& Ferreira, R. F. (2007). A importância da legitimação social na (re) construção da identidade de um alcoolista. Estudos de Psicologia (Campinas), 24(2), 215-226.

Canet, J., Ortiz, M., \& Marquez, M. (2003). Alcoholism in 274 patients with panic disorder in Spain , one of the main producers of wine worldwide. Journal of Affective Disorders, 75, 237-245. http://doi.org/10.1016/S0165-0327(02)00054-X

Carlini, E. L. de A., Noto, A. R., Carlini, C. M. de A., Locatelli, D. P., Abeid, L. R., Amato, T. de C., .. Moura, Y. G. de. (2010). VI Levantamento Nacional sobre o Consumo de Drogas Psicotrópicas entre Estudantes do Ensino Fundamental e Médio das Redes Publica e Privada de Ensino nas 27 Capitais Brasileiras. (CEBRID - Centro Brasileiro de Informaçoes sobre Drogas Psicotropicas: UNIFESP Universidade Federal de São Paulo, Ed.) (1st ed.). Brasília, DF: SENAD - Secretaria Nacional de Politicas sobre Drogas.

Carneiro, H. S. (2005). Pequena enciclopédia da história das drogas. CamPus BB / Elsevier.

Carneiro, H. S. (2008). Autonomia ou heteronomia nos estados alterados de consciência. In H. S. Carneiro, B. C. Labate, S. L. Goulart, M. Fiore, E. MacRae, \& (orgs) (Eds.), Drogas e Cultura: novas perspectivas (pp. 65-90). Salvador, BA: EDUFBA/UFBA.

Carvalho, F. R. M., Brusamarello, T., Guimarães, A. N., Paes, M. R., \& Maftum, M. A. (2011). Causas de recaída e de busca por tratamento referidas por dependents químicos em uma unidade de reabilitação. Colombia Medica, 42(2 SUPPL.1), 57-62.

Carvalho, J. E. C. de. (2008). Violência e sofrimento social: A resistência feminina na obra de veena das. Saude E Sociedade, 17(3), 9-18. http://doi.org/10.1590/S0104-12902008000300003

Charles, V., \& Weaver, T. (2010). A qualitative study of illicit and non-prescribed drug use amongst people with psychotic disorders. Journal of Mental Health (Abingdon, England), 19(1), 99-106. http://doi.org/10.3109/09638230802523039

Childs, H. E., McCarthy-Jones, S., Rowse, G., \& Turpin, G. (2011). The journey through cannabis use: a qualitative study of the experiences of young adults with psychosis. The Journal of Nervous and Mental Disease, 199(9), 703-8. http://doi.org/10.1097/NMD.0b013e318229d6bd

Cohn, A. M., Epstein, E. E., McCrady, B. S., Jensen, N., Hunter-Reel, D., Green, K. E., \& Drapkin, M. L. (2011). Pretreatment clinical and risk correlates of substance use disorder patients with primary depression. Journal of Studies on Alcohol and Drugs, 72(1), 151-157.

Compton, M. T., Simmons, C. M., Weiss, P. S., \& West, J. C. (2011). Axis IV psychosocial problems among patients with psychotic or mood disorders with a cannabis use disorder comorbidity. The 
American Journal on Addictions / American Academy of Psychiatrists in Alcoholism and Addictions, 20(6), 563-7. http://doi.org/10.1111/j.1521-0391.2011.00184.x

Corin, E. (2007). The "other" of culture in psychosis. In J. Biehl, B. J. Good, \& A. Kleinman (Eds.), Subjectivity: Ethongraphic Investigations (pp. 273-314). Berkeley and Los Angeles - California: University of California Press.

Corradi-Webster, C. M. (2009). Consumo problemático de bebidas alcoólicas por mulheres : discursos e histórias. Universidade de São Paulo.

Corradi-Webster, C. M. (2013). Consumo de Drogas: Considerações sobre a clínica no contexto do SUS. Saúde \& Transformação Social/Health \& ..., 4(2), 14-20.

Corradi-Webster, C. M. (2014). Ferramentas teórico-conceituais do discurso construcionista. In C. GuanaesLorenzi, M. dos S. Moscheta, C. M. Corradi-Webster, \& L. Vilela-Souza (Eds.), Construcionismo social: discurso, prática e produção do conhecimento. (1 ed., pp. 73-87). Rio de Janeiro: Editora do Instituto Noos.

Corradi-Webster, C. M., Laprega, M. R., \& Furtado, E. F. (2009). Residentes em psiquiatria têm documentado problemas relacionados ao álcool em pacientes ambulatoriais? SciELO Brasil, 31(16), 187-191. Retrieved from http://www.scielo.br/pdf/rprs/v31n3/a08v31n3.pdf

Costain, W. F. (2008). The effects of cannabis abuse on the symptoms of schizophrenia: Patient perspectives. International Journal of Mental Health Nursing, 17(4), 227-235.

Dalmolin, B. M. (2006). Esperança Equilibrista: Cartografias de sujeitos em sofrimento psíquico. Rio de Janeiro: Fiocruz.

Dalmolin, B. M., \& Vasconcellos, M. da P. (2015). Cartografias de sujeitos que vivenciam o sofrimento psíquico numa comunidade urbana. Ponto Urbe, 1(2007), 1-11.

Dalmolin, B. M., \& Vasconcellos, M. da P. C. (2008). Etnografia de sujeitos em sofrimento psíquico. Rev Saude Publica, 42(1), 49-54. Retrieved from http://www.scielo.br/pdf/rsp/v42n1/5997.pdf

Das, V. (1997). Languagem and body: transactions in the construction of pain. In A. Kleinman, V. Das, \& M. Lock (Eds.), Social Suffering (pp. 67-93). London: University of California Press.

Das, V., \& Das, R. K. (2007). How Body Speaks: Illness and the lifeworld. In J. Biehl, B. Good, \& A. Kleinman (Eds.), Subjectivity: Ethongraphic Investigations (pp. 66-97). Berkeley and Los Angeles California: University of California Press. 
Das, V., Kleinman, A., \& Lock, M. (1997). Introduction. In M. Kleinman, Arthur; Das, Veena; Lock (Ed.), Violence and Subjectivity (1st ed., p. ix-1). Berkeley and Los Angeles - California: University of California Press.

David, H. M. S. L., \& Caufield, C. (2005). Mudando o foco: um estudo exploratório sobre uso de drogas e vioência no trabalho entre mulheres de classes populares a cidade do Rio de Janeiro, Brasil. Revista Latino-Americana de Enfermagem, 13(número especial), 1148-1154.

Delgado, P. G. G., Schechtman, A., Weber, R., Amstalden, A. F., Bonavigo, E., Cordeiro, F., ... Grigolo, T. (2007). Reforma psiquiátrica e política de saúdemental no Brasil. In M. F. Mello, A. A. F. Mello, \& R. Kohn (Eds.), Epidemiologia da Saúde Mental no Brasil (pp. 39-84). Porto Alegre: Artmed.

Drake, R. E., \& Mueser, K. T. (2002). Co-occurring alcohol use disorder and schizophrenia. Alcohol Research and Health, 26(2), 99-102.

Duarte, L. F. D. (1986). Da vida nervosa nas classes trabalhadoras urbanas. Rio de Janeiro: Jorge Zahar Editor Ltda.

Duarte, L. F. D. (1993). Os Nervos e a Antropologia Médica Norte-Americana : Uma Revisão Crítica. Physis Revista de Saúde Coletiva, 3(2), 43-73.

Duarte, L. F. D. (2003). Indivíduo e pessoa na experiência da saúde e da doença. Ciência E Saúde Coletiva, $8(1), 173-183$.

Esdras. (2004). Co-morbidade e dependência química: repercussões na adesão ao tratamento e evolução clínica. In Drogas: Tempos, lugares e olhares sobre o consumo.

Estellita-Lins, C. E. (2000). Notas sobre criação e desrazão em uma certa experiência trágica da loucura. In P. D. de C. Amarante (Ed.), Ensaios: subjetividade, saúde mental, sociedade. Rio de Janeiro: Fiocruz.

Farmer, P. (1997). On suffering and structural violence: a view from below. In A. Kleinman, V. Das, \& M. Lock (Eds.), Social Suffering (1st ed., pp. 261-283). London: University of California Press.

Fassin, D. (2015). La biopolitique n' est pas une politique de la vie, 38, 35-48. http://doi.org/10.7202/016371ar

Figueira, I., \& Mendlowicz, M. (2003). Diagnóstico do transtorno de estresse pós-traumático. Rev Bras Psiquiatr, 25(Supl I), 12-16. http://doi.org/10.1590/S1516-44462007000500003

Fiore, M. (2004). Tensões entre o biológico eo social nas controvérsias médicas sobre uso de "drogas." In Ciências sociais e biologia em cenários comtemporâneos: repensando fronteiras e interfaces. 
Caxambú: XXVIII Reunião Anual da ANPOCS. Retrieved from

http://www.neip.info/downloads/t_mau1.pdf

Fiore, M. (2008). Prazer e Risco: uma discussão a respeito dos saberes médicos sobre uso de "drogas." In H.

S. Carneiro, B. C. Labate, \& S. L. Goulart (Eds.), Drogas e Cultura: novas perspectivas (pp. 141-154). Salvador, BA': EDUFBA/UFBA.

Fiore, M. (2013). Uso de drogas: substâncias, sujeitos e eventos. Universidades Estadual de Campinas.

Fonseca, C. (1999). Quando cada caso não é um caso: pesquisa etnográfica e educação. Revista Brasileira de Educaçao, Jan/Fev/Ma(10), 58-78. Retrieved from

http://scholar.google.com/scholar?hl=en\&btnG=Search\&q=intitle:Quando+cada+caso+NÃO+é+um+ca so\#4

Fonseca, C. (2013). O anonimato e o texto antropológico: Dilemas éticos e políticos da etnografia "em casa." Journal of Chemical Information and Modeling, 53(9), 1689-1699.

http://doi.org/10.1017/CBO9781107415324.004

Fontanella, B. (2010). Sintomas psicóticos e cognitivos associados à busca de tratamento por dependentes de substâncias-Um estudo qualitativo. J Bras Psiquiatr, 59(2), 139-145. Retrieved from http://www.scielo.br/pdf/jbpsiq/v59n2/a10v59n2.pdf

Fontanella, B. J. B., Campos, C. J. G., \& Turato, E. R. (2006). Coleta de dados na pesquisa clínicoqualitativa: uso de entrevistas não-dirigidas de questões abertas por profissionais de saúde. Revista Latino-Americana de Enfermagem, 14(5). Retrieved from http://www.scielo.br/pdf/rlae/v14n5/pt_v14n5a25.pdf

Fontanella, B. J. B., Ricas, J., \& Turato, E. R. (2008). Amostragem por saturação em pesquisas qualitativas em saúde: contribuições teóricas. Cadernos de Saúde Pública, 24(1), 17-27.

Georgakopoulou, A. (2006). The other side of the story: towards a narrative analysis of narratives-ininteraction. Discourse Studies, 8(2), 235-257. http://doi.org/10.1177/1461445606061795

Giampieri, E., Alamia, A., Galimberti, G. L., Tinghino, B., Resentini, M., \& Clerici, M. (2013). "Doppia diagnosi” e consumo di nsorse sanitarie nel DSM. L'esperienza di Monza e Brianza. ["Dual diagnosis" and use of healthcare resources in psychiatric care services. The experience of Monza and Brianza.]. Journal of Psychopathology / Giornale Di Psicopatologia. JOUR DESCRIPTORS - *Dual Diagnosis; *Health Care Costs; *Health Service Needs; *Mental Health Services; Resource Allocation, Giampieri, E.: AO S. Gerardo, via Pergolesi 33, Monza, Italy, 20052, e.giampieri@ hsgerardo.org: Pacini Editore SpA. 
Glasner-Edwards, S., Mooney, L. J., Marinelli-CAsey, P., Ang, A., Rawson, R., Autors, M. T. P. C., ... Rawson, R. (2011). Bulimia Nervosa among methamphetamine dependent adults: association with outcomes 3 years after treatment. Eating Disorders, 19(3), 259-269. http://doi.org/10.1080/10640266.2011.566149.Bulimia

Goldenberg, M. (2005). Gênero e corpo na cultura brasileira. Psicologia Clínica, 17(2), 65-80. http://doi.org/10.1590/S0103-56652005000200006

Gonçalves, R. D. C., \& Lisboa, T. (2007). Sobre o método da história oral em sua modalidade trajetórias de vida. Revista Katálysis, 10 (número especial), 83-92. Retrieved from http://www.scielo.br/pdf/rk/v10nspe/a0910spe.pdf

Good, B. J. (1994). Medicine, rationality, and experience: An anthropological perspective. Cambrigde USA: Cambridge University Press.

Goulart, S. L. (2008). Estigmas de Grupos Ayahuasqueiros. In H. S. Carneiro, B. C. Labate, S. L. Goulart, M. Fiore, \& E. MacRae (Eds.), Drogas e Cultura: novas perspectivas (pp. 251-288). Salvador, BA: EDUFBA/UFBA.

Guerra, A. M. C. (2004). Reabilitação psicossocial no campo da reforma psiquiátrica: uma reflexão sobre o controverso conceito e seus possíveis paradigmas. Revista Latinoamericana de ..., VII(2), 83-96. Retrieved from http://www.fundamentalpsychopathology.org/uploads/files/revistas/volume07/n2/reabilitacao_psicosso cial_no_campo_da_reforma_psiquiatrica.pdf

Hansen, H., Bourgois, P., \& Drucker, E. (2014). Pathologizing poverty: New forms of diagnosis, disability, and structural stigma under welfare reform. Social Science and Medicine, 103, 76-83. http://doi.org/10.1016/j.socscimed.2013.06.033

Hart, C. (2013). High price: a neuroscientist's journey of self discovery that challenges everything you know about drugs and society. Harper Collins.

Hauli, K. a., Ndetei, D. M., Jande, M. B., \& Kabangila, R. (2011). The prevalence of substance use among psychiatric patients: the case study of Bugando Medical centre, Mwanza (northern Tanzania). Substance Abuse : Official Publication of the Association for Medical Education and Research in Substance Abuse, 32(4), 238-41. http://doi.org/10.1080/08897077.2011.599253

Healey, C., Peters, S., Kinderman, P., McCraken, C., \& Moriss, R. (2009). No Title. Journal Of Affective Disorders, 113(1), 118-126. 
Henman, A. R. (2008). A coca como planta mestra: reforma e nva ética. In H. S. Carneiro, B. C. Labate, S. L. Goulart, M. Fiore, \& E. MacRae (Eds.), Drogas e Cultura: novas perspectivas (pp. 369-382). Salvador, BA: EDUFBA/UFBA.

Henrique, I. F. S., Micheli, D. de, Lacerda, R. B. de, Lacerda, L. A. de, Formigoni, M. L. O. de S., \& De Micheli, D. (2004). Validação da versão brasileira do teste de triagem do envolvimento com álcool, cigarro e outras substâncias (ASSIST). Revista Da Associação Médica Brasileira, 5(2), 199-206. http://doi.org/10.1590/S0104-42302004000200039

Hoff, R. A., \& Rosenheck, R. A. (1999). The cost of treating substance abuse patients with and without comorbid psychiatric disorders. Psychiatric Services, 50(10), 1309-1315.

Holt, L., \& Tickle, A. (2013). Exploring the experience of hearing voices from a first person perspective: A meta-ethnographic synthesis. Psychology and Psychotherapy, 1-20. http://doi.org/10.1111/papt.12017

Huang, M.-C., Schwandt, M. L., Ramchandani, V. A., George, D. T., \& Heilig, M. (2012). Impact of Multiple Types of Childhood Trauma Exposure on Risk of Psychiatric Comorbidity Among Alcoholic Inpatients. Alcoholism, Clinical and Experimental Research, 36(6), 1099-107. http://doi.org/10.1111/j.1530-0277.2011.01695.x

Huang, M.-C., Yu, C.-H., Chen, C.-T., Chen, C.-C., Shen, W. W., \& Chen, C.-H. (2009). Prevalence and identification of alcohol use disorders among severe mental illness inpatients in Taiwan. Psychiatry and Clinical Neurosciences, 63(1), 94-100. http://doi.org/10.1111/j.1440-1819.2008.01909.x

Jiménez-Castro, L., Raventós-Vorst, H., \& Escamilla, M. (2012). Substance use disorder and schizophrenia: prevalence and sociodemographic characteristics in the Latin American population. Actas Españolas de Psiquiatría, 39(2), 123-30. Retrieved from

http://www.pubmedcentral.nih.gov/articlerender.fcgi?artid=3395996\&tool=pmcentrez\&rendertype=abs tract

Jorge, M. S. B., Quinderé, P. H. D., Yasui, S., \& Renata Alves, A. (2013). Ritual de consumo do crack: aspectos socioantropológicos e repercussões para a saúde dos usuários. Ciênc. Saúde Coletiva, 18(10), 2909-2918. http://doi.org/10.1590/S1413-81232013001000015

Katz, G., Durst, R., Shufman, E., Bar-Hamburger, R., \& Grunhaus, L. (2008). Substance abuse in hospitalized psychiatric patients. The Israel Medical Association Journal : IMAJ, 10(10), 672-5. Retrieved from http://www.ncbi.nlm.nih.gov/pubmed/19009943

Kavanagh, D. J., \& Connolly, J. M. (2009). Interventions for co-occurring addictive and other mental disorders (AMDs). Addictive Behaviors, 34(10), 838-45. http://doi.org/10.1016/j.addbeh.2009.03.005 
Keizer, I., Gex-Fabry, M., Eytan, A., \& Bertschy, G. (2009). Smoking in psychiatric inpatients: association with working status, diagnosis, comorbid substance abuse and history of suicide attempts. Addictive Behaviors, 34(10), 815-20. http://doi.org/10.1016/j.addbeh.2009.03.018

Kleinman, A., \& Kleinman, J. (1991). Suffering and its professional transformation: Toward an ethnography of interpersonal experience. Culture, Medicine and Psychiatry, 275-301. Retrieved from http://link.springer.com/article/10.1007/BF00046540

Krueger, R. F., \& Markon, K. E. (2006). R EINTERPRETING C OMORBIDITY : A Model-Based Approach to Understanding and Classifying. http://doi.org/10.1146/annurev.clinpsy.2.022305.095213

Laudet, A., \& Magura, S. (2004). Perceived reasons for substance misuse among persons with a psychiatric disorder. American Journal of Orthopsychiatry, 74(3), 365-375. Retrieved from http://psycnet.apa.org/psycinfo/2004-16798-014

Leal, E. M., Godinho Delgado, P. G., Mann, R., Strike, C., Brands, B., \& Khenti, A. (2012). Estudo de Comorbidade: Sofrimento ps??quico e abuso de drogas em pessoas em centros de tratamento, Maca?? Brasil. Texto E Contexto Enfermagem, 21(SPL.ISS), 96-104. http://doi.org/10.1590/S010407072012000500013

Leão, E. A. (2016). Uso de drogas por indivíduos em tratamento psiquiátrco sob a perspectiva de profissionais de um serviço de saúde mental. Universidade de São Paulo - USP.

Lineberry, T., Allen, J., Nash, J., \& Galardy, C. (2009). Population-based prevalence of smoking in psychiatric inpatients: a focus on acute suicide risk and major diagnostic groups. Comprehensive Psychiatry, 50(6), 526-532. http://doi.org/10.1016/j.comppsych.2009.01.004.Population

Lobbana, F., Barrowclough, C., Jeffery, S., Bucci, S., Taylor, K., Mallinson, S., .. Marshall, M. (2010). Understanding factors influencing substance use in people with recent onset psychosis: A qualitative study. Social Science \& Medicine (1982), 70(8), 1141-7. http://doi.org/10.1016/j.socscimed.2009.12.026

Lovell, A. M. (2007). Hoaders and scrappers: madness and the social person in the interstices of the city. In J. Biehl, B. J. Good, \& A. Kleinman (Eds.), Subjectivity: Ethongraphic Investigations2 (pp. 315-340). Berkeley and Los Angeles - California: University of California Press.

Luzio, C. C. A., \& Yasui, S. (2010). Além das portarias: desafios da política de saúde mental. Psicol Estud, 15(1), 17-26. Retrieved from http://www.scielo.br/pdf/pe/v15n1/a03v15n1.pdf

MacDonald, E. M., Luxmoore, M., Pica, S., Tanti, C., Blackman, J.-M. M., Catford, N., ... Stockton, P. (2004). Social networks of people with dual diagnosis: The quantity and quality of relationships at 
different stages of substance use treatment. Community Mental Health Journal, 40(5), 451-464. http://doi.org/10.1023/B:COMH.0000040658.41548.b2

Macrae, E. (2004). Abordagens qualitativas na compreensão do uso de psicoativos. In L. . Tavares, A. . Almeida, E. MacRae, \& O. S. Ferreira (Eds.), Drogas: tempos, lugares e olhares sobre o consumo (pp. 27-48). Salvador: EDUFBA/UFBA.

MacRae, E. (2010). Aspectos socioculturais do uso de drogas e políticas de redução de danos. G:\NEIPNúcleo de Estudos Interdisciplinares Sobre ..., 1-4. Retrieved from www.neio.info

Magnani, J. G. C. (1997). O (velho e bom) caderno de campo. Revista Sexta-Feira, 1(1). Retrieved from http://n-a-u.org/novo/wp-content/uploads/2011/11/caderno_de_campo.pdf

Malfitano, A. P. S., Adorno, R. de C. F., \& Lopes, R. E. (2011). Um relato de vida, um caminho institucional: Juventude, medicalização e sofrimentos sociais. Interface: Communication, Health, Education, 15(38). http://doi.org/10.1590/S1414-32832011005000042

Malta, D. C., Moura, E. C., Silva, S. A., Oliveira, P. P. V. De, \& Silva, V. L. D. C. E. (2010). Prevalência do tabagismo em adultos residentes nas capitais dos estados e no Distrito Federal, Brasil, 2008. Jornal Brasileiro de Pneumologia, 36(1), 75-83. http://doi.org/10.1590/S1806-37132010000100013

Malvasi, P. A. (2012). Interfaces da vida loka: um estudo sobre jovens, tráfico de drogas e violência em São Paulo. Universidade de São Paulo.

Marsiglia, R. G., Silveira, C., \& Carneiro Júnior, N. (2007). Reforma psiquiátrica e política de saúde mental no Brasil. In M. F. de Mello (Ed.), Epidemiologia da Saúde Mental no Brasil (pp. 39-84). Porto Alegre: Artmed.

Martins, V. (2012). Direito à saúde do portador de transtornos mentais: legislação e políticas públicas que regulam a atenção aos usuários de drogas e álcool no Brasil. Universidade do Extremo Sul Catarinense. Retrieved from http://repositorio.unesc.net/handle/1/431

McCreadie, R. G. (2002). Use of drugs, alcohol and tobacco by people with schizophrenia: case-control study. The British Journal of Psychiatry: The Journal of Mental Science, 181, 321-325. http://doi.org/10.1192/bjp.181.4.321

Meade, C., Kershaw, T., Hansen, N., \& Sikkema, K. (2009). Long-term correlates of childhood abuse among adults with severe mental illness: adult victimization, substance abuse, and HIV sexual risk behavior. AIDS and Behavior, 13(2), 207-216. http://doi.org/10.1007/s10461-007-9326-4.Long-term

Mello, M. F., Mello, A. A., \& Kohn, R. (2007). Epidemiologia da Saúde Mental no Brasil. (Artmed, Ed.) $\left(1^{\mathrm{a}}\right)$. Porto Alegre: Artmed. 
Menezes, P. R., \& Ratto, L. R. C. (2004). Prevalence of substance misuse among individuals with severe mental illness in São Paulo. Social Psychiatry and Psychiatric Epidemiology, 39(3), 212-7.

http://doi.org/10.1007/s00127-004-0730-z

Mericle, A. a., Ta Park, V. M., Holck, P., Arria, A. M., Park, V. M. T., Holck, P., \& Arria, A. M. (2012). Prevalence, patterns, and correlates of co-occurring substance use and mental disorders in the United States: Variations by race/ethnicity. Comprehensive Psychiatry, 53(6), 657-665. http://doi.org/10.1016/j.comppsych.2011.10.002

Mewton, L., Teesson, M., Slade, T., \& Cottler, L. (2011). Psychometric performance of DSM-IV alcohol use disorders in young adulthood: evidence from an Australian general population sample. $J$ Stud Alcohol Drugs, 72(5), 811-822.

Midanik, L., \& Room, R. (2005). Contributions of social science to the alcohol field in an era of biomedicalization. Social Science \& Medicine (1982), 60(5), 1107-16. http://doi.org/10.1016/j.socscimed.2004.06.042

Minelli, M. (2006). Agire in quotidiani "stati d'eccezione". Forme di vita e biopolitiche in un'etnografia nel campo della salute mentale. In Antropologia. Retrieved from http://www.ledijournals.com/ojs/index.php/antropologia/article/view/150

Minelli, M. (2013). Jogando (com) o poder no campo da saúde mental. Perspectivas, 43(JAN.-JUN), 219254.

Minelli, M. (2014). Divorare per non essere divorati: Etnografia dei processi di deinstituzionalizzazione nel campo della salute mentale in Brasile.

Ministério da Justiça, S. N. de Po. sobre D. (2013). Prevenção do uso de drogas. (SENAD, Ed.) (5ª). Brasília.

Mordal, J., Holm, B., Gossop, M., Romøren, M., Mørland, J., \& Bramness, J. G. (2011). Psychoactive substance use among patients admitted to an acute psychiatric ward: laboratory findings and associations with clinical characteristics. Nordic Journal of Psychiatry, 65(3), 208-215. Retrieved from http://www.ncbi.nlm.nih.gov/pubmed/21047195

Morris, D. B. (1997). About suffering: voice, genre, and moral community. In A. Kleinman, V. Das, \& M. Lock (Eds.), Social Suffering (pp. 25-46). London: University of California Press.

Mueser, K. T., Drake, R. E., \& Wallach, M. A. (1998). Dual diagnosis: a review of etiological theories. Addictive Behaviors, 23(6), 717-34. Retrieved from http://www.ncbi.nlm.nih.gov/pubmed/9801712 
Peters, B. D., de Koning, P., Dingemans, P., Becker, H., Linszen, D. H., \& de Haan, L. (2009). Subjective effects of cannabis before the first psychotic episode. The Australian and New Zealand Journal of Psychiatry, 43(12), 1155-62. http://doi.org/10.3109/00048670903179095

Pettersen, H., Ruud, T., Ravndal, E., \& Landheim, A. (2013). Walking the fine line : Self-reported reasons for substance use in persons with severe mental illness. International Journal of Qualitative Studies on Health and Well-Being, 8, 21968. Retrieved from http://www.pubmedcentral.nih.gov/articlerender.fcgi?artid=3871834\&tool=pmcentrez\&rendertype=abs tract

Pinho, P. H. P., Oliveira, M. A. De, \& Almeida, M. M. De. (2008). A reabilitação psicossocial na atenção aos transtornos associados ao consumo de álcool e outras drogas: uma estratégia possível? Revista de Psiquiatria Clínica, 35(1), 82-88. http://doi.org/10.1590/S0101-60832008000700017

Pitta, A. (2011). Um balanço da Reforma Psiquiátrica Brasileira: Instituições, Atores e Políticas. Ciênc. Saúde Coletiva, 4579-4589. Retrieved from http://www.scielo.br/pdf/csc/v16n12/02.pdf

Pizza, G. (2005). Antonio Gramsci y la antropología médica contemporánea. Hegemonía, “ capacidad de actuar” (agency) y transformaciones de la persona. Revista de Antrpología Social, 11, 15-32.

Plano, C., \& Querzoli, R. (2003). La Entrevista en la Historia de Vida: Algunas Cuestiones Metodológicas. Observatorio Memoria Y Prácticas Sociales En Direchos Humanos, 22.

Pomerleau, A. C., Sutter, M. E., Owen, K. P., Loomis, E., Albertson, T. E., \& Diercks, D. B. (2012). Amphetamine abuse in emergency department patients undergoing psychiatric evaluation. The Journal of Emergency Medicine, 43(5), 798-802. http://doi.org/10.1016/j.jemermed.2012.01.040

Pompili, M., Innamorati, M., Lester, D., Akiskal, H. S., Rihmer, Z., del Casale, A., ... Tatarelli, R. (2009). Substance abuse, temperament and suicide risk: evidence from a case-control study. Journal of Addictive Diseases, 28(1), 13-20. http://doi.org/10.1080/10550880802544757

Pussetti, C., \& Brazzabeni, M. (2011). Sofrimento social: idiomas da exclusão e políticas do assistencialismo. Etnográfica, 15(3), 467-478.

Quesada, J., Hart, L. K., \& Bourgois, P. (2011). Structural vulnerability and health: Latino migrant laborers in the United States. Medical Anthropology, 30(4), 339-362.

Ratto, L. R. C. (2000). Prevalência da Comorbidade entre Transtornos Mentais Graves e Transtornos Devido ao Uso de Substâncias. Universidade de São Paulo. 
Rauter, C., \& Peixoto, P. de T. de C. (2009). Psiquiatria, saúde mental e biopoder: vida, controle e modulação no contemporâneo. Psicologia Em Estudo, 14(2), 267-275. Retrieved from http://www.scielo.br/pdf/pe/v14n2/v14n2a06.pdf

Regier, D. A., Farmer, M. E., Rae, D. S., Locke, B. Z., Keith, S. J., Judd, L. L., \& Goodwin, F. K. (1990). Comorbidity of Mental Disorders With Alcohol and Other Drug Abuse. JAMA: Journal of the American Medical Association, 264(19), 2511. Retrieved from http://search.ebscohost.com/login.aspx?direct=true\&db=aph\&AN=10416613\&site=ehost-live

Rehm, J., Taylor, B., \& Room, R. (2006). Global burden of disease from alcohol, illicit drugs and tobacco. Drug and Alcohol Review, 25(6), 503-513. http://doi.org/10.1080/09595230600944453

Ribeiro, M. C. S. D. A., Barata, R. B., Almeida, M. F. De, \& Silva, Z. P. Da. (2006). Perfil sociodemográfico e padrão de utilização de serviços de saúde para usuários e não-usuários do SUS PNAD 2003. Ciência \& Saúde Coletiva, 11(4), 1011-1022. http://doi.org/10.1590/S141381232006000400022

Ries, R. K., Yuodelis-Flores, C., Roy-Byrne, P. P., Nilssen, O., \& Russo, J. (2009). Addiction and suicidal behavior in acute psychiatric inpatients. Comprehensive Psychiatry, 50(2), 93-9. http://doi.org/10.1016/j.comppsych.2008.07.003

Robinson, J., Sareen, J., Cox, B. J., \& Bolton, J. M. (2013). Role of Self-medication in the Development of Comorbid Anxiety and Substance Use Disorders: a longitudinal investigation, 68(8), 800-807.

Rodrigues, T. (2008). Tráfico, guerra e proibição. In H. S. Carneiro, B. C. Labate, S. L. Goulart, M. Fiore, \& E. MacRae (Eds.), Drogas e Cultura: novas perspectivas (pp. 91-104). Salvador, BA: EDUFBA/UFBA.

Rodríguez-Jiménez, R., Aragüés, M., Jiménez-Arriero, M. A., Ponce, G., Muñoz, A., Bagney, A., ... Palomo, T. (2008). Dual diagnosis in psychiatric inpatients: prevalence and general characteristics. Investigacion Clinica, 49(2), 195-205.

Romanini, M., \& Roso, A. (2014). Midiatização do crack e estigmatização: corpos habitados por histórias e cicatrizes. Interface - Comunicação, Saúde, Educação, 18(49), 363-376. http://doi.org/10.1590/180757622013.0138

Room, R. (1969). The Cultural Framing of Addiction. Janus Head, 6(2), 221-234. Retrieved from http://www.robinroom.net/cultfram.pdf

Rovatti, P. A. (2013). Restituire la soggettivitá: Lezioni sul pensiero di Franco Basaglia. Trieste: AB Edizioni Alpha Beta Velag. 
Ruddle, A., Mason, O., \& Wykes, T. (2011). A review of hearing voices groups: evidence and mechanisms of change. Clinical Psychology Review, 31(5), 757-66. http://doi.org/10.1016/j.cpr.2011.03.010

Santana, A. M. (2010). Mulher mantenedora/homem chefe de família: uma questão de gênero e poder. 2010, 8(jul.-).

Santos, J. A. T., \& Oliveira, M. L. F. de. (2012). Políticas públicas sobre álcool e outras drogas: breve resgate histórico. Journal of Nursing and ..., 1(2), 82-93. Retrieved from http://www.ufpel.edu.br/revistas/index.php/enfermagemesaude/article/viewArticle/104

Santos, J. F. Q. dos, Nakamura, E., \& Martin, D. (2007). A compreensão da depressão na população pobre, uma ocorrência mais (fortemente) social, do que uma doença (fracamente. Mediações, 12(1), 313-322.

Santucci, K. (2012). Psychiatric disease and drug abuse. Current Opinion in Pediatrics, 24(2), 233-237. http://doi.org/10.1097/MOP.0b013e3283504fbf

São Paulo, S. E. de S. (2007). Plano estadual de saúde - 2012-2015. Retrieved from http://scholar.google.com/scholar?hl=en\&btnG=Search\&q=intitle:Plano+Estadual+de+Saúde\#2

Saraceno, B. (1995). La fine dell'intrattenimento. Milano - Itália: Etas Libre.

Schofield, D., Tennant, C., Nash, L., Degenhardt, L., Cornish, A., Hobbs, C., \& Brennan, G. (2006). Reasons for cannabis use in psychosis. Jpurnal Compalation The Royal Australian and New Zealand College of Psychiatrists.

Severo, C. G. (2006). Sobre o discurso antimanicomial. Revista Querubim, 1(2), 95-104.

Silva, C. R., Kolling, N. de M., Carvalho, J. C. N., Cunha, S. M., \& Kristensen, C. H. (2009). Comorbidade psiquiátrica em dependentes de cocaína/crack e alcoolistas: um estudo exploratório. Aletheia, jul./dez, 101-112. Retrieved from http://pepsic.bvsalud.org/scielo.php?pid=S141303942009000200009\&script=sci_arttext

Silva, S. L. da, \& Adorno, R. de C. F. (2013). A etnografia e o trânsito das vulnerabilidades em territórios de resistências, registros , narrativas e reflexões a partir da Cracolândia. Saúde \& Transformação Social/Health \& ..., 4(2), 21-31.

Simões, J. (2004). Prefácio. In Drogas e Cultura: novas perspectivas.

Sinclair, J. M. a, Latifi, A. H., \& Latifi, A. W. (2008). Co-morbid substance misuse in psychiatric patients: prevalence and association with length of inpatient stay. Journal of Psychopharmacology (Oxford, England), 22(1), 92-9. http://doi.org/10.1177/0269881107082029 
Sou, H. de, \& Dantas, Z. (2009). Transtorno de estresse pós-traumático associado ao abuso e dependência de álcool e drogas: estudo de uma amostra da população da região metropolitana de São Paulo.

Souza, T. de P. (2013). A norma da abstinência e o dispositivo "drogas": direitos universais em territórios marginais de produção de saúde. Universidade Estadual de Campinas.

Spink, M. J. P., Lisboa, M. S., \& Ribeiro, F. R. G. (2009). A construção do tabagismo como problema de Saúde Pública: uma confluência entre interesses políticos e processos de legitimação científica. Interface - Comunicação, Saúde, Educação, 13(29), 353-365.

Spink, P. K. (2003). Pesquisa de Campo em Psicologia Social: uma perspectiva pós-construcionista. Psicologia \& Sociedade, 15(2), 18-42. Retrieved from http://www.scielo.br/pdf/psoc/v18n2/03.pdf

Stahler, G., \& Mennis, J. (2009). The influence of neighborhood environment on treatment continuity and rehospitalization in dually diagnosed patients discharged from acute inpatient care. American Journal of ..., 166(11), 1258-1268. Retrieved from http://focus.psychiatryonline.org/article.aspx ?articleid=101304\&RelatedWidgetArticles=true

Stewart, S. H., Karp, J., Pihl, R. O., \& Peterson, R. A. (1997). Anxiety sensitivity and self-reported reasons for drug use. Journal of Substance Abuse, 9(1), 223-240. http://doi.org/10.1016/S0899-3289(97)900183

Swendsen, J., Conway, K. P., Degenhardt, L., Glantz, M., Jin, R., Merikangas, K. R., ... Kessler, R. C. (2010). Mental disorders as risk factors for substance use, abuse and dependence: results from the 10year follow-up of the National Comorbidity Survey. Addiction, 105(6), 1117-1128. http://doi.org/ADD2902 [pii]ไr10.1111/j.1360-0443.2010.02902.x

Szerman, N., Arias Horcajadas, F., Vega Astudillo, P., Babín Vich, F., Mesías Perez, B., Basurte Villamor, I., ... Poyo Calvo, F. (2011). Pilot study on the prevalence of dual pathology in community mental health and substance misuse services in Madrid. Adicciones, 23(3), 249-255.

Szerman, N., \& Lopez-Castroman, J. (2012). Dual diagnosis and suicide risk in a Spanish outpatient sample. Substance Use \& ..., 47, 383-389. http://doi.org/10.3109/10826084.2011.636135

Terra, M. G., Ribas, D. L., Sarturi, F., \& Erdmann, A. L. (2006). Saúde mental: do velho ao novo paradigma-uma reflexão. Esc Anna Nery Rev ..., 10(4), 711-717. Retrieved from http://www.scielo.br/pdf/ean/v10n4/v10n4a13.pdf

Thornton, L. K., Baker, A. L., Johnson, M. P., Kay-Lambkin, F., \& Lewin, T. J. (2012). Reasons for substance use among people with psychotic disorders: Method triangulation approach. Psychology of Addictive Behaviors. http://doi.org/10.1037/a0026469 
Todd, F. C., Douglas Sellman, J., \& Robertson, P. J. (2002). Barriers to optimal care for patients with coexisting substance use and mental health disorders. Australian and New Zealand Journal of Psychiatry, 36(6), 792-799. http://doi.org/10.1046/j.1440-1614.2002.01049.x

Torcato, C. E. M., Soares, C. B., Corradi-Webster, C. M., Carneiro, H. S., \& Adorno, R. de C. F. (2013). Drogas na sociedade. Saúde \& Transformação Social/Health \& ..., 4(2), 2-5. Retrieved from http://scholar.google.com/scholar?hl=en\&btnG=Search\&q=intitle:Drogas+e+Sociedade\# 1

Turato, E. R. (2005). área da saúde: definições, diferenças e seus objetos de pesquisa Qualitative and quantitative methods in health: definitions, differences and research subjects. Rev Saúde Pública, 39(3). Retrieved from http://www.scielo.br/pdf/rsp/v39n3/24808.pdf

Turato, E. R. (2011). Tratado da metodologia de pesquisa clínico-qualitativa: construção teóricoepistemológica, discussão comparada e aplicação nas áreas da saúde e humanas $\left(5^{\mathrm{a}}\right)$. Petrópolis, RJ: Vozes.

United Nations Office on Drugs and Crime (UNODOC). (2010). World Drug Report 2010. Viena: United Nations Publication Sales. Retrieved from http://books.google.com/books?hl=en\&lr=\&id=HB9PuEhHahQC\&oi=fnd\&pg=PA29\&dq=World+drug +report+2010\&ots=tkKoHhxOpN\&sig=vndcgX1zd03XHnlbmaJze31xpO8

van der Meer Sanchez, Z., \& Nappo, S. A. (2002). Sequência de drogas consumidas por usuários de crack e fatores interferentes. Revista de Saude Publica, 36(4), 420-430. http://doi.org/10.1590/S003489102002000400007

Vargas, E. V. (2001). Entre a extensão e a intensidade: corporalidade, subjetivação e uso de drogas, 600. Retrieved from http://goo.gl/veKWs

Vargas, E. V. (2008). Fármacos e outros objetos sócio-técnicos: notas para uma genealogia das drogas. In H. S. Carneiro, B. C. Labate, S. L. Goulart, M. Fiore, E. MacRae, \& (Orgs) (Eds.), Drogas e Cultura: novas perspectivas (pp. 41-64). Salvador, BA: EDUFBA/UFBA.

Vieira, F. D. S. (2012). Auxiliares de enfermagem de uma unidade de agudos de um hospital especializado em psiquiatria: sua visão sobre a prática profissional e a clientela atendida. Universidade de São Paulo.

Vieira, F. D. S., Caldana, R. H. L., \& Corradi-webster, C. M. (2013). Relatos de auxiliares de enfermagem psiquiátricos sobre suas práticas e sobre pessoas internadas por uso compulsivo de substâncias psicoativas. Saúde \& Transformação Social/Health \& Social ..., 4(2), 1-10. 
Volcov, K., \& Vasconcellos, M. P. (2013). “Crack , é possível vencer” ou é preciso compreender: observações a partir de campanhas publicitárias do governo federal. Saúde \& Transformação Social/Health \& Social ..., 4(2), 99-105.

Weich, L., \& Pienaar, W. (2009). Occurrence of comorbid substance use disorders among acute psychiatric inpatients at Stikland Hospital in the Western Cape, South Africa. African Journal of Psychiatry, 12(3), 213-7. Retrieved from http://www.ncbi.nlm.nih.gov/pubmed/19750250

WHO. (1995). Glosario de términos de alcohol y drogas. Occupational and Environmental Medicine. Glossário, Madrid: Ministerio de Sanidad y Consumo. Retrieved from http://www.ncbi.nlm.nih.gov/pmc/articles/PMC1128253/

WHO, W. H. O. (1992). International Statistical Classification of Diseases and Related Health Problems. Occupational Health (Vol. 1).

WHO, W. H. O. (2002). The Alcohol, Smoking and Substance Involvement Screening Test (ASSIST): development, reliability and feasibility. Addiction (Abingdon, England), 97(9), 1183-94. Retrieved from http://www.ncbi.nlm.nih.gov/pubmed/12199834

Woods, A., Jones, N., Alderson-Day, B., Callard, F., \& Fernyhough, C. (2015). Experiences of hearing voices: analysis of a novel phenomenological survey. The Lancet Psychiatry, 2(4), 323-331. http://doi.org/10.1016/S2215-0366(15)00006-1

World Bank, I. B. for R. and D. (2007). Global Burden of Disease and Risk Factors. (A. D. Lopez, C. D. Mathers, M. Ezzati, D. T. Jamison, \& C. J. L. Murray, Eds.) (Vol. 44). washington, USA: The World Bank and Oxford University Press. http://doi.org/10.5860/CHOICE.44-4479

Wüsthoff, L. E., Waal, H., Ruud, T., \& Gråwe, R. W. (2011). A cross-sectional study of patients with and without substance use disorders in Community Mental Health Centres. BMC Psychiatry, 11(1), 93. Retrieved from http://www.pubmedcentral.nih.gov/articlerender.fcgi?artid=3120743\&tool=pmcentrez\&rendertype=abs tract

Young, A. (1981). When rational men fall sick: An inquiry into some assumptions made by medical anthropologists. Culture, Medicine and Psychiatry, 5(4), 317-335.

Young, A. (1995). The harmony of illusions: inventing post traumatic stress disorder. Princeton, New Jersey: Priceton Press.

Young, A. (1997). Suffering and the origins of traumatic memory. In A. Kleinman, V. Das, \& M. Lock (Eds.), Social Suffering (pp. 245-260). London: University of California Press. 
Young, A. (2006). Antropologie della "illness" e della "sickness." In I. Quaranta \& Traduzione Elena Fabietti (Eds.), Antropologia Medica: I testi fondamentali (prima ediz, pp. 107-147). Milano, Italia: Raffaello Cortina Editore.

Zaleski, M., Laranjeira, R. R., Roselli Marques, A. C. P., Ratto, L., Romano, M., Palhares Alves, H. N., ... Lemos, T. (2006). Diretrizes da Associação Brasileira de Estudos do Álcool e outras Drogas (ABEAD) para o diagnóstico e tratamento de comorbidades psiquiátricas e dependência de álcool e outras substâncias. Revista Brasileira de Psiquiatria. http://doi.org/10.1590/S1516-44462006000200013

Zanella, E. D. (2010). Proibido pra chato: etnografia sobre o consumo de bebidas alcoólicas em um "bar de bairro." Universidade Federal do Rio Grande do Sul. 
Anexos 
Anexo 1. Roteiro de Entrevista 


\section{Roteiro de entrevista}

PARTE I: Identificação/caracterização:

Nome:

Contato telefônico:

Data de Nascimento:

Ocupação:

Estado civil:

Diagnósticos (consulta na pasta):

Serviço de Saúde Mental:

Pessoas com quem reside: NOME PARENTESCO IDADE FORMAÇÃO RENDA APROXIMADA

Renda familiar total/ pessoas que dependem dessa renda:

Religiosidade/ Espiritualidade:

PARTE II: História de Vida Temática

A)- Historia de vida (relato espontâneo)

B) Roteiro de tópicos

- Trajetória dos sintomas (como começou, quais eram, como era a vida naquele momento)

- Descrição da história do diagnóstico (qual, em que serviço, uso inicial de medicação, quem levou, forma como se sentiu, aspectos negativos e positivos do diagnóstico, suporte recebido, suporte considerado necessário) 
- Trajetória de tratamento (como começou, forma como se sentiu, aspectos positivos e negativos de fazer tratamento)

- Uso de drogas (quais, quando começou, quais as influências, porque continuou, parou por algum período, como se sentia, usava sozinho ou com amigos, reação da rede social ao saber)

- Como é a relação entre os sintomas e o uso de drogas (o que vem antes, como um interfere no outro, a medicação psiquiátrica ajuda ou atrapalha nessa interferência, a droga ajuda ou atrapalha na produção de sintomas, ajuda ou atrapalha na diminuição dos sintomas)

- Rede social (apoio ou não da rede social, quem é, como se articula, quem foi mais importante para iniciar o uso de drogas, quem foi importante para buscar ajuda, quem foi mais crítico com o uso de drogas - amigos, família, religião, trabalho)

- Rotina (descrição, forma como se sente)

- Eventos relevantes (histórico de violência e abuso, marcos positivos e negativos na história de vida)

- Perspectiva de futuro (planos e expectativas)

- Depoimento final livre 


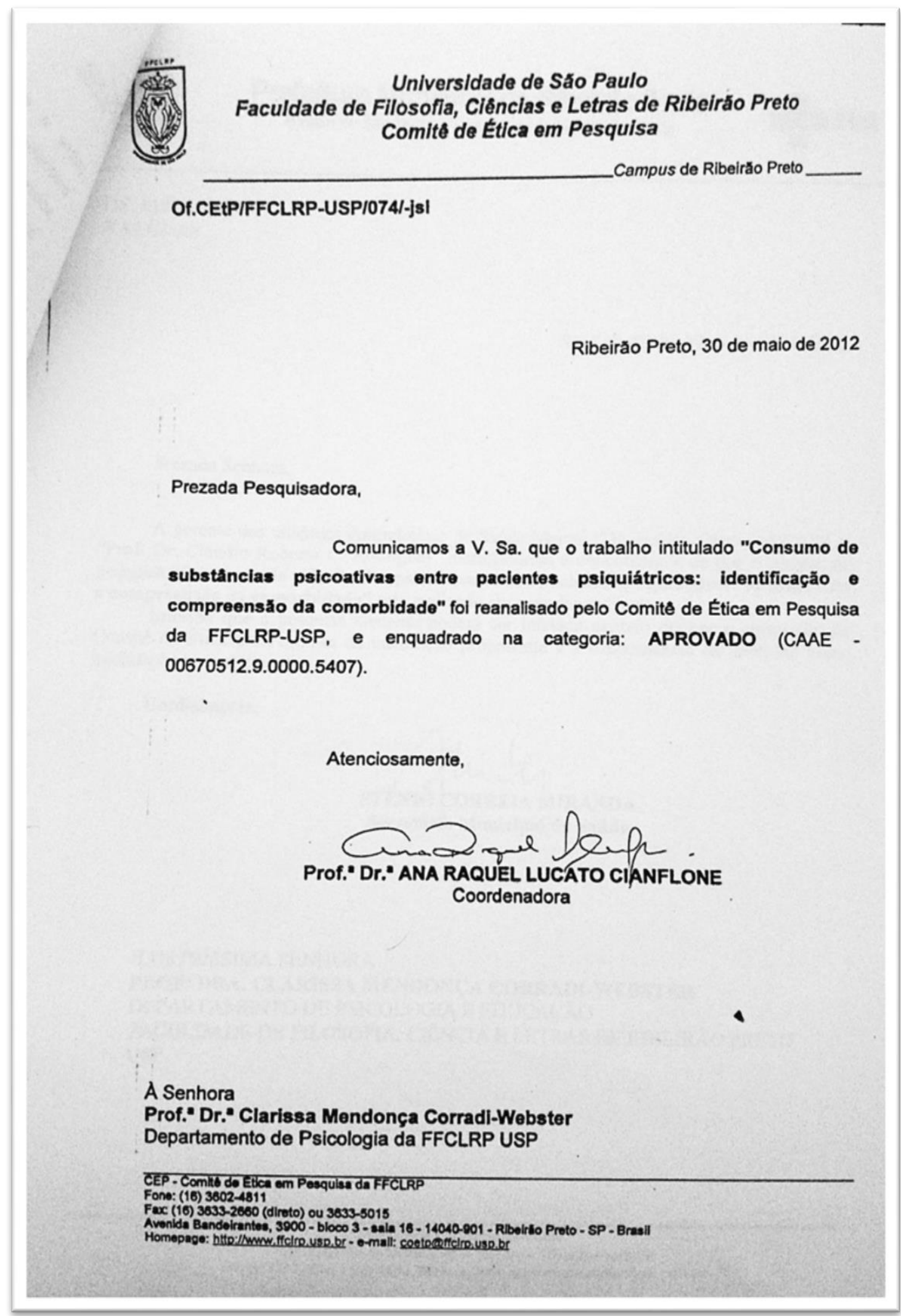


TERMO DE CONSENTIMENTO LIVRE E ESCLARECIDO

Atualmente há muitas pessoas sofrendo com problemas emocionais. Sabemos que estes problemas podem interferir muito na vida destas pessoas. Algumas destas pessoas também consomem ou já consumiram bebidas alcoólicas ou outras drogas. Queremos conhecer como estas pessoas lidam com o sofrimento emocional e o que pensam sobre o consumo de bebidas alcoólicas e outras drogas.

Assim, você está sendo convidado a participar de um estudo que quer conhecer como pessoas em tratamento psiquiátrico lidam com o adoecimento e com o consumo e bebidas alcoólicas e de outras drogas. O nome deste estudo é "Consumo de substâncias psicoativas entre pacientes psiquiátricos: identificação e compreensão da comorbidade".

Iremos te fazer algumas perguntas e pedimos a autorização para gravarmos esta conversa. Caso você concorde em participar, esta entrevista será mantida sob a responsabilidade e a guarda do pesquisador-responsável. O seu nome será mantido em sigilo e as informações serão consideradas como confidenciais. É importante que você saiba que as informações coletadas poderão ser publicadas e/ou apresentadas com objetivo científico, preservando sua não identificação. Não há nenhum desconforto ou risco para você em participar. A única coisa que lhe pedimos é o tempo que você terá que gastar para responder às perguntas. $\mathrm{O}$ tempo para a entrevista fica em torno de 20 minutos à uma hora.

As informações que você nos der serão muito úteis para podermos melhorar o planejamento dos serviços de saúde e para o treinamento dos profissionais. Se você concordar em participar da pesquisa, queremos esclarecer que:

a) você é livre para, a qualquer momento, recusar-se a responder às perguntas que lhe ocasionem constrangimento de qualquer natureza;

b) você pode deixar de participar da pesquisa e não precisa apresentar justificativas para isso.

Agradecemos sua colaboração e colocamo-nos à disposição para esclarecimentos que se fizerem necessários.

Este termo está em duas vias, uma ficará com você e outra com o pesquisador responsável.

Estando de acordo:

Nome:

RG:

Assinatura:

Pesquisadora responsável:

Profa. Dra. Clarissa Mendonça Corradi-Webster

Departamento de Psicologia

Faculdade de Filosofia, Ciências e Letras de Ribeirão Preto - USP

(16) 3602.4811 - clarissac@usp.br 125 
